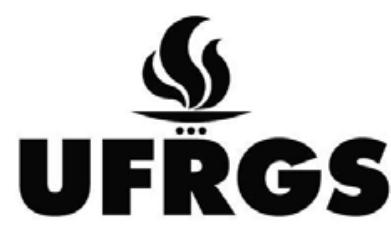

UNIVERSIDADE FEDERAL

DO RIO GRANDE DO SUL

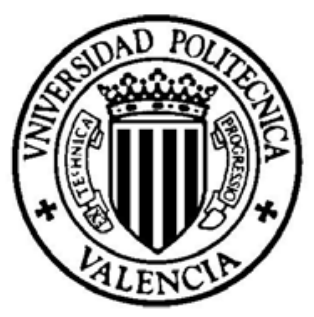

TESIS

presentada en co-tutela en vía de obtener el

DOCTORADO

de la Universidad Politécnica de Valencia

y de la Universidade Federal do Rio Grande do Sul

por

José Luís NEVES XAVIER

\title{
Aplicação de técnicas eletroquímicas na degradação de poluentes orgânicos refratários
}

Orientadores: Dra. Andrea Moura Bernardes

Dr. Valentin Pérez Herranz

Porto Alegre, marzo de 2012 



\author{
Ministério da Educação \\ Universidade Federal do Rio Grande do Sul \\ Escola de Engenharia
}

Programa de Pós-Graduação em Engenharia de Minas, Metalúrgica e de Materiais

\title{
Aplicação de técnicas eletroquímicas na degradação de poluentes orgânicos aromáticos refratários
}

\author{
José Luís Neves Xavier \\ Engenheiro Químico \\ Mestre em Engenharia
}

Porto Alegre 

Esta Tese foi julgada adequada para obtenção do titulo de Doutor em Engenharia, área de concentração Ciência e Tecnologia dos Materiais e aprovada em sua forma final, pelo Orientador e pela Banca Examinadora do Curso de Pós-Graduação.

Orientadores: Dra. Andrea Moura Bernardes

Dr. Valentin Pérez Herranz

\section{Banca Examinadora:}

Dra. Denise Shermann Azambuja, Departamento de Físico-Química, UFRGS - Porto Alegre, Brasil Dra. Jane Zoppas Ferreira, Departamento de Materiais, UFRGS - Porto Alegre, Brasil Dr. José García Antón Profesor, UPV - Valencia, España Dr. Marçal José Rodrigues Pires, Instituto de Química, PUC - Porto Alegre, Brasil.

Dr. Marco Antônio Siqueira Rodrigues, Instituto de Ciências Exatas, FEEVALE - Novo Hamburgo, Brasil

Dr. Telmo Roberto Strohaecker Coordenador do PPGEM 



\title{
MINISTÉRIO DA EDUCAÇÃO \\ UNIVERSIDADE FEDERAL DO RIO GRANDE DO SUL
}

Escola de Engenharia

Programa de Pós-Graduação em Engenharia de Minas, Metalúrgica e de Materiais

\section{Aplicação de técnicas eletroquímicas na degradação de poluentes orgânicos refratários}

\author{
José Luís Neves Xavier \\ Engenheiro Químico \\ Mestre em Engenharia
}

Trabalho realizado em co-tutela no Programa de Pós-Graduação em Engenharia de Minas, Metalúrgica e de Materiais - PPGEM/UFRGS e no Programa de Doctorado em Tecnologia de Membranas, Eletroquímica y Médio Ambiente, Seguridad Nuclear da Universidad Politécica de Valencia (UPV), como parte dos requisitos para a obtenção do título de Doutor em Engenharia

Área de Concentração: Ciência e Tecnologia dos Materiais (UFRGS)

Especialidad: Ingeniería Electroquímica y Corrosión (UPV)

Porto Alegre 

Se as coisas são inatingíveis... ora! Não é motivo para não querê.las... Que tristes os caminhos se não fora A mágica presenfa das estrelas!

Mario Quintana 



\section{AGRADECIMENTOS}

Durante todo o decorrer desse trabalho eu tive o prazer de conviver com pessoas especiais, as quais nesse momento gostaria de manifestar meus agradecimentos, pelo apoio, pelo incentivo e pela convivência sempre agradável e construtiva.

Primeiramente agradeço aos meus orientadores, a professora Andrea Moura Bernardes, da Universidade Federal do Rio Grande do Sul (UFRGS), pela ajuda nos assuntos técnicos, a presença constante, as oportunidades oferecidas e a orientação sempre correta e oportuna, reflexos de sua competência profissional e grande interesse e conhecimento no tema desenvolvido nesse trabalho. Ao meu orientador o professor Valentin Pérez-Herranz da Universidad Politécnica de Valencia (UPV), Espanha, pela acolhida e apoio nos trabalhos desenvolvidos em sua instituição. No período em que estagiei no Laboratório de Ingeniería Electroquímica y Corrosión pude perceber o grande profissional que tive a sorte de ter como orientador.

Não poderia deixar de agradecer ao Laboratório de Corrosão, Proteção e Reciclagem de Materiais (LACOR) do Departamento de Engenharia de Materiais da UFRGS, no qual desenvolvi grande parte deste trabalho. Agradeço a professora Jane Zoppas Ferreira pelo constante apoio e incentivo devotado a todos os integrantes dos grupos de pesquisa do LACOR. Não poderia deixar de agradecer também por sua assessoria em eletroquímica, sempre muito esclarecedoras.

Meu muito obrigado a todos os professores, funcionários, colegas e colaboradores do LACOR pelo incentivo, companheirismo e ajuda. Agradeço em especial a Alessandra Lucas Coelho e Bruno Reginatti Silveira pela ajuda na parte experimental e analítica. Deixo meu agradecimento também a todos os colegas do Laboratório de Ingeniería Electroquímica y Corrosión do departamento de Engenharia Química y Nuclear da UPV, em especial a professora Emma Ortega Navarro pela disponibilidade na elaboração e execução dos experimentos, bem como 0 incentivo $e$ interesse apresentados pelo tema.

Um especial agradecimento ao professor Adão Mautone pelos sábios conselhos, sempre muito pertinentes. Ao professor Marco Antônio Siqueira Rodrigues da 
Universidade FEEVALE, pelo constante apoio na elaboração dos experimentos, análises e discussão dos resultados obtidos.

Agradeço a minha família que sempre foi a maior incentivadora das minhas escolhas. À minha mãe que de sua maneira simples e discreta soube me transmitir valores fundamentais na minha formação, aos meus irmãos Luis Antônio e Ângelo pela companhia e apoio. Um agradecimento especial ao meu irmão o Prof. Dr. José Tadeu Xavier pelo exemplo de profissional que sempre demonstrou ser.

Deixo meu muito obrigado aos funcionários da secretaria do PPGEM, a Beatriz, Alda e Marta.

Agradeço a CAPES pelo suporte financeiro durante todo o período do doutorado.

Por fim agradeço a UFRGS pelo ensino público, gratuito e de alta qualidade. 


\section{SUMÁRIO}

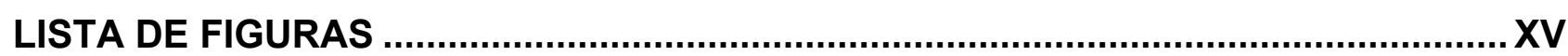

LISTA DE TABELAS

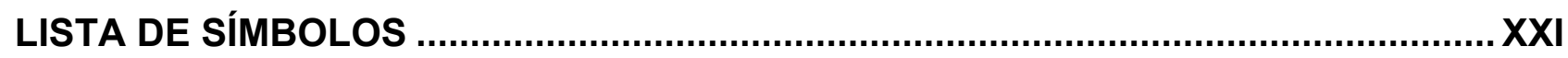

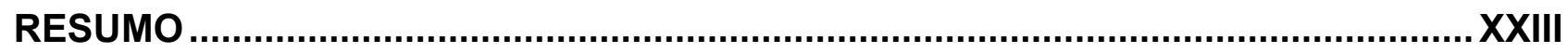



RESUM

ABSTRACT

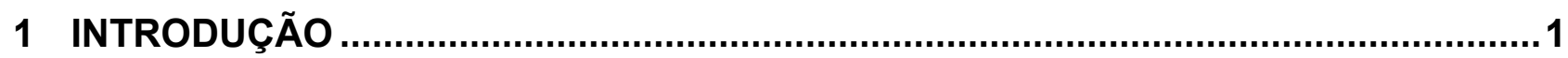

2 OBJETIVOS

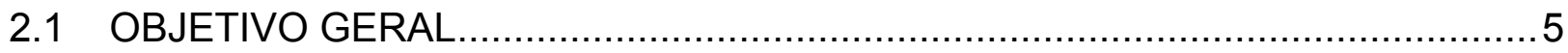

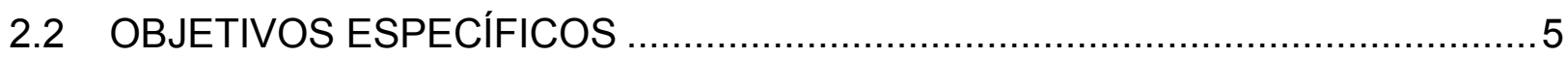

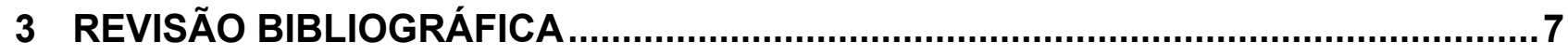

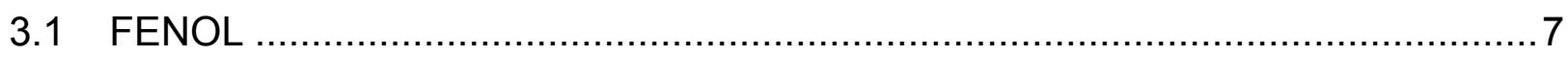

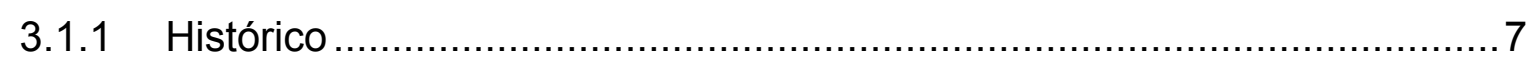

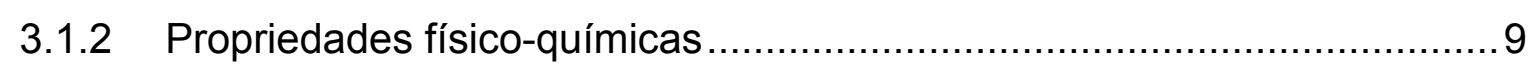

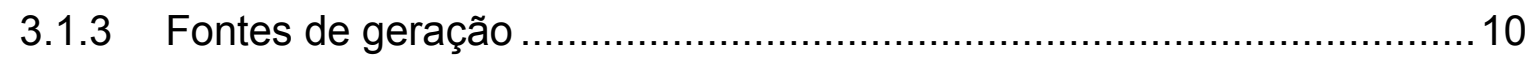

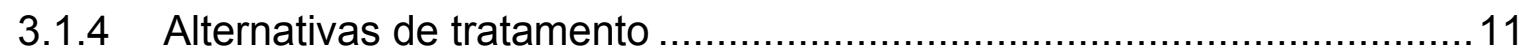

3.2 PROCESSOS OXIDATIVOS AVANÇADOS - POA'S ………........................... 13

3.3 PROCESSOS ELETROQUÍMICOS EM MEIO AQUOSO ...............................17

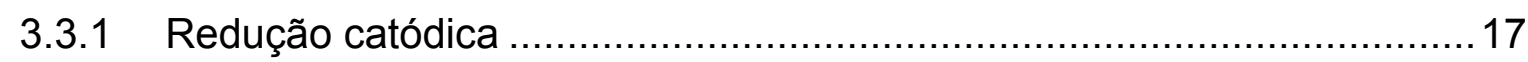

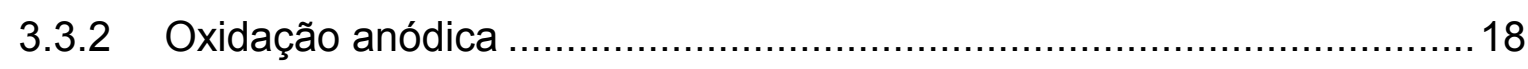

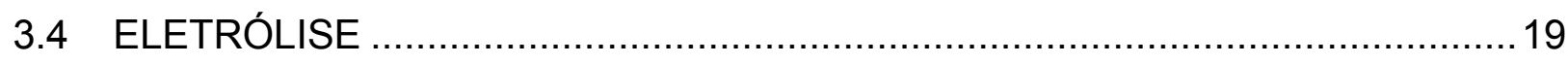

3.4.1 Eletrodos revestidos de óxido metálicos …………………................ 19

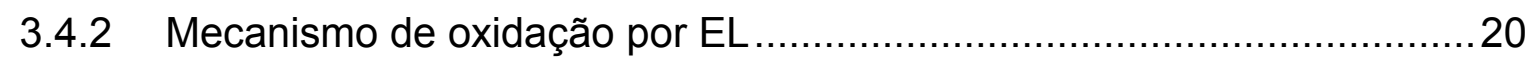

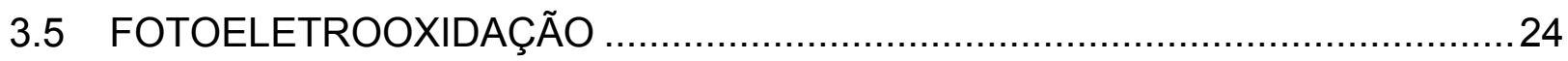

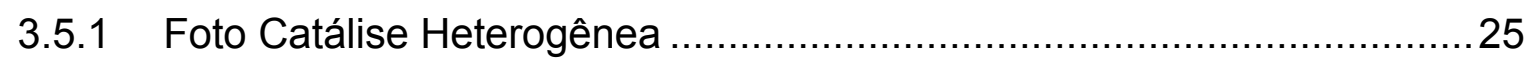

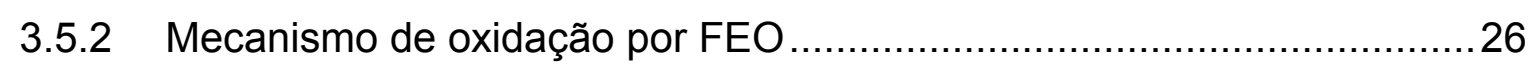

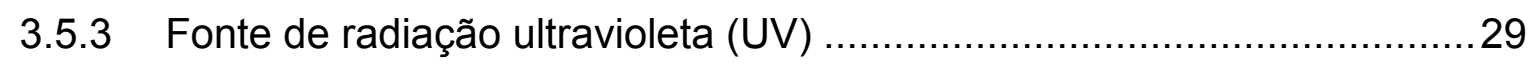

3.6 PROCESSOS DE OXIDAÇÃO ELETROQUÍMICA DE FENOL...........................30 


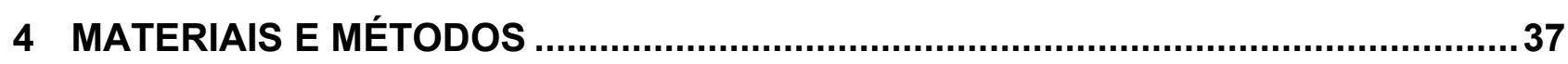

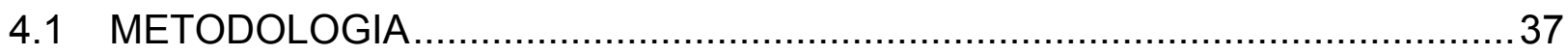

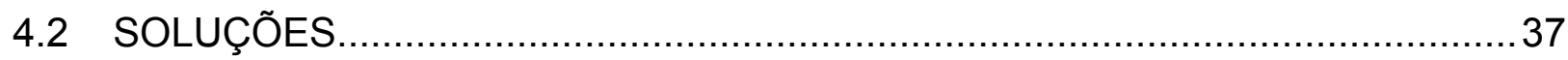

4.3 EXPERIMENTOS DE VOLTAMETRIA CÍCLICA DE VARREDURA .................39

4.4 EXPERIMENTOS DE ELETRÓLISE E FOTOELETROOXIDAÇÃO...................40

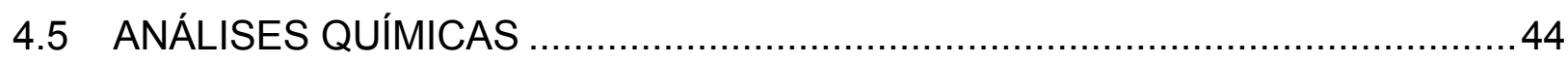

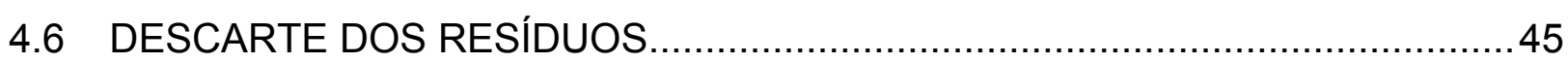

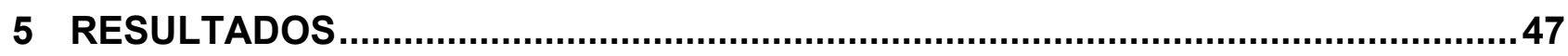

5.1 ESTUDO DO COMPORTAMENTO ELETROQUÍMICO DO MATERIAL

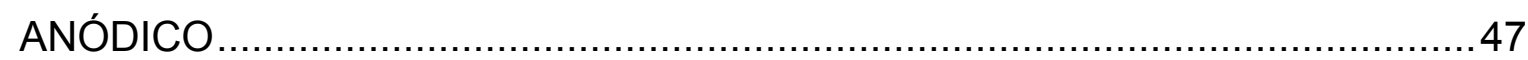

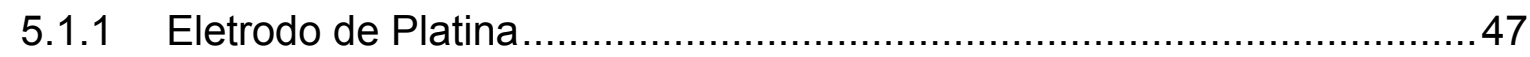

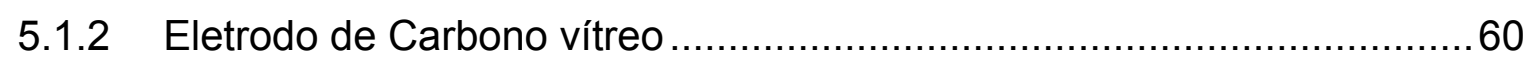

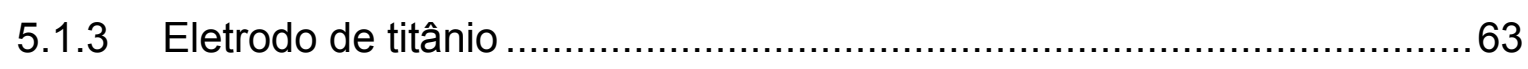

5.1.4 Eletrodo de titânio revestido de óxido de titânio e rutênio.......................65

5.1.5 Discussão dos resultados dos experimentos de VC ...........................73

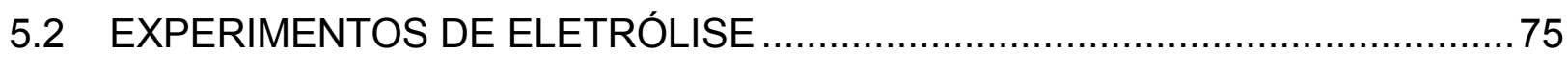

5.2.1 Discussão dos resultados dos experimentos de EL........................... 82

5.3 EXPERIMENTOS DE FOTOELETROOXIDAÇÃO ................................... 84

5.3.1 Discussão dos resultados dos experimentos de FEO .......................... 89

5.4 COMPARAÇÃO DOS EXPERIMENTOS DE ELETRÓLISE E

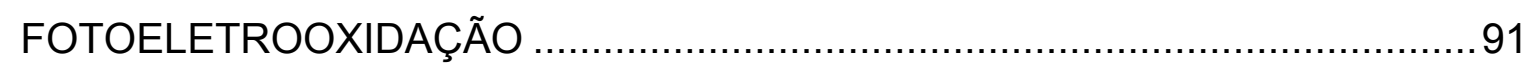

5.4.1 Discussão da comparação dos experimentos de EL e FEO ..................97

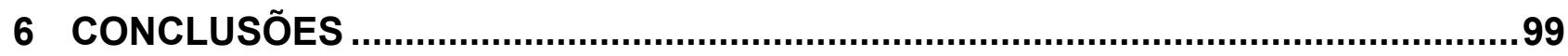

7 SUGESTÕES PARA TRABALHOS FUTUROS ..............................................101

8 PUBLICAÇÕES ORIGINADAS DA TESE ....................................................103

ANEXO I - TABELAS DE CÁLCULOS PARA ELETRODO DE PLATINA.....................121

ANEXO II - TABELAS DE CÁLCULOS PARA ELETRODO DE TI/TI $\mathrm{T}_{0,7} \mathrm{RU}_{0,3} \mathrm{O}_{2} \ldots \ldots \ldots . . .127$

ANEXO III - CONSUMO ENERGÉTICO ............................................................133

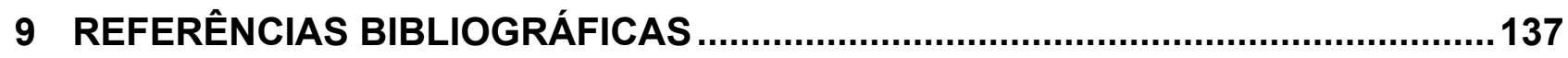




\section{LISTA DE FIGURAS}

Figura 1: Seqüência de reações de degradação do fenol, onde $r_{1}$ representa a rota para conversão eletroquímica e $r_{2}$ para combustão eletroquímica .

Figura 2: $\quad$ Representação esquemática dos mecanismos de oxidação, (A) formação dos radicais hidroxilas $(\bullet \mathrm{OH})$ na superfície do eletrodo; $(\mathrm{B})$ oxidação dos compostos orgânicos 27

Figura 3: Rota de oxidação proposta para o fenol ........................................28

Figura 4: Voltamograma de voltametria cíclica ......................................... 35

Figura 5: Célula eletroquímica de três eletrodos e um compartimento ......................36

Figura 6: Fluxograma da metodologia aplicada no estudo da oxidação de compostos

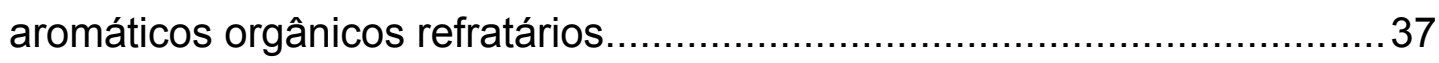

Figura 7: Célula eletroquímica utilizada nos ensaios de voltametria. ........................39

Figura 8: Célula eletroquímica utilizada nos ensaios de voltametria. .......................40

Figura 9: Aparato experimental utilizados nos experimentos de EL e FEO. Sendo: 1) banho ultratermostático, 2) reator de vidro encamisado, 3) agitador magnético e 4) fonte de corrente.

Figura 10: Representação esquemática do reator utilizado nos processos de EL e FEO. Onde: (1) reservatório de vidro; (2) ânodo de titânio revestido com $70 \mathrm{TiO}_{2} / 30 \mathrm{RuO}_{2} ;(3)$ cátodo de titânio revestido de óxido de titânio; (4) tubo de quartzo; (5) lâmpada de vapor de mercúrio.....................................42

Figura 11: Reator batelada utilizado no processo de EL e FEO ..............................42

Figura 12: Tubo de quartzo e Lâmpada de vapor de mercúrio, de $250 \mathrm{~W}$ de potência. 43

Figura 13: Eletrodos utilizados no reator eletroquímico, $\mathrm{A}$ ) cátodo de $\mathrm{Ti} / \mathrm{TiO}_{2}$ com o tubo de quartzo no interior e B) ânodo de $\mathrm{Ti}_{2} \mathrm{Ru}_{0,3} \mathrm{Ti}_{0,7} \mathrm{O}_{2}$.

Figura 14: Fluxograma de blocos das entradas e saídas de produtos químicos na realização dos experimentos, para cada etapa e com volume aproximado de efluente gerado. 46

Figura 15: Voltamogramas cíclicos obtidos em solução de $0,05 \mathrm{M} \mathrm{H}_{2} \mathrm{SO}_{4}$ e diferentes concentrações de fenol, $v=60 \mathrm{mV} \cdot \mathrm{s}^{-1}$. (ET $\left.=\mathrm{Pt}, \mathrm{CE}=\mathrm{Pt}, \mathrm{ER}=\mathrm{Ag} / \mathrm{AgCl}\right) .48$

Figura 16: Densidade de corrente de pico como função da concentração de fenol para diferentes concentrações de ácido sulfúrico $(0,01 ; 0,05 ; 0,5$ e 1,0 M). 49 
Figura 17: Potencial de pico como função da concentração de fenol para diferentes concentrações de ácido sulfúrico $(0,01 ; 0,05 ; 0,5$ e 1,0 M). 50

Figura 18: Voltamogramas cíclicos obtidos para uma solução $0,5 \mathrm{mM}$ fenol / $0,5 \mathrm{M} \mathrm{H}_{2} \mathrm{SO}_{4}, \mathrm{v}=60 \mathrm{mV} \cdot \mathrm{s}^{-1}$. (ET = Pt, $\left.\mathrm{CE}=\mathrm{Pt}, \mathrm{ER}=\mathrm{Ag} / \mathrm{AgCl}\right)$.

Figura 19: Curva potenciostática i-t obtida a $1,1 \mathrm{~V}$ para uma solução $0,5 \mathrm{mM}$ fenol / 0,5 $\mathrm{m} \mathrm{H}_{2} \mathrm{SO}_{4}$. $(\mathrm{ET}=\mathrm{Pt}, \mathrm{CE}=\mathrm{Pt}, \mathrm{ER}=\mathrm{Ag} / \mathrm{AgCl})$

Figura 20: Voltamogramas cíclicos obtidos usando EDR a $\mathrm{v}=60 \mathrm{mV} \cdot \mathrm{s}^{-1}$ para: A) 12,5 M fenol / 0,05 $\mathrm{M} \mathrm{H}_{2} \mathrm{SO}_{4}$ e B) 12,5 M fenol / 0,5 $\mathrm{M} \mathrm{H}_{2} \mathrm{SO}_{4}$. (ET = Pt, $\mathrm{CE}=\mathrm{Pt}, \mathrm{ER}=\mathrm{Ag} / \mathrm{AgCl})$.

Figura 21: Voltamogramas cíclicos obtidos para diferentes velocidades de varredura: $\mathrm{A}$ ) $1 \mathrm{mM}$ fenol / 0,05 $\mathrm{M} \mathrm{H}_{2} \mathrm{SO}_{4}$ e B) 6,25 mM fenol / 0,05 $\mathrm{M} \mathrm{H}_{2} \mathrm{SO}_{4}$. (ET = Pt, $\mathrm{CE}=\mathrm{Pt}, \mathrm{ER}=\mathrm{Ag} / \mathrm{AgCl})$.

Figura 22: Voltamogramas cíclicos obtidos para quatro diferentes concentrações de uma $\mathrm{H}_{2} \mathrm{SO}_{4}$ em solução de fenol: A) $1 \mathrm{mM} \mathrm{e} \mathrm{B)} 6,25 \mathrm{mM}$. v $=60 \mathrm{mV} \cdot \mathrm{s}^{-1}$. $(\mathrm{ET}=\mathrm{Pt}, \mathrm{CE}=\mathrm{Pt}, \mathrm{ER}=\mathrm{Ag} / \mathrm{AgCl})$.

Figura 23: Potencial de pico como uma função do logaritmo da velocidade de varredura para diferentes concentrações de fenol em 0,05 $\mathrm{M} \mathrm{H}_{2} \mathrm{SO}_{4}$.

Figura 24: Densidade de corrente de pico como uma função da raiz quadrada da velocidade de varredura para diferentes concentrações de fenol em $0,05 \mathrm{M} \mathrm{H}_{2} \mathrm{SO}_{4}$

Figura 25: Potencial de pico como uma função do logaritmo da velocidade de varredura de potencial em diferentes concentrações de $\mathrm{H}_{2} \mathrm{SO}_{4}$ para duas concentrações de fenol: A) $1 \mathrm{mM}$ e B) $6,25 \mathrm{mM}$.

Figura 26: Densidade de corrente de pico como uma função da raiz quadrada da velocidade de varredura de potencial em diferentes concentrações de $\mathrm{H}_{2} \mathrm{SO}_{4}$ para duas concentrações de fenol: A) $1 \mathrm{mM}$ e B) $6,25 \mathrm{mM}$. 58

Figura 27: Voltamogramas para o eletrodo de carbono vítreo em meio $0,5 \mathrm{M} \mathrm{H}_{2} \mathrm{SO}_{4} \mathrm{e}$ concentração de fenol de: A) $1 \mathrm{mM}$ e B) 6,25 mM. (ET = CV, CE = Pt, $\mathrm{ER}=\mathrm{Ag} / \mathrm{AgCl})$.

Figura 28: Comparação entre o comportamento dos eletrodos de platina e carbono vítreo (CV) para uma solução $0,5 \mathrm{M} \mathrm{H}_{2} \mathrm{SO}_{4} / 6,25 \mathrm{mM}$ fenol, velocidade de varredura $60 \mathrm{mV} \cdot \mathrm{s}^{-1} .(\mathrm{ET}=\mathrm{CV}, \mathrm{CE}=\mathrm{Pt}, \mathrm{ER}=\mathrm{Ag} / \mathrm{AgCl})$.

Figura 29: Voltamogramas de $V C$ para eletrodo de carbono vítreo, solução $0,5 \mathrm{M} \mathrm{H}_{2} \mathrm{SO}_{4} / 6,25 \mathrm{mM}$ fenol. $(\mathrm{ET}=\mathrm{CV}, \mathrm{CE}=\mathrm{Pt}, \mathrm{ER}=\mathrm{Ag} / \mathrm{AgCl})$. 62 
Figura 30: Voltamogramas obtidos para uma solução $0,5 \mathrm{M} \mathrm{H}_{2} \mathrm{SO}_{4}$ com: A) $1 \mathrm{mM}$ e B) 6,25 $\mathrm{mM}$ de fenol, para diversas velocidades de varredura, $(\mathrm{ET}=\mathrm{Ti}, \mathrm{CE}=\mathrm{Pt}$, $\mathrm{ER}=\mathrm{Ag} / \mathrm{AgCl})$.

Figura 31: Comparação entre o comportamento dos eletrodos de platina e titânio para uma solução $0,5 \mathrm{M} \mathrm{H}_{2} \mathrm{SO}_{4} / 6,25 \mathrm{mM}$ fenol, velocidade de varredura $60 \mathrm{mV} . \mathrm{s}^{-1} .64$

Figura 32: Voltamogramas obtidos para uma solução $0,5 \mathrm{M} \mathrm{H}_{2} \mathrm{SO}_{4} / 1 \mathrm{mM}$ fenol pela técnica de $\mathrm{VC}, \mathrm{v}=60 \mathrm{mV} \cdot \mathrm{s}^{-1}$.(ET=Ti , CE=Pt , ER=Ag/AgCl).

Figura 33: Voltamogramas cíclicos obtidos em solução de 0,5 $\mathrm{M} \mathrm{H}_{2} \mathrm{SO}_{4}$ e diferentes concentrações de fenol, $v=60 \mathrm{mV} \cdot \mathrm{s}^{-1} .\left(\mathrm{ET}=\mathrm{Ti} / \mathrm{Ru}_{0,3} \mathrm{Ti}_{0,7} \mathrm{O}_{2}, \mathrm{CE}=\mathrm{Pt}\right.$ e ER $=$ $\mathrm{Ag} / \mathrm{AgCl})$.

Figura 34: Densidade de corrente de pico como função da concentração de fenol para diferentes concentrações de ácido sulfúrico, $v=20 \mathrm{mV} . \mathrm{s}^{-1}$.

Figura 35: Densidade de corrente de pico como função da concentração de fenol para diferentes concentrações de ácido sulfúrico, $\mathrm{v}=60 \mathrm{mV} . \mathrm{s}^{-1}$....

Figura 36: Potencial de pico como função da concentração de fenol para diferentes concentrações de ácido sulfúrico $(0,01 ; 0,05 ; 0,5$ e 1,0 M).

Figura 37: Voltamogramas cíclicos obtidos para uma solução 0,5 mM fenol / $0,5 \mathrm{M} \mathrm{H}_{2} \mathrm{SO}_{4}, \mathrm{v}=60 \mathrm{mV} \cdot \mathrm{s}^{-1}$. $\left(\mathrm{ET}=\mathrm{Ti} / \mathrm{Ru}_{0,3} \mathrm{Ti}_{0,7} \mathrm{O}_{2}, \mathrm{CE}=\mathrm{Pt}\right.$ e $\left.\mathrm{ER}=\mathrm{Ag} / \mathrm{AgCl}\right) \cdot 69$

Figura 38: Potencial de pico como uma função do logaritmo da velocidade de varredura para diferentes concentrações de fenol em 1,0 $\mathrm{M} \mathrm{H}_{2} \mathrm{SO}_{4}$

Figura 39: Densidade de corrente de pico como uma função da raiz quadrada da velocidade de varredura para diferentes concentrações de fenol em $1 \mathrm{M}$ $\mathrm{H}_{2} \mathrm{SO}_{4} \cdot\left(\mathrm{ET}=\mathrm{Ti} / \mathrm{Ru}_{0,3} \mathrm{Ti}_{0,7} \mathrm{O}_{2}, \mathrm{CE}=\mathrm{Pt}\right.$ e $\left.\mathrm{ER}=\mathrm{Ag} / \mathrm{AgCl}\right)$.

Figura 40: Densidade de corrente de pico como uma função da raiz quadrada da velocidade de varredura de potencial em diferentes concentrações de $\mathrm{H}_{2} \mathrm{SO}_{4}$ para duas concentrações de fenol: A) 6,25 mM e B) 12,5 mM. 71

Figura 41: Voltamogramas obtidos para diferentes velocidades de varredura testadas nos experimentos de VC $\left(E T=\mathrm{Ti} / \mathrm{Ru}_{0,3} \mathrm{Ti}_{0,7} \mathrm{O}_{2}, \mathrm{CE}=\mathrm{Pt}\right.$ e $\left.\mathrm{ER}=\mathrm{Ag} / \mathrm{AgCl}\right) \ldots .72$

Figura 42: Comparação entre o comportamento dos eletrodos de platina e $\mathrm{Ti} / \mathrm{Ru}_{0,3} \mathrm{Ti}_{0,7} \mathrm{O}_{2}$ para uma solução $0,5 \mathrm{M} \mathrm{H} \mathrm{SO}_{4} / 6,25 \mathrm{mM}$ fenol, velocidade de varredura $60 \mathrm{mV} . \mathrm{s}^{-1}$.

Figura 43: Avaliação da agitação mecânica na degradação eletroquímica de fenol. ....77

Figura 44: Avaliação do processo de EL pela técnica de espectroscopia de UV/VIS....79

Figura 45: Análise por $\mathrm{Cl}$ da solução sintética $0,5 \mathrm{M} \mathrm{H}_{2} \mathrm{SO}_{4} / 6,25 \mathrm{mM}$ fenol. 80 
Figura 46: Análise por $\mathrm{Cl}$ da solução sintética $0,5 \mathrm{M} \mathrm{H}_{2} \mathrm{SO}_{4} / 6,25 \mathrm{mM}$ fenol após processo de EL.

Figura 47: Comparação dos cromatrogramas da solução inicial e a tratada por EL......81

Figura 48: Comparação entre os voltamogramas obtidos para a solução de fenol inicial e tratada por $\mathrm{EL}, \mathrm{v}=60 \mathrm{mV} \cdot \mathrm{s}^{-1} .\left(\mathrm{ET}=\mathrm{Ti} / \mathrm{Ru}_{0,3} \mathrm{Ti}_{0,7} \mathrm{O}_{2}, \mathrm{CE}=\mathrm{Pt}\right.$ e $\mathrm{ER}=$ $\mathrm{Ag} / \mathrm{AgCl})$. 82

Figura 49: Soluções: 1) inicial e 2) após o processo de FEO. 86

Figura 50: Avaliação do processo de FEO pela técnica de espectroscopia de UV/VIS. 87

Figura 51: Análise por $\mathrm{Cl}$ da solução sintética $0,5 \mathrm{M} \mathrm{H}_{2} \mathrm{SO}_{4} / 6,25 \mathrm{mM}$ fenol após processo de FEO.

Figura 52: Comparação dos cromatrogramas da solução inicial e a tratada por FEO...88

Figura 53: Comparação entre os voltamogramas obtidos para a solução de fenol inicial e tratada por $\mathrm{EL}, \mathrm{v}=60 \mathrm{mV} \cdot \mathrm{s}^{-1} .\left(\mathrm{ET}=\mathrm{Ti} / \mathrm{Ru}_{0}, 3 \mathrm{Ti}_{0,7} \mathrm{O}_{2}, \mathrm{CE}=\mathrm{Pt} \mathrm{e}\right.$ $\mathrm{ER}=\mathrm{Ag} / \mathrm{AgCl})$. 89

Figura 54: Comparação dos valores médios de redução nos teores de matéria orgânica entre os processos de EL e FEO.

Figura 55: Avaliação dos processos de EL e FEO pela técnica de espectroscopia de UVIVIS.

Figura 56: Comparação entre os voltamogramas obtidos para a solução de fenol inicial, tratada por EL e tratada por FEO, v=60 mV.s ${ }^{-1} .\left(E T=T i / R_{0,3} \mathrm{Ti}_{0,7} \mathrm{O}_{2}, \mathrm{CE}=\mathrm{Pt}\right.$ e $\mathrm{ER}=\mathrm{Ag} / \mathrm{AgCl})$. 95

Figura 57: Amostras das soluções: 1) inicial, 2) após EL e 3) após FEO. 96

Figura 58: Comparação dos cromatrogramas da solução inicial e a tratada por EL e FEO. 


\section{LISTA DE TABELAS}

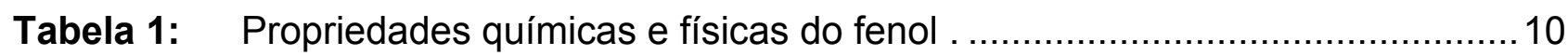

Tabela 2: Potencial eletroquímico dos agentes oxidantes mais utilizados ..................14

Tabela 3: Medidas de $\mathrm{pH}$ e condutividade para as soluções testadas nos experimentos

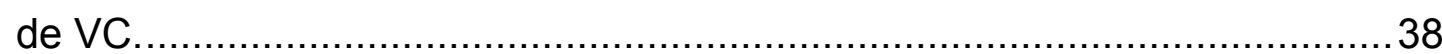

Tabela 4: Valores de $n_{\alpha}$ e coeficiente de difusão encontrados para o fenol. .................60

Tabela 5: Estudo do efeito da agitação mecânica no processo de eletrooxidação, em sistema de batelada. Tempo de reação: $5 \mathrm{~h}$

Tabela 6: Influência da intensidade da força motriz no processo de eletrooxidação de fenol. Tempo de reação: $5 \mathrm{~h}$. 78

Tabela 7: Experimentos de FEO a diferentes densidades de corrente, para uma solução de $0,5 \mathrm{M} \mathrm{H}_{2} \mathrm{SO}_{4} / 6,25 \mathrm{mM}$ fenol. 85

Tabela 8: Concentração de ácidos orgânicos obtidas por $\mathrm{Cl}$ para os experimentos $02 \mathrm{e}$ 06 



\section{LISTA DE SÍMBOLOS}

\begin{tabular}{ll} 
A & Área do eletrodo de trabalho \\
BDD & Eletrodo de boro diamante dopado \\
BC & Banda de Condução \\
BQ & Benzoquinona \\
BV & Banda de Valência \\
C & Concentração \\
CE & Contra eletrodo \\
CFC & Cloro flúor carbono \\
CLAP & Cromatografia líquida de alta performance \\
COT & Carbono Orgânico Total \\
Cl & Cromatografia iônica \\
CV & Carbono Vítreo \\
D & coeficiente de difusão \\
DSA & Dimensionally Stable Anodes \\
DQO & Demanda Química de Oxigênio \\
E & Potencial do eletrodo \\
Ep & Potencial de pico anódico \\
Ep1/2 & Potencial de meia onda \\
$\Delta E p$ & Variação do Ep \\
ER & Eletrodo de referência \\
ET & Eletrodo de trabalho \\
FEO & Fotoeletrooxidação \\
F & Constante de Faraday \\
hv & Lacuna positiva \\
\hline
\end{tabular}




$\begin{array}{ll}\text { i } & \text { densidade de corrente } \\ \text { ip } & \text { densidade de corrente de pico anódica } \\ \text { Ip } & \text { corrente } \\ \mathrm{MO}_{\mathrm{x}} & \text { Corrente de pico anódica } \\ \mathrm{MO}_{\mathrm{x}+1} & \text { Superóxido metálico } \\ \mathrm{na} & \text { Coeficiente de transferência de carga } \\ \cdot \mathrm{OH} & \text { Radical Hidroxila } \\ \cdot \mathrm{OH} & \text { Radical hidroxila adsorvido } \\ \mathrm{POA} & \text { Processo Oxidativo Avançado } \\ \mathrm{R} & \text { Composto Orgânico / Constante real dos gases } \\ \mathrm{UV} & \text { Ultravioleta } \\ \mathrm{V} & \text { velocidade de varredura } \\ \mathrm{VC} & \text { Voltametria cíclica de varredura } \\ \mathrm{VIS} & \text { Visível } \\ \lambda & \text { Comprimento de onda } \\ \end{array}$




\section{RESUMO}

Nas mais diversas atividades industriais hoje existentes está presente a problemática dos resíduos gerados e seu gerenciamento. Os efluentes líquidos são uma grande fonte de poluição dos recursos hídricos, sendo necessário o controle das condições de seu descarte. Alguns parâmetros são regulamentados por legislação, nacional e estadual, contudo, mesmo atendendo as exigências da legislação, essa água é descartada com baixas concentrações de poluentes. Alguns poluentes orgânicos aromáticos apresentam problemas de toxicidade e bioacumulação mesmo a baixas concentrações. Em geral constituem um problema para o tratamento biológico devido a sua toxicidade, pois são nocivos aos microorganismos depuradores da matéria orgânica e sua baixa degradabilidade faz com que passem pelo processo biológico de tratamento sem se decompor.

Para efluentes contendo poluentes orgânicos uma das alternativas de tratamento que vem sendo muito investigada é o uso de Processos Oxidativos Avançados - POA's. Esses processos têm como objetivo a degradação dos compostos orgânicos presentes, inclusive os refratários, em curto intervalo de tempo e com alta eficiência.

Neste trabalho se investiga a aplicação dos processos de eletrólise - EL e fotoeletrooxidação - FEO na degradação de poluentes orgânicos aromáticos refratários em soluções sintéticas, visando um maior entendimento dos fenômenos envolvidos nesses processos de tratamento de efluentes, bem como sua viabilidade técnica de aplicação. Outro ponto estudado é o uso da técnica de voltametria cíclica de varredura como ferramenta para a avaliação do comportamento eletroquímico do material anódico e definição de parâmetros de trabalho para os processos oxidativos investigados.

Ambos os processos oxidativos investigados demonstraram ser capazes de degradar o composto orgânico refratário, sendo que no processo de FEO se atingiu uma maior eficiência de degradação do fenol, gerando compostos muito menos prejudiciais ao meio ambiente, como os ácidos orgânicos. Tanto o processo de eletrólise como o de fotoeletrooxidação representam ser uma alternativa tecnológica para a degradação desses perigosos compostos. 



\section{RESUMEN}

Muchas de las actividades industriales existentes actualmente presentan el problema de los residuos generados y su gestión. Los residuos líquidos son una fuente importante de contaminación de los recursos hídricos, siendo necesario el control de las condiciones de su eliminación. Algunos parámetros están regulados por la legislación, nacional y estatal, sin embargo, incluso cumpliendo los requisitos de la legislación, este agua se elimina con concentraciones de contaminantes bajas. Algunos contaminantes orgánicos aromáticos presentan problemas de toxicidad y bioacumulación, incluso a bajas concentraciones. En general son un problema para el tratamiento biológico debido a su toxicidad (ya que son perjudiciales para los microorganismos depuradores de materia orgánica) y por su baja degradabilidad pueden pasar a través del tratamiento biológico sin descomponerse.

Para los efluentes que contienen contaminantes orgánicos se han investigado ampliamente varios tratamientos alternativos, como el uso de los Procesos de Oxidación Avanzada - POA. Estos procesos están dirigidos a la degradación de los compuestos orgánicos, incluidos los refractarios, en un corto período de tiempo y con alta eficiencia.

En este trabajo se investiga la aplicación de los procesos de electrólisis - EL y fotoelectrooxidation - FEO a la degradación de contaminantes orgánicos aromáticos refractarios en soluciones sintéticas, para comprender mejor los fenómenos involucrados en el proceso de tratamiento de efluentes, así como su viabilidad técnica de aplicación. Otro punto estudiado fue el uso de la técnica de voltametría cíclica de barrido como una herramienta para evaluar el comportamiento electroquímico del material del ánodo y la definición de los parámetros de trabajo para investigar los procesos de oxidación evaluados.

Ambos procesos de oxidación investigados han demostrado ser capaces de degradar compuestos orgánicos refractarios, y en el proceso de FEO se logró una mayor eficiencia de la degradación de fenol y la producción de compuestos menos perjudiciales para el medio ambiente, tales como los ácidos orgánicos. Tanto el proceso de electrólisis como fotoelectrooxidación representan una alternativa tecnológica para la degradación de estos compuestos peligrosos. 



\section{RESUM}

Moltes de les activitats industrials existents actualment presenten el problema dels residus generats i la seua gestió. Els residus líquids són una font important de contaminació dels recursos hídrics, fent-se necessari el control de les condicions de la seua eliminació. Alguns dels paràmetres estan regulats per la legislació, nacional i estatal, tanmateix, acomplint els requisits de la legislació, aquesta aigua s'elimina amb concentracions de contaminants baixes. Alguns contaminants orgànics presenten problemes de toxicitat i bioacumulació, fins i tot a concentracions baixes. En general són un problema per al tractament biològic degut a la seua toxicitat (perquè són perjudicials per als microorganismes depuradors de matèria orgànica) i per la seua baixa degradabilitat poden passar pel tractament biològic sense descompondre's.

Per als efluents que contenen contaminants orgànics s'han investigat àmpliament tractaments alternatius, com la utilització dels Processos d'Oxidació Avançada - POA. Aquests processos estan dirigits a la degradació dels compostos orgànics, inclosos els refractaris, en un curt període de temps $i$ amb eficiència alta.

En aquest treball s'investiga l'aplicació del procés d'electròlisi - EL i fotoelectrooxidació - FEO a la degradació de contaminants orgànics aromàtics refractaris en dissolucions sintètiques, per a comprendre millor els fenòmens involucrats en el procés de tractament d'efluents, al mateix temps que la seua viabilitat tècnica d'aplicació. Un altre punt estudiat ha sigut l'ús de la tècnica de voltametria cíclica com a ferramenta per avaluar el comportament electroquímic del material de l'anode i la definició dels paràmetres de treball per a investigar els processos d'oxidació avaluats.

Els dos processos d'oxidació investigats han demostrat ser capaços de degradar compostos orgànics refractaris, $i$ en el procés de FEO es va aconseguir una major eficiència de la degradació de fenol i la producció de compostos menys perjudicials per al medi ambient, com per exemple els àcids orgànics. Tant el procés d'electròlisi com de fotoelectrooxidació es presenten una alternativa tecnològica per a la degradació d'aquests compostos perillosos. 



\begin{abstract}
In different industrial activities existing today there is the problem of waste generated and its management. Liquid wastes are a major source of water resources pollution, being necessary the control of the disposal conditions. Some parameters are regulated by legislation, in national and in state level, however, even meeting the requirements of legislation, this water is disposed of with low concentrations of pollutants. Some aromatic organic pollutants present problems of toxicity and bioaccumulation even at low concentrations. In general they are a problem for biological treatment due to their toxicity, since they are detrimental to the microorganisms debuggers of organic matter and their low degradability make them pass through the biological treatment without decaying.

For effluents containing organic pollutants an alternative treatment, that has been widely investigated, is the use of Advanced Oxidation Processes - AOP's. These processes are aimed at the degradation of organic compounds, including refractory, in a short period of time and with high efficiency.

This work investigates the application of electrolysis - $E L$ and photoelectrooxidation - PEO in the degradation of refractory aromatic organic pollutants in synthetic solutions, in order to better understand the phenomena involved in the process of effluent treatment, as well as their technical feasibility of implementation. Another point studied is the use of of scan cyclic voltammetry technique as a tool for evaluating the electrochemical behavior of anode material and the definition of working parameters for the oxidation processes investigated.
\end{abstract}

Both oxidation processes investigated have proved to be capable of degrading refractory organic compound, and in the PEO process greater efficiency of phenol degradation was achieved, producing compounds far less damaging to the environment, such as organic acids. Both processes, electrolysis and photoelectrooxidation, represent a technological alternative for the degradation of these hazardous compounds. 



\section{INTRODUÇÃO}

Ao longo da História, o homem tem passado por uma profunda mudança nos seus conceitos e idéias sobre o mundo em que vive. Uma crise ambiental mundial tem sido enfrentada, paradigma esse intimamente ligado ao modelo de desenvolvimento adotado, onde os recursos naturais de um modo geral vêm escasseando em quantidade e qualidade, comprometendo a qualidade de vida e os sistemas econômicos. A deterioração ambiental deve ser encarada não como uma conseqüência inevitável do crescimento, mas sim como uma limitação a ser superada, na busca de um desenvolvimento sustentável.

A água doce é um dos recursos naturais mais escassos e importantes, se não o mais importante, de todos os que constituem a vida na Terra. Além de problemas de quantidade disponível, outro problema com o qual nos deparamos é a qualidade da água. Ela é afetada devido aos despejos industriais e urbanos, às atividades mineradoras, ao carregamento de fertilizantes e agrotóxicos das lavouras para os corpos hídricos e ao desmatamento de mananciais.

A indústria demanda uma alta quantidade de água para a execução de seus processos, contudo, geralmente, essa água após usada é tratada para atingir os parâmetros exigidos pela legislação e descartada. Nesse descarte no corpo receptor são despejados juntos os poluentes em baixas concentrações e os produtos químicos usados para o tratamento. Além disso, no tratamento do efluente pode ocorrer a geração de lodo, o qual deve ser seco e disposto em local apropriado.

Órgãos governamentais de controle ambiental exigem efluentes dentro de padrões de lançamento, o que significa que os sistemas de tratamento têm de ser ajustados para esse controle. Este tratamento consiste, basicamente, de duas etapas: tratamento primário ou físico-químico e tratamento secundário ou biológico. No tratamento primário ocorre uma grande redução na toxicidade do efluente permitindo que o tratamento secundário opere em condições mais favoráveis ao desenvolvimento de microrganismos depuradores da matéria orgânica restante. 
Os tratamentos de efluentes aquosos industriais, baseados em processos biológicos de degradação, são os mais utilizados para a oxidação de poluentes orgânicos. Isso se deve a características como baixo custo e possibilidade de tratar grandes volumes. Entretanto, a capacidade de certos microrganismos para degradar alguns compostos orgânicos é limitada. Além disso, variações de $\mathrm{pH}$, ou da concentração de poluentes, podem inibir ou paralisar o metabolismo dos microorganismos. Pequenas diferenças na estrutura de um composto poluente ou na composição do meio também podem prejudicar o funcionamento de um sistema biológico estabelecido.

Paralelamente, a coloração de efluentes aquosos é outra forte limitação para os tratamentos biológicos, sendo também altamente interferente nos processos fotossintéticos naturais nos leitos dos rios e em lagoas, provocando alterações na biota aquática, principalmente nas imediações da descarga. Os tratamentos biológicos convencionais são pouco eficientes na remoção de cor e, em muitos casos, o efluente tratado pode apresentar uma coloração mais acentuada.

O tratamento convencional utilizado pela grande maioria das indústrias brasileiras, mesmo aquelas que atendem aos padrões de lançamento de efluentes, não é suficiente para restabelecer as características iniciais da água utilizada na produção. Os processos eletroquímicos surgem como métodos alternativos ao tratamento de efluentes industriais, pois apresentam a vantagem de possibilitar a recuperação/reutilização ou oxidação das substâncias químicas presentes nos efluentes, diminuindo, assim, o impacto ambiental das atividades industriais.

Para o tratamento de efluentes com contaminantes orgânicos optou-se pela aplicação de Processos Oxidativos Avançados (POA`s), os quais são responsáveis pela degradação da matéria orgânica presente no efluente.

Os POA's são processos de oxidação que envolvem a formação de radicais hidroxila $(\cdot \mathrm{OH})$, que tem alto potencial de oxidação, sendo depois do flúor o agente oxidante mais forte. Portanto, o princípio básico que caracteriza um POA é a formação desse radical, seja por meio químico, físico, eletroquímico ou fotoquímico.

Em reações eletroquímicas, a oxidação anódica permite a formação de radicais hidroxila como espécie intermediária da evolução de oxigênio. $O$ uso dos eletrodos, cujo ânodo é revestido de óxidos de semicondutores, na oxidação 
eletroquímica de compostos orgânicos, permite ainda que a eletrólise (EL) possa ser assistida pela fotocatálise heterogênea quando a superfície do eletrodo apresenta fotoatividade. Esse processo eletroquímico fotoassistido é denominado de fotoeletrooxidação (FEO) e consiste na passagem da solução a ser tratada através de uma célula eletroquímica onde o ânodo, revestido com óxidos metálicos, permanece sob a incidência de radiação UV. Portanto, o uso de materiais anódicos especiais que promovem a formação de radicais hidroxila, tanto por via eletroquímica como fotoquímica, caracterizam esses processos como POA`s. Com a aplicação dos processos oxidativos de EL e FEO pode-se modificar, degradar ou mineralizar compostos orgânicos sem a necessidade de adição de produtos químicos, os únicos reagentes envolvidos são os elétrons e os fótons. Além disso, esses processos possibilitam que substâncias refratárias podem ser degradadas e substâncias tóxicas podem ser convertidas em compostos não tóxicos.

Tendo em vista a crescente demanda por novas tecnologias que auxiliem na conservação ou recuperação da qualidade dos recursos hídricos disponíveis, esses métodos mais sofisticados de oxidação podem ser uma ferramenta eficiente e versátil de controle da poluição aquosa.

Visando o estudo dos processos de degradação de poluentes orgânicos aromáticos refratários foi utilizado como poluente o fenol, tendo em vista que este composto vem sendo objeto de estudo de diversos trabalhos de pesquisa nesta área devido sua facilidade de manuseio e trabalho em condições normais de temperatura e pressão, além de ser um poluente presente em diversos efluentes industriais. Os resultados obtidos nessa investigação com o fenol podem ser estendidos para o tratamento de outras espécies de poluentes orgânicos aromáticos refratários, considerando ainda que os compostos fenólicos halogenados são dentre essa espécie de poluentes os mais perigosos e prejudiciais ao meio ambiente. 



\section{OBJETIVOS}

\subsection{OBJETIVO GERAL}

Visando o gerenciamento dos recursos hídricos e a redução do impacto ambiental das atividades industriais, tem-se como principal objetivo deste trabalho a investigação da aplicação dos processos eletroquímicos e fotoeletroquímicos de EL e FEO na degradação de poluentes orgânicos aromáticos refratários.

\subsection{OBJETIVOS ESPECÍFICOS}

Buscando atingir o objetivo principal do trabalho de investigação proposto foram estabelecidos os seguintes passos:

- Estudo por meio de ensaios de voltametria cíclica de varredura do comportamento eletroquímico de soluções sintéticas de fenol, avaliando o efeito da concentração de fenol, e o pH do meio, utilizando eletrodo de trabalho de platina.

- Avaliação do comportamento eletroquímico de diferentes materiais anódicos.

- Investigação do processo de eletrólise aplicado na degradação de fenol.

- Investigação do processo de eletrólise associado à radiação UV fotoeletrooxidação - aplicado na degradação de fenol.

- Comparação entre os processos oxidativos investigados e otimização de parâmetros de processo. 



\section{REVISÃO BIBLIOGRÁFICA}

\subsection{FENOL}

Processos industriais geram uma grande variedade de moléculas que podem ser poluentes do ar, água e solo devido a seu impacto negativo para ecossistemas e humanos (propriedades tóxicas, carcinogênicas e mutagênicas). Fenol é um preocupante poluente orgânico aquoso devido a sua toxicidade mesmo a baixas concentrações, bio-acumulação e baixa degradabilidade, além da possibilidade de formação de compostos substituídos durante o processo de desinfecção da água, compostos esses ainda mais perigosos para a saúde humana que o próprio fenol. O fenol também é relevante no campo de pesquisa ambiental, pois tem sido utilizado como modelo de poluente orgânico aromático refratário e muitos dados avaliados para sua remoção ou destruição são empregados para o tratamento de efluentes industriais contendo os mais diferentes poluentes orgânicos aromáticos [1].

\subsubsection{Histórico}

Compostos fenólicos são componentes naturais de muitas substâncias como chá preto, vinho e comidas defumadas; também são emitidos na queima de combustíveis fósseis e tabaco; e na decomposição de matéria orgânica. Contudo, são compostos que apresentam baixa toxicidade se comparados com os gerados em efluentes industriais.

O fenol foi parcialmente isolado pela primeira vez do alcatrão de carvão pelo pesquisador Friedlieb Ferdinard Runge em 1834, o qual denominou a substância de ácido carbônico ou ácido do óleo de carvão. Em 1841 o professor Auguste Laurent preparou pela primeira vez fenol puro, em seus estudos sobre o destilado de carvão/alcatrão e cloro, obtendo soluções de diclorofenol e triclorofenol, denominando o radical fundamental dos dois compostos de phéne. Durante seus estudos ele obteve cristais de fenol que foram empregados primeiramente para 
tratamento de dores de dente, sendo depois não mais empregado, pois, apesar de reduzir as dores, foi considerado muito agressivo para os lábios e gengivas. Em 1843 Charles Frederic Gerhardt obteve fenol a partir do aquecimento de ácido salicílico com cal, denominando então a substância de fenol. Durante toda a década de 1840 o fenol foi objeto de diversos estudos e acaloradas discussões sobre seus mecanismos de reação, sendo Laurent defensor da teoria de substituição do hidrogênio por cloro, teoria essa fortemente atacada por Berzélius, o qual não acreditava na existência da nova molécula e, portanto não aceitava a hipótese defendida por Laurent e seu orientador Dumas [2]. Em 1867 a BASF já dominava a síntese de fenol e investigava a produção de fenol e formaldeído. Em 1865 passou a ser utilizado como desinfetante em hospitais tanto para a assepsia de tecidos e mucosas como para esterilização de instrumentos cirúrgicos e curativos. Na época de sua utilização obteve bons resultados e os pacientes apresentaram melhores chances de recuperação. Hoje, mais de 140 anos após, seu uso para essa finalidade foi totalmente banido dos estabelecimentos de saúde, tendo em vista o conhecimento das desvantagens para a saúde humana, devido sua toxicidade e efeito corrosivo na pele e mucosas. Hoje o fenol para fins farmacêuticos tem uso limitado na fabricação de medicamentos, como a Aspirina ${ }^{\circledR}$.

A contaminação por fenol pode ocorrer pela inalação, ingestão, contato com os olhos e absorção pela pele. O contato com essa perigosa substância pode provocar graves queimaduras, coma, convulsão e levar até a morte, a ingestão de $1 \mathrm{~g}$ de fenol é letal para o ser humano. Em algumas prisões americanas ele é empregado na fabricação da injeção letal utilizada na execução de prisioneiros devido sua eficiência e baixo custo. No século passado pessoas utilizavam o fenol para provocar as chagas de Cristo em suas mãos e pés, simulando falsos milagres. Embora altamente tóxico para o ser humano, não se tem evidências de que o fenol tenha potencial carcinogênico. A presença destes compostos em doses subletais afeta os sistemas nervoso e circulatório, com redução do crescimento de células sanguíneas, mesmo em concentrações extremamente baixas (0,002 mg/L). Outro problema relacionado ao fenol é a alteração de sabor na água, esta característica constitui-se em problemas operacionais em cervejarias, destilarias e unidades de engarrafamento de água mineral. 
Outros usos industriais dessa perigosa substância ainda persistem nos dias atuais, como: fabricação de resinas, aditivo na gasolina, preservação da madeira, pesticidas, herbicidas, fungicidas, inibidores de corrosão, desengraxantes, produção de plásticos, coquerias, fabricação de tintas e removedores de tinta, solvente, reagente para análises químicas e explosivos. Atualmente a produção mundial de fenol esta na ordem de 6 milhões de toneladas por ano [1]. O processo de obtenção de fenol não se baseia mais na destilação do alcatrão de carvão utilizada no século XIX por Runge, um processo conhecido por Hock é o mais utilizado. Esse processo consiste na síntese simultânea de fenol e acetona a partir de benzeno, propileno e oxigênio, e é aplicado para a produção de aproximadamente $95 \%$ do fenol utilizado no mundo.

\subsubsection{Propriedades físico-químicas}

O fenol é uma função orgânica caracterizada por uma ou mais hidroxilas ligadas a um anel aromático. Apesar de possuir um grupo - $\mathrm{OH}$ característico de um álcool, o fenol é mais ácido que este. O composto fenol também é conhecido por outros nomes como: benzenol, ácido carbólico, ácido fênico, ácido fenílico, hidróxibenzeno e monohidroxibenzeno. A temperatura e pressão ambientes os fenóis são sólidos cristalinos brancos, sendo que a coloração pode variar com a presença de impurezas. Apresenta grande solubilidade em álcool etílico, éter e em diversos solventes polares. Em água apresenta solubilidade limitada e comportamento como ácido fraco. Quando líquido o fenol ataca a borracha e alguns plásticos, já quando líquido aquecido pode atacar metais como alumínio, magnésio, chumbo e zinco. É caracterizado por um odor agridoce, medicinal ou de alcatrão. Fenol é um composto combustível. Algumas propriedades físicas e químicas do fenol estão reportadas na Tabela 1. 
Tabela 1: Propriedades químicas e físicas do fenol [1].

\begin{tabular}{|l|c|}
\hline Fórmula & \\
\hline Peso molecular $(\mathrm{g} / \mathrm{mol})$ & \\
\hline Temperatura de fusão $\left({ }^{\circ} \mathrm{C}\right)$ & 94,11 \\
\hline Temperatura de ebulição $\left({ }^{\circ} \mathrm{C}\right)$ & 40,90 \\
\hline pKa & 181,75 \\
\hline Solubilidade em água $(\mathrm{g} / 100 \mathrm{ml})$ & 9,89 \\
\hline
\end{tabular}

\subsubsection{Fontes de geração}

O fenol está presente em efluentes de diversos tipos de processos industriais, tanto como substância pura como na forma de compostos substituídos de fenol. Ao serem descartados em corpos hídricos, estes efluentes causam sérios problemas ambientais, tanto aos ecossistemas do corpo receptor como ao ser humano. Os efluentes de plantas industriais, tais como coquerias, refinarias de petróleo e produtoras de resinas, entre outros, freqüentemente contêm compostos fenólicos. As coquerias são responsáveis pela produção de gás e coque para aplicações na indústria metalúrgica e obtenção de outros subprodutos como benzeno, tolueno, antraceno e nafteno aplicados na síntese de corantes, drogas e explosivos. Os efluentes líquidos gerados por essas indústrias são altamente poluentes, de difícil tratamento e apresentam em sua composição compostos amoniacais, cianetos e, especialmente, compostos fenólicos na faixa de concentração de 80 a 123 mg/L. [3]. Nas refinarias de petróleo, o craqueamento catalítico em leito fluidizado gera efluentes contendo concentrações consideráveis de fenol (50 a $260 \mathrm{mg} / \mathrm{L}$ ) e concentrações comparáveis de íons sulfeto e amônia. $\mathrm{Na}$ indústria petroquímica, as unidades de pirólise produzem etileno a partir do craqueamento térmico da nafta, sendo identificada a presença de compostos fenólicos nos efluentes gerados nos processos de pirólise de hidrocarbonetos [4]. $\mathrm{Na}$ 
produção de resinas poliméricas, como por exemplo, a baquelite, o fenol é utilizado como preservante e constitui um dos poluentes presentes em seus efluentes.

Indústrias de pesticidas e herbicidas utilizam compostos fenólicos em seus processos, gerando efluentes com altas concentrações desses contaminantes. O Brasil figura em terceiro lugar entre os principais mercados de pesticidas do mundo [5]. Outra fonte de poluição dos recursos hídricos por pesticidas e herbicidas é o arraste desses compostos das lavouras pela ação das chuvas, gerando contaminação dos corpos receptores, como rios, lagoas e banhados. Muitos desses corpos hídricos são utilizados na captação de água para abastecimento urbano, sendo que os processos de potabilização da água geralmente são pouco eficientes na remoção desses perigosos compostos.

Face ao exposto, é de extrema importância o desenvolvimento de tecnologias que viabilizem o tratamento adequado desses poluentes.

\subsubsection{Alternativas de tratamento}

As principais tecnologias convencionais empregadas no abatimento de fenol em efluentes industriais são: o tratamento biológico, os processos de extração, o tratamento com carvão ativado, os processos térmicos, o arraste com ar ou a osmose reversa [6,7]. No que diz respeito ao tratamento biológico, a tecnologia de lodo ativado é amplamente utilizada, especialmente em centrais de tratamento de efluentes industriais [8]. O método consiste na degradação de compostos orgânicos em tanques de lodo, com sistemas biológicos aeróbicos e anaeróbicos, monitorandose continuamente a temperatura, a demanda química de oxigênio (DQO) e os contaminantes a serem degradados. A elevada toxicidade dos compostos fenólicos torna, entretanto, inconveniente a aplicação deste método em correntes com elevadas concentrações de fenóis, pois tais compostos são recalcitrantes à biodegradação e tóxicos aos microorganismos, uma vez que concentrações acima de 70 mg/L de fenol são consideradas tóxicas à população microbial.

A extração líquido-líquido, por sua vez, é uma tecnologia eficiente e economicamente viável na remoção e recuperação de fenol, em correntes nas quais este contaminante se encontra presente em concentrações superiores a 1\%. Neste processo, um ou mais solutos são removidos de uma corrente líquida por 
transferência do soluto para uma segunda fase líquida, imiscível ou parcialmente miscível com a primeira. Uma vez que não se requer a vaporização da corrente, a extração pode ser conduzida a baixas temperaturas e, portanto, é um processo de separação aplicável a moléculas termo instáveis. Entretanto, nos casos de sistemas com concentrações mais baixas de soluto, como é o caso de efluentes industriais contaminados com compostos fenólicos, o custo operacional de uma unidade de extração é muito elevado em função das utilidades requeridas e pode inviabilizar a sua aplicação [1].

A adsorção com carvão ativado é uma técnica empregada, com sucesso, no tratamento de efluentes contaminados com baixas concentrações de compostos fenólicos, por ser eficiente e econômica [9]. O processo apresenta, entretanto, a desvantagem de exigir uma etapa de regeneração, durante a qual o contaminante é concentrado na fase vapor. Além disso, o processo de adsorção não resolve o problema ambiental, uma vez que o resíduo gerado, freqüentemente, deve ser disposto no meio ambiente.

Os tratamentos térmicos são os processos mais comuns e amplamente usados na remediação de águas contaminadas por compostos voláteis e podem envolver as operações de arraste com ar ou de extração. A metodologia envolve a injeção de ar para dentro do aqüífero contaminado, a transferência dos contaminantes voláteis para a fase gasosa e sua separação por um sistema de extração de vapor. Entretanto, esse processo apresenta baixa eficiência para a remoção de compostos fenólicos, usualmente de maior solubilidade em água.

Outros processos tais como a floculação, precipitação ou osmose reversa requerem um tratamento posterior para a remoção do poluente e, portanto, apresentam aplicações limitadas.

Existem métodos alternativos a estas técnicas já bem estabelecidos, que envolvem a oxidação de poluentes com reagentes como o ar ou o oxigênio em fase aquosa, tais como a oxidação supercrítica, a oxidação eletroquímica e o uso de permanganato de potássio, peróxido de hidrogênio ou ozônio. Dentre estas técnicas, os processos oxidativos avançados (POA's) aparecem como os mais promissores para aplicação em água e solos contaminados, por promoverem a degradação total dos poluentes. Estas técnicas podem também levar à formação de contaminantes 
menos poluentes, usualmente compostos orgânicos oxigenados e ácidos de baixo peso molecular, sendo aplicáveis ao tratamento de águas contaminadas com baixas concentrações de poluentes.

A preocupação com a qualidade do ambiente e das águas tem se intensificado nas últimas décadas devido a uma maior conscientização dos riscos eminentes à saúde humana e da deterioração das águas. Neste contexto, maior rigor nos descartes de efluentes tem sido uma estratégia para minimizar o impacto ambiental. Contudo, o controle do descarte de efluentes ainda é insuficiente, sendo necessário que se desenvolvam novos processos de tratamento que garantam um nível mais baixo de contaminantes [10].

\subsection{PROCESSOS OXIDATIVOS AVANÇADOS - POA'S}

Em função da crescente necessidade de procedimentos que apresentem uma maior eficiência no tratamento de efluentes, várias técnicas têm sido testadas, servindo de alternativas para a degradação de compostos orgânicos. Muitos trabalhos de pesquisa têm surgido, principalmente nas duas últimas décadas, sobre uma classe especial de técnicas de oxidação denominada de Processos Oxidativos Avançados - POA's, os quais operam usualmente a temperatura e pressão próximas a ambiente [11, 12]. Embora esses processos utilizem diferentes sistemas de reações, apresentam como característica comum a produção do radical hidroxila $(\cdot \mathrm{OH})$, que tem alto poder oxidante.

Os POA's podem promover a degradação de vários compostos poluentes em poucos minutos, inclusive os compostos conhecidos como refratários, que resistem ao tratamento convencional de efluentes [13]. Na Tabela 2 pode-se verificar o alto potencial de oxidação do radical hidroxila.

Vários processos de produção do radical hidroxila têm sido estudados, geralmente utilizando ozônio, peróxido de hidrogênio, fotocatálise com dióxido de titânio, ultra-som e o Reagente de Fenton. Esses POA's são estudados quando aplicados isoladamente ou combinados entre si, ou ainda, associados à radiação UV. 
O ozônio, por ser um oxidante enérgico, é muito utilizado em processos de degradação de compostos orgânicos, entre eles os organoclorados. Na presença de radiação ultravioleta (UV), o ozônio também pode formar o radical hidroxila [14].

Tabela 2: Potencial eletroquímico dos agentes oxidantes mais utilizados [6].

\begin{tabular}{|l|c|}
\hline \multicolumn{1}{|c|}{ Agente Oxidante } & Potencial Padrão de Redução $\mathbf{( V}_{\mathbf{H}} \mathbf{~}$ \\
\hline Flúor & 3,06 \\
\hline Radical Hidroxila & $\mathbf{2 , 8 0}$ \\
\hline Oxigênio (atômico) & 2,42 \\
\hline Ozônio & 2,08 \\
\hline Peróxido de hidrogênio & 1,78 \\
\hline Hipoclorito & 1,49 \\
\hline Cloro & 1,36 \\
\hline Dióxido de cloro & 1,27 \\
\hline Oxigênio (molecular) & 1,23 \\
\hline
\end{tabular}

Outra forma de se obter o radical hidroxila é a partir de uma mistura de ozônio e peróxido de hidrogênio $\left(\mathrm{O}_{3} / \mathrm{H}_{2} \mathrm{O}_{2}\right)$, na ausência ou presença de radiação ultravioleta $\left(\mathrm{O}_{3} / \mathrm{H}_{2} \mathrm{O}_{2} / \mathrm{UV}\right)$, ou simplesmente utilizando-se um meio fortemente alcalino $\left(\mathrm{O}_{3} / \mathrm{pH}\right.$ elevado $)$ [15].

Utilizando-se peróxido de hidrogênio e radiação UV, também tem sido verificada a geração de radicais hidroxila e a decomposição de vários poluentes orgânicos [16].

Outro método de produção dos radicais hidroxilas é a partir de uma mistura de peróxido de hidrogênio e sais ferrosos. Usualmente esta mistura é conhecida por "Reagente de Fenton", por ter sido Fenton quem observou essa reação pela primeira vez.

Uma técnica que também vem sendo estudada para a degradação de várias espécies orgânicas poluentes é o processo de oxidação por meio de ultrasom, que provoca a clivagem da molécula de água com formação de radicais hidroxila [17]. 
A tecnologia eletrolítica oferece opções viáveis para solucionar problemas ambientais, particularmente de efluentes aquosos. É capaz de oxidar ou reduzir íons metálicos, cianetos, compostos organoclorados, hidrocarbonetos aromáticos e alifáticos. Neste processo o elétron é o principal reagente, evitando o uso de outros compostos químicos [18].

Um POA de extrema importância dentro do contexto das novas alternativas para a degradação de poluentes é a fotoeletrooxidação (FEO), que ocorre com a combinação dos processos de eletrólise e fotocatálise heterogênea [19].

Para efluentes da indústria têxtil, a presença de altas concentrações de corantes orgânicos e sólidos dissolvidos não é satisfatoriamente reduzida por processos biológicos de tratamentos. Neelavannan e outros [20] propuseram um tratamento com aplicação de FEO, que consistia em dois reatores em série, primeiro um reator foto catalítico seguido de um reator eletroquímico. Obtiveram redução total da coloração e de $96 \%$ do DQO, em 7 horas de tratamento com solução sintética de corante azul. Pelegrini e outros [21] também investigaram a degradação deste corante azul, porém em um reator único de fluxo continuo, similar ao utilizado neste trabalho de pesquisa, aplicando uma corrente de $23 \mathrm{~mA} . \mathrm{cm}^{-2}$, lâmpada de vapor de mercúrio de $250 \mathrm{~W}$ e tempo de 2 horas. Foi obtida redução total da cor e de $50 \%$ do carbono orgânico total (COT).

Quando aplicado para efluentes de curtume Rodrigues e outros [22] propuseram a aplicação do processo de FEO associado ao processo de eletrodiálise, e obtiveram uma redução do DQO deste efluente em torno de 98 \%, constatando também uma redução na coloração.

Tauchert e outros [23] investigaram a aplicação do processo de FEO para o tratamento de chorume de aterro sanitário comparando com processo de precipitação/ sedimentação. Utilizando o reator batelada, ânodo de $70 \mathrm{TiO}_{2} / 30 \mathrm{RuO}_{2}$, cátodo de titânio, lâmpada de vapor de mercúrio de $125 \mathrm{~W}$ e densidade de corrente de $10 \mathrm{~mA} \cdot \mathrm{cm}^{-2}$, obtiveram uma redução da coloração de $50 \%$ e de DQO de $20 \%$ para um tempo de tratamento de 5 horas. Para este mesmo efluente Moraes e Bertazzoli [24] também investigaram a aplicação de FEO, utilizando o mesmo material de ânodo e cátodo que Tauchert, porém aplicando uma corrente continua 
de $116 \mathrm{~mA} \cdot \mathrm{cm}^{-2}$ e lâmpada de vapor de mercúrio de $400 \mathrm{~W}$ para um período de tratamento de 3 horas. Os autores verificaram a redução de: $73 \%$ do DQO, 57 \% do COT e $86 \%$ da cor.

A degradação de ácidos húmicos por FEO foi pesquisada por Pinhedo e outros [25], utilizando eletrodos de $70 \mathrm{TiO}_{2} / 30 \mathrm{RuO}_{2}$ como ânodo, tela de titânio como cátodo e reator de fluxo contínuo. Para uma densidade de corrente de $20 \mathrm{~mA} . \mathrm{cm}^{-2} \mathrm{e}$ em um tempo de 3 horas de tratamento os autores obtiveram uma redução de $65 \%$ do COT.

Para o tratamento de efluente da indústria de papel e celulose, Freire e outros [26] utilizaram um reator batelada muito similar ao deste trabalho, quanto ao material dos eletrodos e sua configuração, aplicando uma densidade de corrente de $20 \mathrm{~mA} \cdot \mathrm{cm}^{-2}$, lâmpada de vapor de mercúrio de $125 \mathrm{~W}$ por um período de 1,5 horas de tratamento. Verificaram uma redução de $40 \%$ do COT. Pelegrini e outros [27] também pesquisaram a possibilidade da aplicação do processo de FEO no tratamento deste efluente, utilizando um reator de fluxo contínuo, o mesmo material de eletrodo, lâmpada de $250 \mathrm{~W}$, corrente de $95 \mathrm{~mA}$ e com tempo de tratamento de 6 horas; obtiveram 51 \% de redução do COT e 83 \% de redução da concentração de fenol. Catalkaya e Kargi [28] realizaram um estudo comparativo de diferentes POA's para a degradação de efluente real de indústria de papel e celulose, compararam tratamentos por peróxido de hidrogênio, reagente de Fenton $\left(\mathrm{H}_{2} \mathrm{O}_{2} / \mathrm{Fe}^{2+}\right), \mathrm{UV}$, $\mathrm{UV} / \mathrm{H}_{2} \mathrm{O}_{2}$, foto-Fenton (UV/ $\left.\mathrm{H}_{2} \mathrm{O}_{2} / \mathrm{Fe}^{2+}\right)$ ozonização e ozônio/ $\mathrm{H}_{2} \mathrm{O}_{2}$ em escala laboratorial, avaliando parâmetros como cor, carbono orgânico total e halogenados adsorvíveis. Quase todos os métodos utilizados resultaram em algum grau de remoção de cor do efluente, no entanto com o uso de reagente de Fenton obteve-se maiores reduções de cor, COT e halogenados adsorvíveis em pH 5 em 30 minutos de tratamento. O processo de foto-Fenton obteve reduções similares ao de Fenton para esses parâmetros, em tempo de tratamento de 5 minutos.

R. Alnaizy, A. Akgerman [29] estudaram a degradação de fenol aplicando o processo oxidativo avançado de $\mathrm{UV} / \mathrm{H}_{2} \mathrm{O}_{2}$, a fonte de radiação UV utilizada foi uma lâmpada de baixa pressão de vapor de mercúrio. Os efeitos da dosagem de peróxido de hidrogênio, concentração inicial de fenol, $\mathrm{pH}$ (4 a 10) e temperatura foram investigados. Os resultados experimentais indicaram que há uma razão molar 
de $\mathrm{H}_{2} \mathrm{O}_{2} /$ fenol ótima na faixa de 100-250. As constantes taxas de reação obtidas foram inversamente afetadas pela concentração inicial de fenol. Não foi observado efeito do $\mathrm{pH}$. Os produtos da reação de oxidação incluíram hidroquinonas, benzoquinonas e ácidos carboxílicos alifáticos com até seis átomos de carbono.

A aplicação de POA's têm um importante papel no tratamento de águas residuais e podem ser adicionados em vários pontos do processo de tratamento dependendo do propósito a serem utilizados: remoção de cor e odor [30], degradação de compostos orgânicos [31], precipitação de metais [32] e destruição de microrganismos [33].

A utilização de POA's no tratamento de efluentes, com presença de contaminantes orgânicos, é freqüentemente mais cara do que o tratamento biológico, mas em certas circunstâncias podem ser utilizados como pré-tratamento de um processo biológico para destruição de contaminantes resistentes a biodegradação, ou após o tratamento biológico para melhoria da qualidade do efluente final, antes de ser descartado em corpos receptores ou reutilizado no processo produtivo [34].

\subsection{PROCESSOS ELETROQUÍMICOS EM MEIO AQUOSO.}

Hoje, compostos orgânicos refratários são encontrados em concentração relativamente alta em efluentes industriais e domésticos e muitos tratamentos tecnológicos têm sido propostos para recuperação ou degradação do fenol. A degradação eletroquímica de espécies orgânicas venenosas é um método promissor para tratamento de efluentes industriais [35].

\subsubsection{Redução catódica}

O método eletroquímico que envolve reações de redução sobre a superfície do cátodo é denominado redução catódica; amplamente empregado em processos de revestimento de materiais e eletroobtenção de metais, também pode ser empregado no tratamento de efluentes contendo compostos orgânicos poluentes. 
$\mathrm{Na}$ degradação de contaminantes orgânicos, a redução catódica é utilizada principalmente para desalogenação de compostos clorados orgânicos utilizados como solventes $\left(\mathrm{CHCl}_{3}, \mathrm{CCl}_{4}\right)$, fluidos refrigerantes (CFCs), pesticidas,etc., quando estão presentes em pequenas concentrações em águas residuais. $\mathrm{O}$ processo ocorre com aplicação de um potencial em torno de $-1 \mathrm{~V}$ em relação ao eletrodo de calomelano saturado, a $25^{\circ} \mathrm{C}$, conforme reação e seguir:

$$
\mathrm{R}-\mathrm{Cl}+2 \mathrm{H}^{+}+2 \mathrm{e}^{-} \rightarrow \mathrm{R}-\mathrm{H}+\mathrm{HCl}
$$

Em solução aquosa a reação acima compete com a reação de evolução de $\mathrm{H}_{2}$, portanto se empregam cátodos com elevado sobrepotencial de hidrogênio para se obter eficiências de degradação satisfatórias. Os materiais mais usados são o carbono, $\mathrm{Pb}, \mathrm{Hg}, \mathrm{Pt}, \mathrm{Cu}, \mathrm{Ni}$, ligas de $\mathrm{Ni}, \mathrm{Ti}, \mathrm{TiO}_{2}$ e hidretos metálicos. O processo de desalogenação eletroquímica tem a vantagem de conduzir a produtos menos tóxicos e mais biodegradáveis que os compostos clorados iniciais, contudo a eficiência de corrente costuma ser baixa [36].

\subsubsection{Oxidação anódica}

A oxidação anódica é um método muito popular para a síntese de muitos compostos orgânicos e inorgânicos, sendo também capaz de eliminar contaminantes orgânicos tóxicos, como anilinas, fenóis, benzoquinonas, herbicidas, etc., de efluentes aquosos. Costuma-se utilizar ânodos eletrocatalíticos como Pt, $\mathrm{IrO}_{2}, \mathrm{RuO}_{2}$, $\mathrm{PbO}_{2}, \mathrm{SnO}_{2}$ dopados ou não, aplicando elevados potenciais anódicos para que se produza a eletrólise da água com evolução simultânea de oxigênio. Sob estas condições, se geram radicais hidroxila adsorvidos sobre o ânodo $\left(\cdot \mathrm{OH}_{(\mathrm{ads})}\right)$ segundo a seguinte reação:

$$
\mathrm{H}_{2} \mathrm{O} \rightarrow \cdot \mathrm{OH}_{(\text {ads })}+\mathrm{H}^{+}+\mathrm{e}^{-}
$$

O radical hidroxila é a segunda espécie mais oxidante conhecida, depois do flúor, e é capaz de reagir rapidamente com os compostos orgânicos transformando-os em seus derivados desidrogenados até mineralizá-los, isto é, oxidar completamente a $\mathrm{CO}_{2}, \mathrm{H}_{2} \mathrm{O}$ e íons inorgânicos. 


\subsection{ELETRÓLISE}

Muitas tecnologias estão em uso ou têm sido propostas para recuperação ou destruição de fenol. A oxidação eletroquímica do fenol vem sendo utilizada para a produção de hidroquinonas e benzoquinonas, bem como no tratamento de efluentes industriais [37]. A técnica consiste na aplicação de uma corrente elétrica em uma célula eletroquímica composta de um ou mais pares de eletrodos (ânodos e cátodos), gerando assim um campo elétrico. Os pares de eletrodos polarizados atuam nas reações de redução, que ocorrem na zona do cátodo, e nas reações de oxidação, as quais ocorrem na zona do ânodo.

Desde a década de 70 muitos trabalhos de pesquisa têm voltado seu foco na eficiência de oxidação de diversos poluentes em diferentes materiais de eletrodo, explorando a atividade catalítica e estabilidade eletroquímica do material do eletrodo, avaliando os fatores que afetam a performance dos processos, além da investigação dos mecanismos e cinética das reações de degradação dos poluentes [38].

\subsubsection{Eletrodos revestidos de óxido metálicos}

A técnica de eletrólise convencional não se caracteriza como um POA, condudo com a utilização de materiais especiais como ânodo é possível promover a geração de radical hidroxila como agente oxidante. $O$ uso de eletrodos metálicos revestidos de óxidos de metais nobre propicia a geração de radical hidroxila fisicamente adsorvido na superfície anódica durante a eletrólise da água. A geração desse agente oxidante é realizada sem que ocorra a perda ou dissolução do material anódico, sendo por esse motivo denominados como ânodos dimensionalmente estáveis, usualmente conhecidos por sua sigla em inglês DSA ${ }^{\circledR}$-Dimensionally Stable Anodes.

O processo eletroquímico baseia-se na aplicação de um potencial capaz de oxidar ou reduzir substratos de interesse [39]. A tecnologia eletroquímica é capaz de oxidar ou reduzir íons metálicos, cianetos, compostos organoclorados, hidrocarbonetos aromáticos e alifáticos. A eletrooxidação de compostos orgânicos, em meio aquoso, ocorre competitivamente com a reação de evolução do oxigênio, 
conseqüentemente, cresce a pesquisa de materiais semicondutores imobilizados em eletrodos visando à diminuição desta competição [40,41].

Os eletrodos mais utilizados são de titânio metálico, revestidos com óxidos de metais nobres. Antes de sua utilização, o principal eletrodo aplicado na indústria era de grafite maciço, mas estes eletrodos sofriam desgastes intensos ao serem usados como ânodo, além de necessitarem de grandes distâncias entre o ânodo/cátodo. Essa distância era necessária para permitir a saída dos gases e não haver o bloqueio na superfície de reação. Com o emprego de eletrodos DSA foi possível diminuir a queda ôhmica e reduzir os gastos com energia elétrica. São muito utilizados em indústrias de produção de cloro e soda [43,54,42].

O uso dos eletrodos de óxido, do tipo DSA, na oxidação eletroquímica de compostos orgânicos permite ainda que a eletrólise possa ser assistida pela fotocatálise heterogênea quando a superfície do eletrodo apresenta fotoatividade.

Nos processos tecnológicos de tratamento que propõe o objetivo dessa investigação, a aplicação desse tipo de eletrodo é de fundamental importância, propiciando um cenário favorável à oxidação de compostos refratários.

Nesse estudo foi utilizado como opção tecnológica eletrodos do tipo DSA de titânio revestido de óxidos de titânio e rutênio, produzidos pela empresa De'Nora.

\subsubsection{Mecanismo de oxidação por EL}

A oxidação anódica de contaminantes orgânicos em meio aquoso pode ocorrer por duas vias:

1) Conversão eletroquímica: onde os compostos não biodegradáveis são transformados em compostos biodegradáveis.

2) Combustão eletroquímica: onde todos os contaminantes orgânicos são totalmente mineralizados.

Um mecanismo simplificado de como ocorre o processo de oxidação anódica de compostos orgânicos foi proposto por Comninellis e também por Trassati em seus estudos e é amplamente aceito na comunidade acadêmica $[37,43]$. 
Supondo que a superfície do ânodo é constituída por um óxido metálico $\left(\mathrm{MO}_{x}\right)$ o processo de oxidação começa pela descarga da água em meio ácido ( ou $\mathrm{OH}^{-}$em meio básico) no ânodo para dar lugar a formação do radical hidroxila adsorvido sobre o ânodo, segundo a equação:

$$
\mathrm{MO}_{x}+\mathrm{H}_{2} \mathrm{O} \rightarrow \mathrm{MO}_{x}(\cdot \mathrm{OH})+\mathrm{H}^{+}+\mathrm{e}^{-}
$$

Em um segundo passo, o radical hidroxila pode reagir com o oxigênio presente no óxido anódico formando um óxido superior, conforme:

$$
\mathrm{MO}_{x}(\cdot \mathrm{OH}) \rightarrow \mathrm{MO}_{x+1}+\mathrm{H}^{+}+\mathrm{e}^{-}
$$

Então, pode-se considerar que coexistem na superfície do ânodo dois estágios de oxigênio ativo, um quimicamente adsorvido e outro, o radical hidroxila, fisicamente adsorvido.

Na ausência de matéria orgânica oxidável, ambos os estágios de oxigênio ativo produzem $\mathrm{O}_{2}$, conforme:

$$
\begin{aligned}
& \mathrm{MO}_{x}(\cdot \mathrm{OH}) \rightarrow 1 / 2 \mathrm{O}_{2}+\mathrm{MO}_{x}+\mathrm{H}^{+}+\mathrm{e}^{-} \\
& \mathrm{MO}_{x+1} \rightarrow 1 / 2 \mathrm{O}_{2}+\mathrm{MO}_{x}
\end{aligned}
$$

$\mathrm{Na}$ presença de matéria orgânica oxidável $(\mathrm{R})$ pode-se ter a completa mineralização com a ação do radical hidroxila ou a interação com o oxigênio ativo quimicamente adsorvido, obtendo produtos da oxidação seletiva, conforme:

$$
\begin{aligned}
& \mathrm{R}+\mathrm{zMO}_{x}(\cdot \mathrm{OH}) \rightarrow \mathrm{CO}_{2}+\mathrm{H}_{2} \mathrm{O}+\mathrm{zMO}_{x}+\mathrm{zH}^{+}+\mathrm{ze}^{-} \\
& \mathrm{R}+\mathrm{MO}_{x+1} \rightarrow \mathrm{RO}+\mathrm{MO}_{x}
\end{aligned}
$$

Sendo assim, os materiais anódicos que favorecem a conversão eletroquímica apresentam uma concentração de $\mathrm{MO}_{x}(\cdot \mathrm{OH})$ próxima de zero, ocorrendo a reação 04 muito mais rápida que a reação 03 . Ao contrário, na combustão eletroquímica a superfície anódica apresenta elevada concentração de radicais hidroxilas, sendo insignificante a velocidade da reação 04. A eficiência de corrente do processo dependerá da proporção relativa entre combustão e conversão, representadas pelas reações 07 e 08, respectivamente.

A combustão eletroquímica pode ocorrer por duas rotas: combustão direta, onde o composto orgânico é degradado a $\mathrm{CO}_{2}$ em uma única etapa, ou 
combustão indireta, que compreende a hidroxilação (reação 09) e a desidrogenação (reação 10) de compostos orgânicos (R e R'H) com radicais hidroxila.

$$
\begin{aligned}
& \mathrm{R}+\mathrm{MO}_{x}(\cdot \mathrm{OH}) \rightarrow \mathrm{R}(\cdot \mathrm{OH})+\mathrm{MO}_{x} \\
& \mathrm{R}^{\prime} \mathrm{H}+\mathrm{MO}_{x}(\cdot \mathrm{OH}) \rightarrow \mathrm{R}^{\prime} \cdot+\mathrm{MO}_{x}+\mathrm{H}_{2} \mathrm{O}
\end{aligned}
$$

Nesse último passo o oxigênio pode reagir com o radical orgânico R'• resultando num radical hidroperóxido R'OO• (reação 11), o qual é suficientemente ativo para subtrair um hidrogênio de outro contaminante R"'H (reação 12). Os hidroperóxidos assim obtidos são relativamente instáveis e podem quebrar sua estrutura molecular para gerar outros intermediários. Estas reações de ruptura continuam até a produção final de $\mathrm{CO}_{2}$, água e íons inorgânicos.

$$
\begin{aligned}
& \mathrm{R}^{\prime} \bullet+\mathrm{O}_{2} \rightarrow \mathrm{R}^{\prime} \mathrm{OO} \bullet \\
& \mathrm{R}^{\prime} \mathrm{OO} \bullet+\mathrm{R}{ }^{\prime \prime} \mathrm{H} \rightarrow \mathrm{R} \mathrm{ROH}^{\prime} \mathrm{O} \mathrm{R}^{\prime} \bullet
\end{aligned}
$$

A oxidação de fenol por conversão eletroquímica ocorre primeiro com a formação do radical fenox, que pode reagir com outras espécies presentes na solução formando quinonas ou pode reagir com outras moléculas de fenol e formar, predominantemente, radicais para. Este radical pode futuramente ser oxidado com a perda de um próton para formar um dímero neutro, acoplação de dois monômeros. O dímero formado pode polimerizar, esta formação de polifenol insolúvel resulta na desativação da superfície do eletrodo. A taxa relativa dos dois caminhos, polimerização e formação de estrutura quinônica, depende da concentração de compostos fenólicos. A alta concentração favorece a polimerização na superfície do eletrodo, baixas concentrações favorecem a oxidação para espécies quinonas [44].

Uma vez formadas as espécies quinonas, elas podem sofrer combustão eletroquímica sobre a superfície do anodo (rota $r_{2}$ ) ou conversão eletroquímica até a formação de ácidos carboxílicos (rota $r_{1}$ ). Os ácidos carboxílicos formados são difíceis de ser oxidados eletroliticamente, contudo são compostos biodegradáveis e não tóxicos, podendo ser degradados por processos biológicos. Essa rota de oxidação esta representada na Figura 1. 
Outros parâmetros importantes no processo de eletrooxidação de compostos fenólicos são: a natureza do eletrodo, $\mathrm{pH}$ do meio, solvente, potencial utilizado, densidade de corrente e eletrólito [45].

A polimerização do fenol é mais característica em meios alcalinos, a formação de polímeros ou oligômeros bloqueia a superfície do eletrodo por adsorção, reduzindo a área reacional.

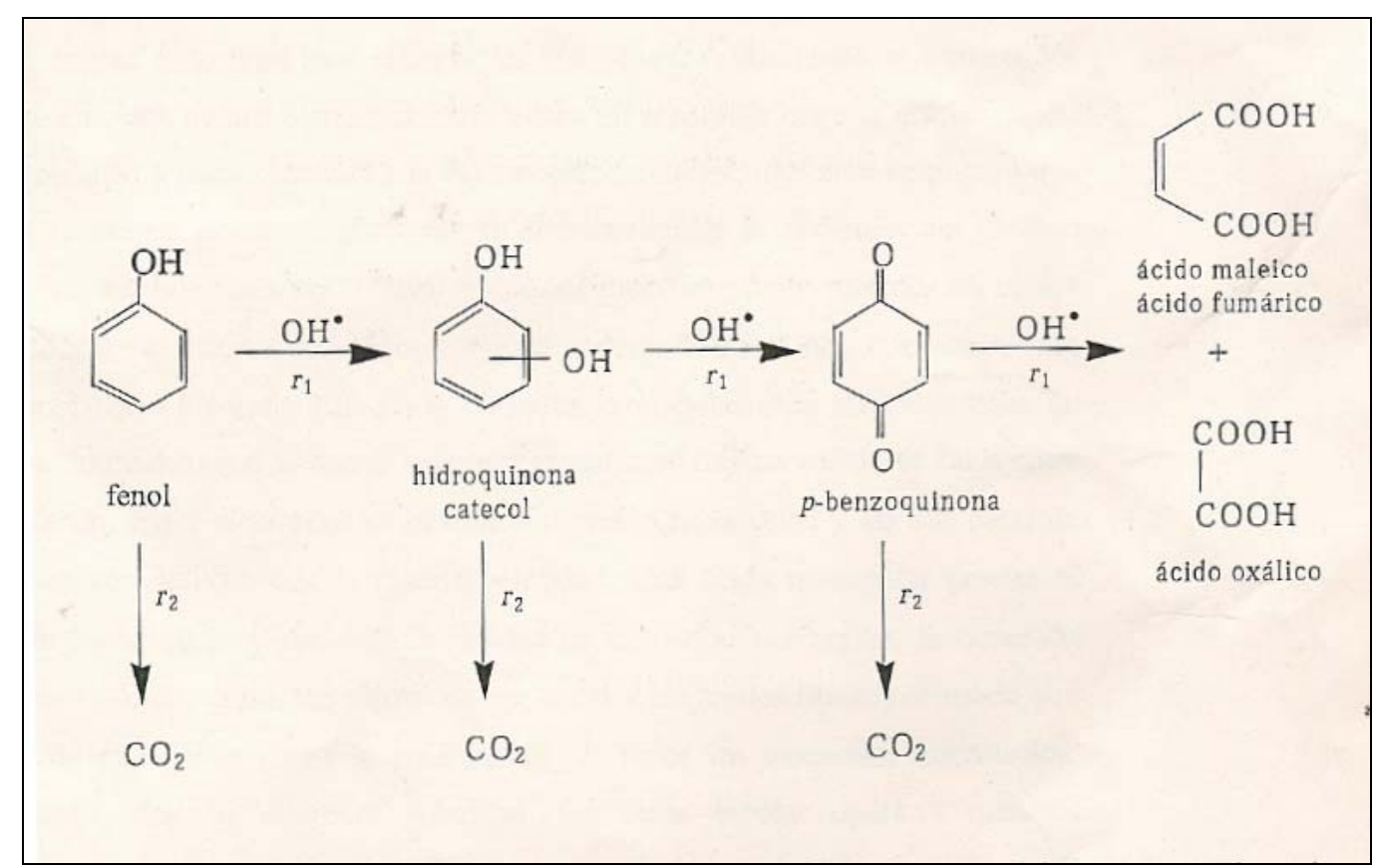

Figura 1: Seqüência de reações de degradação do fenol, onde $r_{1}$ representa a rota para conversão eletroquímica e $r_{2}$ para combustão eletroquímica. [46] 


\subsection{FOTOELETROOXIDAÇÃO}

O processo de fotoeletrooxidação (FEO) baseia-se na combinação de: fotólise, eletrólise e fotocatálise heterogênea, ou seja, a aplicação de uma densidade de corrente ou potencial juntamente com uma fonte de radiação ultravioleta iluminando a superfície semicondutora do ânodo da célula eletroquímica. Neste processo os únicos reagentes envolvidos são os fótons e os elétrons. A técnica temse revelado bastante eficiente na geração de radicais hidroxilas $(\cdot \mathrm{OH})$, os quais oxidam compostos orgânicos presentes nos efluentes aquosos [47].

Portanto, o processo de FEO consiste na percolação da solução a ser tratada através de um reator eletrolítico onde o ânodo, revestido com óxidos metálicos, permanece sob a incidência da radiação UV [19, 55]. O processo deve ser conduzido a temperaturas entre 20 e $75^{\circ} \mathrm{C}$ [48].

Pesquisas recentes têm apontado para o emprego de processos combinados, fazendo uso das vantagens de diferentes métodos e seus efeitos sinérgicos ou complementares $[13,14]$.

Essa tecnologia apresenta algumas vantagens em relação aos tratamentos convencionais:

- não troca o contaminante somente de fase e sim o transforma quimicamente.

- geralmente se consegue a mineralização completa (destruição) do contaminante.

- usualmente não gera lodo, que requer um processo de tratamento ou disposição.

- não requer a adição de produtos químicos.

- é muito útil para contaminantes refratários que resistem a outros métodos de tratamento, principalmente o biológico.

Como desvantagens, pode-se citar:

- formação de subprodutos de reação, em alguns casos.

- pode necessitar de grandes tempos de retenção. 
- os custos podem ser elevados quando comparados aos processos biológicos, por exemplo.

- necessita de mão de obra treinada para sua operação.

Na literatura o processo de FEO está sendo estudado para a degradação de fenóis e outros compostos aromáticos refratários, organoclorados, efluente de papel e celulose, corantes da indústria têxtil e chorume de aterro sanitário e industrial [16, 27-51].

\subsubsection{Foto Catálise Heterogênea}

No processo fotoquímico uma espécie semicondutora é irradiada para a promoção de um elétron da banda de valência (BV) para a banda de condução (BC), a região entre as duas bandas é denominada "bandgap". Com o elétron promovido para a BC e com a lacuna positiva $\left(\mathrm{h}^{+}\right)$gerada na $\mathrm{BV}$, criam-se sítios redutores e oxidantes capazes de catalisar reações químicas. A degradação se dá por meio da oxidação da matéria orgânica que pode ser conduzida até $\mathrm{CO}_{2}$ e $\mathrm{H}_{2} \mathrm{O}$ [52].

Atualmente o dióxido de titânio é o semicondutor mais utilizado em processos de fotodegradação de compostos orgânicos, principalmente devido a várias características favoráveis, $[43,53,39]$ dentre os quais se destacam:

- Possibilidade de fotoativação;

- Insolubilidade em água;

- Estabilidade química numa ampla faixa de $\mathrm{pH}$;

- Possibilidade de imobilização em sólidos;

- Baixo custo;

- Ausência de toxicidade.

Entretanto, muitos outros semicondutores como $\mathrm{CdS}, \mathrm{ZnO}, \mathrm{WO}_{3}, \mathrm{ZnS}$ e $\mathrm{Fe}_{2} \mathrm{O}_{3}$ podem ser utilizados em processos fotocatalíticos $[54,39,55]$.

$\mathrm{O} \mathrm{TiO}_{2}$ existe em três formas alotrópicas: anátase, rutilo e brookite, sendo a primeira a mais fotoativa e, portanto, a mais empregada nesse tipo de processo. Como a eficiência do processo está fortemente ligada ao passo de formação e 
recombinação do par elétron/lacuna, a introdução de mistura de óxidos de metais nobres no revestimento do ânodo é uma maneira de inibir a etapa de recombinação. Um metal muito utilizado para essa finalidade é o rutênio [54, 39, 55].

Como exemplo de aplicação de processos fotoquímicos pode-se citar o Japão, que tem pesquisado e utilizado o dióxido de titânio na presença de luz ultravioleta [56], para vários fins:

- Como bactericida em banheiros, ou seja, impregna-se sobre os azulejos e sob irradiação UV os mesmos mantêm-se limpos e isentos de microrganismos.

- Em placas de sinalização de estradas, que também são impregnadas com dióxido de titânio e sob irradiação UV natural, do sol, comportam-se como um sistema auto-limpante.

- Nas paredes de túneis de auto-estradas que são impregnadas com esse semicondutor e que quando iluminados com luz ultravioleta atuam na degradação dos compostos tóxicos liberados pelos motores dos carros.

\subsubsection{Mecanismo de oxidação por FEO}

O mecanismo de reação do processo de FEO ainda é motivo de muitas discussões entre os pesquisadores, existindo algumas divergências. Os principais pontos de discussão com relação ao processo de oxidação são: identificação da espécie iniciadora do processo, a região onde ocorre e as espécies intermediárias formadas $[13,39]$.

A oxidação anódica pode ocorrer por troca direta entre composto orgânico e a superfície do eletrodo ou de forma indireta pela intermediação de espécies eletroativas oxidantes formadas no ânodo. Quando a eletrólise é conduzida a potenciais tais que a evolução de oxigênio ocorre de forma simultânea, a oxidação indireta parece ser o principal caminho $[52,39]$. A hipótese mais aceita atualmente para o mecanismo de fotoeletrooxidação está representada de forma esquemática na Figura $2[57,58]$. 
(A)

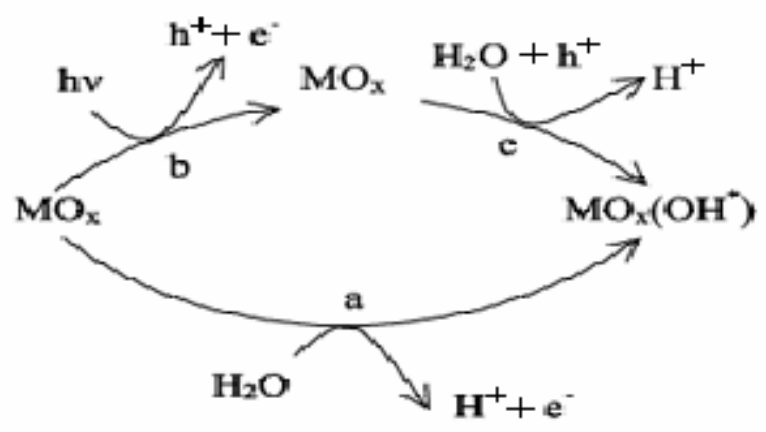

(B)

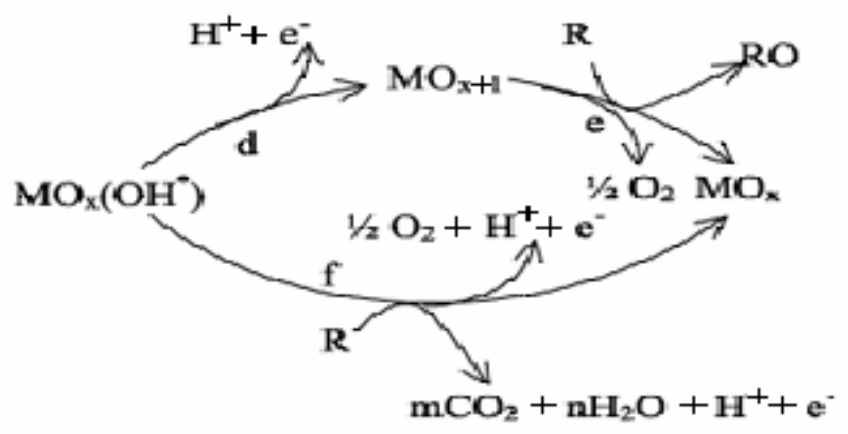

Figura 2: Representação esquemática dos mecanismos de oxidação, (A) formação dos radicais hidroxilas $(\cdot \mathrm{OH})$ na superfície do eletrodo; $(B)$ oxidação dos compostos orgânicos [57].

Na eletrólise, a descarga das moléculas de água na superfície do ânodo forma radicais hidroxila fisicamente adsorvidos, de acordo com a reação 13:

$$
\mathrm{MO}_{\mathrm{x}}+\mathrm{H}_{2} \mathrm{O} \rightarrow \mathrm{MO}_{\mathrm{x}}(\cdot \mathrm{OH})+\mathrm{H}^{+}+\mathrm{e}^{-}
$$

De forma paralela, a incidência de radiação, com energia $h v$, sobre o óxido promove elétrons para a banda de condução, ocorrendo a formação do par elétron/lacuna, conforme reação 14 :

$$
\mathrm{MO}_{\mathrm{x}} \rightarrow \mathrm{MO}_{\mathrm{x}}+\mathrm{h}^{+}+\mathrm{e}^{-}
$$

A formação da lacuna positiva $\left(\mathrm{h}^{+}\right)$possibilita a descarga anódica da água, de acordo com o processo (reação 15):

$$
\mathrm{MO}_{\mathrm{x}}+\mathrm{H}_{2} \mathrm{O}+\mathrm{h}^{+} \rightarrow \mathrm{MO}_{\mathrm{x}}(\cdot \mathrm{OH})+\mathrm{H}^{+}
$$


Após a formação do radical hidroxila duas linhas são possíveis para a oxidação: direta ou gradativa [57].

Na oxidação gradativa ocorre a promoção dos óxidos a óxidos superiores, reação 16:

$$
\mathrm{MO}_{\mathrm{x}}(\cdot \mathrm{OH}) \rightarrow \mathrm{MO}_{\mathrm{x}+1}+\mathrm{H}^{+}+\mathrm{e}^{-}
$$

Esses óxidos superiores oxidam os compostos orgânicos, conforme reação 17:

$$
\mathrm{MO}_{\mathrm{x}+1}+\mathrm{R} \rightarrow \mathrm{MO}_{\mathrm{x}}+\mathrm{RO}
$$

$\mathrm{Na}$ oxidação direta os radicais hidroxila podem oxidar diretamente os compostos orgânicos, de acordo com a reação 18:

$$
\mathrm{MO}_{\mathrm{x}}(\cdot \mathrm{OH})+\mathrm{R} \rightarrow \mathrm{MO}_{\mathrm{x}}+\mathrm{m} \mathrm{CO}+\mathrm{n} \mathrm{H}_{2} \mathrm{O}+\mathrm{H}^{+}+\mathrm{e}^{-}
$$

A evolução de oxigênio concorre com os processos (17) e $(18)[39,57]$.

Na Figura 3 pode-se verificar a rota de oxidação do fenol, com seus possíveis produtos intermediários da reação e os produtos finais. Embora, conforme as condições experimentais, pode-se seguir o caminho da polimerização.

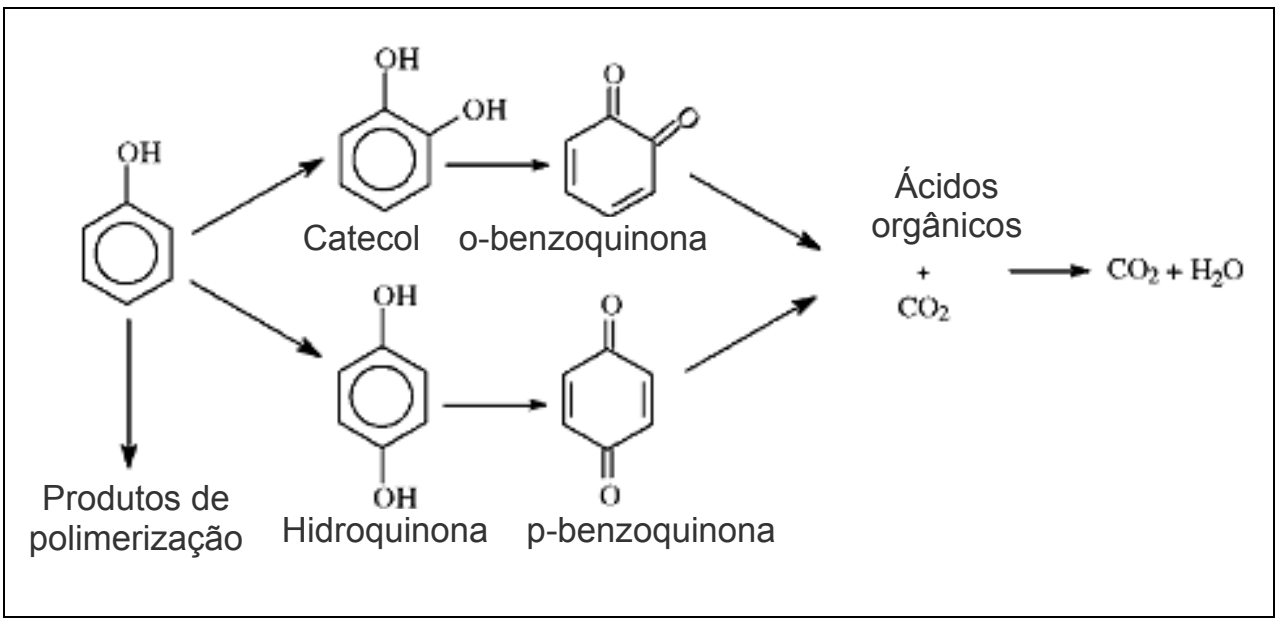

Figura 3: Rota de oxidação proposta para o fenol [59]. 


\subsubsection{Fonte de radiação ultravioleta (UV)}

A radiação ultravioleta cobre a região do espectro eletromagnético entre 400 e $100 \mathrm{~nm}$, sendo classificada em:

$$
\begin{aligned}
& -\quad \text { UV-A (400-315 nm); } \\
& \text { - UV-B (315-280 nm); } \\
& \text { - UV-C (280-100 nm). }
\end{aligned}
$$

Refere-se à primeira faixa como ultravioleta próximo e à última como ultravioleta extremo ou de vácuo [60].

Na prática, o aproveitamento do espectro ultravioleta é limitado pelos três tipos de fontes disponíveis comercialmente: lâmpadas de deutério, xenônio e vapor de mercúrio. Entre elas, as de vapor de mercúrio são as mais usadas em aplicações de laboratório e industriais. Isto se deve ao fato delas terem, relativamente, custo baixo e facilidade de funcionamento. Além disso, possuem dois outros pontos favoráveis: boa eficiência energética (proporção de potência elétrica convertida em radiação) e espectral (proporção de radiação emitida no UV). O espectro de emissão depende fortemente da pressão dos gases no interior do bulbo havendo, por este motivo, a distinção entre lâmpadas de baixa, média e alta pressão [60, 61].

As lâmpadas de baixa pressão são essencialmente monocromáticas com $\lambda=253 \mathrm{~nm}$, sua eficiência de conversão da potência em radiação UV é melhor do que as lâmpadas de média e alta pressão que, apesar de apresentarem potência nominal aproximadamente uma ordem de grandeza maior, convertem em luz UV somente cerca de $30 \%$ da potência elétrica consumida. No entanto, para compensar a baixa intensidade luminosa das lâmpadas de baixa pressão, torna-se conveniente a construção de bulbos compridos, às vezes enrolados em forma de espiral, de maneira a se obter um maior fluxo luminoso total [60, 62].

Já as fontes de média e alta pressão apresentam um espectro de emissão caracterizado por linhas mais alargadas e um fundo contínuo que cobre toda a região UV, inclusive a faixa do ultravioleta próximo (UV-A) e têm incursão na região visível, emitindo também uma grande quantidade de calor [60]. 
Cabe registrar a possibilidade de se utilizar, como fontes de UV, lâmpadas de mercúrio (e respectivo reator) do tipo usado em larga escala para iluminação pública, facilmente disponíveis no comércio, a custo relativamente baixo. Para tanto, é suficiente remover o bulbo externo de vidro, cujas paredes internas são cobertas por material fluorescente, expondo o núcleo interno da lâmpada, constituído precisamente por uma lâmpada de mercúrio de média/alta pressão num invólucro de quartzo. Para possibilitar que a mesma seja imersa na solução e não bloquear a passagem da radiação UV coloca-se no lugar do bulbo de vidro um de quartzo. Como todas as lâmpadas de mercúrio, estas também devem ser operadas com o suporte de um reator externo $[60,62]$.

\subsection{PROCESSOS DE OXIDAÇÃO ELETROQUÍMICA DE FENOL}

Na literatura é possível encontrar inúmeros trabalhos que tratam sobre a oxidação eletroquímica de fenol e compostos fenólicos, pelos mais diferentes métodos. Nesta seção será apresentada a produção científica mais relevante encontrada sobre o tema de uma forma resumida e direta, serão abordados os principais resultados obtidos por esses autores, além das conclusões mais pertinentes relativas à eletrooxidação de compostos refratários.

Comninellis e Pulgarin [37] foram pioneiros no estudo da oxidação anódica de fenol. Em seu trabalho de 1991 investigaram o uso de ânodo de platina para uma solução inicial de $23 \mathrm{mM}$ de fenol em pH de 12,5 e 3, utilizando $\mathrm{H}_{2} \mathrm{SO}_{4}$ ou $\mathrm{NaOH}$ para ajustar o $\mathrm{pH}$ e $\mathrm{Na}_{2} \mathrm{SO}_{4}$ como eletrólito. Para analisar os resultados foram utilizadas medidas de COT e DQO e análises por CLAP. Obtiveram resultados importantes, como a observação de um filme amarelo escuro sobre a superfície do ânodo, além de verificarem que algumas condições favorecem o crescimento desse filme, como $\mathrm{pH}$ superior a 9 , temperaturas superiores a $50^{\circ} \mathrm{C}$, baixas densidades de corrente e altas concentrações de fenol. Concluíram também que nas condições onde é favorecida a polimerização não se observa a presença de produtos intermediários da oxidação do fenol, como a hidroquinonas e benzoquinonas, tampouco se observou a presença de ácidos orgânicos.

Em parceria com Simond [58,63], Comninellis publicou em 1997 dois artigos sobre o uso de ânodos de óxidos metálicos na oxidação de compostos 
orgânicos, abrindo caminho para a investigação de novos materiais de eletrodo. Nesses trabalhos se investigou o uso de eletrodos de titânio revestidos de óxido de irídio ou de estanho na degradação de alcoóis alifáticos, como o iso-propanol, resultando em um mecanismo teórico de oxidação de compostos orgânicos para eletrodos de óxidos metálicos. Esse mecanismo é amplamente aceito até os dias de hoje e consiste na geração de superóxidos que, paralelo a eletrólise da água, propicia a formação do radical hidroxila, agente fortemente oxidante. Outra informação interessante que se obteve foi que a reação de oxidação do composto orgânico compete com a de liberação de oxigênio. Portanto, a eficiência do processo de oxidação de matéria orgânica pode ser medida de forma indireta pela liberação de oxigênio no ânodo da célula eletroquímica.

Outro dois artigos publicados por Comninellis e outros [64,65] investigaram o uso de eletrodos de boro diamante dopado (BDD) na eletrooxidação de fenol e compostos fenólicos, já trabalhando exclusivamente em condições que não favorecem o processo de polimerização, ou seja, meio ácido e com baixas concentrações de soluto. Nesses trabalhos foi testada a validade do mecanismo de reação para a degradação de fenol proposto em um trabalho anterior [37]. A partir dos resultados experimentais obtidos em ambos os trabalhos, foi confirmada a validade desse mecanismo de reação. Contudo, é preciso salientar que em ambos os trabalhos foi constatado o bloqueio do eletrodo. Pacheco e outros [66] estudaram a aplicação do eletrodo de BDD na degradação de fenol, cresol, catecol e guaiacol, freqüentemente encontrados em efluentes industriais. Trabalhando com baixas densidades de corrente, entre 0,25 e $3 \mathrm{~mA} \cdot \mathrm{cm}^{-2}$, uma temperatura de $25^{\circ} \mathrm{C}$ e concentração de fenol de $2 \mathrm{mM}$, esses autores relataram que o aumento da densidade de corrente contribuiu para a mineralização dos compostos, contudo se obteve uma menor eficiência energética. Cañizares e outros [67] também investigaram a aplicação desse eletrodo na degradação de compostos fenólicos, relatando bom desempenho desse material na mineralização do fenol e de seus compostos clorados, embora para compostos fenólicos nitrogenados o efeito da polimerização tenha sido acentuado.

Santos e outros [59] estudaram rotas de oxidação catalítica do fenol em meio aquoso; utilizaram catalisador de cobre e altas temperaturas, de 140 a $160^{\circ} \mathrm{C}$. Embora seus estudos não fossem de eletrooxidação, utilizaram como base de seus 
estudos o mecanismo de reação proposto por Comninellis e Simond obtendo conclusões concordantes; em ambos os trabalhos obtive-se como produtos intermediários da oxidação hidroquinonas e benzoquinas e como produtos finais ácidos orgânicos de cadeia curta e $\mathrm{CO}_{2}$. Outro ponto de convergência é que o aumento da temperatura favorece a formação de compostos poliméricos, sejam polímeros ou oligômeros, os quais conferem a solução uma coloração marrom amarelada.

Um grupo específico de compostos tem sido objeto de estudos devido a seu preocupante impacto ambiental sobre os ecossistemas aquáticos, são denominados de compostos organoclorados. Ureta-Zañartu e outros [68] pesquisaram a eletrooxidação do 2,4-dicloro fenol com o uso de eletrodo de carbono vítreo, em ampla faixa de $\mathrm{pH}(0,2$ a 10$)$ e concentração de fenol (0,5 a 10mM), avaliando os resultados obtidos em experimentos de voltametria cíclica de varredura (VC). Obtiveram através de suas análises informações importantes, tais como: que a reação de oxidação desse composto é irreversível, e que o bloqueio da superfície do eletrodo é acelerado com o aumento da concentração de soluto e com o aumento de $\mathrm{pH}$.

Alves e outros [69] investigaram a influência do material anódico na degradação de fenol em meio neutro; foram comparados o comportamento eletroquímico dos ânodos de $\mathrm{Ti} / \mathrm{Ru}_{0,3} \mathrm{Ti}_{0,7} \mathrm{O}_{2}, \quad \mathrm{Ti} / \mathrm{Ru}_{0,3} \mathrm{Sn}_{0,7} \mathrm{O}_{2}, \quad \mathrm{Ti} / \mathrm{Ir}_{0,3} \mathrm{Ti}_{0,7} \mathrm{O}_{2}$ e $\mathrm{Ti} / \mathrm{Ir}_{0,3} \mathrm{Sn}_{0,7} \mathrm{O}_{2}$, para uma solução de $11 \mathrm{mM}$ de fenol. Foi avaliada a atividade catalítica do material, obtendo como resultado: $\mathrm{Ti} / \mathrm{Ru}_{0,3} \mathrm{Ti}_{0,7} \mathrm{O}_{2}>\mathrm{Ti} / \mathrm{Ru}_{0,3} \mathrm{Sn}_{0,7} \mathrm{O}_{2}>$ $\mathrm{Ti} / \mathrm{Ir}_{0,3} \mathrm{Ti}_{0,7} \mathrm{O}_{2}>\mathrm{Ti} / \mathrm{Ir}_{0,3} \mathrm{Sn}_{0,7} \mathrm{O}_{2}$. Contudo, para todos os materiais testados foi relatado o bloqueio da superfície após poucos ciclos em experimentos de VC. Com o uso de eletrodo de $\mathrm{Ti} / \mathrm{Ru}_{0,3} \mathrm{Ti}_{0,7} \mathrm{O}_{2}$ se atingiu uma redução no teor de COT de $80 \%$, o maior valor dentre os eletrodos estudados. Foi relatado que a benzoquinona, produto intermediário da oxidação do fenol, foi formada na primeira hora de eletrólise e consumida gradativamente com o progresso da reação. Ácidos málico, tartárico e maleico também foram identificados como sub-produtos da oxidação do fenol. Estudo similar foi realizado por $\mathrm{Li}$ e outros [70] para eletrodos de $\mathrm{Ti} / \mathrm{SnO}_{2}-\mathrm{Sb}$, $\mathrm{Ti} / \mathrm{RuO}_{2}$ e $\mathrm{Pt}$, para soluções de 1 a $5 \mathrm{mM}$ de fenol em meio ácido. Esses autores aplicaram o processos de EL na degradação do fenol, para um tempo de tratamento de 5 horas e densidade de corrente de $20 \mathrm{~mA} \cdot \mathrm{cm}^{-2}$. Com o eletrodo de $\mathrm{Ti} / \mathrm{SnO}_{2}-\mathrm{Sb}$ 
obtiveram melhores resultados, tanto na mineralização da matéria orgânica, quanto na degradação do fenol. O melhor desempenho do eletrodo de $\mathrm{Ti} / \mathrm{SnO}_{2}-\mathrm{Sb}$ foi atribuído a uma maior rapidez desse no rompimento do anel aromático.

Yavuz e Koparal [71] estudaram a aplicação de eletrodo de $\mathrm{Ti} / \mathrm{RuO}_{2}$ na degradação de fenol por EL galvanostática, com enfoque especial em efluentes de refinaria de petróleo. Utilizaram um reator de placas paralelas, densidades de corrente entre 3 e $20 \mathrm{~mA} \cdot \mathrm{cm}^{-2}$, temperaturas entre 20 e $50^{\circ} \mathrm{C}$ e $\mathrm{pH}$ de 3,7 e 11. Foram utilizadas soluções sintéticas de fenol de 0,5; 2 e $5 \mathrm{mM}$ e efluente real de refinaria de petróleo ( $2 \mathrm{mM}$ de fenol e $\mathrm{pH}$ de 1,97). Obtiveram melhores resultados aplicando densidade de corrente de $15 \mathrm{~mA} \cdot \mathrm{cm}^{-2}$ na solução sintética de $2 \mathrm{mM}$ de fenol em meio ácido, atingindo reduções de 99,7\% da concentração de fenol e $88,9 \%$ na DQO. Para o efluente real alcançaram reduções de $94,5 \%$ no teor de fenol e $70 \%$ na DQO aplicando $\mathrm{i}=20 \mathrm{~mA} \cdot \mathrm{cm}^{-2}$. Os autores relatam uma importante observação relativa ao efeito da temperatura sobre o processo; quando se trabalha com temperaturas mais altas a redução na concentração de fenol é maior, contudo isso não significa que o fenol foi degradado ou mineralizado. Essa redução possivelmente está relacionada com o processo de polimerização do fenol que é favorecido com o aumento da temperatura.

Guohua Chen [38] realizou uma revisão sobre a aplicação de técnicas eletroquímicas no tratamento de efluentes, no qual aborda os processos de eletrodeposição, eletrocoagulação, eletroflotação e eletrooxidação. Na seção sobre o processo de eletrooxidação, ele salienta a importância da escolha do material anódico, a forma da célula eletroquímica e as características físico-químicas do efluente na eficiência de degradação e/ou mineralização da matéria orgânica presente. Também enfoca os dois caminhos possíveis de eletrooxidação da matéria orgânica: combustão e conversão eletroquímica.

Heras e outros [72] investigaram o comportamento de eletrodos de platina revestidos de material polimérico e o uso de surfactantes contendo grupos hidrofílicos. Utilizando revestimento polimérico de poli(3,4-etilenodioxitiofeno) e poli(sódio-4-estirenosulfonado) como surfactante esses autores obtiveram uma redução no bloqueio da superfície do eletrodo em meio neutro, para concentrações de fenol de 0,5 a 8mM, contudo não se eliminou a desativação do eletrodo. 
Arslan e outros [35] avaliaram o efeito do pH, temperatura e concentração no processo de eletrooxidação do fenol; verifica para uma faixa de temperatura de 15 a $60^{\circ} \mathrm{C}$, que o pico de oxidação diminui com o aumento da temperatura. Para uma faixa de concentração de fenol de 12,5 a 100 mM, em 0,5M H $\mathrm{H}_{2} \mathrm{SO}_{4}$ e $1 \mathrm{M} \mathrm{NaOH}$, foi observado o bloqueio da superfície do eletrodo tanto em meio alcalino como ácido, causando rápida desativação do eletrodo. Os autores sugerem que esse comportamento esteja envolvido com o processo de polimerização do fenol nas condições testadas.

Borras e outros [45] estudaram a cinética da eletrooxidação de compostos fenólicos utilizando eletrodo de $\mathrm{Sb}-\mathrm{SnO}_{2}$. Verificaram que a redução da concentração inicial dos compostos avaliados diminui o efeito da adsorção dos produtos intermediários das reações de oxidação. Outra importante constatação foi o surgimento de coloração amarela na solução, efeito esse devido à formação de quinonas, como a benzoquinona. Essa coloração surge porque as moléculas de quinona possuem uma ligação dupla a mais que a molécula de fenol.

Alguns autores estudaram o processo de polimerização do fenol; esses estudos envolvem a formação de filmes poliméricos sobre a superfície do ânodo, geralmente aplicados como uma barreira de proteção a corrosão. Kennedy e outros [73] investigaram a eletrooxidação e polimerização de compostos meta-substituídos de fenol sobre eletrodo de ouro. Trabalhando com concentrações elevadas desses compostos, $100 \mathrm{mM}$, e em pH neutro, foi constatado, por meio de análise dos voltamogramas obtidos, a formação de um filme polimérico sobre a superfície do eletrodo, promovendo rápido bloqueio do eletrodo.

Analisando os resultados obtidos pelos autores estudados pode-se verificar que a concentração inicial do fenol influencia no processo de oxidação, sendo o processo facilitado em concentrações mais baixas. Outro parâmetro importante é o pH do meio, que quanto mais ácido mais favoráveis são as reações de oxidação e mais desfavoráveis as reações de polimerização. O efeito da temperatura foi avaliado, sendo que a elevação da temperatura a valores superiores a $50^{\circ} \mathrm{C}$ promove uma aumento das reações de polimerização. Em muitos estudos se salienta a importância da escolha adequada do material anódico no processo de EL. Face a essas observações, foi realizada uma escolha criteriosa do material anódico 
a ser utilizado na célula eletroquímica e se aplicou condições experimentais que inibam as reações de polimerização e favoreçam as de oxidação, tais como baixas concentrações iniciais de fenol, pH extremamente ácido e temperatura ambiente.

\subsection{VOLTAMETRIA CÍCLICA DE VARREDURA}

Técnicas eletroquimicas constituem um grupo de métodos analíticos que são baseados nas propriedades eletroquímicas de um eletrólito que é parte de uma célula eletroquímica. [74, 75]. As técnicas eletroanalíticas são capazes de produzir baixos limites de detecção e fornecer uma riqueza de informações que descrevem a caracterização de sistemas eletroquímicos.

A voltametria estuda as relações entre voltagem, corrente e tempo durante a eletrólise em uma célula eletroquímica, envolvendo a determinação de substâncias em solução que podem ser oxidadas ou reduzidas na superfície do eletrodo de trabalho (ET). Sobre o ET é aplicado um potencial variável contínuo e a corrente resultante do circuito é medida. Dependendo da polaridade do potencial aplicado, os componentes da solução sofrem oxidação ou redução em potenciais característicos que podem ser usados para identificar as espécies ativas. O gráfico de potencial em função da corrente obtido é conhecido como voltamograma, um típico voltamograma é apresentado na Figura 4 [36].



Figura 4: Voltamograma de voltametria cíclica [76].

No voltamograma é possível observar nas zonas catódicas e anódicas a presença de picos de redução e oxidação, nos quais ocorre um aumento da corrente 
até que se atinja um valor máximo, denominado corrente de pico (Ip), e o potencial referente a essa corrente se denomina potencial de pico (Ep).

A voltametria cíclica de varredura (VC) compreende um grupo de métodos eletroanalíticos nos quais as informações sobre a concentração do eletrólito são derivadas a partir das medidas de corrente em função do potencial aplicado sob condições de completa polarização do eletrodo de trabalho.

A célula eletroquímica (Figura 5) é constituída de três eletrodos, sendo um deles o eletrodo de trabalho, outro eletrodo de material inerte de superfície relativamente grande (o contra-eletrodo) e o eletrodo de referência. O potencial é aplicado entre os eletrodos de trabalho e contra eletrodo em forma de varredura, isto é, variando-o a uma velocidade constante em função do tempo. O potencial e a corrente resultante são registrados simultaneamente, obtendo-se assim o voltamograma.

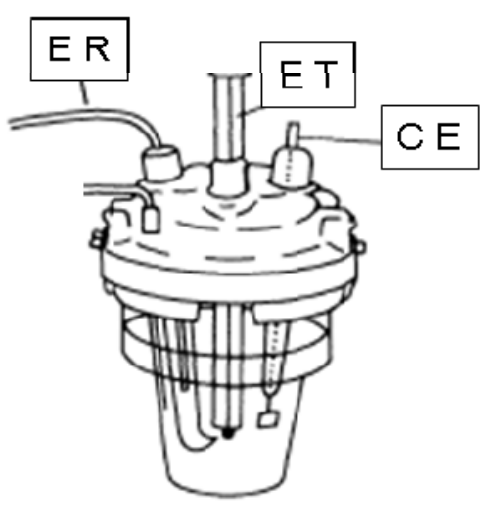

Figura 5: Célula eletroquímica de três eletrodos e um compartimento [76].

A instrumentação necessária para a realização dessa técnica é um potenciostato com gerador de programa de potencial, computador para registrar os gráficos de corrente em função do potencial, célula convencional de três eletrodos e uma solução contendo o eletrólito.

O potenciostato é um dispositivo eletrônico que controla a diferença de potencial elétrico entre o eletrodo de trabalho e o eletrodo de referência presentes em uma célula eletroquímica. Ao realizar este controle o potenciostato atua como um catalisador ou inibidor de reações eletroquímicas, ou seja, com um equipamento destes é possível controlar, através do potencial elétrico, estas reações. 


\section{MATERIAIS E MÉTODOS}

\subsection{METODOLOGIA}

Para alcançar os objetivos propostos nesse trabalho de pesquisa se adotou a seguinte metodologia de trabalho:

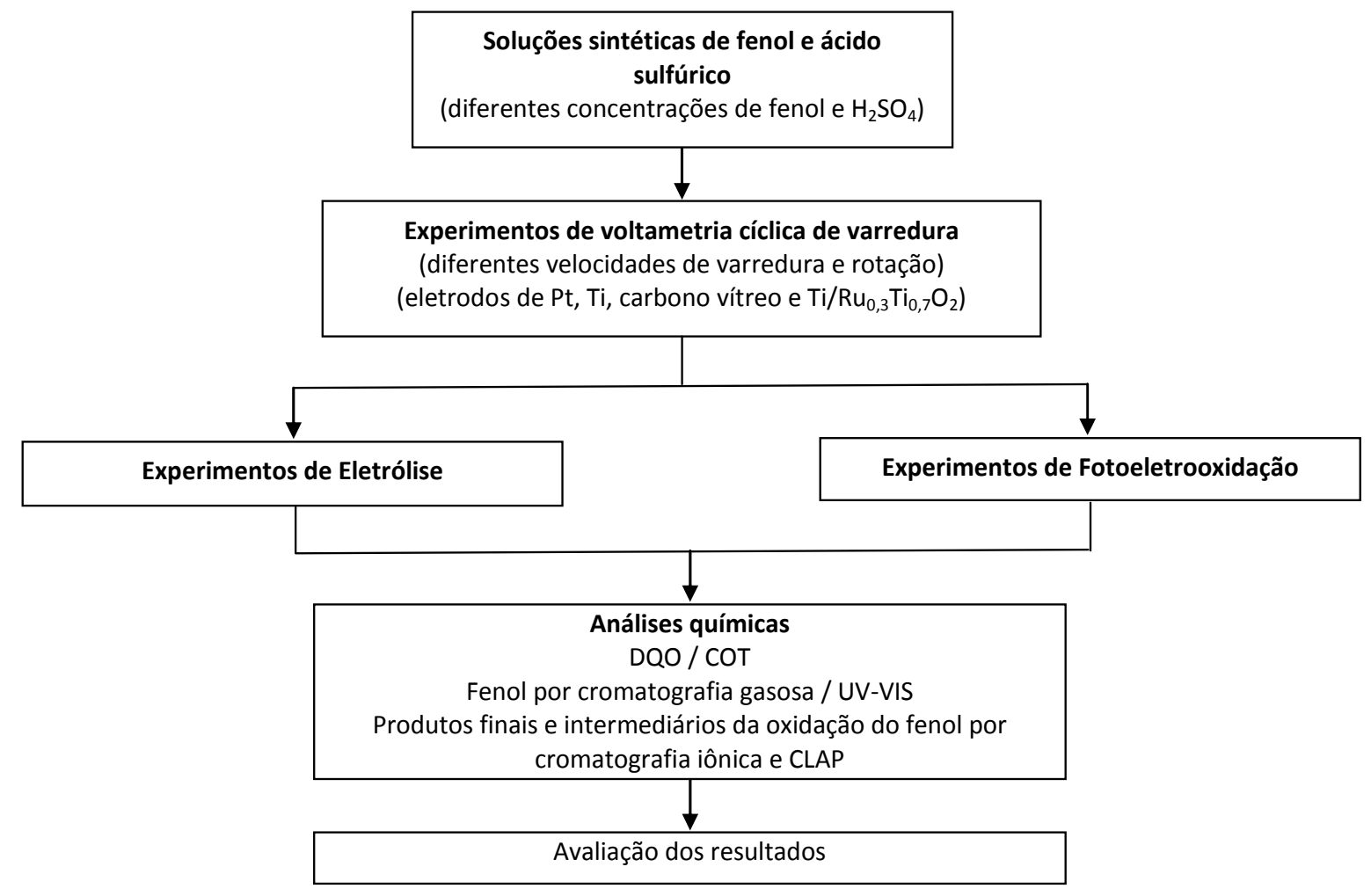

Figura 6: Fluxograma da metodologia aplicada no estudo da oxidação de compostos aromáticos orgânicos refratários.

\subsection{SOLUÇÕES}

Foram utilizados reagentes de grau analítico, fenol da marca CRQ $(99,5 \%)$ e ácido sulfúrico da marca F. Maia (95 - $97 \%$ ), sendo testadas concentrações de fenol entre $0,5 \mathrm{mM}$ e $25 \mathrm{mM}$ e concentrações de ácido sulfúrico entre $0,05 \mathrm{M}$ e $1 \mathrm{M}$. As soluções foram preparadas com água destilada e a temperatura ambiente, o pH ácido foi elegido para impedir o fenômeno indesejável de polimerização do fenol. Esse fenômeno é indesejável no processo de tratamento 
proposto nesse trabalho por provocar o bloqueio da superfície do eletrodo, reduzindo a atividade do eletrodo pela redução da área superficial de reação [37].

Primeiramente foi realizada uma caracterização das soluções com medidas de $\mathrm{pH}$ e condutividade.

Foram realizados no Laboratório de Ingeniería Electroquímica y Corrosión da UPV, Espanha, estudos do comportamento eletroquímico do processo de degradação eletroquímica do fenol em diferentes materiais anódicos com o uso da técnica de VC. Utilizaram-se soluções sintéticas com diferentes teores de fenol, caracterizadas conforme Tabela 3.

Tabela 3: Medidas de pH e condutividade para as soluções testadas nos experimentos de VC.

\begin{tabular}{|c|c|c|c|}
\hline $\begin{array}{c}\text { Conc. de } \mathrm{H}_{2} \mathrm{SO}_{4} \\
\text { (M) }\end{array}$ & $\begin{array}{l}\text { Conc. Fenol } \\
(\mathrm{mM})\end{array}$ & $\begin{array}{c}\text { Condutividade } \\
(\mathrm{mS})\end{array}$ & $\begin{array}{l}\mathrm{pH} \\
\ldots .\end{array}$ \\
\hline \multirow[t]{5}{*}{0,01} & 25,0 & 4,25 & 1,92 \\
\hline & 12,5 & 4,25 & 1,92 \\
\hline & 6,25 & 4,37 & 1,91 \\
\hline & 1,0 & 4,50 & 1,89 \\
\hline & 0,5 & 4,31 & 1,92 \\
\hline \multirow[t]{5}{*}{0,05} & 25,0 & 14,65 & 1,10 \\
\hline & 12,5 & 13,73 & 1,14 \\
\hline & 6,25 & 13,68 & 1,15 \\
\hline & 1,0 & 13,21 & 1,18 \\
\hline & 0,5 & 12,10 & 1,23 \\
\hline \multirow[t]{5}{*}{0,5} & 25,0 & 14,75 & 0,45 \\
\hline & 12,5 & 14,57 & 0,44 \\
\hline & 6,25 & 14,94 & 0,42 \\
\hline & 1,0 & 15,14 & 0,42 \\
\hline & 0,5 & 14,60 & 0,47 \\
\hline \multirow[t]{5}{*}{1,0} & 25.0 & 16,34 & 0,21 \\
\hline & 12,5 & 16,54 & 0,20 \\
\hline & 6,25 & 16,86 & 0,20 \\
\hline & 1,0 & 17,12 & 0,19 \\
\hline & 0,5 & 17,71 & 0,19 \\
\hline
\end{tabular}




\subsection{EXPERIMENTOS DE VOLTAMETRIA CÍCLICA DE VARREDURA}

Neste trabalho foram realizados experimentos de voltametria cíclica de varredura, primeiramente no Laboratório de Ingeniería Electroquímica y Corrosión da UPV, Espanha, em uma célula de três eletrodos, (AutoLab PGSTAT 20 potenciostato/galvanostato) conforme Figura 7 .

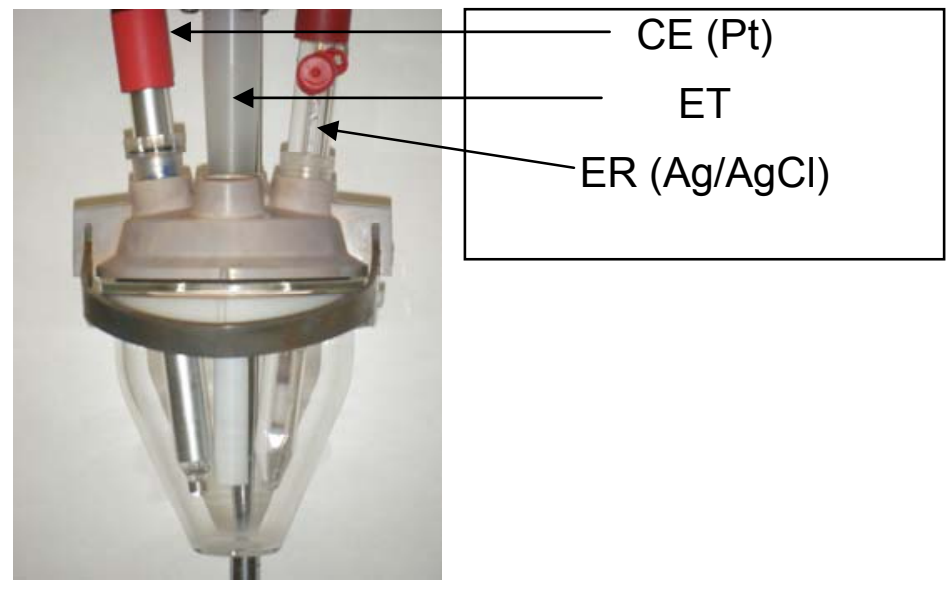

Figura 7: Célula eletroquímica utilizada nos ensaios de voltametria.

A célula é composta de um compartimento de $100 \mathrm{ml}$, contra eletrodo de platina, eletrodo de referência de $\mathrm{Ag} / \mathrm{AgCl}$ e como eletrodo de trabalho foram utilizados diversos materiais:

- Platina, com área de $0,058 \mathrm{~cm}^{2}$, por ser o elemento utilizado como padrão para estudos eletroquímicos.

- Carbono vítreo com área de $0,066 \mathrm{~cm}^{2}$.

- Titânio com área de $0,29 \mathrm{~cm}^{2}$.

- $\mathrm{Ti} / \mathrm{Ru}_{0,3} \mathrm{Ti}_{0,7} \mathrm{O}_{2}$, com área geométrica de $0,68 \mathrm{~cm}^{2}$, investigado como opção tecnológica para tratamento eletroquímico de efluentes.

Foram testadas diferentes velocidades de varredura $(10,20,40,60,80$, 100 e $200 \mathrm{mV} \cdot \mathrm{s}^{-1}$ ) e diferentes números de ciclos, visando verificar a presença de picos de oxidação e definição da densidade de corrente a ser aplicada nos processos de eletrooxidação. Foi investigado o efeito da rotação do eletrodo com o uso de um eletrodo de disco rotatório (EDR) de platina.

Os experimentos foram realizados em temperatura ambiente e com um volume de solução de $25 \mathrm{ml}$. Os eletrodos de platina e titânio foram submetidos a 
uma limpeza mecânica antes de cada experimento, com alumina em pó e papel rugoso, seguido de lavagem com água destilada. Os eletrodos de carbono vítreo e $\mathrm{Ti} / \mathrm{Ru}_{0,3} \mathrm{Ti}_{0,7} \mathrm{O}_{2}$ foram limpos com detergente e água destilada.

Também foram realizados experimentos de VC no laboratório LACOR do Departamento de Engenharia de Materiais da Universidade Federal do Rio Grande do Sul (AutoLab PGSTAT 302 potenciostato/galvanostato) em uma célula de três eletrodos, conforme Figura 8. Como eletrodo de trabalho foi utilizado $\mathrm{Ti} / \mathrm{Ru}_{0,3} \mathrm{Ti}_{0,7} \mathrm{O}_{2}$, com área geométrica de $0,68 \mathrm{~cm}^{2}$ e soluções de fenol originais e eletrooxidadas.

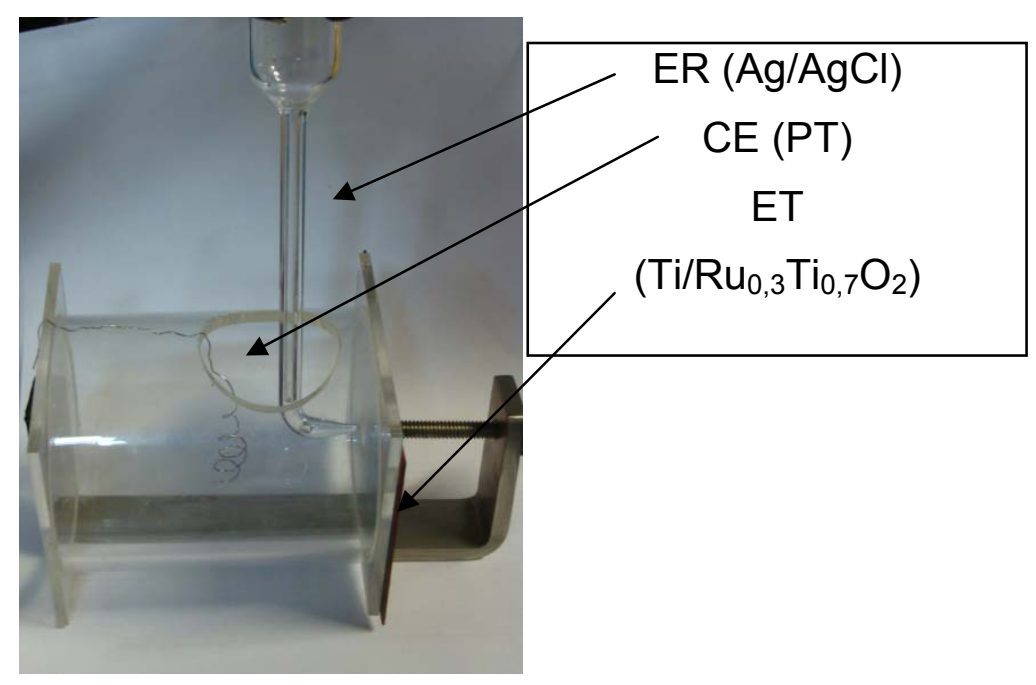

Figura 8: Célula eletroquímica utilizada nos ensaios de voltametria.

Os potencias apresentados nos resultados são referenciados ao eletrodo de $\mathrm{Ag} / \mathrm{AgCl}$.

\subsection{EXPERIMENTOS DE ELETRÓLISE E FOTOELETROOXIDAÇÃO}

Foram realizados no LACOR experimentos de eletrólise galvanostática e fotoeletrooxidação. $O$ aparato experimental é apresentado na Figura 9. Foram utilizados um banho ultratermostático (Nova Ética - 521/3D), fonte de corrente (ICEL - PS/6000), medidor de pH (PHTEK - PHS-3B), condutivímetro (Scholt - Handlab LF1) e agitador magnético (Fisatom - 752A, 900 RPM) . 


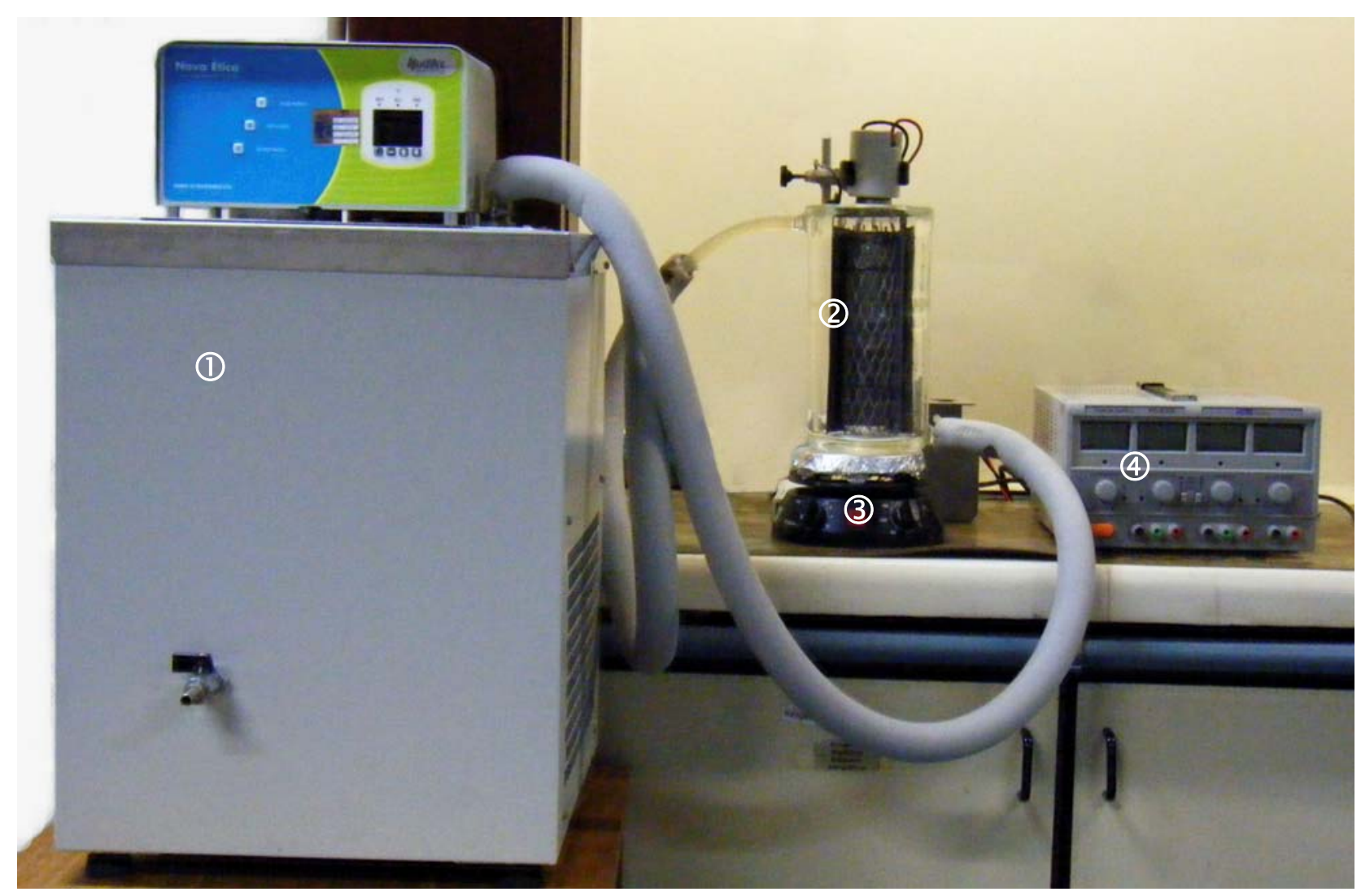

Figura 9: Aparato experimental utilizados nos experimentos de EL e FEO. Sendo:

1) banho ultratermostático, 2) reator de vidro encamisado, 3) agitador magnético e 4) fonte de corrente.

A célula foi montada de forma radial, sendo a parte externa composta pelo ânodo e a interna pelo cátodo, com uma distância entre os eletrodos de $1 \mathrm{~cm}$.

Foi utilizado um reator de vidro, Figura 10, com ânodo de $\mathrm{Ti} / \mathrm{Ru}_{0,3} \mathrm{Ti}_{0,7} \mathrm{O}_{2}$ com área geométrica de $814 \mathrm{~cm}^{2}$ e cátodo de $\mathrm{Ti} / \mathrm{TiO}_{2}$, trabalhando em sistema de batelada. Ele está conectado a um banho ultratermostático, o qual controla a temperatura com uma solução de etilenoglicol $(50 \% \mathrm{v} / \mathrm{v})$. Neste reator o volume total é de $1,5 \mathrm{~L}$, sendo o volume útil de $1 \mathrm{~L}$ e a agitação é promovida com o uso de um agitador magnético, conforme Figura 11. 


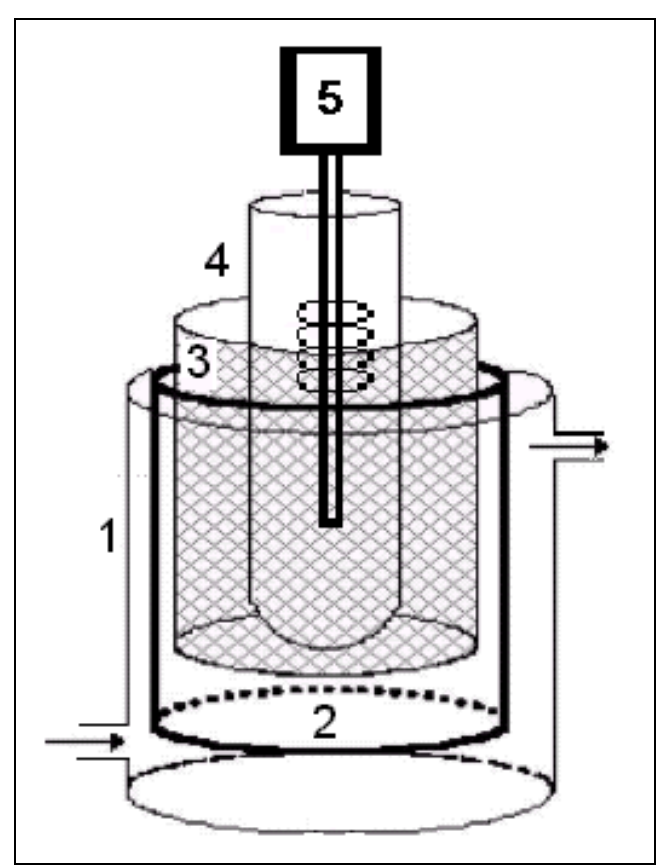

Figura 10: Representação esquemática do reator utilizado nos processos de EL e FEO. Onde: (1) reservatório de vidro; (2) ânodo de titânio revestido com $70 \mathrm{TiO}_{2} / 30 \mathrm{RuO}_{2}$; (3) cátodo de titânio revestido de óxido de titânio; (4) tubo de quartzo; (5) lâmpada de vapor de mercúrio.

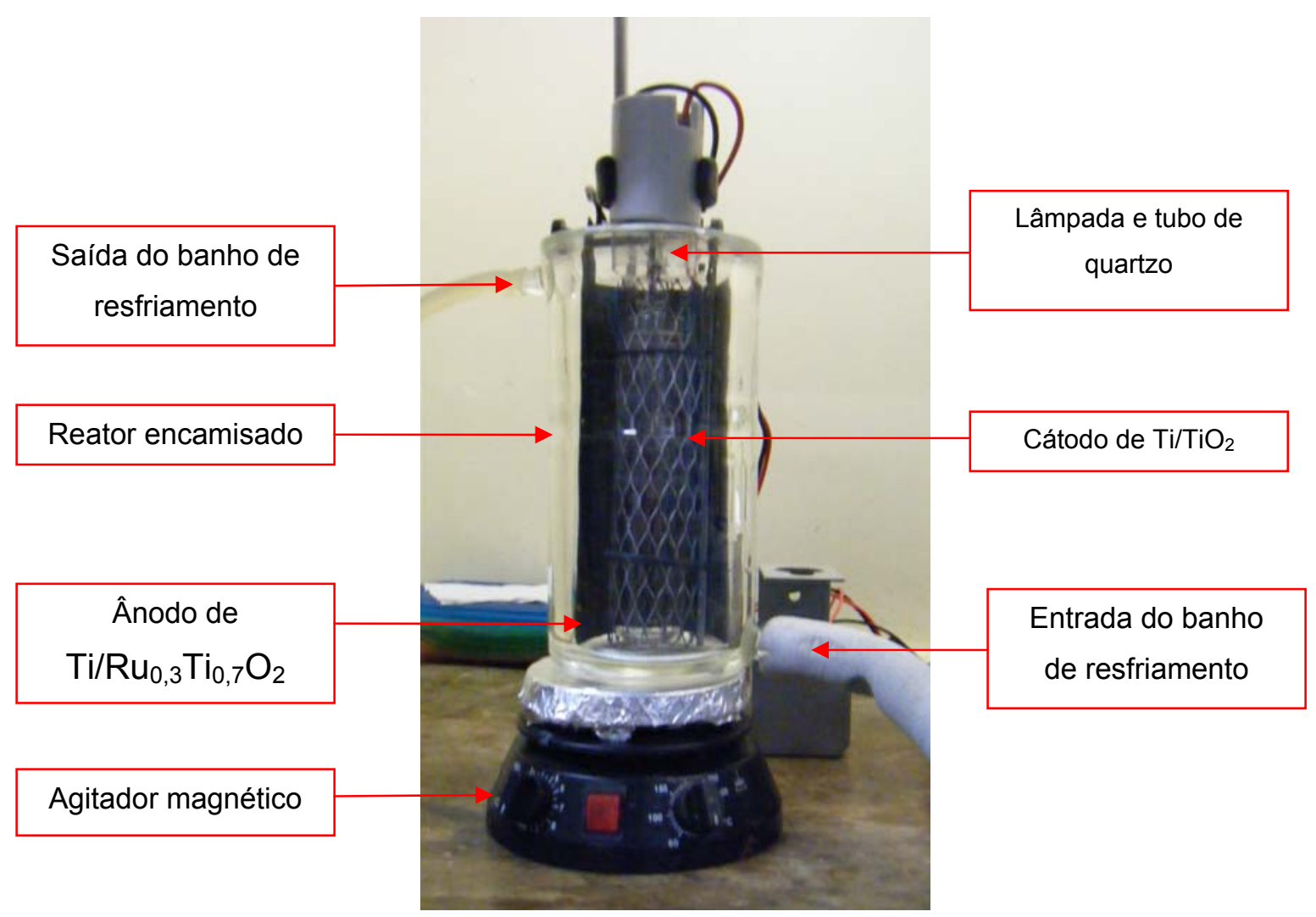

Figura 11: Reator batelada utilizado no processo de EL e FEO. 
Utiliza-se como fonte de radiação UV lâmpadas de vapor de mercúrio de média/alta pressão de $250 \mathrm{~W}$ de potência (Philips), o bulbo de vidro substituído por um de quartzo, visando permitir a passagem da radiação UV, conforme ilustra a Figura 12.

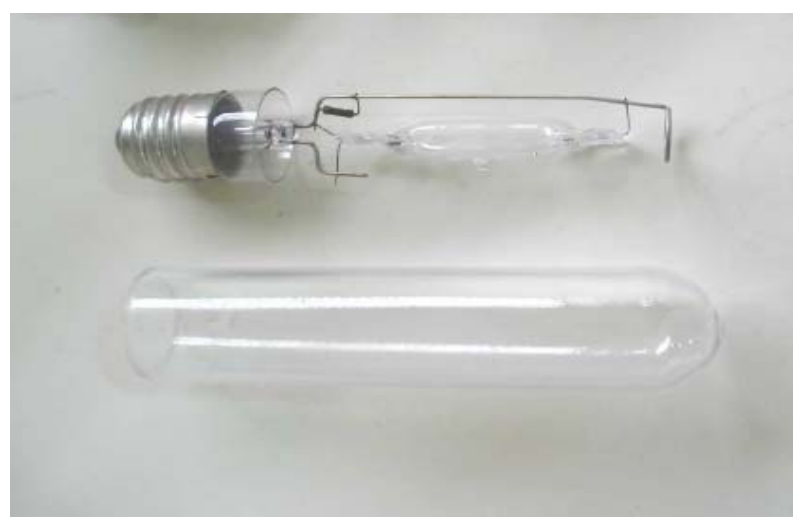

Figura 12: Tubo de quartzo e Lâmpada de vapor de mercúrio, de $250 \mathrm{~W}$ de potência.

Os ânodos utilizados são de titânio revestido de óxido de titânio como cátodo e de titânio revestido de óxidos de titânio e rutênio, na proporção $70 \mathrm{TiO}_{2} / 30 \mathrm{RuO}_{2}$ em massa, do tipo DSA. O ânodo foi produzido pela empresa De Nora do Brasil ${ }^{\circledR}$, Figura 13.

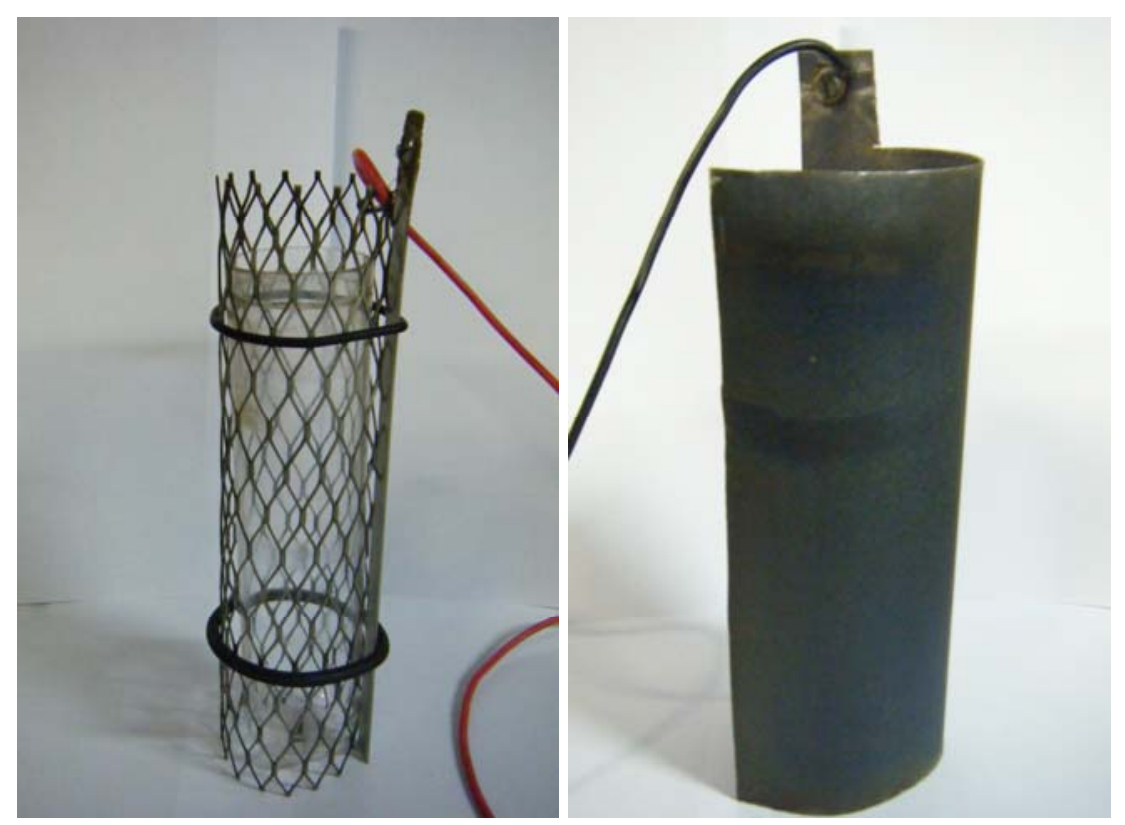

A

B

Figura 13: Eletrodos utilizados no reator eletroquímico, A) cátodo de $\mathrm{Ti}^{\mathrm{T}} / \mathrm{TiO}_{2} \mathrm{com} \mathrm{o}$ tubo de quartzo no interior e B) ânodo de $\mathrm{Ti} / \mathrm{Ru}_{0,3} \mathrm{Ti}_{0,7} \mathrm{O}_{2}$. 
Os experimentos foram conduzidos a temperatura de $25^{\circ} \mathrm{C}$ por 5 horas. Foram realizados ensaios sem e com uso de agitador magnético. Nos experimentos de EL a lâmpada permanecia desligada, sendo ligada nos experimentos de FEO.

A intensidade de radiação UV sobre a superfície do ânodo foi medida utilizando o radiômetro da marca Instruterm - MRUR 203, foi considerada a distância entre a superfície do tubo de quartzo e o ânodo de $1,5 \mathrm{~cm}$. Foram realizadas medidas para três situações: sem fluído, com água e com a solução de fenol.

\subsection{ANÁLISES QUÍMICAS}

Considerando que no processo de oxidação de compostos orgânicos por via eletroquímica ou fotoeletroquímica ocorre mineralização da matéria orgânica, foram realizadas análises de DQO e COT visando mensurar essa redução no teor de matéria orgânica.

As análises de DQO foram feitas pelo método titulométrico, segundo o Standard Methods for the examination of water and wastewater [77]. Para se ter uma análise mais exata da redução da matéria orgânica, amostras foram enviadas para o Laboratório de Biogeoquímica Ambiental, Faculdade de Agronomia - UFRGS - para a realização de análises de carbono total, carbono inorgânico e carbono orgânico total (COT), pelo método de combustão catalítica e detecção por infravermelho do $\mathrm{CO}_{2}$ gerado em equipamento da marca Shimadzu modelo TOC-VCSH.

O teor de fenol foi medido por cromatografia gasosa. O teor de fenol foi medido por esse método, que apresenta grande exatidão de medidas, com limite de detecção de 0,01 ppm. Essas análises foram realizadas pelo Laboratório PróAmbiente - Análises Químicas e Toxicológicas Ltda. O equipamento utilizado na análise de fenol é o Cromatógrafo a Gás VARIAN, modelo 3350, com amostrador automático. As análises de benzoquinona (BQ) também foram realizadas por esse laboratório pela técnica de cromatografia líquida de alta performance (CLAP). O equipamento utilizado na análise da benzoquinona foi o Cromatógrafo Líquido VARIAN, modelo ProStar.

Para a determinação de ácidos orgânicos de cadeia molecular curta, que são possíveis produtos da oxidação eletroquímica do fenol foi utilizada a técnica de 
cromatografia de troca iônica (Cl). Como fase móvel se utilizou solução $100 \mathrm{mM}$ $\mathrm{Na}_{2} \mathrm{SO}_{4}$, em uma coluna da marca Acclaim® OA $5 \mu \mathrm{m}$ para detecção de ácidos orgânicos, na qual se analisou ácido oxálico, tartárico, acético e cítrico. As análises foram realizadas no cromatógrafo iônico IC Dionex - ICS 3000, com programa de aquisição de dados Chrameleon e detecção por UV.

Foram realizados estudos comparativos aplicando a técnica de espectroscopia UV/visível. Devido ao fato de fenol em meio ácido apresentar espectro bem característico, foram realizadas varreduras no espectro de UV e visível antes e após a aplicação dos processos oxidativos, com uma diluição de dez vezes. Essas análises foram realizadas no espectrofotômetro da marca PG Instruments, modelo T-80 + UVIVIS.

Os valores apresentados nos resultados dos experimentos de EL e FEO representam a média das duplicatas realizadas.

\subsection{DESCARTE DOS RESÍDUOS}

Durante a realização das etapas proposta para essa investigação foram gerados resíduos, principalmente líquidos. Conforme apresentado nos capítulos iniciais desse trabalho, as sustâncias químicas utilizadas nos experimentos devem ser manuseadas e descartadas com todos os cuidados necessários. No diagrama de blocos da Figura 14 estão apresentadas as principais entradas e saídas de produtos químicos perigosos. São apresentadas também informações sobre o volume de efluente gerado.

O sistema de descarte dos efluentes era realizado da seguinte forma:

- Segregação dos resíduos gerados (solução Fenol/ $\mathrm{H}_{2} \mathrm{SO}_{4}$ ou solução Fenol $/ \mathrm{H}_{2} \mathrm{SO}_{4}$ tratada + reagentes utilizados nas análises).

- Acondicionamento em bombonas de $5 \mathrm{~L}$, com etiqueta identificando composição principal do efluente, $\mathrm{pH}$, fonte geradora e responsável técnico.

- Encaminhamento para a central de tratamento de resíduos da UFRGS. 
No centro de Gestão e Tratamento de Resíduos Químicos (CGTRQ) da UFRGS esses compostos químicos são recuperados e utilizados em aulas de laboratório de disciplinas da graduação, onde não é necessário o uso de reagentes com alto grau de pureza. As amostras enviadas a outros laboratórios para realização de análises químicas foram adequadamente acondicionadas e no volume mínimo exigido para uma segura realização da análise.

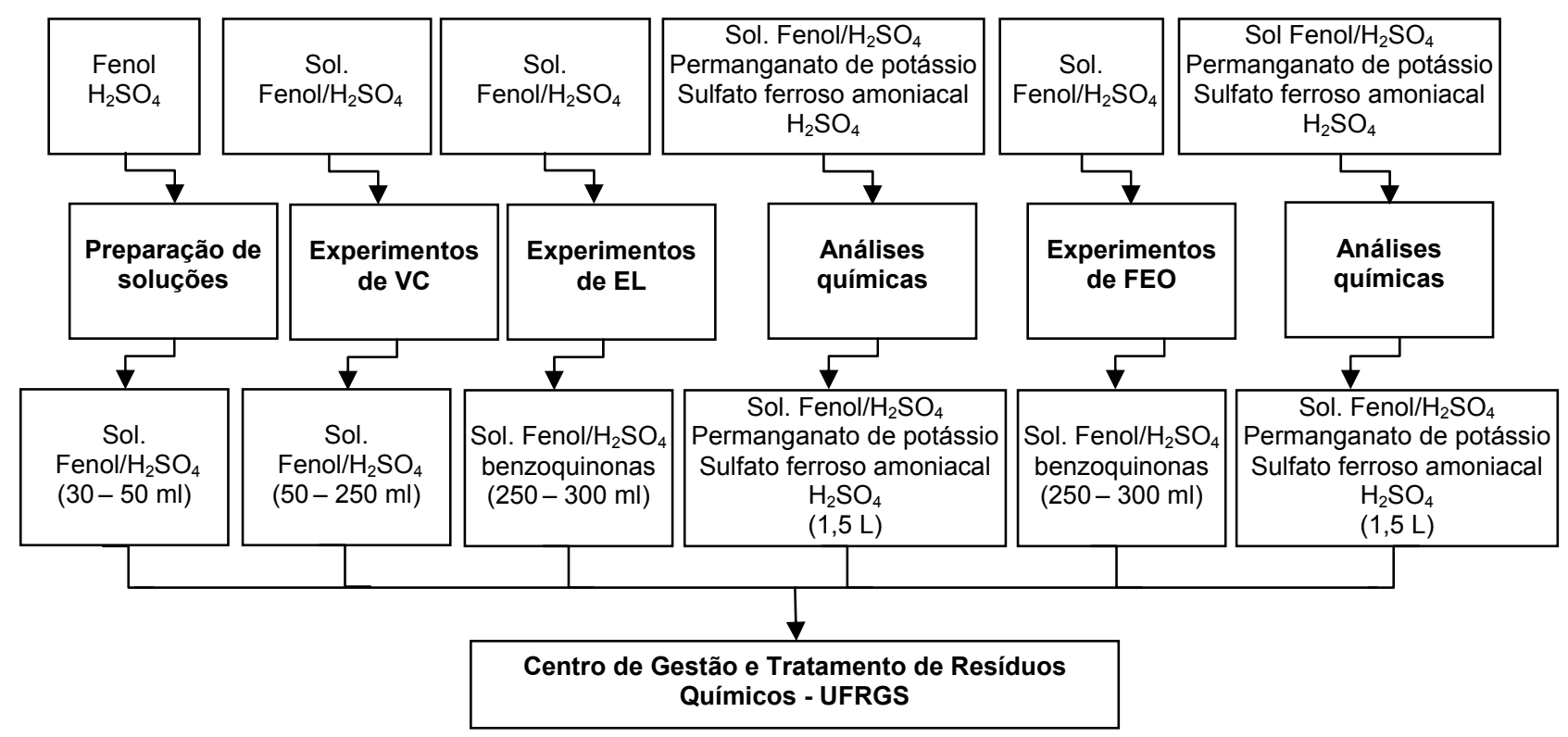

Figura 14: Fluxograma de blocos das entradas e saídas de produtos químicos na realização dos experimentos, para cada etapa e com volume aproximado de efluente gerado. 


\section{RESULTADOS}

\subsection{ESTUDO DO COMPORTAMENTO ELETROQUÍMICO DO MATERIAL ANÓDICO}

\subsubsection{Eletrodo de Platina}

Estudos do comportamento eletroquímico com eletrodo de platina como ET são muito aplicados quando se pretende avaliar propriedades eletroquímicas de materiais, sendo a platina o material padrão para se começar uma investigação cientifica nesse sentido.

A Figura 15 mostra os voltamogramas cíclicos em diferentes concentrações de fenol $(0 ; 0,5 ; 1 ; 6,25 ; 12,5$ e $25 \mathrm{mM})$ em meio de ácido sulfúrico $0,05 \mathrm{M}$, a uma velocidade de varredura de $60 \mathrm{mV} \cdot \mathrm{s}^{-1}$. A comparação entre os voltamogramas cíclicos obtidos na presença e ausência de fenol mostra que ocorre a formação de um pico de oxidação sempre que se tem a presença de fenol, sendo que a oxidação do fenol ocorre em um potencial de eletrodo em torno de $1 \mathrm{~V}$. Este pico é proporcional à concentração de fenol e é deslocado para potenciais menos positivos como o aumento da concentração de fenol. Os voltamogramas cíclicos de todas as soluções investigadas contendo fenol apresentam forma similar.

A densidade de corrente de pico de oxidação em função da concentração de fenol é representada na Figura 16 para diferentes concentrações de ácido sulfúrico. Esta figura mostra que o pico de densidade de corrente anódico aumenta com a concentração de fenol, atinge um valor máximo e depois permanece praticamente constante para concentrações de fenol superiores a 6,25 mM. Esse comportamento pode ser devido a uma diminuição da atividade do eletrodo a altas concentrações de fenol, provavelmente devido à competição por sítios ativos na superfície do eletrodo ou a formação de uma maior quantidade de radicais fenox. Estes radicais são envolvidos em processos de eletropolimerização, causando rápida desativação do eletrodo, com o aumento da concentração de fenol. Wang e Lee [78] observaram que o bloqueio do eletrodo com os produtos da oxidação é mais proeminente em concentrações mais elevadas. 


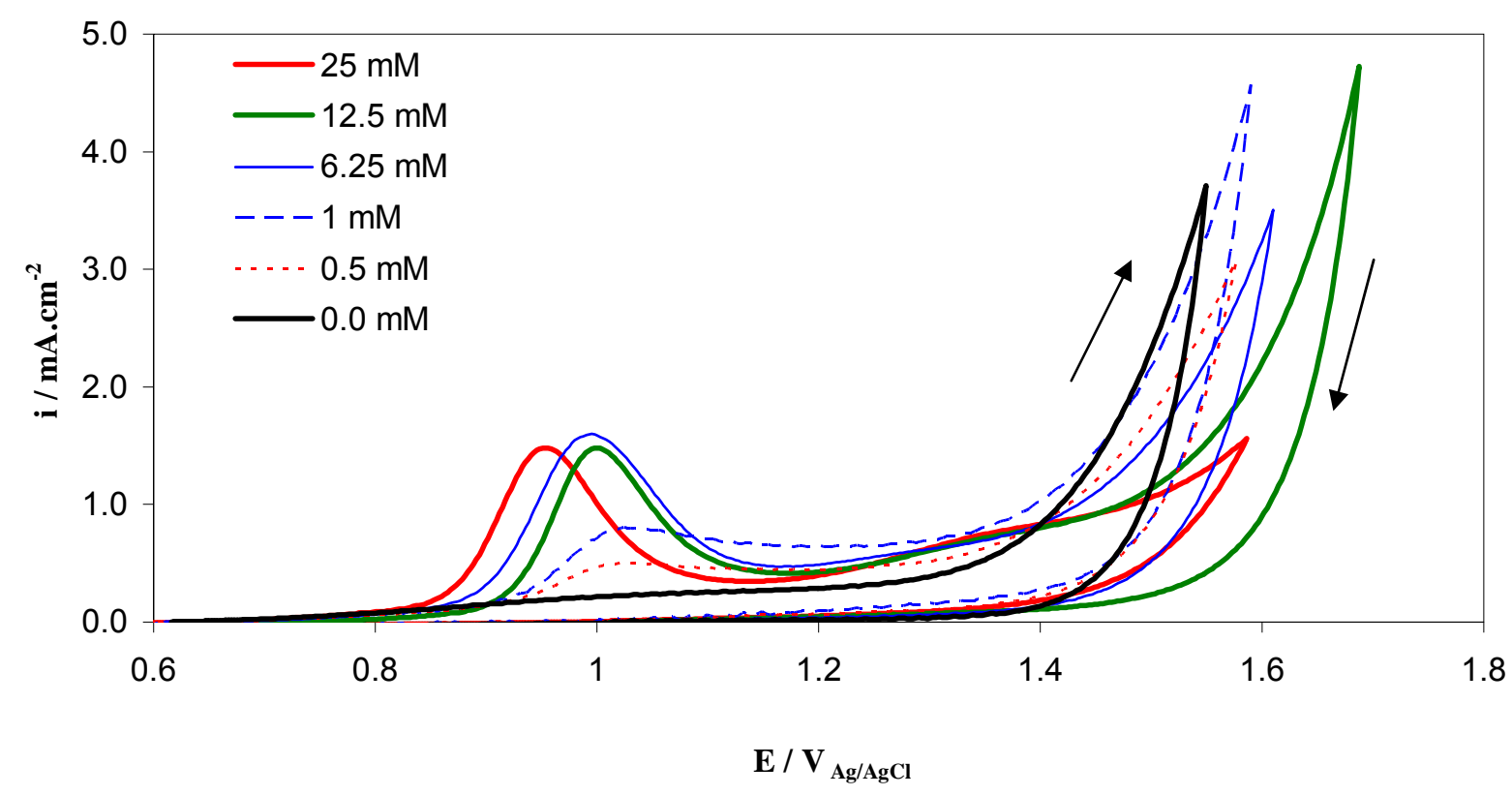

Figura 15: Voltamogramas cíclicos obtidos em solução de $0,05 \mathrm{M} \mathrm{H}_{2} \mathrm{SO}_{4} \mathrm{e}$ diferentes concentrações de fenol, $\mathrm{v}=60 \mathrm{mV} \cdot \mathrm{s}^{-1}$. $(\mathrm{ET}=\mathrm{Pt}, \mathrm{CE}=\mathrm{Pt}$, $\mathrm{ER}=\mathrm{Ag} / \mathrm{AgCl})$.

Resultados semelhantes foram encontrados por outros autores estudando a oxidação de compostos fenólicos, tanto em meio ácido como alcalino [35, $81,79,80]$. Desta forma, para concentrações de fenol abaixo de $10 \mathrm{mM}$, a densidade de corrente de pico aumenta proporcionalmente com a concentração de fenol, enquanto que para maiores concentrações de fenol, a densidade de corrente de pico permanece constante ou diminui com a concentração de fenol. Por outro lado, como pode ser visto na Figura 16, para uma dada concentração de fenol, o pico de densidade de corrente de pico aumenta com a concentração de ácido sulfúrico, uma vez que a polimerização de fenol é menos favorecida em baixo $\mathrm{pH}[37,73]$. 


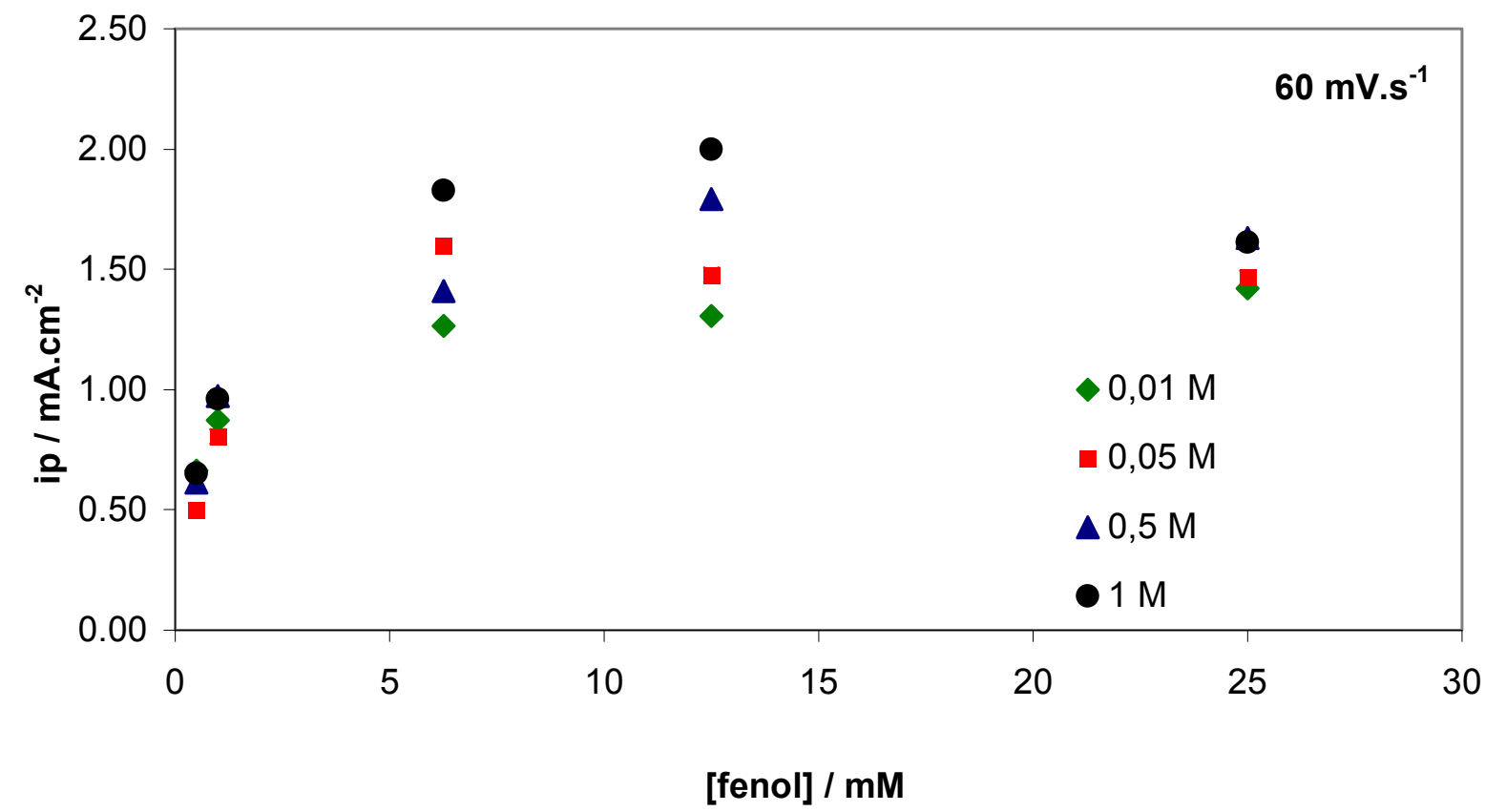

Figura 16: Densidade de corrente de pico como função da concentração de fenol para diferentes concentrações de ácido sulfúrico $(0,01 ; 0,05 ; 0,5$ e 1,0 M).

Os potenciais de pico também estão relacionados à concentração de fenol, a Figura 17 mostra a variação do potencial de pico em relação ao logaritmo da concentração de fenol em diferentes concentrações de ácido sulfúrico. Para as concentrações de fenol inferior $6,25 \mathrm{mM}$, o potencial de pico encontra-se praticamente inalterado com a concentração de fenol. No entanto, para concentrações de fenol superiores a $6,25 \mathrm{mM}$ ocorrem mudanças nos potenciais de pico anódico para valores menores, entre 1,05 e $0,90 \mathrm{~V}$, com o aumento da concentração de fenol. Singh e outros [81] observaram que para concentrações de fenol inferior a $5 \mathrm{mM}$ o potencial de pico fica praticamente inalterado com a variação da concentração de fenol, enquanto Arslan e outros [35] observaram que quando a concentração de fenol é aumentada ( de 12,5 a 100mM) o potencial de pico vai se deslocado para valores negativos, tanto em meio ácido como alcalino. Esse comportamento pode ser explicado por uma maior disponibilidade de radicais fenox associada a uma maior concentração de fenol, o que favorece as reações de oxidação que ocorrem em menor potencial anódico. 


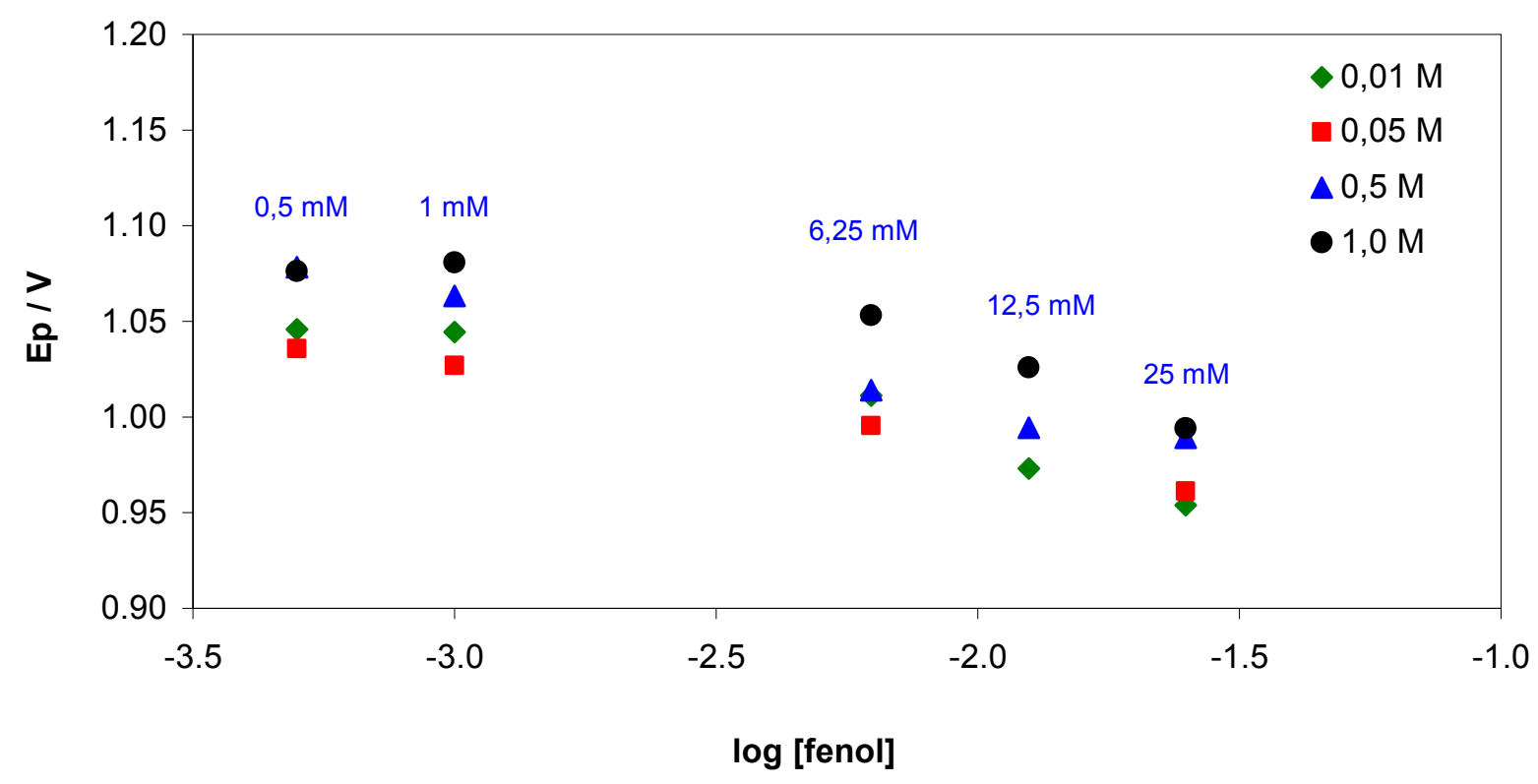

Figura 17: Potencial de pico como função da concentração de fenol para diferentes concentrações de ácido sulfúrico $(0,01 ; 0,05 ; 0,5$ e 1,0 M).

Eletrodos nobres geralmente apresentam uma atividade de curta duração para a oxidação de fenol como consequência do bloqueio da superfície do eletrodo por películas aderentes, gerada pela polimerização dos radicais fenox produzidos na oxidação. Portanto, a fim de analisar a estabilidade do eletrodo, ensaios de VC com repetitivos ciclos foram realizados para uma solução contendo $0,5 \mathrm{mM}$ de fenol em $0,5 \mathrm{M} \mathrm{H}_{2} \mathrm{SO}_{4}$ a uma velocidade de varredura de $60 \mathrm{mV} . \mathrm{s}^{-1}$. A corrente envolvida na oxidação de fenol cai gradualmente com o aumento do número de ciclos até quase zero após cerca de quatro ciclos, conforme pode ser observado na Figura 18.

Este processo de inibição pode ser atribuído ao envenenamento do eletrodo produzido pela formação de um produto não condutor polimérico, proveniente da oxidação do fenol, que bloqueia a superfície do eletrodo. Esse produto forma uma camada de polímero que inibe a oxidação direta do fenol na superfície do ânodo. Similar desativação de diferentes eletrodos na presença de substratos orgânicos aromáticos como o fenol, clorofenol e safrol já foi relatado na literatura $[64,68,81,82,83]$. Assim, em estudos posteriores, a densidade da corrente de pico de oxidação do primeiro ciclo anódico foi considerada para análise dos resultados. 


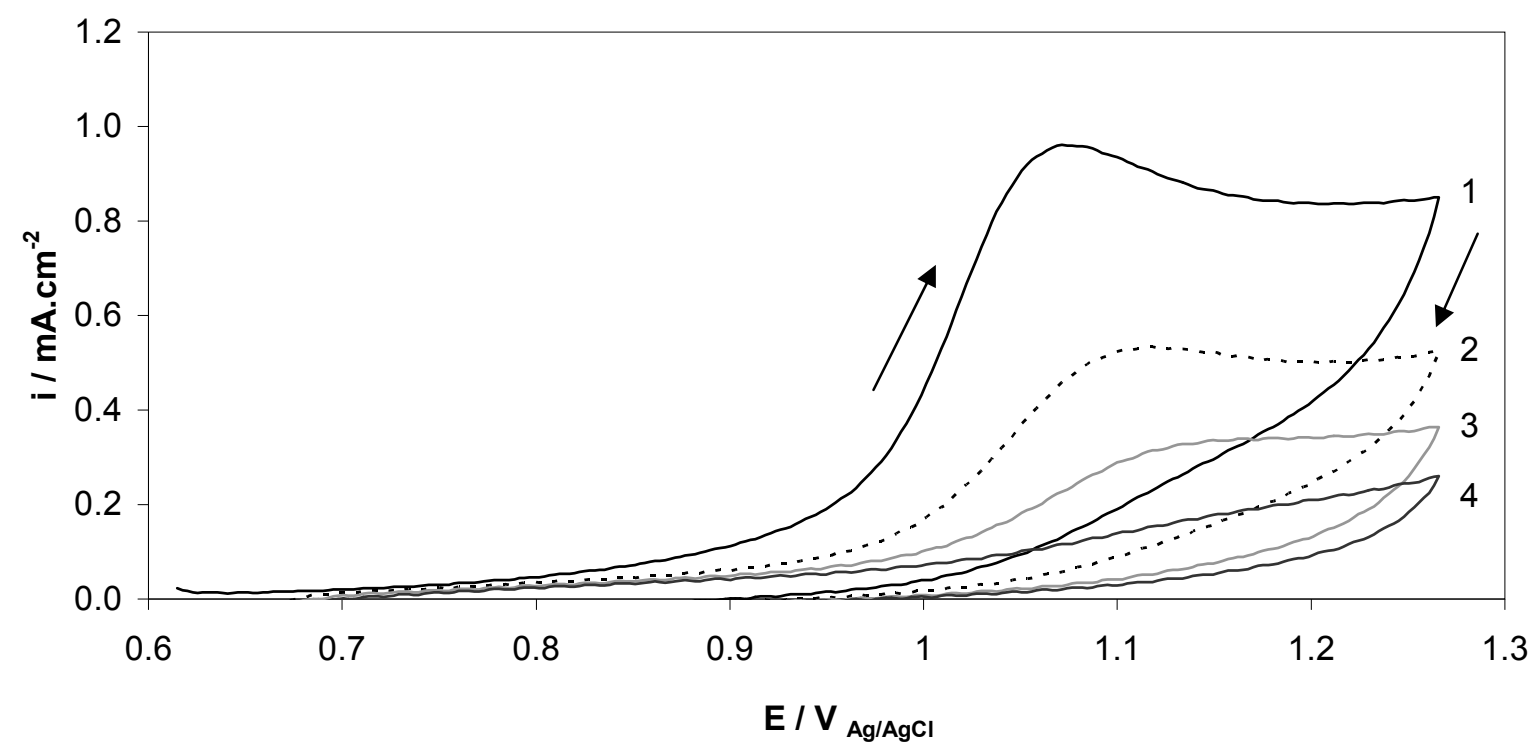

Figura 18: Voltamogramas cíclicos obtidos para uma solução $0,5 \mathrm{mM}$ fenol / $0,5 \mathrm{M} \mathrm{H}_{2} \mathrm{SO}_{4}, \mathrm{v}=60 \mathrm{mV} \cdot \mathrm{s}^{-1}$. (ET = Pt, $\left.\mathrm{CE}=\mathrm{Pt}, \mathrm{ER}=\mathrm{Ag} / \mathrm{AgCl}\right)$.

A cronoamperometria foi usada para mostrar a estabilidade do eletrodo de Pt. A Figura 19 exibe a curva potenciostática obtida em uma solução agitada de 0,5 mM de fenol em um potencial aplicado de 1,1 V no eletrodo de Pt. Observa-se que a densidade de corrente diminui para valores muito baixos após alguns segundos, devido ao bloqueio da superfície do eletrodo pela deposição de produtos adesivos poliméricos. Esse comportamento reafirma o que já foi reportado nos resultados obtidos nos experimentos de VC. 


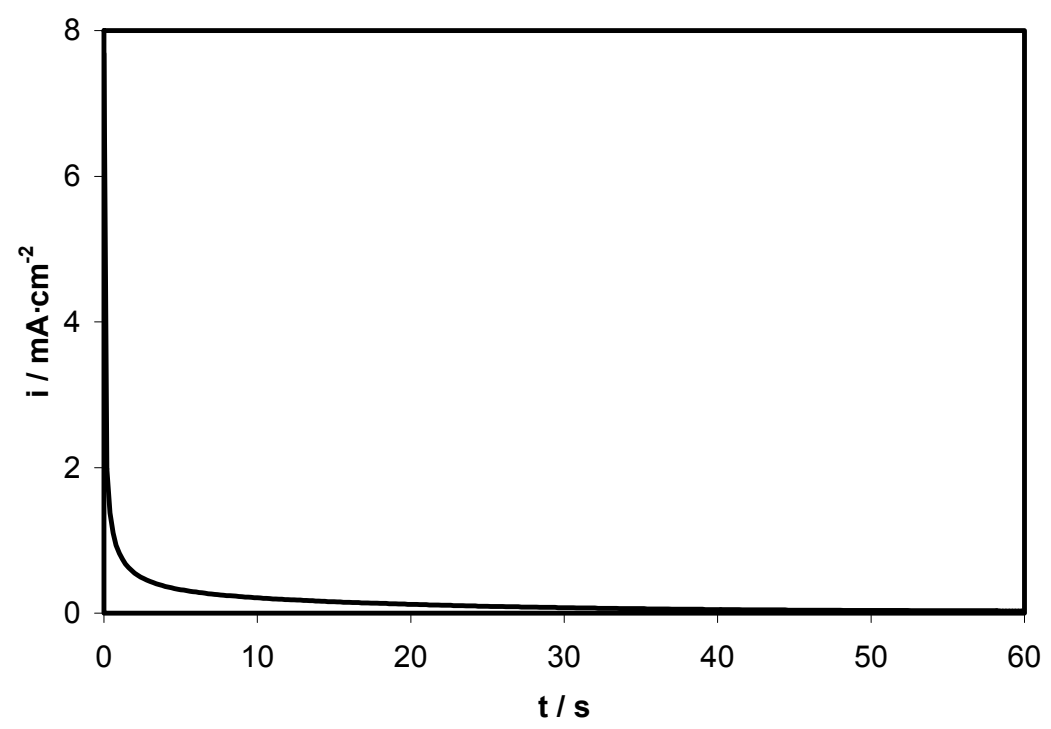

Figura 19: Curva potenciostática i-t obtida a $1,1 \mathrm{~V}$ para uma solução $0,5 \mathrm{mM}$ fenol / 0,5 $\mathrm{m} \mathrm{H}_{2} \mathrm{SO}_{4} .(\mathrm{ET}=\mathrm{Pt}, \mathrm{CE}=\mathrm{Pt}, \mathrm{ER}=\mathrm{Ag} / \mathrm{AgCl})$

A comparação entre os voltamogramas cíclicos obtidos em diferentes taxas de rotação EDR para uma concentração de fenol de $12,5 \mathrm{mM}$ e duas concentrações de ácido sulfúrico 0,05 e 0,5 M é mostrado na Figura $20 \mathrm{~A}$ e $\mathrm{B}$, respectivamente. A taxa de rotação do EDR não tem influência importante no potencial de pico para ambas as concentrações de ácido testadas. Observando a intensidade do pico se verifica uma variação para as condições testadas, contudo não se verifica claramente uma dependência dessa variação com a velocidade de rotação do eletrodo. Sendo assim, se faz necessário uma análise mais aprofundada para definir o sistema de controle do processo, ou seja, se difusional ou cinético. 


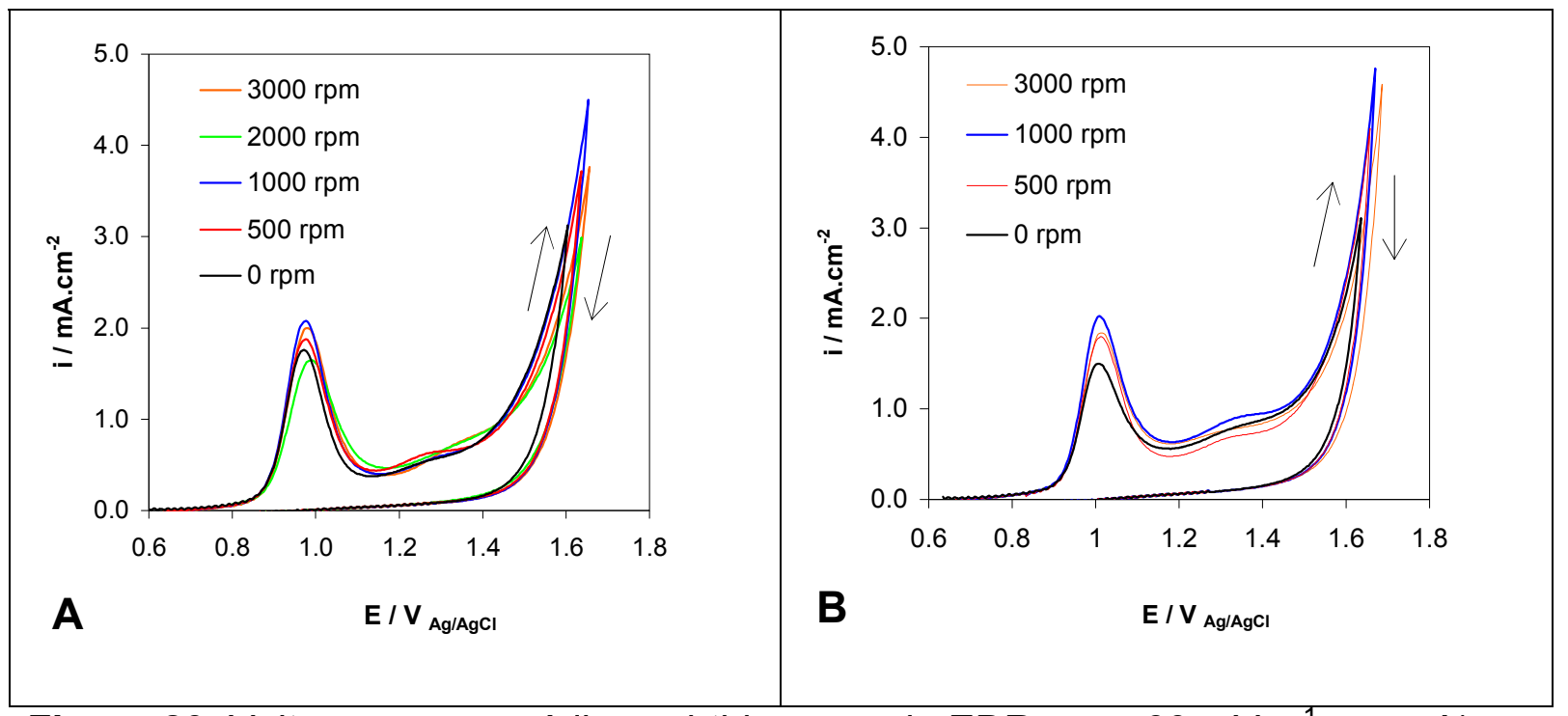

Figura 20: Voltamogramas cíclicos obtidos usando EDR a $\mathrm{v}=60 \mathrm{mV} \cdot \mathrm{s}^{-1}$ para: $\mathrm{A}$ ) 12,5 $\mathrm{M}$ fenol / 0,05 $\mathrm{M} \mathrm{H}_{2} \mathrm{SO}_{4}$ e B) 12,5 M fenol / 0,5 $\mathrm{M} \mathrm{H}_{2} \mathrm{SO}_{4}$. (ET = Pt, $\mathrm{CE}=\mathrm{Pt}, \mathrm{ER}=\mathrm{Ag} / \mathrm{AgCl})$.

A Figura 21 mostra uma comparação entre os voltamogramas cíclicos de fenol em função da velocidade de varredura para uma concentração de ácido sulfúrico de 0,05 M e duas concentrações de fenol de 1 e 6,25 mM (Figuras A e B, respectivamente). O potencial de pico anódico, bem como as correntes de pico correspondente, mudaram com a velocidade de varredura. Um aumento da velocidade de varredura de potencial aumenta a densidade de corrente de pico e desloca o potencial de pico no sentido positivo como é típico de sistemas totalmente irreversíveis [80]. Este efeito foi mais pronunciado para a maior concentração de fenol (Figura 21 B). Em todos os casos, a diferença no valor de | Ep - Ep 1/2| é muito superior ao valor necessário para um processo reversível (24,7 mV em 373K) [36], indicando que, na faixa das condições experimentais utilizadas neste trabalho, a oxidação de fenol em ácido sulfúrico com eletrodo de Pt não é apenas controlado por difusão, mas também pela cinética de transferência de carga. 


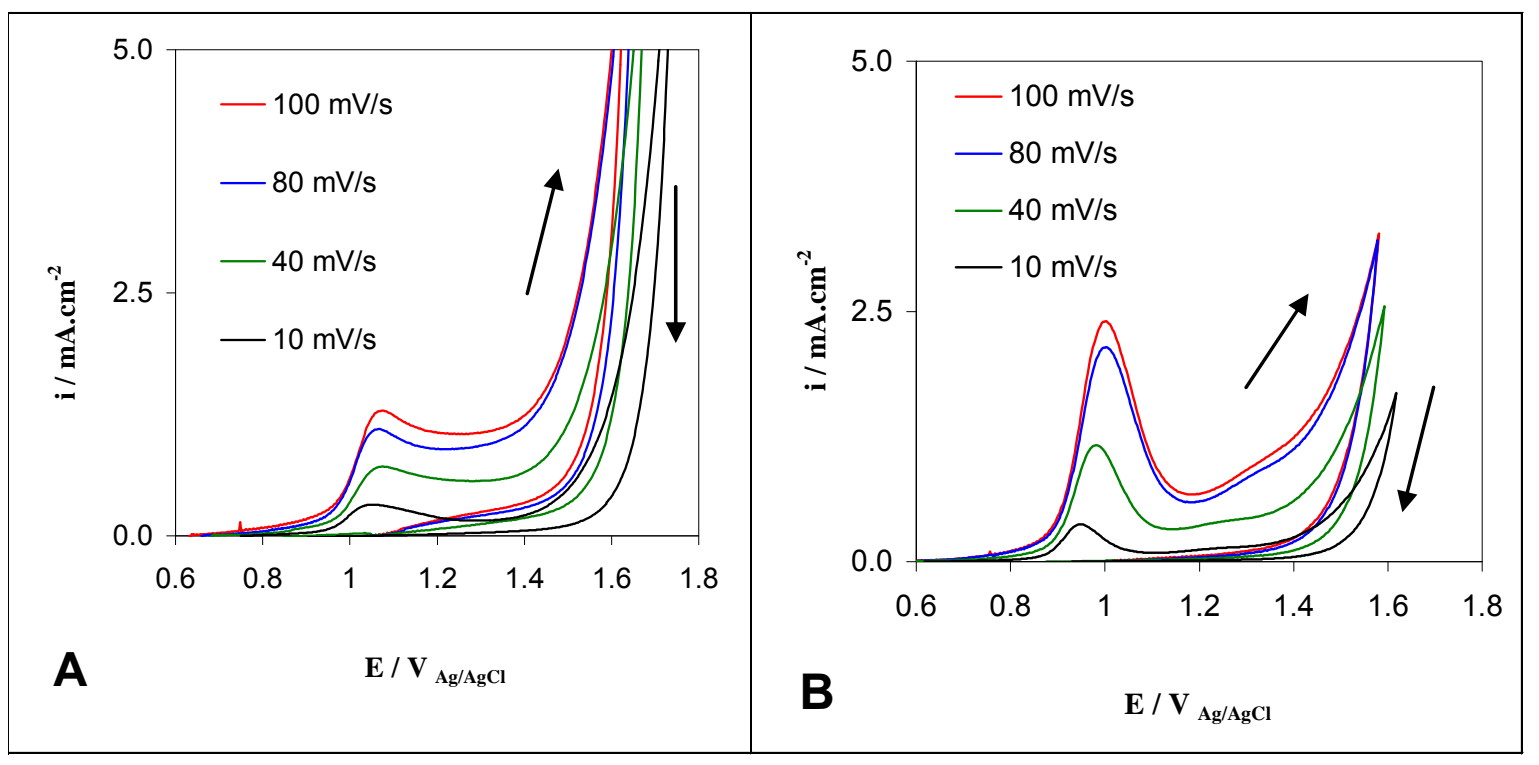

Figura 21: Voltamogramas cíclicos obtidos para diferentes velocidades de varredura: A) $1 \mathrm{mM}$ fenol / 0,05 $\mathrm{M} \mathrm{H}_{2} \mathrm{SO}_{4}$ e $\quad$ B) $6,25 \mathrm{mM}$ fenol / $0,05 \mathrm{M} \mathrm{H}_{2} \mathrm{SO}_{4}$. $(\mathrm{ET}=\mathrm{Pt}, \mathrm{CE}=\mathrm{Pt}, \mathrm{ER}=\mathrm{Ag} / \mathrm{AgCl})$.

Os experimentos foram realizados para diferentes concentrações de ácido sulfúrico, uma vez que estudos sobre o assunto enfatizam a influência do $\mathrm{pH}$ no processo de eletrooxidação de fenol, indicam que em meio fortemente ácido a reação de oxidação seria favorecida. O efeito do ácido sulfúrico sobre a eletrooxidação de fenol é mostrado na Figura 22, que apresenta os voltamogramas cíclicos obtidos para duas concentrações de fenol de 1 e 6,25 mM (A e B, respectivamente) e diferentes concentrações de ácido sulfúrico em uma velocidade de varredura de $60 \mathrm{mV} . \mathrm{s}^{-1}$. Conforme mostrado na Figura 22, nas condições investigadas neste trabalho, a concentração de ácido sulfúrico tem pouco efeito sobre a densidade de corrente de pico, especialmente para valores de $\mathrm{pH}$ variando entre 0,2 e 0,4, correspondendo às concentrações de ácido sulfúrico 1 e 0,5 M, respectivamente. No entanto, há uma mudança significativa no potencial de pico para valores mais positivos na maior concentração de ácido sulfúrico $1 \mathrm{M}(\mathrm{pH}=0,2)$ para todas as concentrações de fenol estudados neste trabalho. Este deslocamento para valores mais positivos de potencial observada em $\mathrm{pH} \mathrm{0,2}$ pode ser devido a uma menor influência dos fenômenos de polimerização e adsorção na superfície do eletrodo, em soluções fortemente ácidas [35]. 


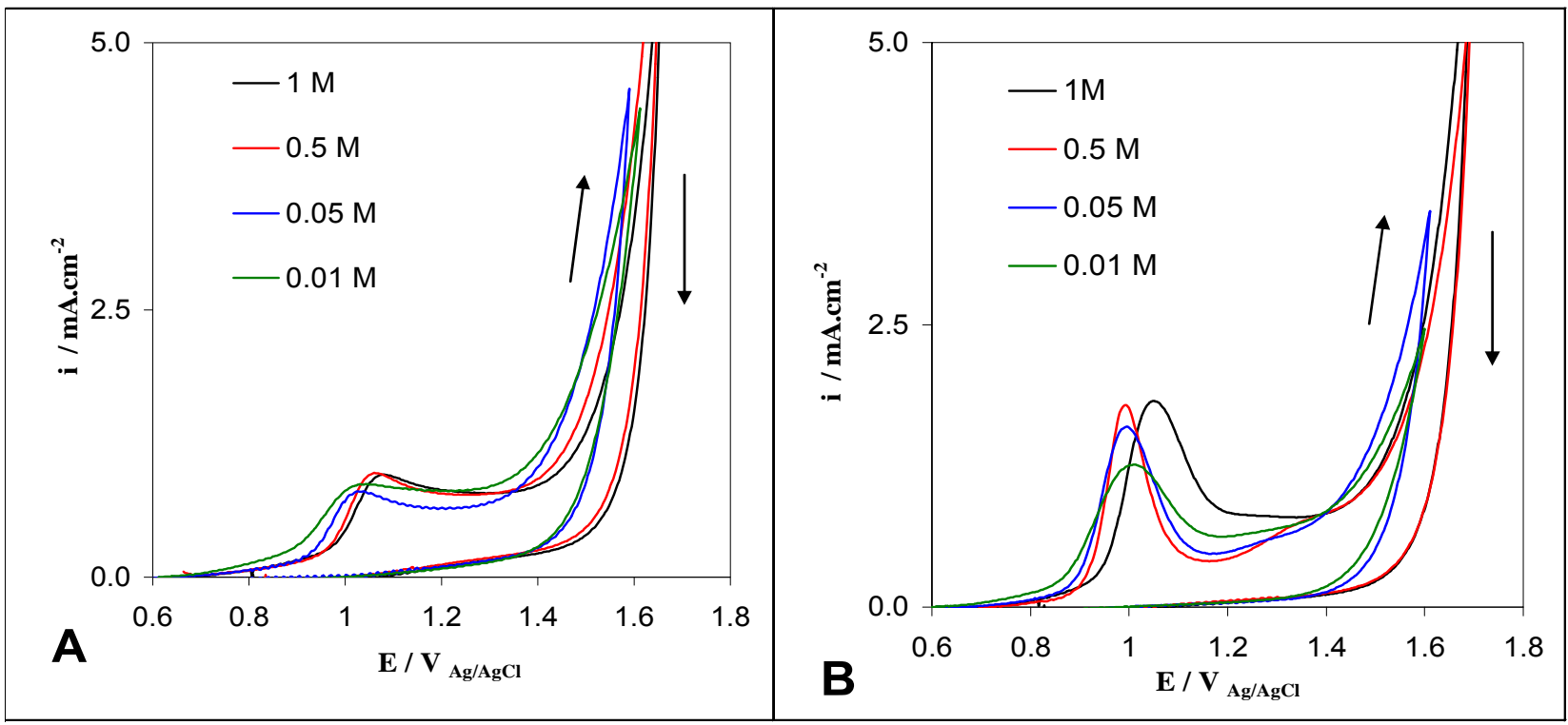

Figura 22: Voltamogramas cíclicos obtidos para quatro diferentes concentrações de uma $\mathrm{H}_{2} \mathrm{SO}_{4}$ em solução de fenol: A) $1 \mathrm{mM}$ e B) $6,25 \mathrm{mM} . \mathrm{v}=60 \mathrm{mV} \cdot \mathrm{s}^{-1}$. $(\mathrm{ET}=\mathrm{Pt}, \mathrm{CE}=\mathrm{Pt}, \mathrm{ER}=\mathrm{Ag} / \mathrm{AgCl})$.

A partir dos resultados discutidos anteriormente, pode-se concluir que, nas condições utilizadas neste trabalho, a concentração de ácido sulfúrico tem pouco efeito sobre a eletrooxidação de fenol, enquanto que há uma maior influência da concentração de fenol na densidade de corrente de pico, potencial de pico e na forma do pico de oxidação. Também foi observado um aumento na densidade de corrente de pico e um deslocamento do potencial de pico para valores mais anódicos com a velocidade de varredura, o que pode indicar um mecanismo irreversível no processo de oxidação do fenol. A fim de proceder a uma análise mais detalhada da influência dos diferentes parâmetros utilizados neste trabalho, sobre o processo de eletrooxidação de fenol, um estudo sobre a variação do potencial de pico e a densidade de corrente de pico, associada à velocidade de varredura, para diferentes concentrações de fenol e ácido sulfúrico, foi realizado.

A parcela do potencial de pico anódico (Ep) em função do logaritmo da velocidade de varredura (log v) para a oxidação de fenol em eletrodo de Pt é mostrado na Figura 23, para uma concentração de ácido sulfúrico de 0,05 M e diferentes concentrações de fenol. Para concentrações abaixo de $1 \mathrm{mM}$ de fenol, a concentração de fenol não afeta os potenciais de pico, enquanto que para concentrações acima de $1 \mathrm{mM}$, o pico de potencial diminui com a concentração de 
fenol. Esse comportamento pode ser devido à disponibilidade do radical fenox. Para baixas concentrações de fenol, a disponibilidade de radicais fenox é menor, assim que o fenômeno de polimerização ou adsorção do radical fenox na superfície do eletrodo é menos provável ou mais lento. Como conseqüência, um maior potencial de pico será necessário para produzir o bloqueio da superfície do eletrodo. Esse mesmo comportamento foi observado por Arslan e outros [35] em seus estudos sobre a eletrooxidação de fenol.

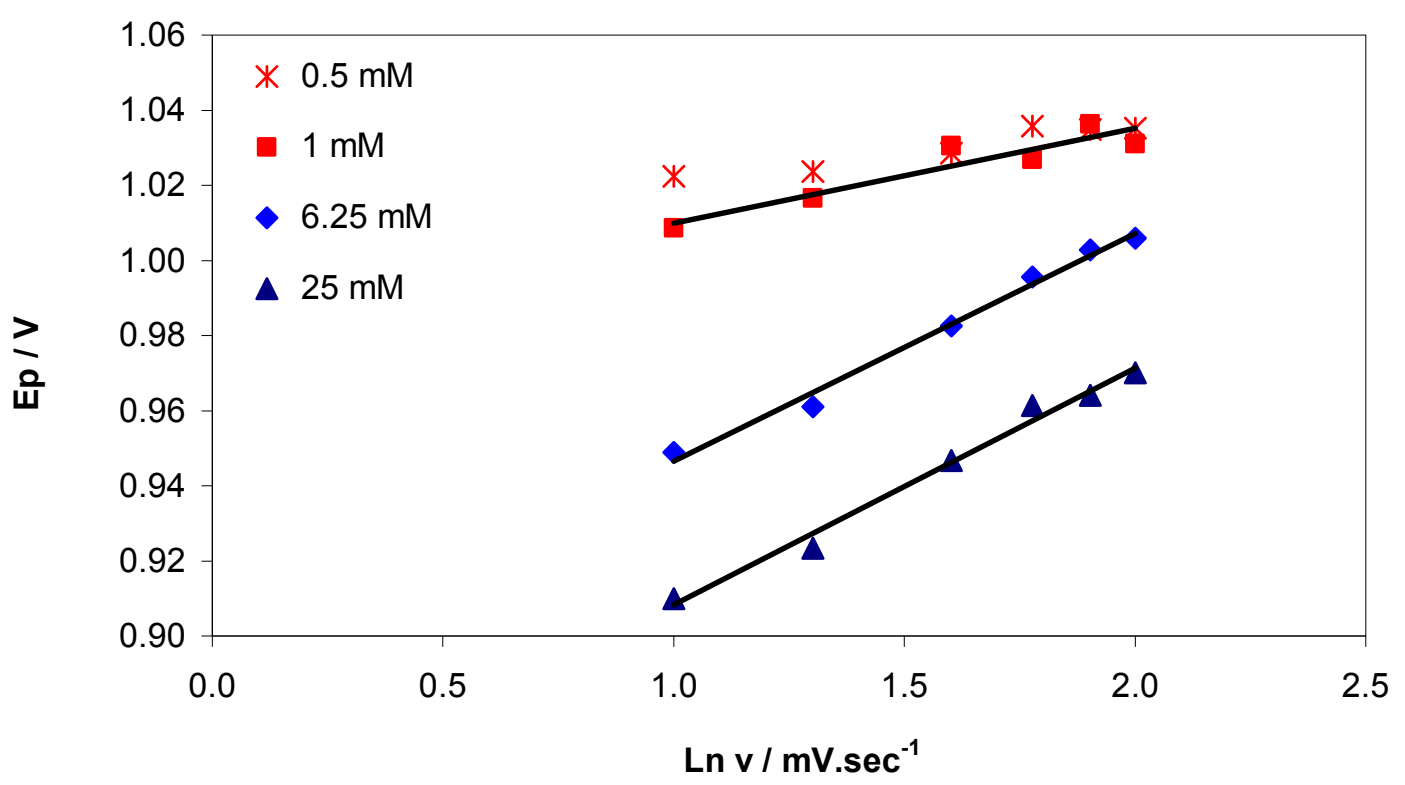

Figura 23: Potencial de pico como uma função do logaritmo da velocidade de varredura para diferentes concentrações de fenol em $0,05 \mathrm{M} \mathrm{H}_{2} \mathrm{SO}_{4}$.

A corrente de pico anódica variou linearmente com a raiz quadrada da velocidade de varredura de potencial, como mostrado na Figura 24 para uma solução 0,05 M de ácido sulfúrico em diferentes concentrações de fenol, mostrando que o processo do eletrodo é controlado por difusão $[68,80,84]$. Pode-se observar que para concentrações de fenol abaixo $6,25 \mathrm{mM}$, o pico de densidade de corrente aumenta com a concentração de fenol, enquanto que para concentrações superiores a 6,25 mM, a densidade de corrente de pico não varia com a concentração de fenol. 


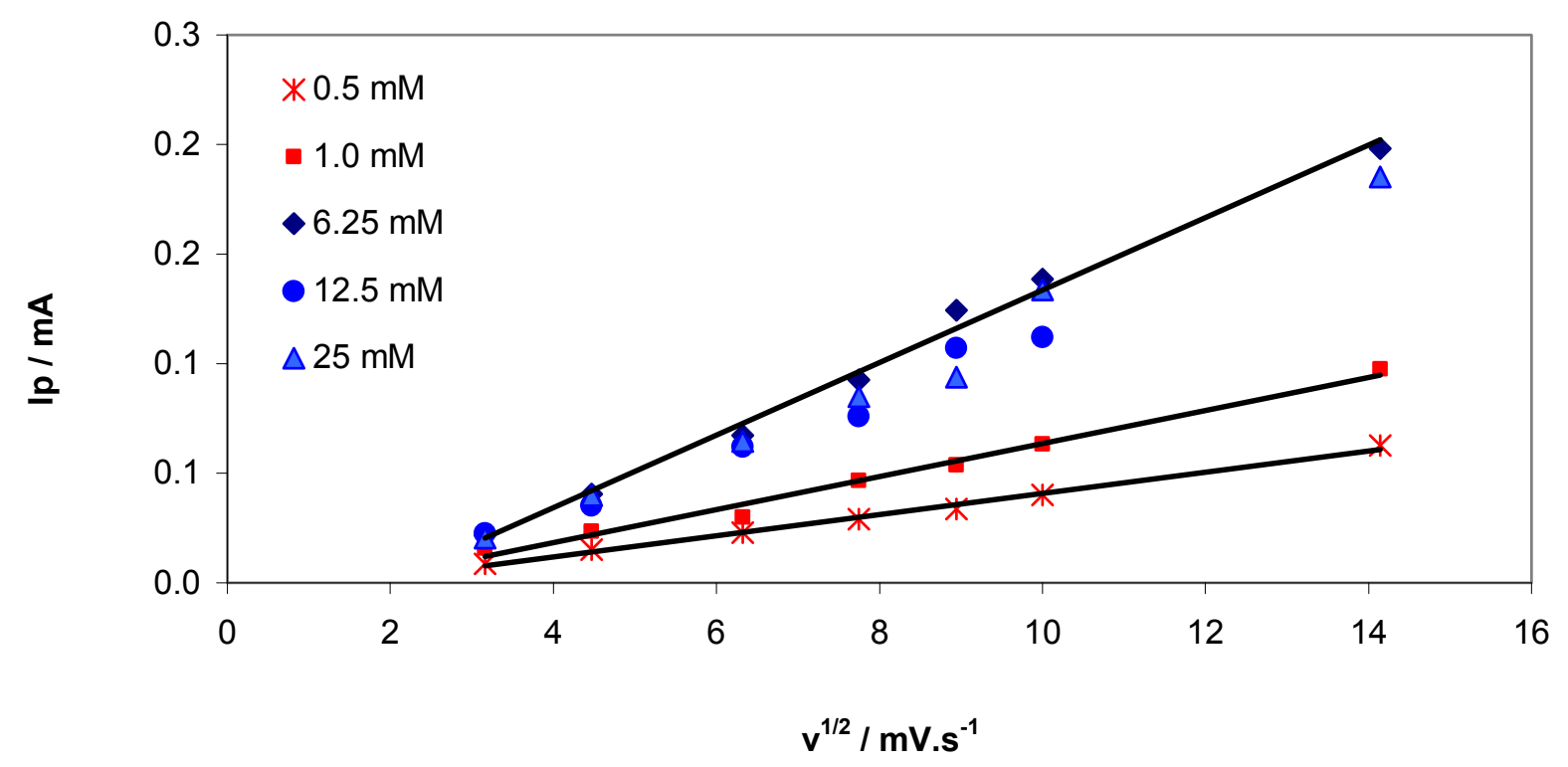

Figura 24: Densidade de corrente de pico como uma função da raiz quadrada da velocidade de varredura para diferentes concentrações de fenol em $0,05 \mathrm{M} \mathrm{H}_{2} \mathrm{SO}_{4}$.

O potencial de pico anódico (Ep) foi representado em função do logaritmo neperiano da velocidade de varredura (In v), Figura 25, para duas diferentes concentrações de fenol (1 e 6,25 mM) e quatro de ácido sulfúrico, variando de 0,01 a $1 \mathrm{M}$. Para ambas as soluções de fenol pode ser observado que quanto maior a concentração do ácido, maior o potencial de pico. Também é possível ver dois diferentes intervalos de variação, um para as duas concentrações mais elevadas de ácido sulfúrico (0,5 e $1 \mathrm{M})$, e outro para as outras duas concentrações de ácido, que pode ser associada a uma menor influência dos fenômenos de polimerização e adsorção na superfície do eletrodo em soluções fortemente ácidas, como foi comentado anteriormente. 


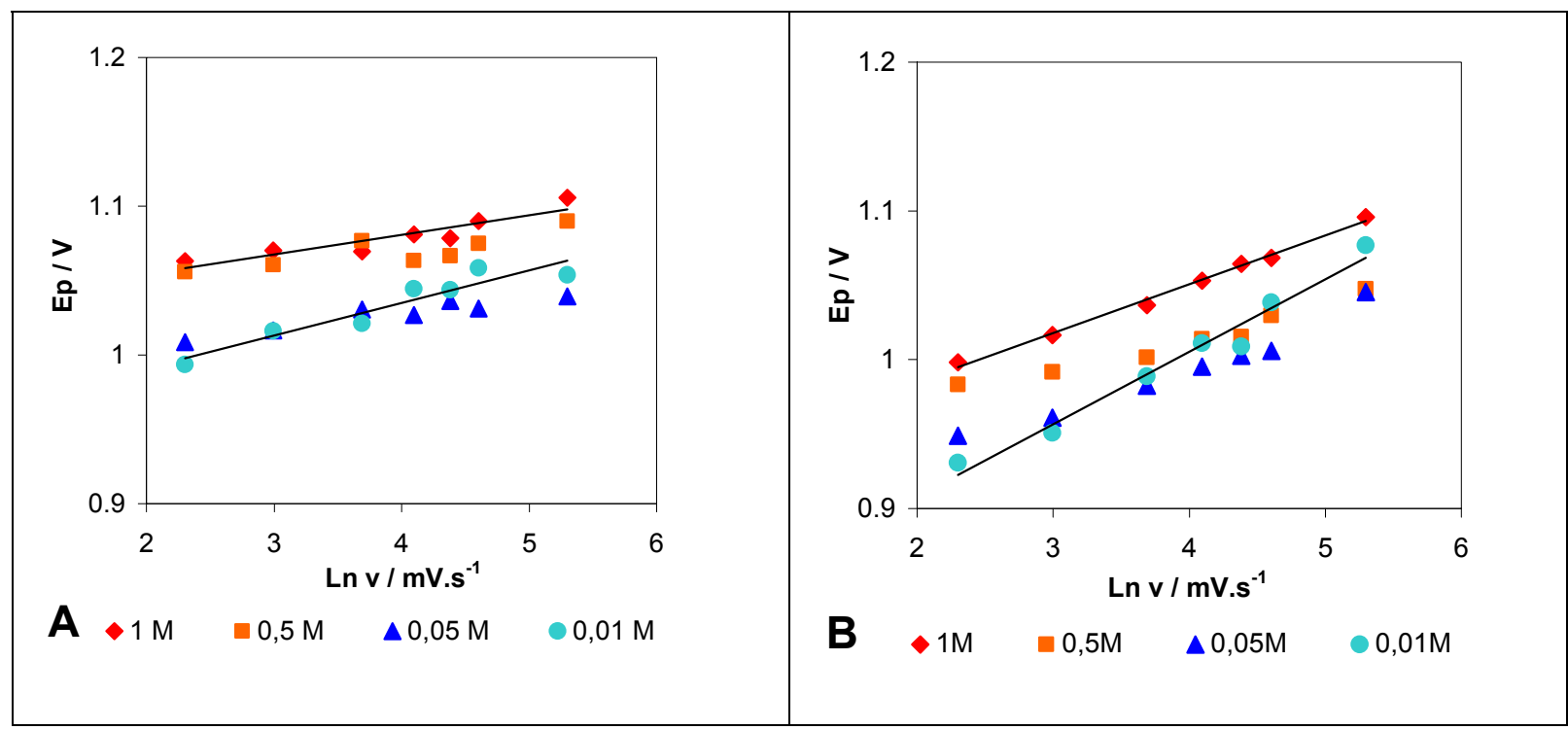

Figura 25: Potencial de pico como uma função do logaritmo da velocidade de varredura de potencial em diferentes concentrações de $\mathrm{H}_{2} \mathrm{SO}_{4}$ para duas concentrações de fenol: A) $1 \mathrm{mM} \mathrm{e} \mathrm{B)} \mathrm{6,25} \mathrm{mM.}$

A Figura 26 mostra a densidade de corrente de pico em função da raiz quadrada da velocidade de varredura de duas diferentes concentrações de fenol (1 e $6,25 \mathrm{mM}$ ) e ácido sulfúrico, variando de 0,01 a 1M. Pode ser visto que, para ambas as concentrações de fenol, a densidade de corrente de pico aumenta com a raiz quadrada da velocidade de varredura e com a concentração de ácido sulfúrico.

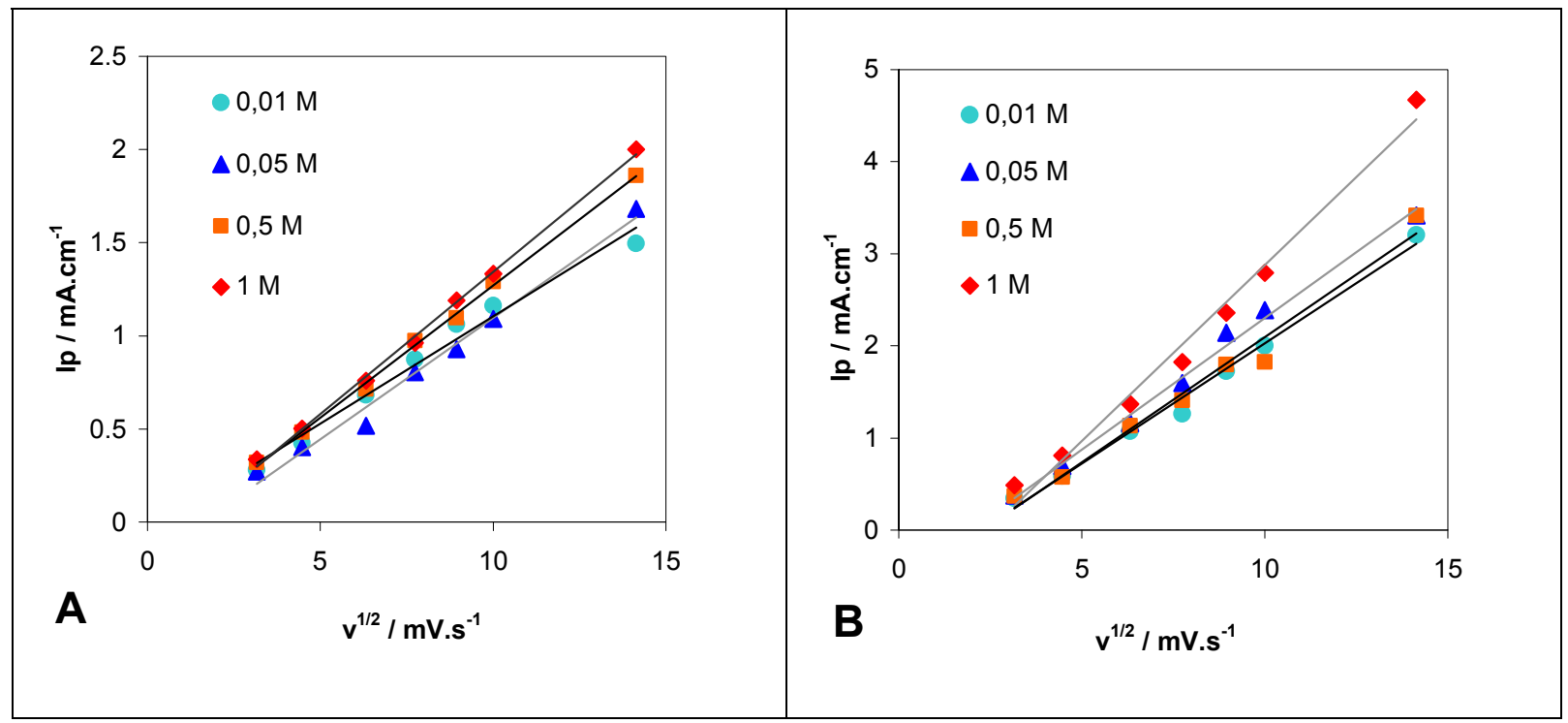

Figura 26: Densidade de corrente de pico como uma função da raiz quadrada da velocidade de varredura de potencial em diferentes concentrações de $\mathrm{H}_{2} \mathrm{SO}_{4}$ para duas concentrações de fenol: A) $1 \mathrm{mM} \mathrm{e} \mathrm{B)} \mathrm{6,25} \mathrm{mM.}$ 
Para um processo não-reversível, em condições potenciodinâmicas, a mudança no Ep para um aumento de 10 vezes na velocidade de varredura é dada pela equação [36]:

$$
\Delta E_{p}=\frac{1,15 R T}{\alpha \cdot n_{\alpha} F}
$$

Onde: $\alpha$ é o coeficiente de transferência de carga e representa uma medida de barreira de simetria em um processo de eletrodo não-reversível, $\mathrm{n}_{\alpha}$ é o número de elétrons envolvidos na etapa determinante da velocidade, $\mathrm{F}$ a constante de Faraday, $\mathrm{R}$ a constante ideal dos gases e $\mathrm{T}$ é a temperatura absoluta em $\mathrm{K}$.

Por outro lado, a relação entre a densidade de corrente de pico anódica $\left(\mathrm{i}_{\mathrm{p}}\right.$ ) e a velocidade varredura (v) para um processo irreversível, é dado pela seguinte equação [36,85]:

$$
i_{p}=0.496 n F C D^{1 / 2}\left(\frac{\left(\alpha \cdot n_{\alpha}\right) F v}{R T}\right)^{1 / 2}
$$

Onde: $n$ é o número de elétrons transferidos, $D$ é o coeficiente de difusão da espécie a ser oxidada em $\mathrm{cm}^{2} \cdot \mathrm{s}^{-1}$, C é a concentração de fenol no seio da solução em mol.cm ${ }^{-3} \mathrm{e} v$ é a velocidade de varredura em V.s ${ }^{-1}$.

Como pode ser visto nas Figura 24 e Figura 26, a densidade de corrente de pico é proporcional à raiz quadrada da velocidade de varredura, mas não passa pela origem, que é também uma característica da irreversibilidade do processo de oxidação de fenol $[68,86]$.

A partir da inclinação da variação linear do Ep em função do logaritmo da velocidade de varredura, dados apresentados nas Figura 23 e Figura 25, pode ser determinado o valor de $\alpha \mathrm{n}_{\alpha}$ através da equação (1). Uma vez que o valor de $\alpha \mathrm{n}_{\alpha}$ é conhecido, o coeficiente de difusão do fenol pode ser estimado a partir da inclinação 
das retas apresentadas nas Figura 24 e Figura 26 através da equação (2). Os valores de $\alpha \mathrm{n}_{\alpha}$ e do coeficiente de difusão do fenol são apresentados na Tabela 4.

Tabela 4: Valores de $n_{\alpha}$ e coeficiente de difusão encontrados para o fenol.

\begin{tabular}{|c|c|c|c|c|c|c|c|c|}
\hline$\left[\mathrm{H}_{2} \mathrm{SO}_{4}\right]$ & \multicolumn{2}{|c|}{$0,01 \mathrm{M}$} & \multicolumn{2}{|c|}{$0,05 \mathrm{M}$} & \multicolumn{2}{c|}{$0,5 \mathrm{M}$} & \multicolumn{2}{c|}{$1 \mathrm{M}$} \\
\hline $\begin{array}{c}{[\mathrm{fenol}]} \\
(\mathrm{mM})\end{array}$ & $\alpha \cdot \mathrm{n}_{\alpha}$ & $\begin{array}{c}\mathrm{D} \times 10^{12} \\
\left(\mathrm{~m}^{2} \cdot \mathrm{s}^{-1}\right)\end{array}$ & $\alpha \cdot \mathrm{n}_{\alpha}$ & $\begin{array}{c}\mathrm{D} \times 10^{12} \\
\left(\mathrm{~m}^{2} \cdot \mathrm{s}^{-1}\right)\end{array}$ & $\alpha \cdot \mathrm{n}_{\alpha}$ & $\begin{array}{l}\mathrm{D} \times 10^{12} \\
\left(\mathrm{~m}^{2} \cdot \mathrm{s}^{-1}\right)\end{array}$ & $\alpha \cdot \mathrm{n}_{\alpha}$ & $\begin{array}{c}\mathrm{D} \times 10^{12} \\
\left(\mathrm{~m}^{2} \cdot \mathrm{s}^{-1}\right)\end{array}$ \\
\hline 0,5 & 0,64 & 23,16 & 0,97 & 8,02 & 0,93 & 10,18 & 1,92 & 7,93 \\
\hline 1 & 0,58 & 7,16 & 1,01 & 4,69 & 1,35 & 4,19 & 0,97 & 6,68 \\
\hline 6,25 & 0,26 & 1,87 & 0,42 & 1,41 & 0,60 & 0,88 & 0,39 & 2,71 \\
\hline 12,5 & 0,27 & 0,42 & -- & -- & 0,56 & 0,36 & -- & -- \\
\hline 25 & 0,29 & 0,12 & 0,36 & 0,10 & 0,53 & 0,12 & 0,56 & 0,13 \\
\hline
\end{tabular}

Os valores de $\alpha \mathrm{n}_{\alpha}$ diminuem com o aumento da concentração de fenol e com a diminuição da concentração de ácido sulfúrico devido a oxidação do fenol ser favorecida a baixas concentrações de fenol e em soluções ácidas, onde a polimerização não é favorecida. A diminuição dos coeficientes de difusão calculados com o aumento da concentração de fenóis e os valores obtidos neste trabalho são semelhantes aos obtidos por outros autores [87], e difusividade do fenol na água é $8,47 \times 10^{-10} \mathrm{~cm}^{2} \mathrm{~s}^{-1}$, calculado a partir da equação de Wilke e Chang [88].

\subsubsection{Eletrodo de Carbono vítreo}

Devido ao efeito de bloqueio ou desativação do eletrodo de platina foram realizados testes com eletrodo de diferentes materiais, utilizando as mesmas soluções sintéticas de fenol em meio ácido.

Um dos materiais testados foi o carbono vítreo (CV). Na Figura 27 está representado o comportamento do eletrodo em função da velocidade de varredura. Pode-se verificar a formação do pico de oxidação do fenol em todas as velocidades de varredura e concentrações testadas. Verifica-se, também, que quanto maior a concentração de fenol maior a intensidade do pico, o mesmo comportamento se observa em relação à velocidade de varredura, quanto mais alta v mais intenso o 
pico. Resultados semelhantes foram apresentados no trabalho realizado por UretaZañartu e outros [68].

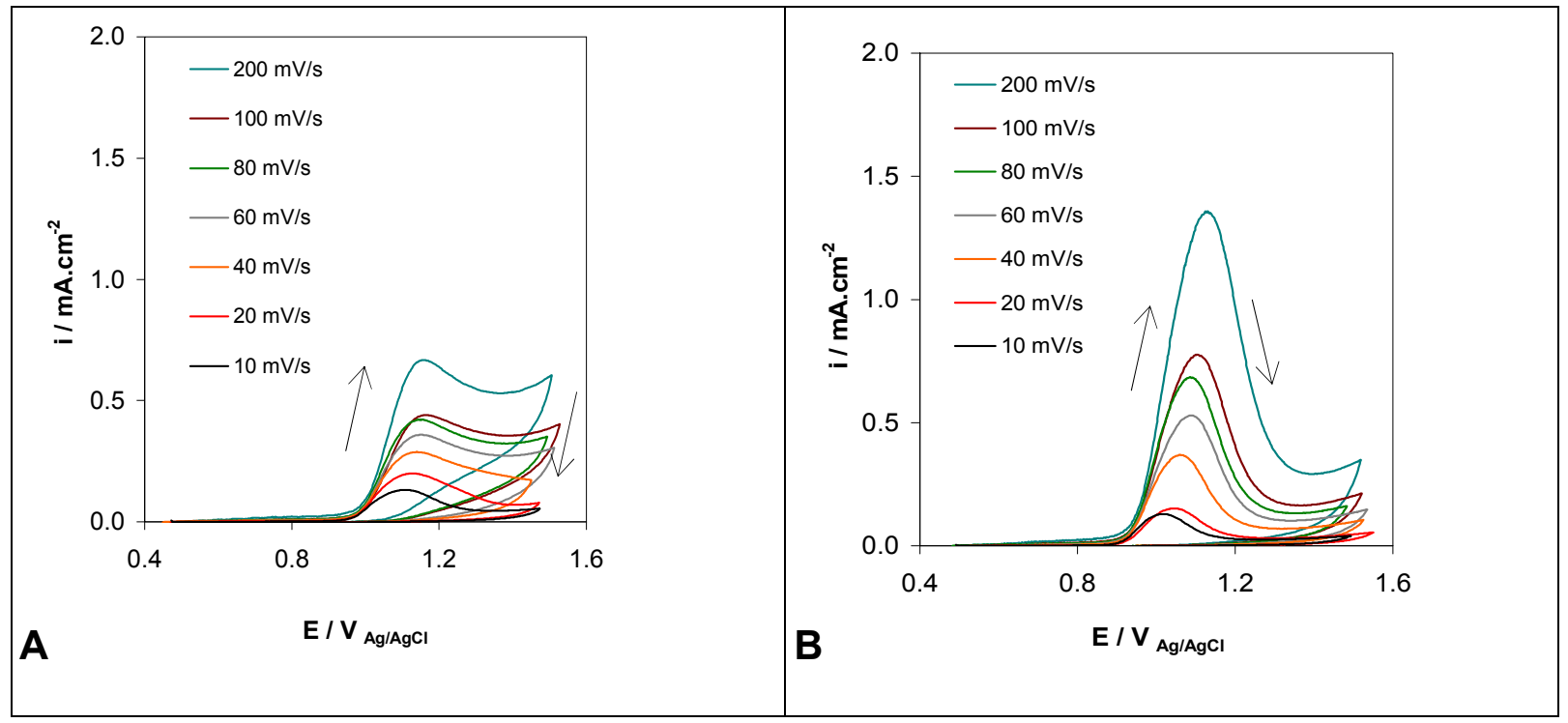

Figura 27: Voltamogramas para o eletrodo de carbono vítreo em meio $0,5 \mathrm{M} \mathrm{H}_{2} \mathrm{SO}_{4} \mathrm{e}$ concentração de fenol de: A) $1 \mathrm{mM}$ e B) 6,25 mM. (ET = CV, CE = Pt, $\mathrm{ER}=\mathrm{Ag} / \mathrm{AgCl})$.

$\mathrm{Na}$ comparação com o eletrodo de platina mostrada na Figura 28 observa-se para ambos o formação do pico, sendo que o pico formado com o uso de eletrodo de carbono vítreo mostra um deslocamento a valores mais positivos de potencial quando comparado com o eletrodo de platina. Todavia a intensidade do pico é muito menor para carbono vítreo, sendo o Ip para carbono vítreo menos da metade que para platina.

Para verificar o comportamento do sistema sobre a superfície do eletrodo foram realizados testes de voltametria cíclica de varredura com múltiplos ciclos, nos resultados obtidos são apresentados os primeiros três ciclos (Figura 29). Pode-se verificar que ocorre o bloqueio ou desativação da superfície do eletrodo com o passar dos ciclos, o que torna a aplicação desse eletrodo na oxidação eletroquímica do fenol não recomendada, sendo descartado, portanto, análises mais aprofundadas do comportamento eletroquímico desse material.

Todas as concentrações de fenol e ácido testadas apresentaram resultados similares. 


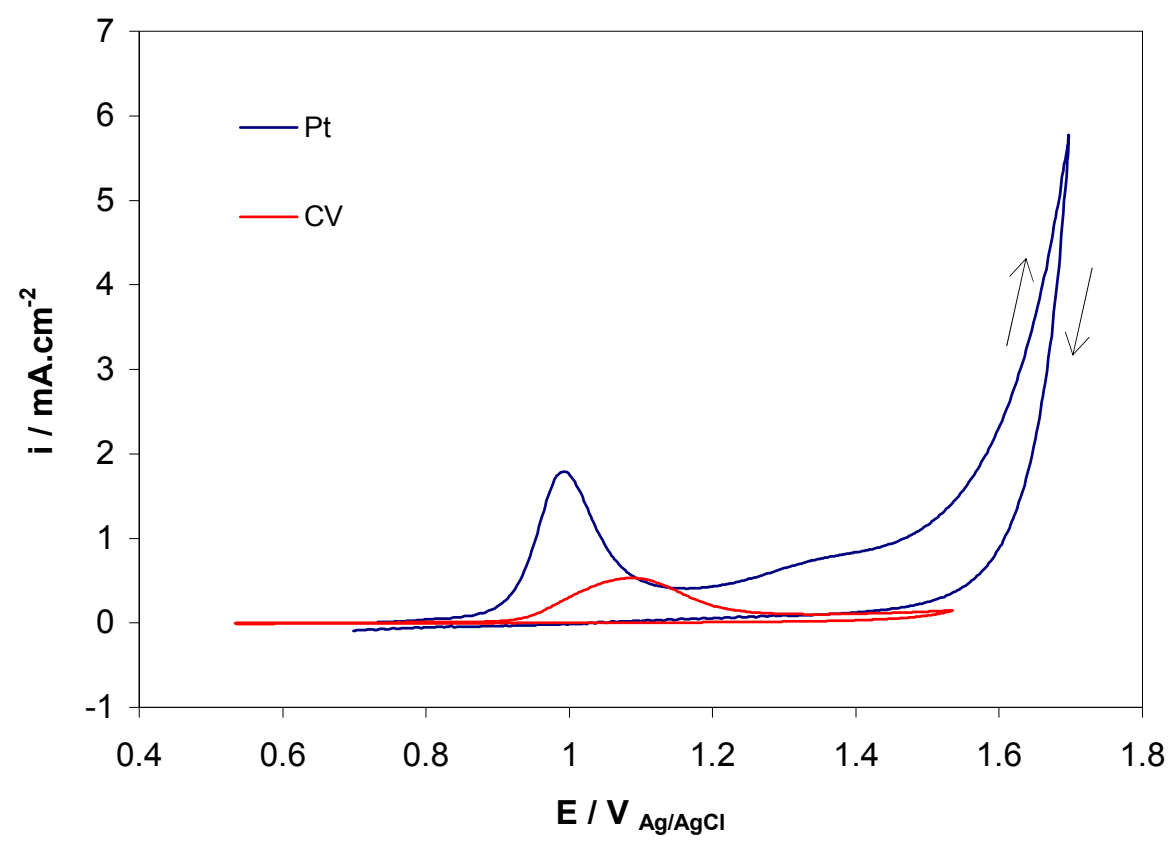

Figura 28: Comparação entre o comportamento dos eletrodos de platina e carbono vítreo (CV) para uma solução $0,5 \mathrm{M} \mathrm{H}_{2} \mathrm{SO}_{4} / 6,25 \mathrm{mM}$ fenol, velocidade de varredura $60 \mathrm{mV} \cdot \mathrm{s}^{-1} .(\mathrm{ET}=\mathrm{CV}, \mathrm{CE}=\mathrm{Pt}, \mathrm{ER}=\mathrm{Ag} / \mathrm{AgCl})$.

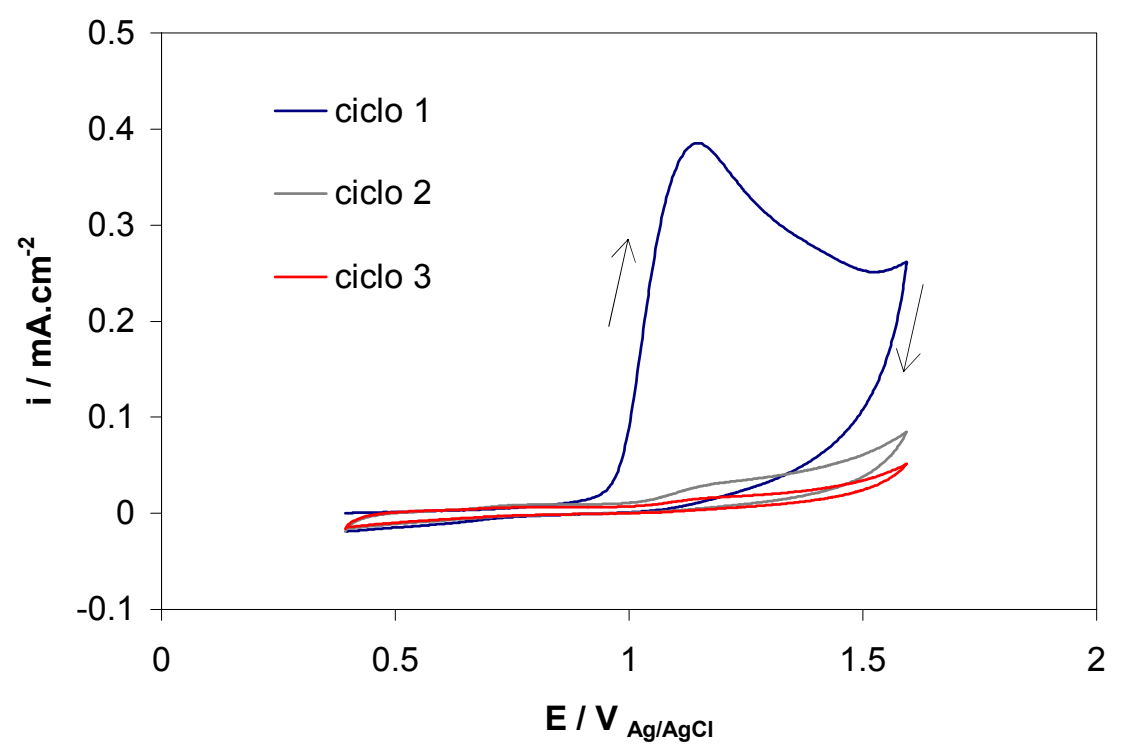

Figura 29: Voltamogramas de VC para eletrodo de carbono vítreo, solução $0,5 \mathrm{M} \mathrm{H}_{2} \mathrm{SO}_{4} / 6,25 \mathrm{mM}$ fenol. $(\mathrm{ET}=\mathrm{CV}, \mathrm{CE}=\mathrm{Pt}, \mathrm{ER}=\mathrm{Ag} / \mathrm{AgCl})$. 


\subsubsection{Eletrodo de titânio}

Foram realizados também experimentos com eletrodo de titânio. Primeiramente se verificou a influência da velocidade de varredura de potencial.

Analisando a Figura 30 é possível verificar a presença do pico de oxidação em torno dos $200 \mathrm{mV}$, seguido de um platô. Pode-se observar que Ip é maior quanto maior a velocidade de varredura e que Ep se desloca para valores negativos quanto mais se eleva a velocidade de varredura, esse comportamento está relacionado a uma reação irreversível de oxidação. Segundo Bond [89] o aumento de Ip e o deslocamento para valores de potencial mais negativo de Ep com - aumento da velocidade de varredura de potencial sugerem a adsorção de reagentes da reação de oxidação sobre a superfície do eletrodo, ou seja, do radical fenox. Além disso, o fenômeno de adsorção de material sobre a superfície do eletrodo está também caracterizado pelo formato de voltamograma obtido, com a presença de um platô de potencial após a formação do pico de oxidação.

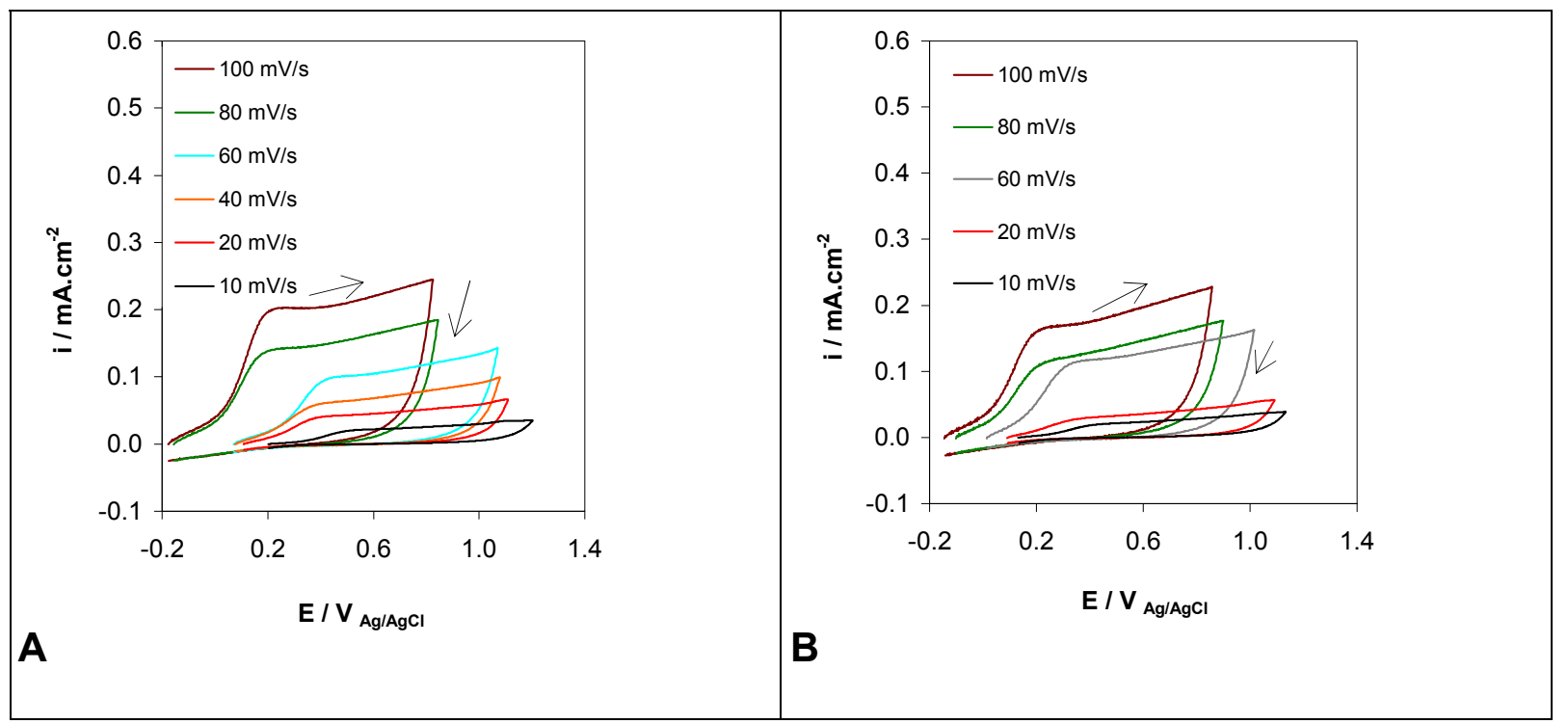

Figura 30: Voltamogramas obtidos para uma solução $0,5 \mathrm{M} \mathrm{H}_{2} \mathrm{SO}_{4}$ com: A) $1 \mathrm{mM}$ e B) 6,25 mM de fenol, para diversas velocidades de varredura, $(\mathrm{ET}=\mathrm{Ti}$, $\mathrm{CE}=\mathrm{Pt}, \mathrm{ER}=\mathrm{Ag} / \mathrm{AgCl})$.

Quando se compara os voltamogramas obtidos, nas mesmas condições experimentais, com ET de platina e titânio, Figura 31, o Ep obtido para eletrodo de Ti apresenta valor mais positivo e o Ip mais baixo, o que demonstra uma cinética mais lenta na reação de oxidação do fenol ou um bloqueio mais rápido do eletrodo. 
Foram realizados experimentos de VC de múltiplos ciclos, sendo os resultados obtidos apresentados na Figura 32. Verifica-se que já no segundo ciclo o eletrodo não mais apresenta pico de oxidação, o que demonstra um rápido bloqueio da superfície do eletrodo, sendo dentre todos os matériais utilizados como ET neste estudo o que apresentou mais rápida desativação.

Foram realizados experimentos para todas as concentrações de fenol e ácido sulfúrico testadas nesse estudo, obtendo para todas as condições experimentais comportamento similar.

Em face aos resultados obtidos para esse material, não se precedeu a investigações eletroquímicas mais aprofundadas.

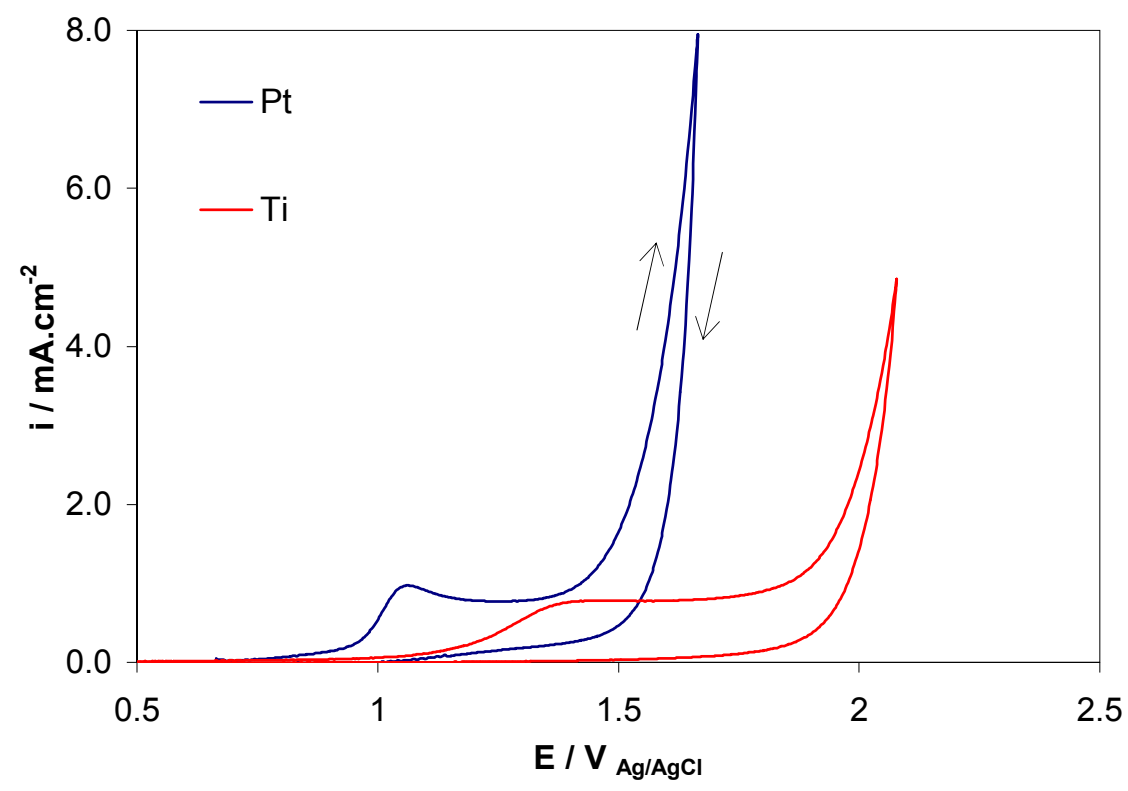

Figura 31: Comparação entre o comportamento dos eletrodos de platina e titânio para uma solução $0,5 \mathrm{M} \mathrm{H}_{2} \mathrm{SO}_{4} / 6,25 \mathrm{mM}$ fenol, velocidade de varredura $60 \mathrm{mV} \cdot \mathrm{s}^{-1}$. 


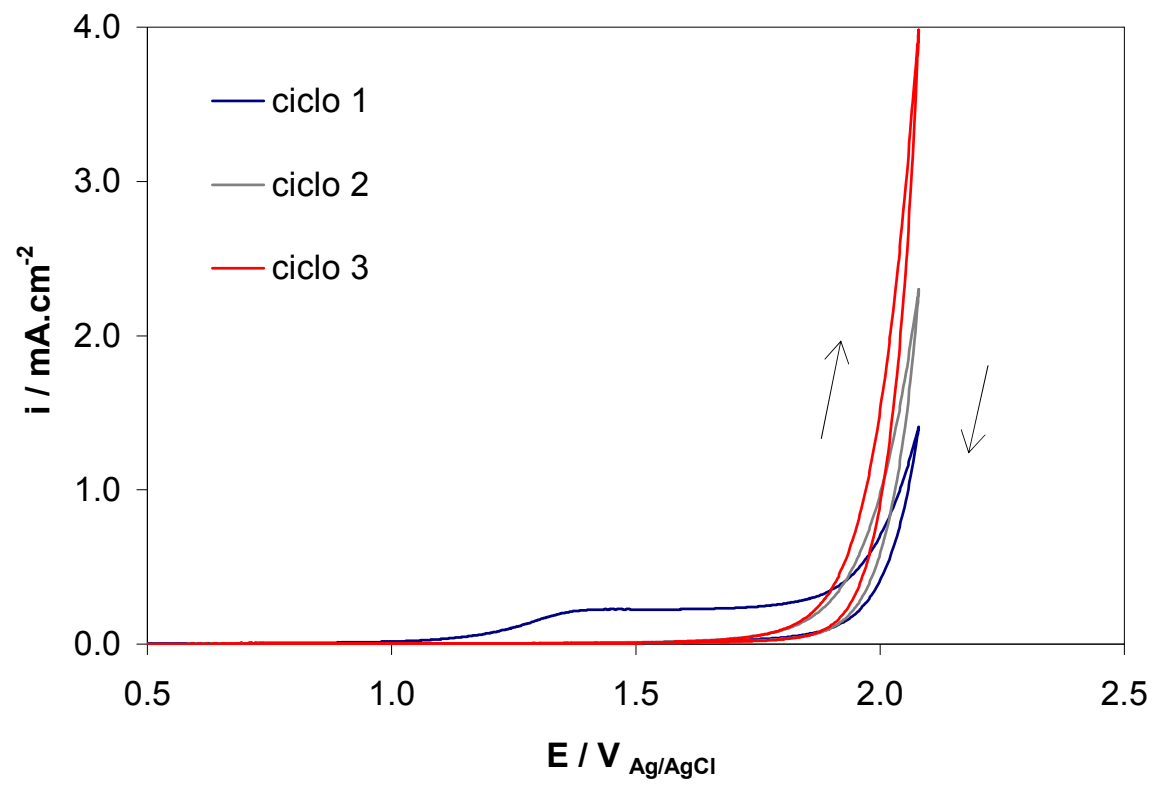

Figura 32: Voltamogramas obtidos para uma solução $0,5 \mathrm{M} \mathrm{H} \mathrm{H}_{2} \mathrm{SO}_{4} / 1 \mathrm{mM}$ fenol pela técnica de $V C, v=60 \mathrm{mV} \cdot \mathrm{s}^{-1}$. $(\mathrm{ET}=\mathrm{Ti}, \mathrm{CE}=\mathrm{Pt}, \mathrm{ER}=\mathrm{Ag} / \mathrm{AgCl})$.

\subsubsection{Eletrodo de titânio revestido de óxido de titânio e rutênio}

Conforme visto na revisão bibliográfica realizada no tema, a aplicação de eletrodos revestidos de óxidos metálicos tem despertado crescente interesse na degradação de compostos orgânicos refratários, devido sua eficiência e estabilidade. Dentre os eletrodos revestidos de óxidos metálicos os do tipo DSA são os que apresentam uma promissora alternativa na eletrooxidação desses compostos.

Dentre os eletrodos do tipo DSA existentes no mercado, foi elegido o eletrodo de titânio revestido de óxidos de titânio e rutênio, na proporção mássica de 70/30, respectivamente. Esse eletrodo apresenta boa estabilidade química e vem sendo estudado por muitos pesquisadores no tratamento eletroquímico de efluentes $[22,25,49,51]$.

Foram realizados experimentos de $\mathrm{VC}$ a diferentes concentrações de fenol $(0,5 ; 1 ; 6,25 ; 12,5$ e 25 mM). Na Figura 33 são apresentados os voltamogramas obtidos para uma solução de $0,5 \mathrm{M}$ de ácido sulfúrico e todas de fenol. Verifica-se a presença de um pico de oxidação em torno de $1 \mathrm{~V}$, contudo, pode-se observar nas tabelas do anexo II que nem sempre ocorre o aparecimento do pico de oxidação. 


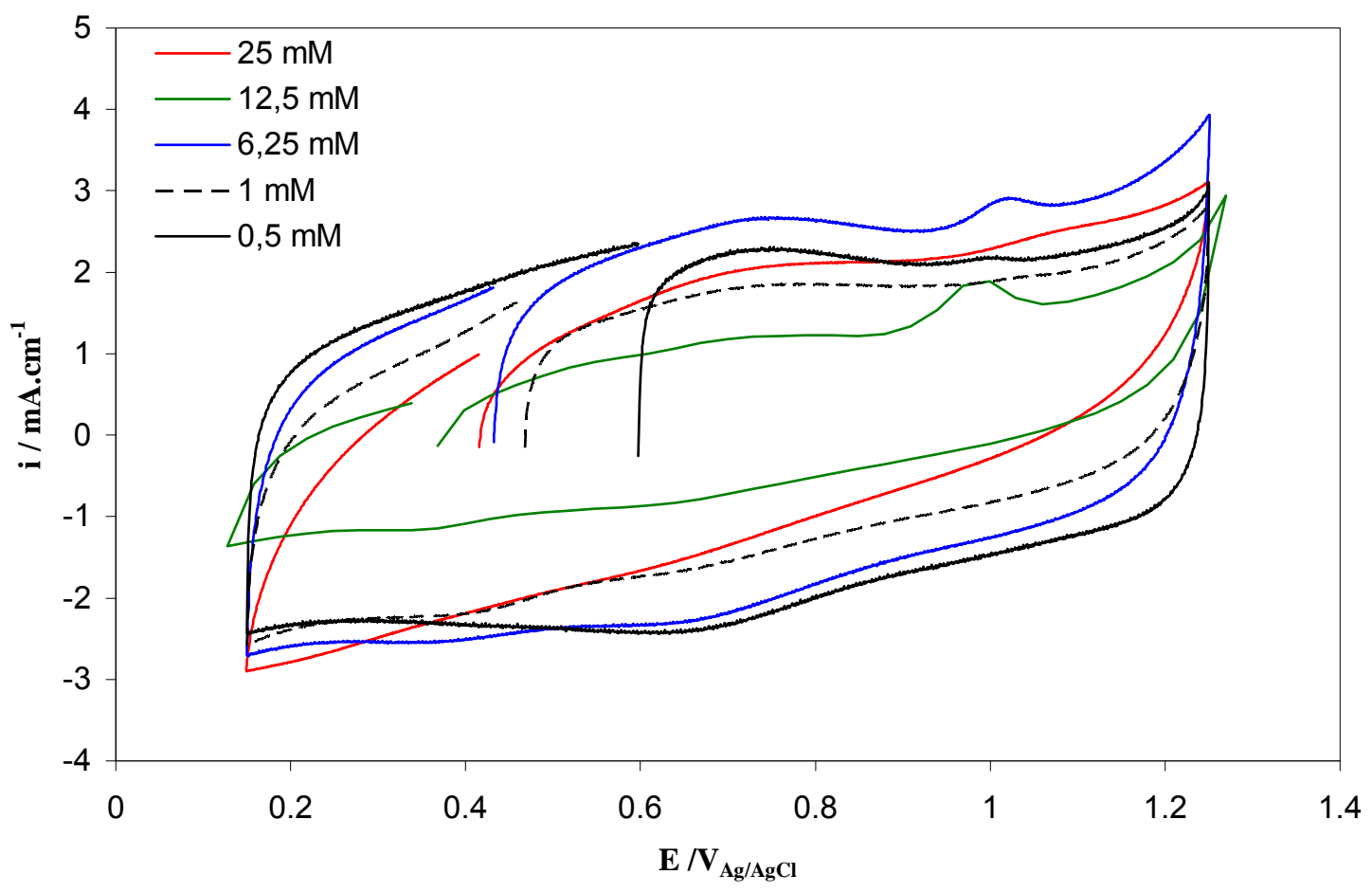

Figura 33: Voltamogramas cíclicos obtidos em solução de $0,5 \mathrm{M} \mathrm{H}_{2} \mathrm{SO}_{4}$ e diferentes concentrações de fenol, $v=60 \mathrm{mV} \cdot \mathrm{s}^{-1} \cdot\left(\mathrm{ET}=\mathrm{Ti} / \mathrm{Ru}_{0,3} \mathrm{Ti}_{0,7} \mathrm{O}_{2}, \mathrm{CE}=\mathrm{Pt} \mathrm{e}\right.$ $\mathrm{ER}=\mathrm{Ag} / \mathrm{AgCl})$.

Na Figura 34 está representada a ip em relação à concentração de fenol, para uma velocidade de $20 \mathrm{mV} \cdot \mathrm{s}^{-1}$ e todas as concentrações de ácido. Observam-se maiores valores de ip para a concentração de 6,25 mM de fenol, sendo o valor de ip máximo obtido para a concentração de $0,5 \mathrm{M}$ de ácido sulfúrico. Na Figura 35 é apresentada a mesma relação da figura anterior para uma velocidade de varredura de $60 \mathrm{mV} . \mathrm{s}^{-1}$, pode-se observar que as correntes de pico mais elevadas são obtidas para a concentração de fenol de $6,25 \mathrm{mM}$ e $1 \mathrm{M}$ de ácido sulfúrico. Observando as Figuras 33,34 e 35 verifica-se que para a concentração de fenol de 6,25 mM de fenol foram atingidos maiores valores de densidade de corrente de pico. 




Figura 34: Densidade de corrente de pico como função da concentração de fenol para diferentes concentrações de ácido sulfúrico, $\mathrm{v}=20 \mathrm{mV} \cdot \mathrm{s}^{-1}$.

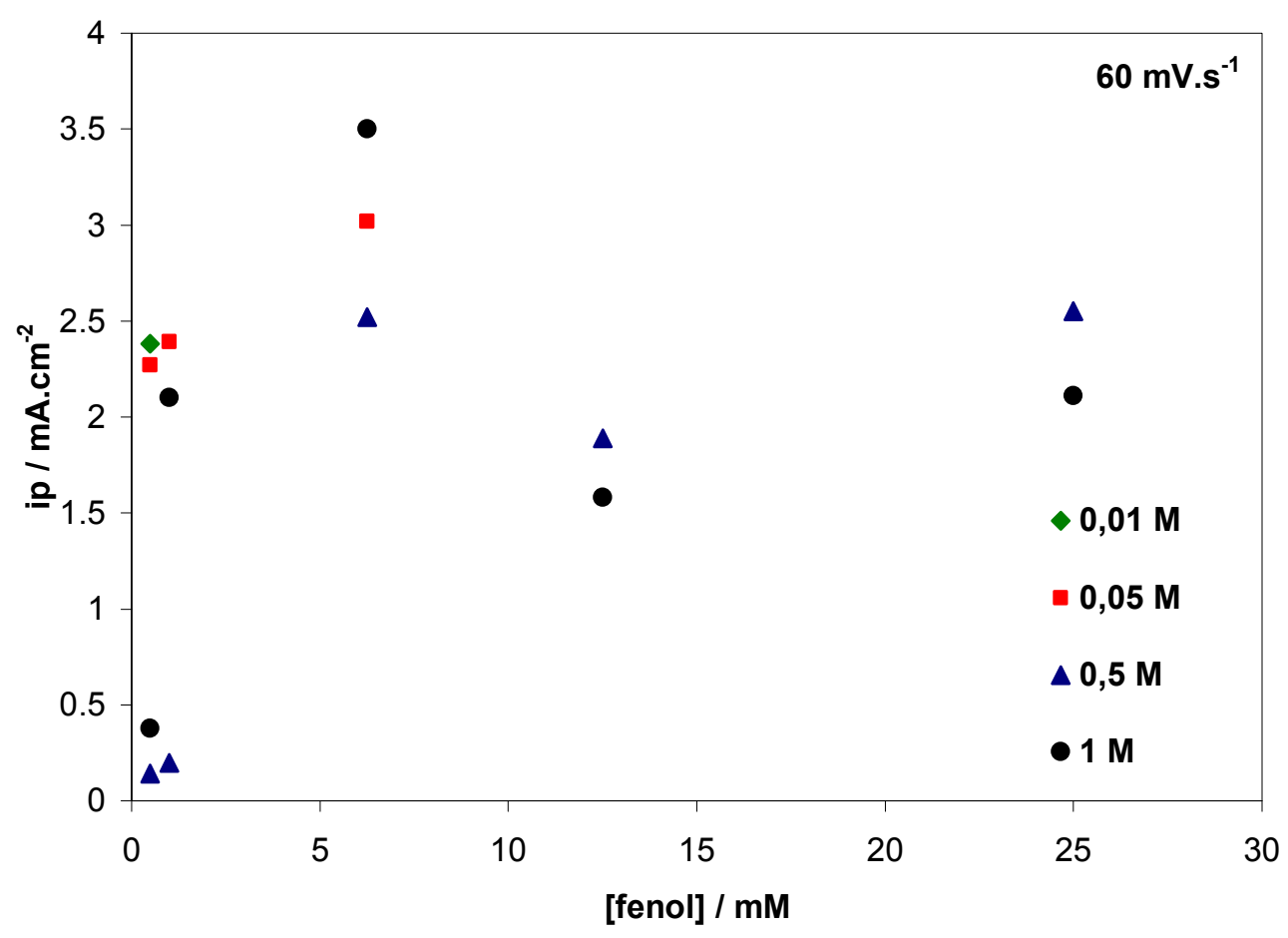

Figura 35: Densidade de corrente de pico como função da concentração de fenol para diferentes concentrações de ácido sulfúrico, v=60mV. $\mathrm{s}^{-1}$. 
Os potenciais de pico também estão relacionados à concentração de fenol, a Figura 36 mostra a variação do potencial de pico em relação ao logaritmo da concentração de fenol em diferentes concentrações de ácido sulfúrico. Para as duas concentrações de ácido sulfúrico mais baixas o pico de oxidação só aparece em concentrações de fenol inferiores a $12,5 \mathrm{mM}$. Contudo, para as duas concentrações maiores de ácido o pico aparece em todas as concentrações de fenol. Portanto, o processo de oxidação parece ser favorecida para concentrações de fenol igual ou menores que $12,5 \mathrm{mM}$, nas quais se obtêm valores mais baixos de Ep. Para concentrações de fenol entre 1 e 12,5 mM e concentrações de ácido de 0,5 e $1 \mathrm{M}$ o Ep diminui com o aumento da concentração de fenol.

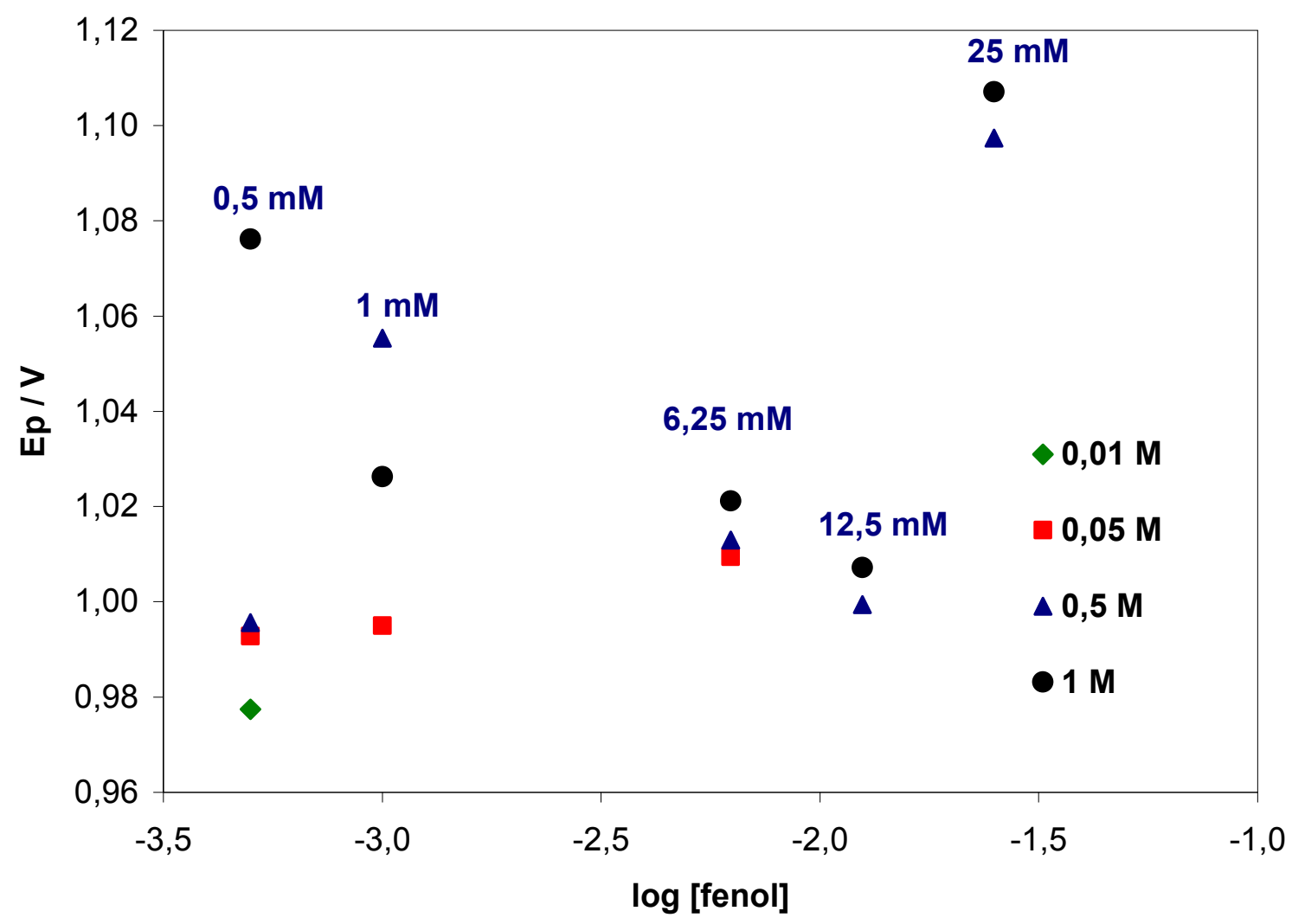

Figura 36: Potencial de pico como função da concentração de fenol para diferentes concentrações de ácido sulfúrico $(0,01 ; 0,05 ; 0,5$ e 1,0 M).

Nos experimentos de VC com mais de um ciclo, Figura 37, se verifica uma redução do pico de oxidação do primeiro para o segundo ciclo e depois permanece praticamente constante tanto o valor de Ip como o Ep. Esse comportamento indica que a superfície do eletrodo de óxido não sofre bloqueio durante a eletrólise, nas 
condições experimentais aplicadas, o que viabiliza a investigação do uso desse material na oxidação eletroquímica do fenol. Os voltamogramas cíclicos de todas as soluções investigadas, em que se observa um pico de oxidação fenol, apresentam forma similar.

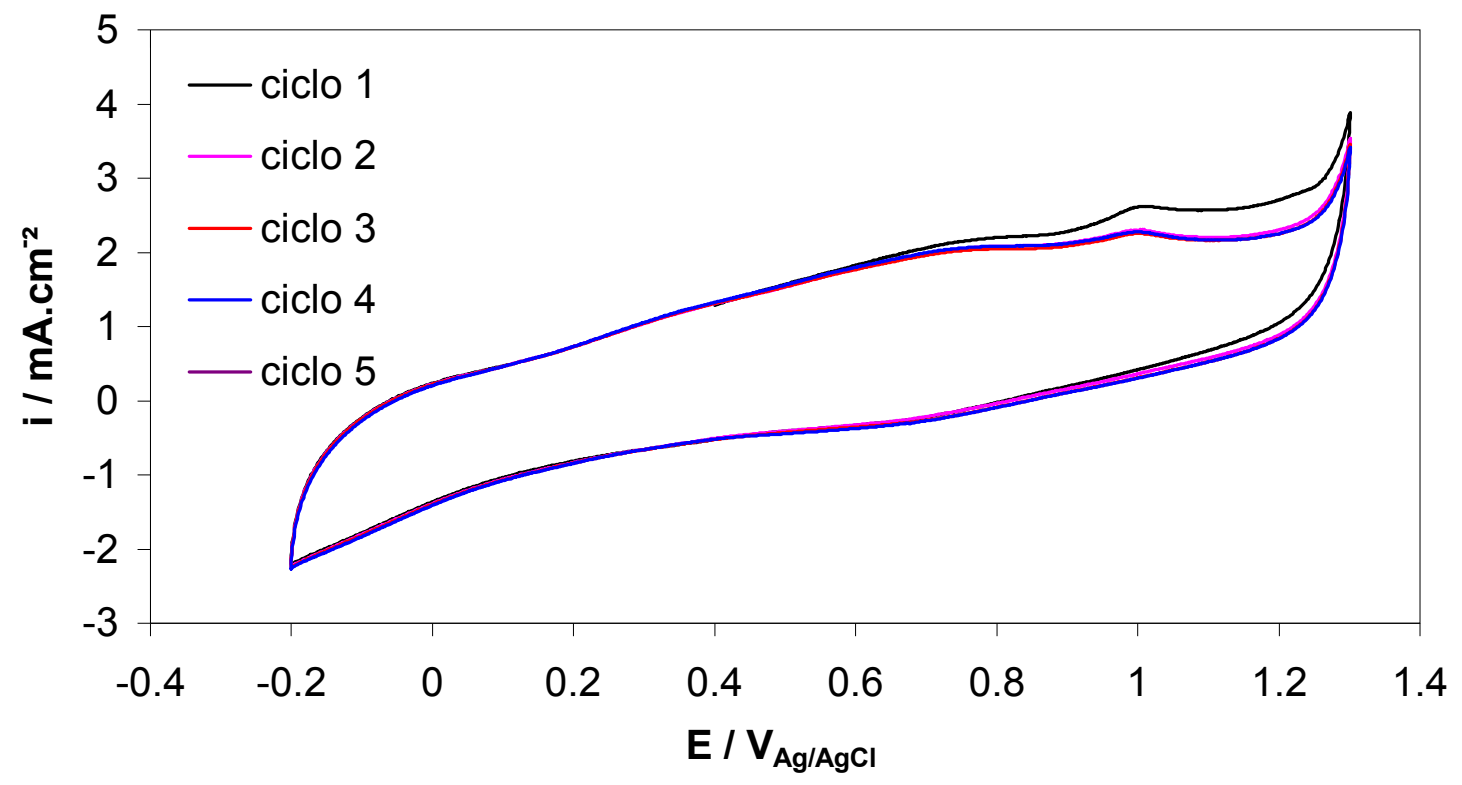

Figura 37: Voltamogramas cíclicos obtidos para uma solução $0,5 \mathrm{mM}$ fenol / $0,5 \mathrm{M} \mathrm{H}_{2} \mathrm{SO}_{4}, v=60 \mathrm{mV} \cdot \mathrm{s}^{-1} .\left(\mathrm{ET}=\mathrm{Ti} / \mathrm{Ru}_{0,3} \mathrm{Ti}_{0,7} \mathrm{O}_{2}, \mathrm{CE}=\mathrm{Pt}\right.$ e ER = $\mathrm{Ag} / \mathrm{AgCl})$.

A parcela do potencial de pico anódico (Ep) em função do logaritmo neperiano da velocidade de varredura ( $\ln v$ ) é mostrado na Figura 38, para uma concentração de ácido sulfúrico de $1 \mathrm{M}$ e diferentes concentrações de fenol. Para concentração de $25 \mathrm{mM}$ de fenol se obtiveram os maiores valores de Ep. Para concentrações de fenol entre 1 e 12,5 mM de fenol os valores de Ep foram muito próximos. Observando o comportamento apresentado na Figura 38 indica que as reações de oxidação do fenol sobre esse tipo de eletrodo dependem menos da disponibilidade de radical fenox na solução que para o eletrodo de platina. 


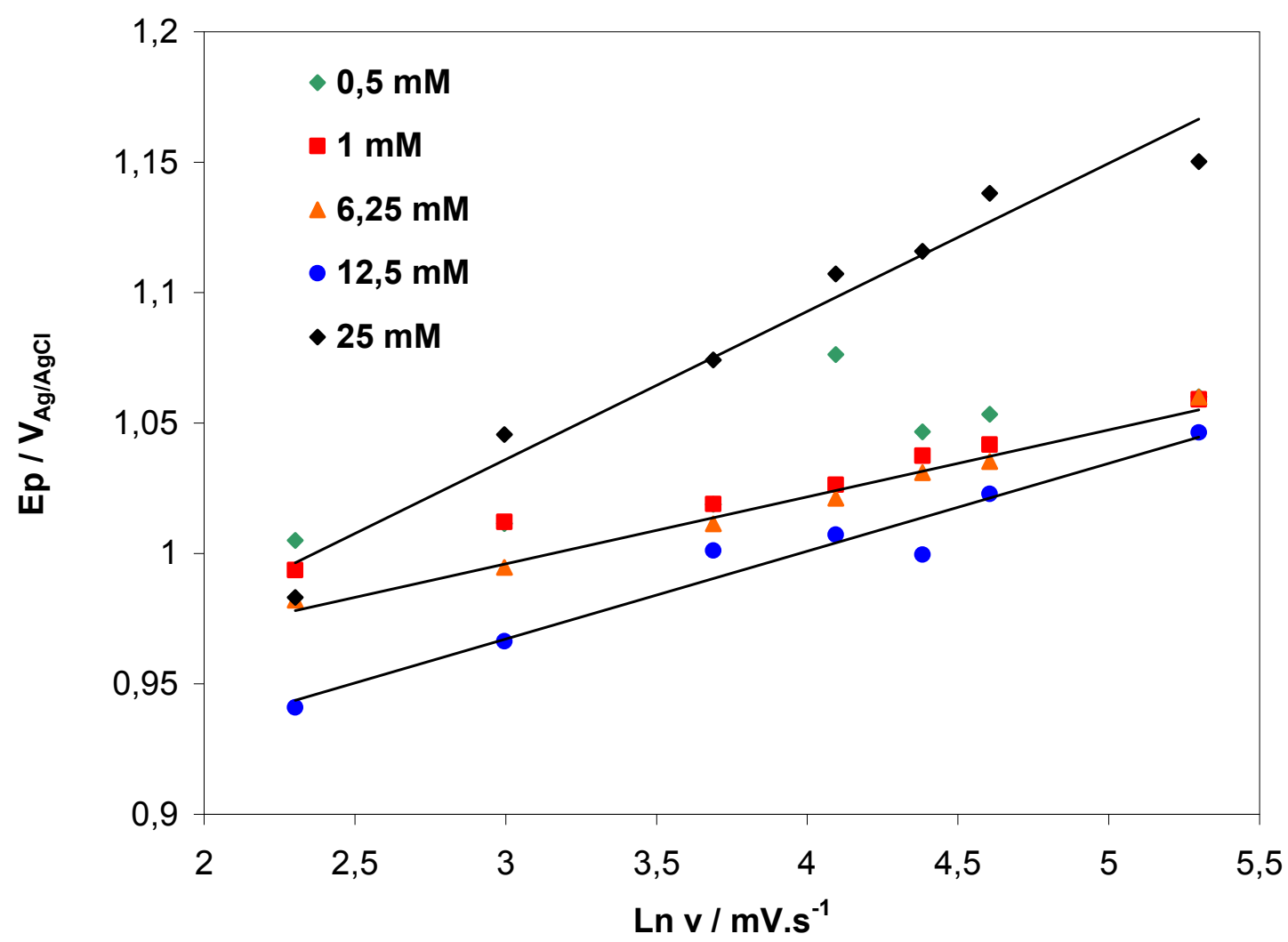

Figura 38: Potencial de pico como uma função do logaritmo da velocidade de varredura para diferentes concentrações de fenol em 1,0 $\mathrm{M} \mathrm{H}_{2} \mathrm{SO}_{4}$.

Analisando o gráfico obtido da representação do Ip em função da raiz quadrada de $v$ para a solução $1 \mathrm{M}$ de ácido sulfúrico, Figura 39 , pode-se verificar o comportamento linear, mostrando que o processo de oxidação sobre a superfície do eletrodo é controlado por difusão [68,80,90]. A corrente de pico anódica variou linearmente com a raiz quadrada da velocidade de varredura de potencial, principalmente, para as soluções de 6,25 e 12,5 mM de fenol.

A Figura 40 mostra a densidade de corrente de pico em função da raiz quadrada da velocidade de varredura de duas diferentes concentrações de fenol $(6,25$ e 12,5 mM) e ácido sulfúrico, variando de 0,01 a 1M. Pode ser visto que, para ambas as concentrações de fenol, a densidade de corrente de pico aumenta com a raiz quadrada da velocidade de varredura, sendo que para a concentração de fenol de 6,25 mM a variação é linear e ip aumenta com o aumento da concentração de ácido sulfúrico. Já para a concentração de 12,5 mM o aumento não é linear. 


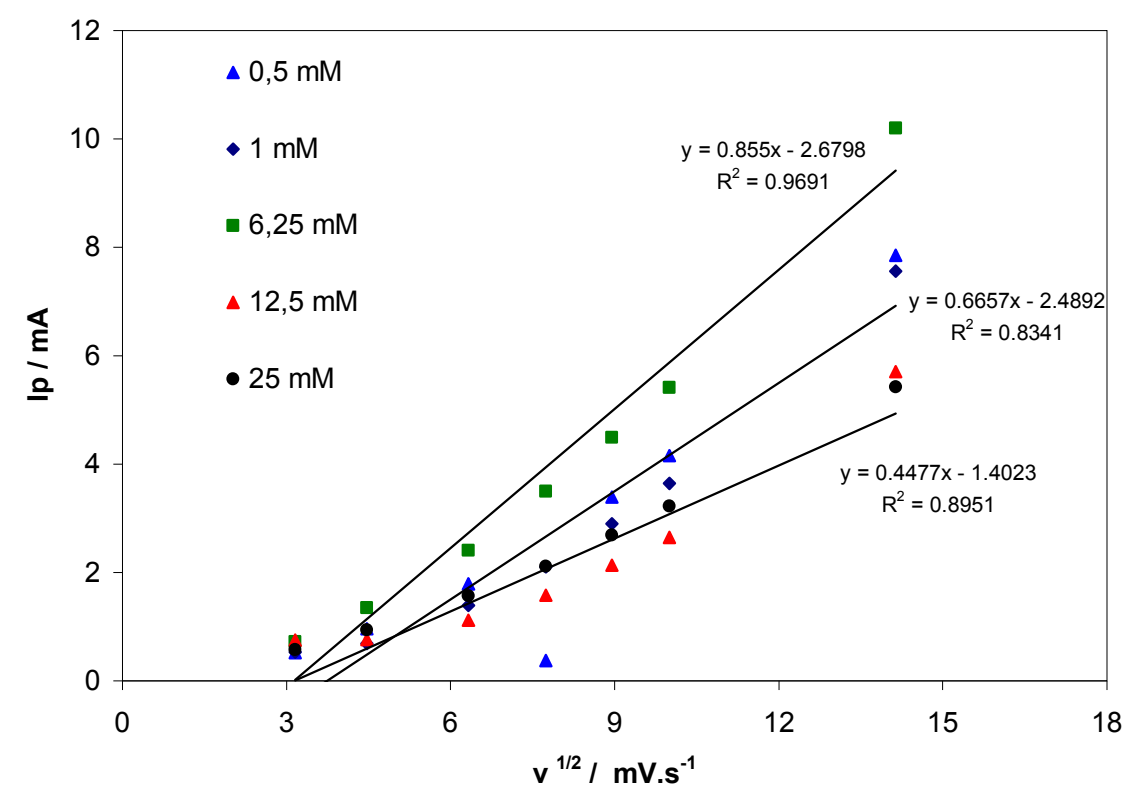

Figura 39: Densidade de corrente de pico como uma função da raiz quadrada da velocidade de varredura para diferentes concentrações de fenol em $1 \mathrm{M}$ $\mathrm{H}_{2} \mathrm{SO}_{4} .\left(\mathrm{ET}=\mathrm{Ti} / \mathrm{Ru}_{0,3} \mathrm{Ti}_{0,7} \mathrm{O}_{2}, \mathrm{CE}=\mathrm{Pt}\right.$ e ER $\left.=\mathrm{Ag} / \mathrm{AgCl}\right)$.

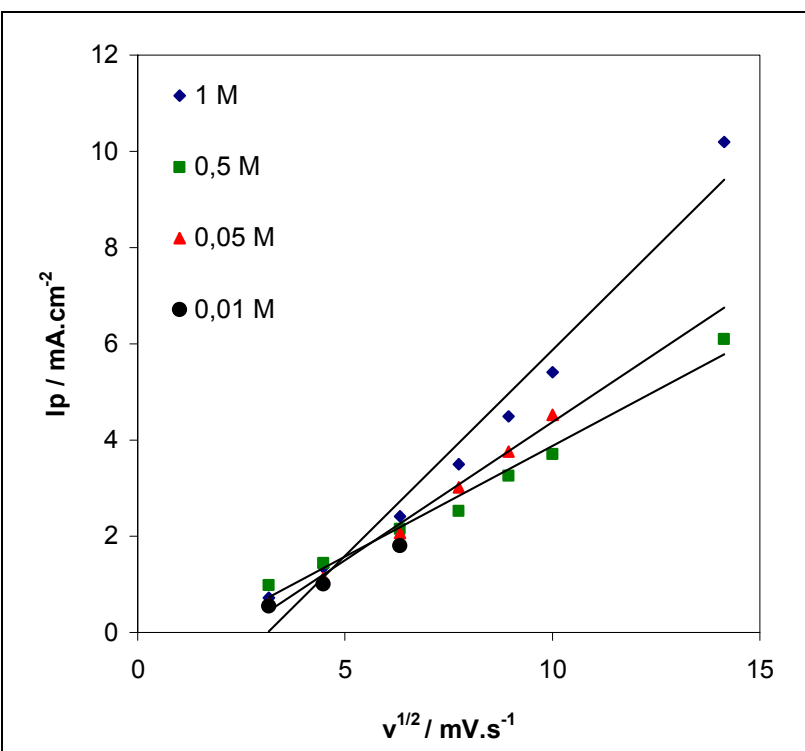

A

Figura 40: Densidade de corrente de pico como uma função da raiz quadrada da velocidade de varredura de potencial em diferentes concentrações de $\mathrm{H}_{2} \mathrm{SO}_{4}$ para duas concentrações de fenol: A) 6,25 mM e B) $12,5 \mathrm{mM}$.

Analisando os resultados verifica-se que concentrações de ácido de 1 e $0,5 \mathrm{M}$ e de fenol de 6,25 e 12,5 mM apresentaram um melhor comportamento eletroquímico quando comparado a outras soluções estudadas. Optou-se por se 
trabalhar na condição de acidez menos extrema, ou seja, 0,5 $\mathrm{M} \mathrm{H}_{2} \mathrm{SO}_{4}$, e com a concentração de fenol de 6,25 mM por apresentar na maioria das condições testadas os maiores valores de corrente de pico. Essa solução será utilizada nos experimentos de EL e FEO.

Foram realizados experimentos de VC a diferentes velocidades de varredura utilizando eletrodo de trabalho do tipo DSA, para a solução $0,5 \mathrm{M}$ $\mathrm{H}_{2} \mathrm{SO}_{4} / 6,25 \mathrm{mM}$ fenol, conforme Figura 41.Verifica-se a presença de um pico de oxidação em torno de $1 \mathrm{~V}$ e a ausência de pico de redução. Observa-se um deslocamento do Ep para valores mais anódicos e o aumento da intensidade da Ip com o aumento da velocidade de varredura. Esse comportamento de Ep e Ip evidencia a ocorrência de um processo irreversível de oxidação, salientando que a ausência de pico de redução reforça essa observação.

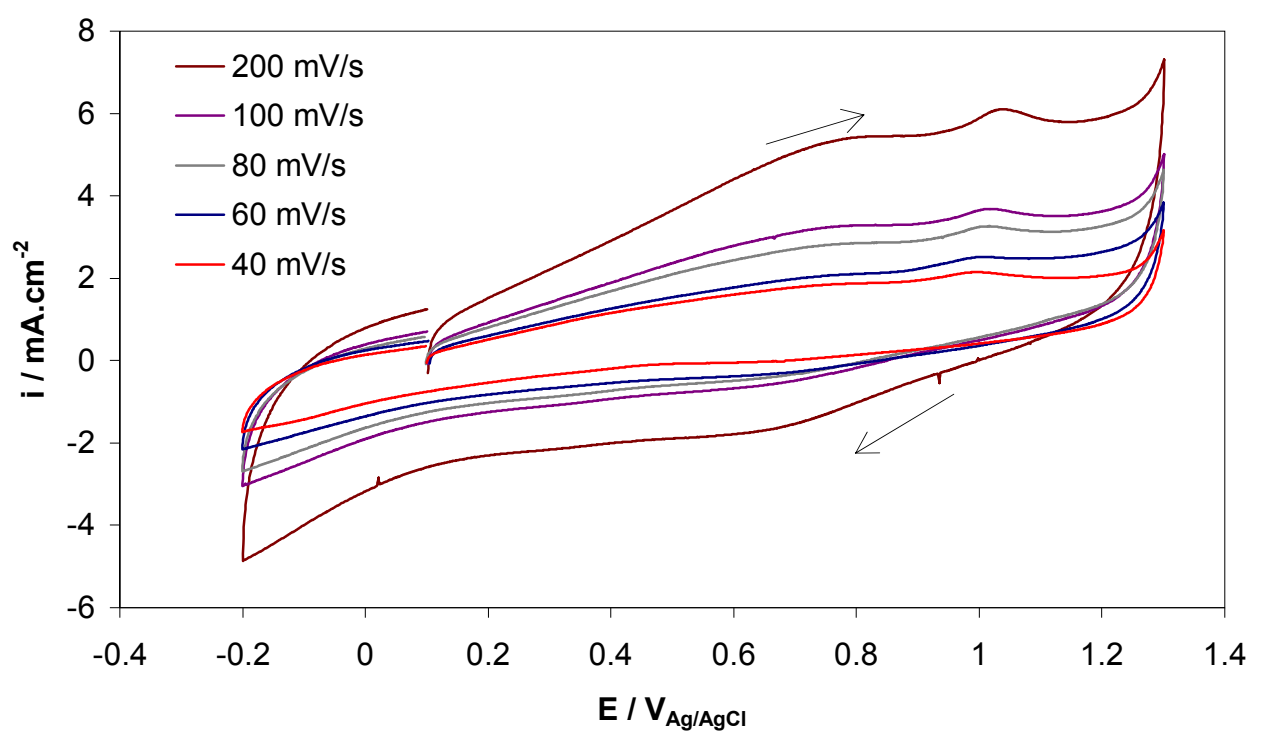

Figura 41: Voltamogramas obtidos para diferentes velocidades de varredura testadas nos experimentos de VC $\left(\mathrm{ET}=\mathrm{Ti} / \mathrm{Ru}_{0,3} \mathrm{Ti}_{0,7} \mathrm{O}_{2}, \mathrm{CE}=\mathrm{Pt}\right.$ e ER $=$ $\mathrm{Ag} / \mathrm{AgCl})$.

Foram realizados o cálculo dos valores de na e $D$ do fenol nessas

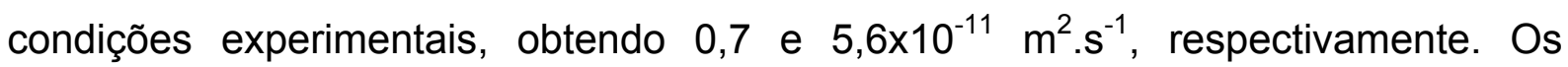
valores obtidos nessas condições experimentais com eletrodo de platina foram de 0,6 para na e $8,8 \times 10^{-13} \mathrm{~m}^{2} \cdot \mathrm{s}^{-1}$ para o coeficiente de difusão. Sendo o processo 
controlado por difusão, pode-se verificar uma maior difusividade do fenol com a aplicação de eletrodo de $\mathrm{Ti} / \mathrm{Ru}_{0,3} \mathrm{Ti}_{0,7} \mathrm{O}_{2}$.

Analisando a comparação entre o eletrodo de $\mathrm{Ti} / \mathrm{Ru}_{0,3} \mathrm{Ti}_{0,7} \mathrm{O}_{2}$ e o de platina apresentado na Figura 42 pode-se observar que o pico de oxidação ocorre praticamente no mesmo potencial para ambos os materiais. Contudo, o eletrodo de $\mathrm{Ti} / \mathrm{Ru}_{0,3} \mathrm{Ti}_{0,7} \mathrm{O}_{2}$ atinge maiores densidades de corrente de pico para um mesmo potencial.

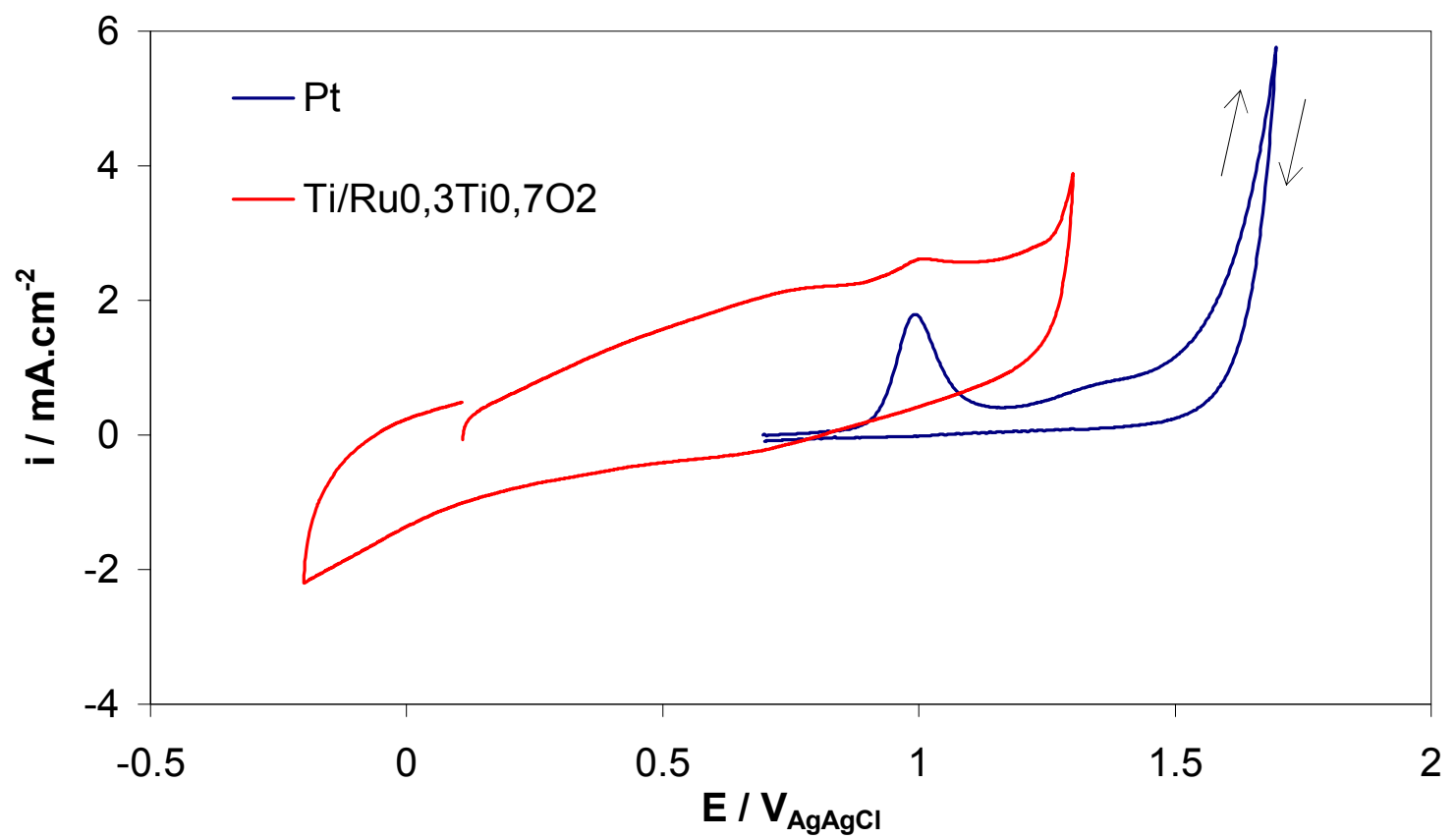

Figura 42: Comparação entre o comportamento dos eletrodos de platina e $\mathrm{Ti} / \mathrm{Ru}_{0,3} \mathrm{Ti}_{0,7} \mathrm{O}_{2}$ para uma solução $0,5 \mathrm{M} \mathrm{H} \mathrm{SO}_{4} / 6,25 \mathrm{mM}$ fenol, velocidade de varredura $60 \mathrm{mV} \cdot \mathrm{s}^{-1}$.

\subsubsection{Discussão dos resultados dos experimentos de VC}

Nessa etapa do trabalho foi investigado o comportamento eletroquímico do fenol em função de sua concentração, acidez do meio, velocidade de varredura de potencial e material de eletrodo. Conforme os resultados apresentados é conveniente destacar algumas importantes informações: 
- Para todos os eletrodos testados se observou a formação de pico de oxidação sempre que se tem a presença de fenol na solução de trabalho.

- O eletrodo do tipo DSA foi o único dentre os testados que não apresentou bloqueio da superfície ou envenenamento nos experimentos de $\mathrm{VC}$ com vários ciclos.

- O processo de oxidação no eletrodo do tipo DSA demonstrou ser irreversível e controlado prioritariamente por difusão

- Avaliando o comportamento eletroquímico do fenol em função da variação de Ep e Ip com a velocidade de varredura de potencial, concentração de fenol e acidez, quando aplicado o eletrodo do tipo DAS, as concentrações de 12,5 e 6,25 mM de fenol e de 0,5 e $1 \mathrm{M}$ de $\mathrm{H}_{2} \mathrm{SO}_{4}$ parecem ser mais favoráveis ao processo de oxidação.

- Optou-se realizar os experimentos com uma solução de 0,5 M de $\mathrm{H}_{2} \mathrm{SO}_{4}$ por menor consumo de reagente e com $6,25 \mathrm{mM}$ de fenol por ter apresentado maiores valores de Ip.

- Foram realizado experimentos de EL e FEO na faixa de densidade de corrente de 1 a $10 \mathrm{~mA} . \mathrm{cm}^{-2}$, abrangendo todas as Ip obtidas nos experimentos de VC.

- O fenol apresentou maior coeficiente de difusão com o uso do eletrodo do tipo DSA que com o eletrodo de $\mathrm{Pt}$, o que favorece o processo de oxidação, sendo ele controlado por difusão. 


\subsection{EXPERIMENTOS DE ELETRÓLISE}

Foram realizados no LACOR os experimentos de EL galvanostática em regime de batelada, para um volume de $1 \mathrm{~L}$, em reator de vidro encamisado, sob controle de temperatura, $\mathrm{T}=25^{\circ} \mathrm{C}$ [Figura 10]. A célula eletroquímica foi composta de um par de eletrodos, sendo o cátodo uma tela de titânio revestido de óxido de titânio $\left(\mathrm{Ti} / \mathrm{TiO}_{2}\right)$, como ânodo uma placa de titânio revestida de óxido de titânio e rutênio ( $\mathrm{Ti} / \mathrm{Ru}_{0,3} \mathrm{Ti}_{0,7} \mathrm{O}_{2}$ ), material do tipo DSA. A célula foi montada de forma radial, sendo a parte externa composta pelo ânodo e a interna pelo cátodo, a uma distância entre os eletrodos de $1 \mathrm{~cm}$.

Como foram obtidos diferentes valores para Ip dependendo da velocidade de varredura utilizada nos experimentos de VC, Foram realizadas medidas de $\mathrm{pH} \mathrm{e}$ temperatura das soluções testadas, no início e no final dos ensaios, o teor de matéria orgânica foi monitorado por análises de DQO e COT, foram monitorados também o teor de fenol e de produtos intermediários do processo de eletrooxidação do fenol, como a benzoquinona (BQ) e ácidos orgânicos de cadeia curta.

Foi escolhida a solução de $0,5 \mathrm{M} \mathrm{H}_{2} \mathrm{SO}_{4} / 6,25 \mathrm{mM}$ fenol para ser utilizada na avaliação dos processos de EL e FEO. Essa solução representa condições intermediarias de acidez e concentração de fenol dentre as soluções testadas nos experimentos de voltametria cíclica de varredura. Será conveniente para a comparação dos próximos resultados apresentar que essa concentração de fenol é o equivalente a $588 \mathrm{mg} \cdot \mathrm{L}^{-1}$.

Em muitos processos, onde as reações ocorrem na interface com uma superfície catalítica, é pertinente avaliar o efeito da agitação magnética no interior do reator. A agitação pode promover um aumento no numero de moléculas que colidem sobre a superfície catalítica do ânodo, em reações que apresentam cinética rápida e o controle ocorre por difusão. Contudo para processos que apresentam controle cinético a agitação pode reduzir o tempo de contato com a superfície catalítica e dificultar a completa reação das moléculas.

Analisando os resultados apresentados na Tabela 5 pode-se verificar o importante efeito da agitação mecânica sobre esse sistema reacional. Obteve-se redução do teor de fenol superior a $97 \%$ quando agitado mecanicamente o meio 
reacional, e apenas 7\% quando não se utiliza agitação. A grande influência da agitação está de acordo com a análise dos resultados dos experimentos de VC, nos quais foi observado controle difusional do processo de oxidação do fenol sobre o eletrodo de $\mathrm{Ti} / \mathrm{Ru}_{0,3} \mathrm{Ti}_{0,7} \mathrm{O}_{2}$, Figura 39, sendo assim, um aumento no numero de colisões de partículas na superfície do eletrodo produz efeito positivo no processo EL.

Cabe salientar que nesses experimentos foram utilizadas soluções de fenol bem diluídas e em um processo controlado por difusão a fase mais lenta é o transporte da molécula de fenol até a superfície do ânodo, uma vez as moléculas atinjam a superfície anódica as reações ocorrem rapidamente. Portanto o uso de mecanismos que facilitem o transporte do reduzido número de moléculas na solução promoveu um grande aumento de eficiência do processo.

Tabela 5: Estudo do efeito da agitação mecânica no processo de eletrooxidação, em sistema de batelada. Tempo de reação: $5 \mathrm{~h}$.

\begin{tabular}{|c|c|c|c|c|c|c|c|c|}
\hline $\begin{array}{c}\text { Experimentos de } \\
\text { EL }\end{array}$ & $\begin{array}{c}\text { Fenol } \\
(\mathbf{m M})\end{array}$ & $\begin{array}{c}\text { BQ } \\
(\mathbf{m M})\end{array}$ & $\begin{array}{c}\text { DQO } \\
\left(\mathbf{m g O}_{\mathbf{2}} \cdot \mathbf{L}^{-1}\right)\end{array}$ & $\begin{array}{c}\text { COT } \\
\left(\mathbf{m g}^{-1} \mathbf{L}^{-1}\right)\end{array}$ & $\begin{array}{c}\text { Temperatura } \\
\left({ }^{\circ} \mathbf{C}\right)\end{array}$ & \multicolumn{2}{|c|}{$\mathbf{p H}$} \\
\cline { 5 - 9 } & & & & & Inicial & Final & Inicial & Final \\
\hline Inicial & 6,41 & ${ }^{*}$ N.D. & 1250,0 & 602,5 & 25,0 & --- & 0,55 & -- \\
\hline Sem agitação & 4,97 & 0,85 & 1196,4 & 444,5 & 26,5 & 30,5 & 0,54 & 0,51 \\
\hline Com agitação & 0,17 & ${ }^{*}$ N.D. & 1113,2 & 444,7 & 22,0 & 28,5 & 0,56 & 0,60 \\
\hline
\end{tabular}

*N.D. - Não detectado.

Nas reações de combustão eletroquímica temos como produto da reação de oxidação na presença de matéria orgânica $\mathrm{O}^{\mathrm{CO}_{2}}$, transformando carbono orgânico em inorgânico, ou seja, mineralizando a matéria orgânica. Outro possível mecanismo de oxidação do fenol é a sua conversão em moléculas menores, com o rompimento das ligações atômicas, até a obtenção de $\mathrm{CO}_{2}$ como produto final das reações. Analisando a Figura 43 pode-se verificar uma redução no teor de matéria orgânica. Essa redução indica a formação de $\mathrm{CO}_{2}$, ou seja, que ocorreu durante o processo de EL a mineralização parcial do carbono orgânico. Contudo, avaliando a baixa redução nos teores de DQO e COT e a elevada redução do teor de fenol, pode-se dizer que a reação de oxidação do fenol ocorreu mais por conversão 
eletroquímica do que por combustão eletroquímica, tendo gerado compostos intermediários e subprodutos da reação de eletrooxidação do fenol.

Observou-se o aparecimento de uma coloração amarelada na solução tratada, essa coloração aparece por dois possíveis motivos: pela formação de produtos intermediários da oxidação do fenol como benzoquinona; ou pela formação de oligômeros, pois devido às condições experimentais que desfavorece a rota de polimerização do fenol, não ocorre a geração de moléculas de elevado grau de polimerização, contudo moléculas com baixo grau de polimerização podem se formar. Esses oligômeros apresentam colorações entre amarelo e marrom. O surgimento de coloração em soluções de fenol submetidas a processos oxidativos foi relatado em alguns trabalhos, sendo relacionada à geração de benzoquinona e produtos intermediários das reações de polimerização [45,59].

Não foi observada variação significativa nos valores de $\mathrm{pH}$ e temperatura em ambas condições experimentais aplicadas.

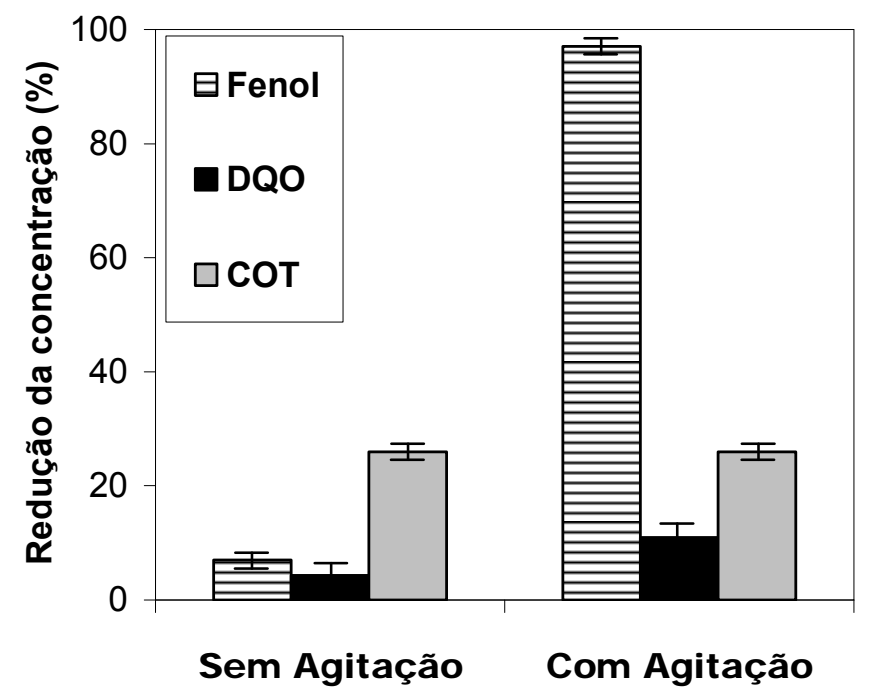

Figura 43: Avaliação da agitação mecânica na degradação eletroquímica de fenol.

Para verificar o efeito da densidade de corrente sobre o processo de oxidação foram realizados experimentos com densidades de corrente abaixo e acima de 3,7 mA.cm ${ }^{-2}$. Os experimentos foram conduzidos por 5 horas, sob agitação, a temperatura da camisa do reator de $25^{\circ} \mathrm{C}$, em regime de batelada. 
Analisando os resultados apresentados na Tabela 6, pode-se verificar que o melhor resultado foi com aplicação de $3,7 \mathrm{~mA} \cdot \mathrm{cm}^{-2}$, atingindo redução no teor de fenol superior a $96 \%$. Quando se aplicou densidades de corrente mais baixas $\left(1 \mathrm{~mA} . \mathrm{cm}^{-2}\right)$ a redução do teor de fenol foi em torno de $30 \%$ e para densidades de corrente maiores $\left(6,1\right.$ e $\left.10 \mathrm{~mA} . \mathrm{cm}^{-2}\right)$ as reduções de fenol alcançaram valores pouco superiores a $50 \%$. Tal comportamento está de acordo com o trabalho publicado por Pannizza e outros [65] em que sugere a existência de uma corrente limite, na qual o processo trabalha com melhor eficiência de conversão e energética. Conforme apresentado nesse trabalho, em processos de eletrólise galvanostática pode-se trabalhar em três regimes distintos: $\mathrm{i}_{\text {aplicado }}<\mathrm{i}_{\text {limite }}$, trabalhando abaixo da corrente limite se obtêm produtos intermediários de oxidação e decaimento linear do teor de matéria orgânica; $i_{\text {aplicado }}>\mathrm{i}_{\text {limite, }}$ trabalhando acima da corrente limite se intensifica as reações de eletrólise da água e diminui a eficiência energética do processo e $\mathrm{i}_{\text {aplicado }}=\mathrm{i}_{\text {limite }}$, trabalhando com corrente igual à corrente limite se tem uma melhor eficiência energética e decaimento exponencial da matéria orgânica. Portanto a corrente limite no processo de eletrooxidação de fenol investigado nesse trabalho deve ser um valor igual ou próximo a $3 \mathrm{~A}$, valor de corrente relativo a densidade de corrente de $3,7 \mathrm{~mA} . \mathrm{cm}^{-2}$, experimento 02 .

Tabela 6: Influência da intensidade da força motriz no processo de eletrooxidação de fenol. Tempo de reação: $5 \mathrm{~h}$.

\begin{tabular}{|c|c|c|c|c|c|c|c|c|c|}
\hline Parâmetros & \multirow{2}{*}{$\begin{array}{c}\mathrm{i} \\
\left(\mathrm{mA} \cdot \mathrm{cm}^{-2}\right)\end{array}$} & \multirow{2}{*}{$\begin{array}{l}\text { Fenol } \\
(\mathrm{mM})\end{array}$} & \multirow{2}{*}{$\begin{array}{c}\mathrm{BQ} \\
(\mathrm{mM})\end{array}$} & \multirow{2}{*}{$\begin{array}{c}\text { COT } \\
\left(\mathrm{mg}^{-1} \mathrm{~L}^{-1}\right)\end{array}$} & \multirow{2}{*}{$\begin{array}{c}\text { DQO } \\
\left(\mathrm{mgO}_{2} \cdot \mathrm{L}^{-1}\right)\end{array}$} & \multicolumn{2}{|c|}{$\begin{array}{c}\text { Temperatura } \\
\left({ }^{\circ} \mathrm{C}\right)\end{array}$} & \multicolumn{2}{|c|}{$\mathrm{pH}$} \\
\hline Experimento & & & & & & Inicial & Final & Inicial & Final \\
\hline Inicial & --- & 6,41 & ${ }^{*}$ N.D. & 602,5 & 1250,0 & 25,0 & --- & 0,55 & --- \\
\hline 01 & 1,0 & 4,46 & *N.D. & 451,0 & 1217,5 & 18,5 & 28,4 & 0,62 & 0,60 \\
\hline 02 & 3,7 & 0,21 & ${ }^{*}$ N.D & 440,0 & 1103.2 & 22,0 & 28,0 & 0,55 & 0,60 \\
\hline 03 & 6,1 & 2,94 & 0,76 & 443,0 & 1102,4 & 21,6 & 29,0 & 0,58 & 0,59 \\
\hline 04 & 10,0 & 3,87 & ${ }^{* *}$ N.A. & 444,5 & 1161,3 & 20,0 & 31,0 & 0,59 & 0,59 \\
\hline
\end{tabular}

*N.D. - Não detectado.

**N.A. - Não analisado.

Aplicando a técnica de espectroscopia de UVIVIS foi realizada a avaliação do processo de EL. Foram comparadas as soluções inicial e pós-tratamento nas 
condições do experimento 02, as amostras foram diluídas 10 vezes. Analisando os espectros mostrados na Figura 44 observam-se dois picos, em torno de 200 e $270 \mathrm{~nm}$, esses picos após o processo de EL aparecem sobrepostos aos da solução inicial, com um alargamento do segundo pico, $270 \mathrm{~nm}$, devido ao surgimento de outro pico relativo à formação de compostos aromáticos oriundos da oxidação parcial do fenol por conversão eletroquímica, hidroquinonas e benzoquinonas. Observando o primeiro pico vê-se que ocorreu um aumento de sua intensidade, esse efeito foi relatado por outros autores [45], sendo associado à formação de ácidos orgânicos alifáticos, formados da ruptura do anel aromático.

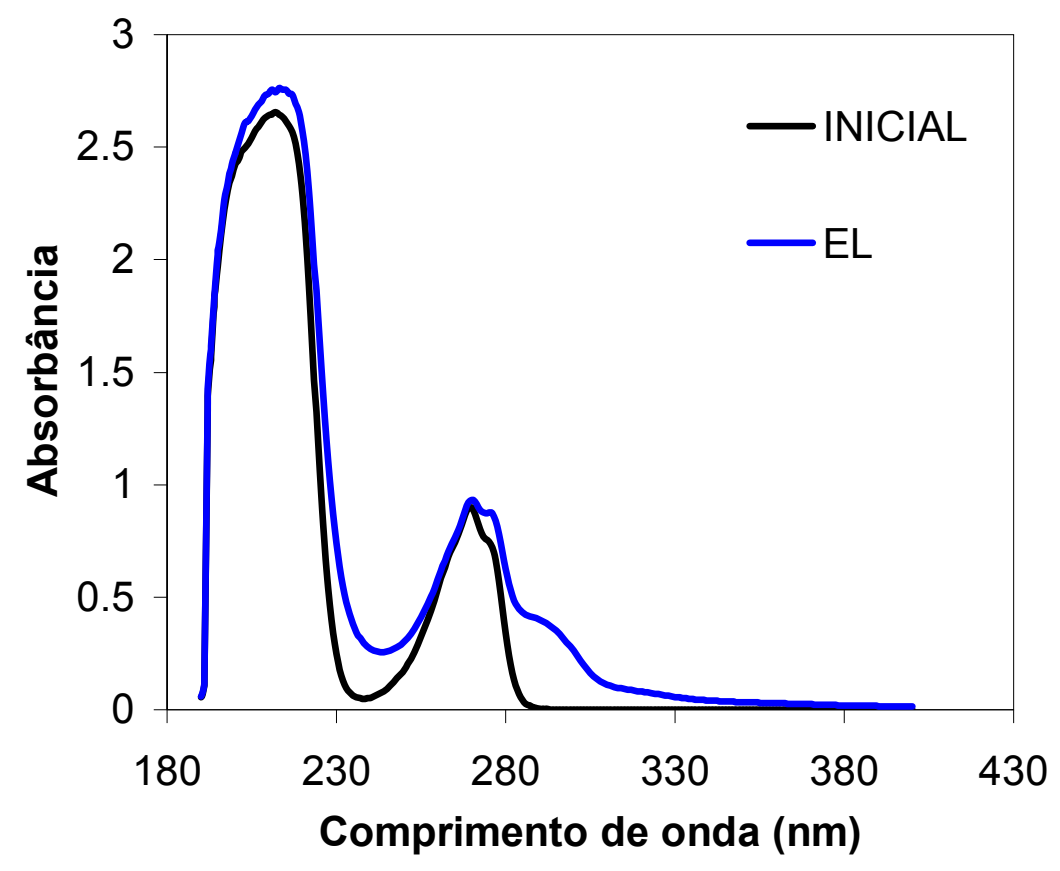

Figura 44: Avaliação do processo de EL pela técnica de espectroscopia de UV/VIS.

Foi investigada a presença de ácidos orgânicos de cadeia curta por meio de cromatografia iônica, como o ácido oxálico, tartárico, acético e cítrico. Na Figura 45 pode-se ver o cromatrograma da solução inicial de $6,25 \mathrm{mM}$ de fenol/0,5 $\mathrm{M}$ de $\mathrm{H}_{2} \mathrm{SO}_{4}$, com a presença de um grande pico em 3 min de retenção e outro menor em torno de $8 \mathrm{~min}$. Na Figura 46, após o processo de EL, observa-se a formação de picos menos intensos na região entre 2 e $3 \mathrm{~min}$, o que demonstra que ocorreu a degradação do fenol durante o processo de EL, verifica-se também a formação de alguns ácidos orgânicos de cadeia curta. Na Figura 47 apresenta-se a comparação entre os dois cromatogramas, podendo verificar a significativa redução dos picos da 
solução inicial e surgimento de picos menores em maior número, alguns deles absorvem nos tempos de retenção de alguns ácidos orgânicos.

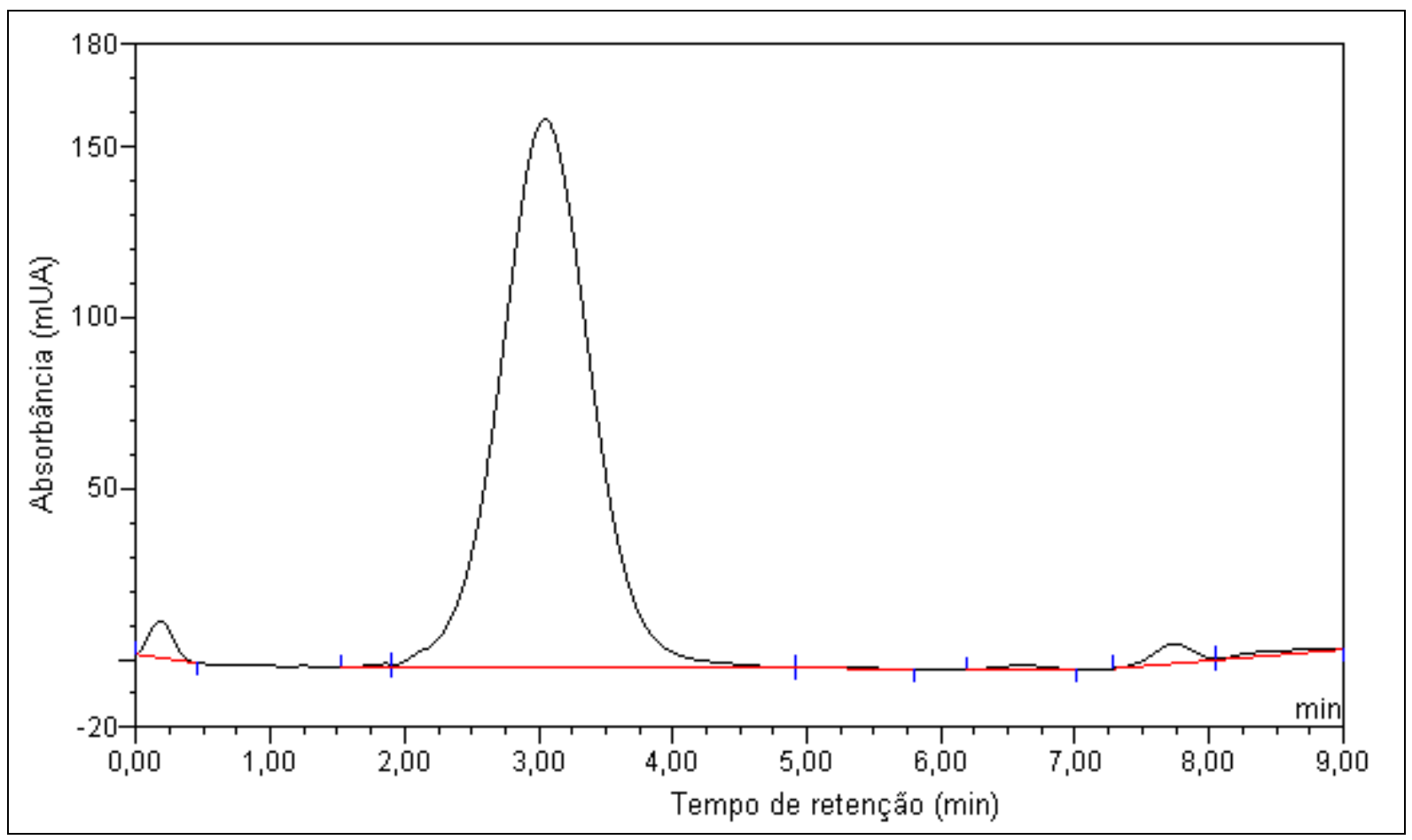

Figura 45: Análise por $\mathrm{Cl}$ da solução sintética 0,5M H2SO4/6,25mM fenol.

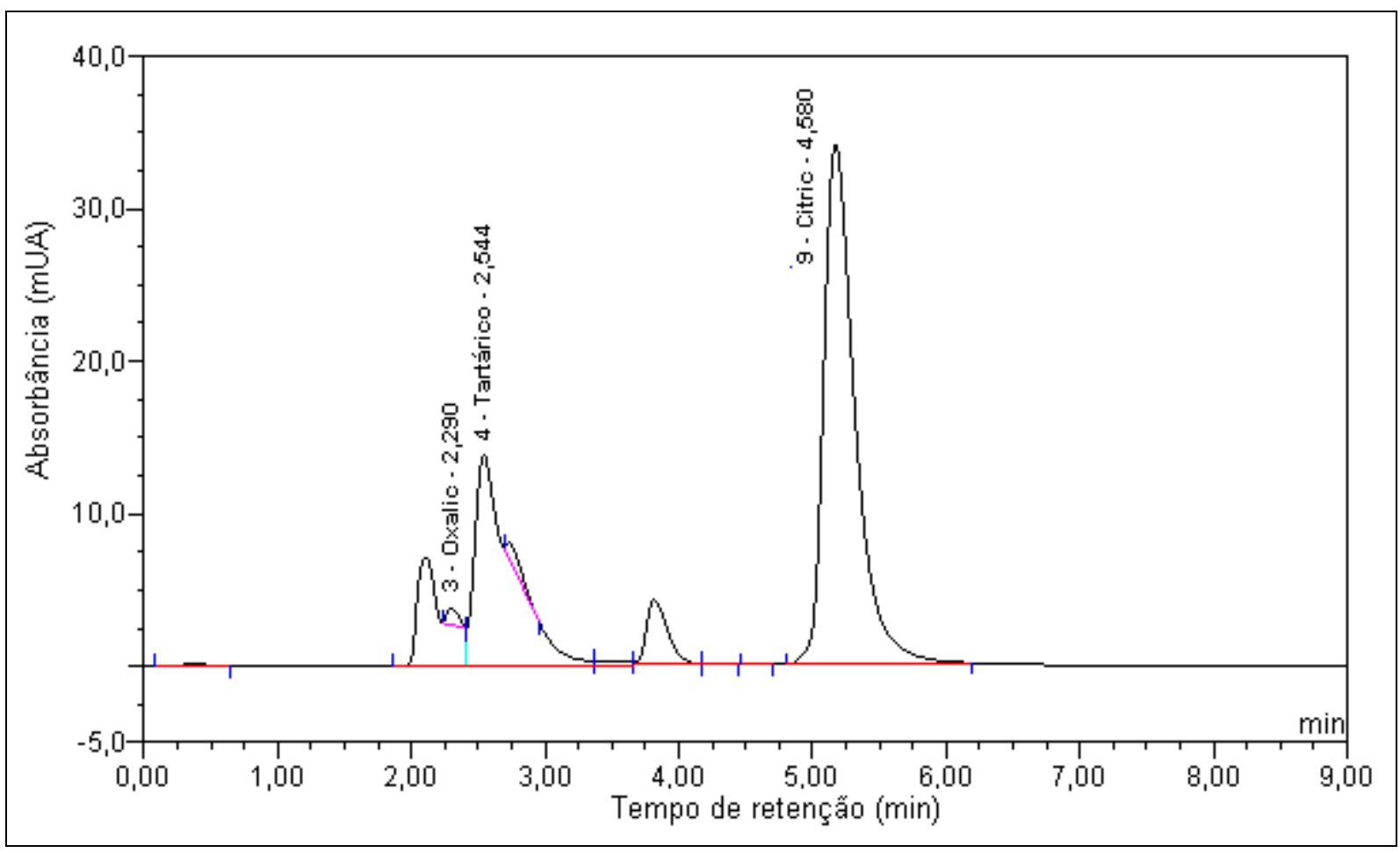

Figura 46: Análise por $\mathrm{Cl}$ da solução sintética $0,5 \mathrm{M} \mathrm{H}_{2} \mathrm{SO}_{4} / 6,25 \mathrm{mM}$ fenol após processo de EL. 
Com as análises realizadas por $\mathrm{Cl}$ podemos verificar que o teor de ácidos orgânicos após o tratamento por EL foi de 12,32 mg. $\mathrm{L}^{-1}$, sendo que na amostra inicial não foi detectado a presença desses compostos. A detecção de ácidos orgânicos de cadeia curta indica que a oxidação do fenol seguiu a rota de formação de hidroquinonas, benzoquinonas e ácidos orgânicos em detrimento à rota de polimerização.

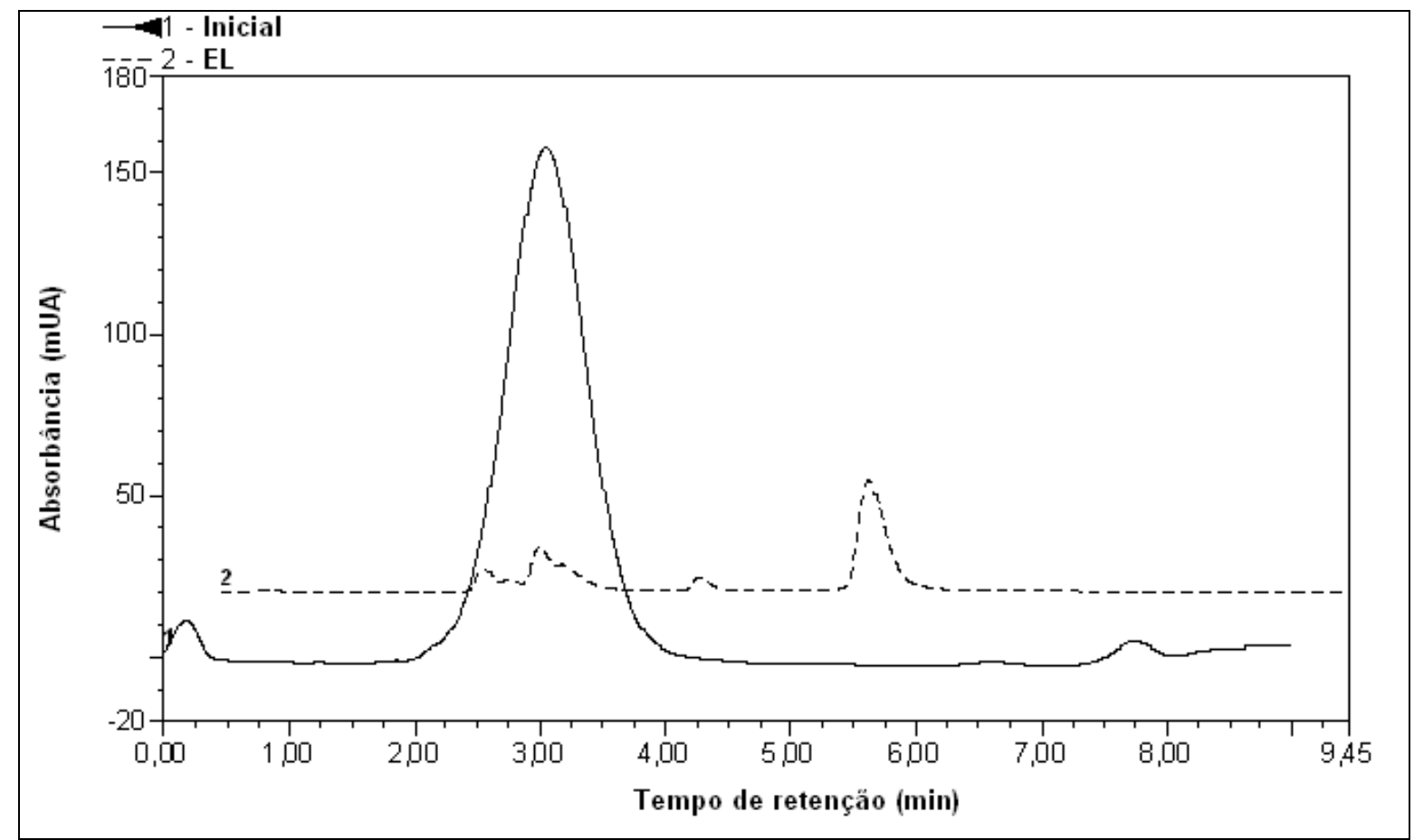

Figura 47: Comparação dos cromatrogramas da solução inicial e a tratada por EL.

Foram realizados experimentos de VC com a solução após o processo de EL, na Figura 48 é apresentada sua comparação com a solução inicial. Pode-se observar que ocorre um aumento na Ip, sem deslocamento do Ep. É provável que o aumento na Ip seja devido à oxidação do fenol não ter evoluído até as últimas etapas da reação de conversão eletroquímica, ou seja, produção de ácidos orgânicos de cadeia curta que dificilmente são oxidados por via eletroquímica. A produção desses ácidos pode não influenciar ou provocar redução na Ip.

Analisando a redução do teor de COT e DQO e o aumento da Ip após o tratamento de EL, é possível que esse comportamento esteja relacionado à formação de compostos intermediários que oxidam na mesma faixa de potencial que o fenol. 
Analisando a região entre 0,25 e 0,50 V vs $\mathrm{Ag} / \mathrm{AgCl}$, observa-se um aumento nas reações de redução, possivelmente pela formação de compostos menos instáveis, com reações redox reversíveis. Isso produziria um aumento na intensidade das reações de oxidação e de redução, como se observa na Figura 48. Alguns produtos intermediários da oxidação do fenol como benzoquinonas e hidroquinosnas podem apresentar esse comportamento, sendo a formação dessas quinonas uma possível causa do aumento das correntes de oxidação.

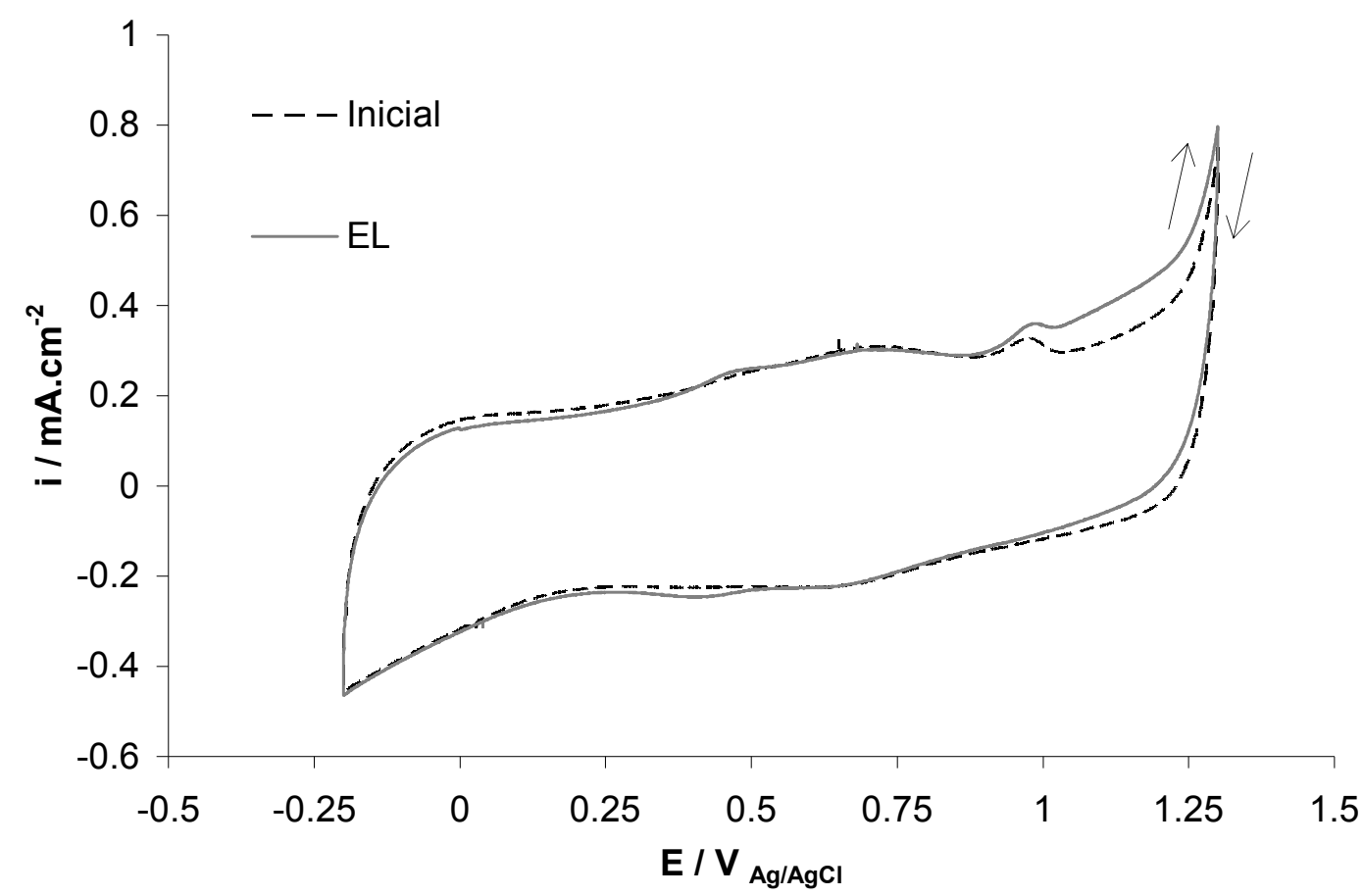

Figura 48: Comparação entre os voltamogramas obtidos para a solução de fenol inicial e tratada por $\mathrm{EL}, \mathrm{v}=60 \mathrm{mV} \cdot \mathrm{s}^{-1} .\left(\mathrm{ET}=\mathrm{Ti} / \mathrm{Ru}_{0,3} \mathrm{Ti}_{0,7} \mathrm{O}_{2}, \mathrm{CE}=\mathrm{Pt}\right.$ e $\mathrm{ER}=$ $\mathrm{Ag} / \mathrm{AgCl})$.

\subsubsection{Discussão dos resultados dos experimentos de EL}

Face ao exposto nos resultados podem-se fazer algumas aferições, tais como: a agitação mecânica mostrou-se um importante parâmetro nesse processo oxidativo. A reação de eletrooxidação do fenol ocorreu predominantemente por meio de conversão eletroquímica, de forma irreversível, gerando produtos intermediários de reação, como benzoquinona e ácidos orgânicos. A mineralização da matéria orgânica, tanto por combustão como por conversão eletroquímica, atingiu baixos 
percentuais, sendo talvez necessário um tempo maior de tratamento ou mudança nos parâmetros aplicados. A superfície anódica não apresentou bloqueio, contudo não foi possível a mineralização total da matéria orgânica presente. O surgimento de coloração na solução tratada pode ser resultado da geração de benzoquinonas e oligômeros, oriundos da oxidação ou polimerização do fenol. O processo de EL demonstrou ser capaz de degradar esse composto orgânico refratário, portanto, representa uma alternativa tecnológica para a degradação desses perigosos compostos. 


\subsection{EXPERIMENTOS DE FOTOELETROOXIDAÇÃO}

Foram realizados no LACOR experimentos de FEO em regime de batelada, para um volume de $1 \mathrm{~L}$, em reator de vidro encamisado, sob controle de temperatura, $T=25^{\circ} \mathrm{C}$. A célula eletroquímica foi acrescida de uma fonte de radiação UV, lâmpada de vapor de mercúrio de $250 \mathrm{~W}$, com a finalidade de promover a foto ativação do material anódico, ânodo do Tipo DSA: placa de titânio revestida de óxido de titânio e rutênio $\left(\mathrm{Ti} / \mathrm{Ru}_{0,3} \mathrm{Ti}_{0,7} \mathrm{O}_{2}\right)$. A célula foi montada de forma radial, sendo a parte externa composta pelo ânodo e a interna pelo cátodo, a uma distância entre os eletrodos de $1 \mathrm{~cm}$, e na parte central a lâmpada.

Medidas de $\mathrm{pH}$ e temperatura das soluções testadas foram tomadas, no início e no final de cada experimento, o teor de matéria orgânica foi monitorado por análises de DQO e COT, foram monitorados também os produtos intermediários do processo de fotoeletrooxidação do fenol.

Nas medidas da intensidade de radiação UV sobre a superfície do eletrodo foram obtidos os seguintes resultados:

- Sem fluído: 5,0 mW.cm².

- Com água 5,0 mW.cm².

- Com solução de fenol: $0,3 \mathrm{~mW} \cdot \mathrm{cm}^{-2}$.

Pode-se verificar que a solução de fenol diminui consideravelmente a incidência de radiação UV sobre o ânodo. Observando os espectrogramas de absorção no UV/visível verifica-se que o fenol absorve entre 190 e $280 \mathrm{~nm}$, essa banda se encontra na zona do ultravioleta, o que explicaria essa redução na penetração da radiação UV na solução.

Os resultados obtidos nos experimentos de FEO estão apresentados na Tabela 7. Foi obtida uma maior redução na concentração de fenol no experimento 06, cerca de $98 \%$. Já para DQO e COT, a redução obtida foi de $23 \%$ e $31 \%$, respectivamente. No experimento 07 se atingiu maiores reduções no teor de matéria orgânica, contudo se aplicando maior corrente e com menor redução da concentração de fenol. Aplicando a densidade de corrente de $3,7 \mathrm{~mA} . \mathrm{cm}^{-2}$ se obteve 
uma redução maior da concentração de fenol, também observa-se que não foi detectada a presença de BQ.

Tabela 7: Experimentos de FEO a diferentes densidades de corrente, para uma solução de $0,5 \mathrm{M} \mathrm{H}_{2} \mathrm{SO}_{4} / 6,25 \mathrm{mM}$ fenol.

\begin{tabular}{|c|c|c|c|c|c|c|c|c|c|}
\hline Parâmetros & \multirow{2}{*}{$\begin{array}{c}\mathrm{i} \\
\left(\mathrm{mA} \cdot \mathrm{cm}^{-2}\right)\end{array}$} & \multirow{2}{*}{$\begin{array}{l}\text { Fenol } \\
\text { (mM) }\end{array}$} & \multirow{2}{*}{$\begin{array}{c}\mathrm{BQ} \\
(\mathrm{mM})\end{array}$} & \multirow{2}{*}{$\begin{array}{c}\text { COT } \\
\left(\mathrm{mg} \cdot \mathrm{L}^{-1}\right)\end{array}$} & \multirow{2}{*}{$\begin{array}{c}\mathrm{DQO} \\
\left(\mathrm{mgO}_{2} \cdot \mathrm{L}^{-1}\right)\end{array}$} & \multicolumn{2}{|c|}{$\begin{array}{c}\text { Temperatura } \\
\left({ }^{\circ} \mathrm{C}\right)\end{array}$} & \multicolumn{2}{|c|}{$\mathrm{pH}$} \\
\hline Experimento & & & & & & Inicial & Final & Inicial & Final \\
\hline Inicial & --- & 6,41 & ${ }^{*}$ N.D. & 602,5 & 1250,0 & 25,0 & --- & 0,55 & --- \\
\hline 05 & 1,0 & 1,68 & ${ }^{*}$ N.D. & 435,3 & 980,0 & 22,5 & 32,5 & 0,58 & 0,63 \\
\hline 06 & 3,7 & 0,10 & ${ }^{*} \mathrm{~N} . \mathrm{D}$ & 415,0 & 956,0 & 19,5 & 31,0 & 0,54 & 0,52 \\
\hline 07 & 10,0 & 0,34 & ${ }^{*} \mathrm{~N} . \mathrm{A}$. & 412,7 & 905,3 & 20,0 & 29,5 & 0,52 & 0,64 \\
\hline
\end{tabular}

*N.A. - Não analisado.

*N.D. - Não detectado.

A solução, após o tratamento por FEO, apresentou coloração marrom amarelada, coloração distinta da que apresentou os experimentos de EL. Na Figura 49 pode-se ver a diferença de coloração após os processos de FEO, são apresentas a solução inicial de $0,5 \mathrm{M} \mathrm{H}_{2} \mathrm{SO}_{4} / 6,25 \mathrm{mM}$ fenol, que é incolor, e após o tratamento por FEO. Esse efeito deve-se possivelmente à formação de oligômeros, subprodutos da reação de polimerização do fenol, pois, devido às altas temperaturas atingidas na interface tubo de quartzo e solução, a polimerização do fenol é favorecida. Comninellis e Pulgarin [37] observaram que temperaturas superiores a $50^{\circ} \mathrm{C}$ favorecem os processos de polimerização do fenol. Arslan e outros [35] relataram que temperaturas superiores a $50^{\circ} \mathrm{C}$ aceleram o bloqueio da superfície anódica. $\mathrm{A}$ fonte de radiação UV gera calor, possibilitando que a superfície do tubo de quartzo aqueça a valores superiores a $50^{\circ} \mathrm{C}$, promovendo a polimerização parcial do fenol, gerando oligômeros que produzem coloração marrom amarelada na solução. 


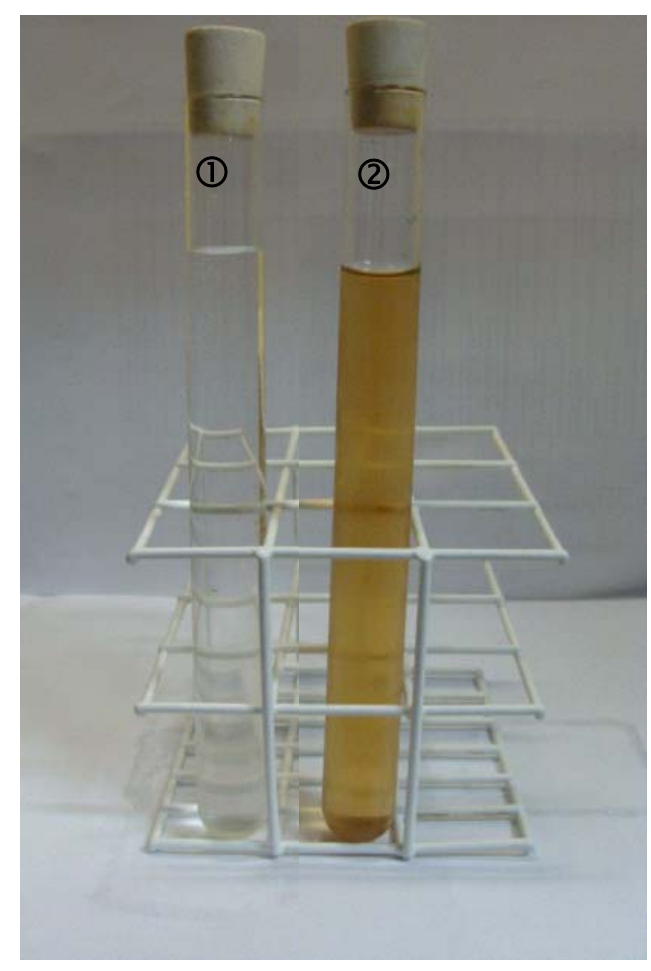

Figura 49: Soluções: 1) inicial e 2) após o processo de FEO.

Os espectrogramas obtidos por espectroscopia de UV/Visível estão apresentados na Figura 50, comparando a solução inicial e os resultados obtidos com o experimento 06. Observa-se para o experimento de FEO uma redução da absorbância para ambos os picos, e um alargamento do pico em torno de $270 \mathrm{~nm}$. Esse comportamento de alargamento do pico em torno de $270 \mathrm{~nm}$, como já foi observado para os experimentos de EL, pode estar relacionado com a geração de ácidos orgânicos. Já a redução na intensidade dos picos pode ter ocorrido devido à diminuição na concentração de fenol e à diminuição na formação de quinonas, visto que se obteve uma grande redução no teor de fenol e não foi detectada a presença de benzoquinona. Esse resultado indica que o processo de eletrooxidação do fenol por FEO pode ter avançado mais no sentido da formação de ácidos orgânicos, produzindo uma maior eficiência na quebra do anel aromático. 


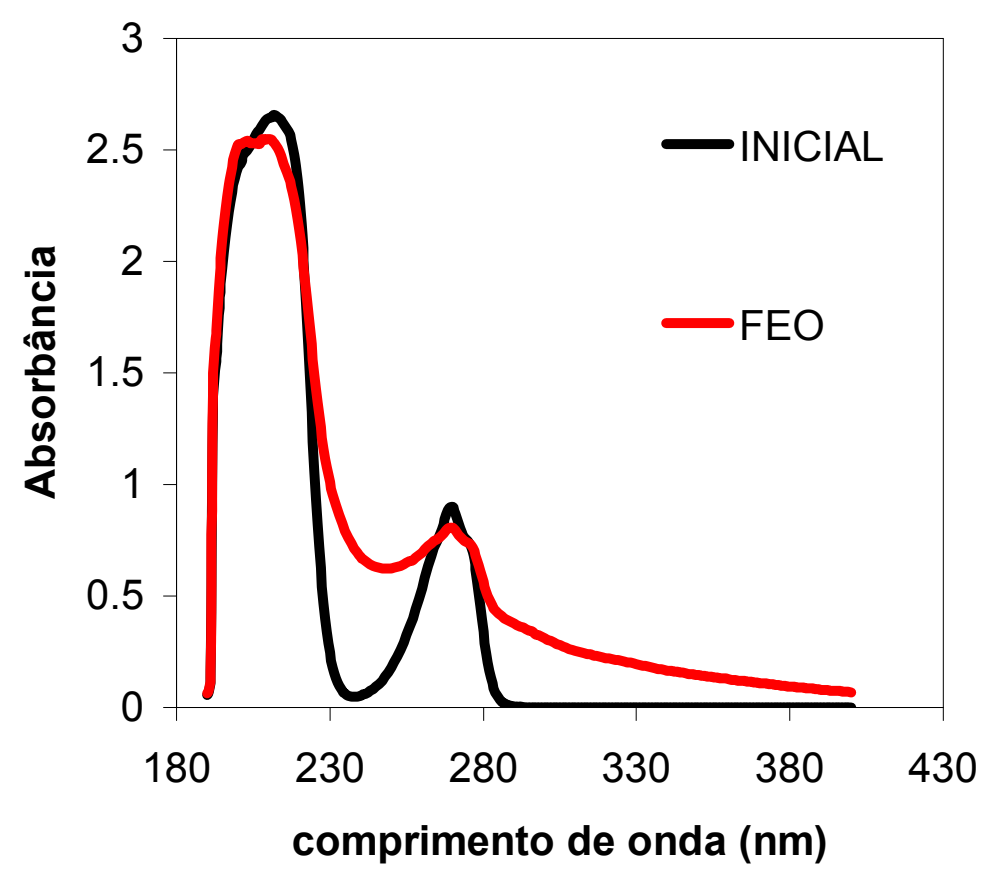

Figura 50: Avaliação do processo de FEO pela técnica de espectroscopia de UV/VIS.

Foram realizadas analises por cromatografia iônica, sendo o cromatograma obtido apresentado na Figura 51, e na Figura 52 é apresentada a comparação com a solução inicial.

Com as análises realizadas por $\mathrm{Cl}$ podemos verificar que o teor de ácidos orgânicos após o tratamento por FEO foi de aproximadamente $60 \mathrm{mg} \cdot \mathrm{L}^{-1}$, sendo que na amostra inicial não foi detectado a presença desses compostos e que após o processo de EL ficou em torno de $12 \mathrm{mg} \cdot \mathrm{L}^{-1}$. A detecção de ácidos orgânicos de cadeia curta, principalmente ácido cítrico, indica que a oxidação do fenol seguiu a rota de formação de hidroquinonas e seguiu com a formação de ácidos orgânicos em detrimento à rota de polimerização. 


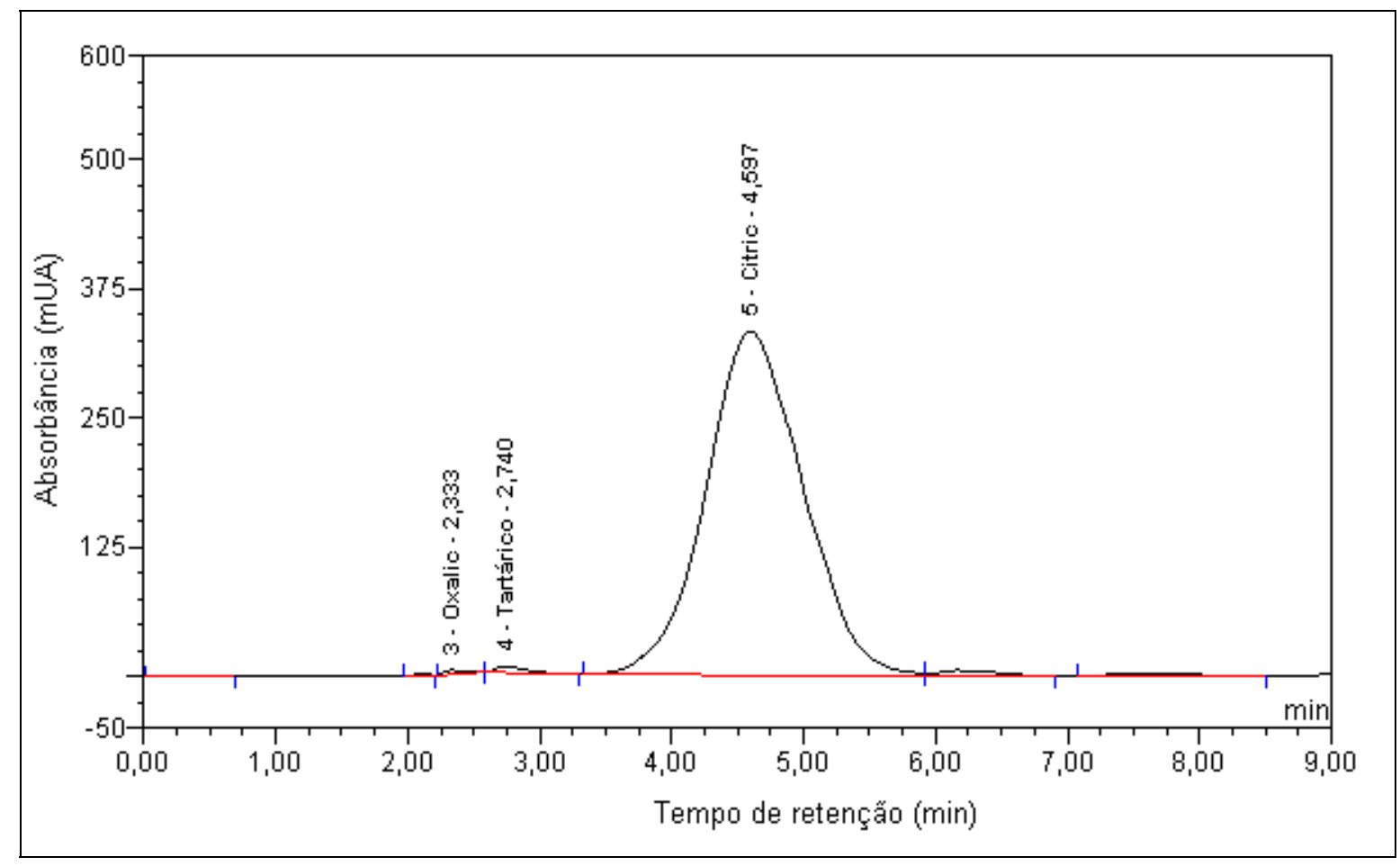

Figura 51: Análise por $\mathrm{Cl}$ da solução sintética $0,5 \mathrm{M} \mathrm{H}_{2} \mathrm{SO}_{4} / 6,25 \mathrm{mM}$ fenol após processo de FEO.

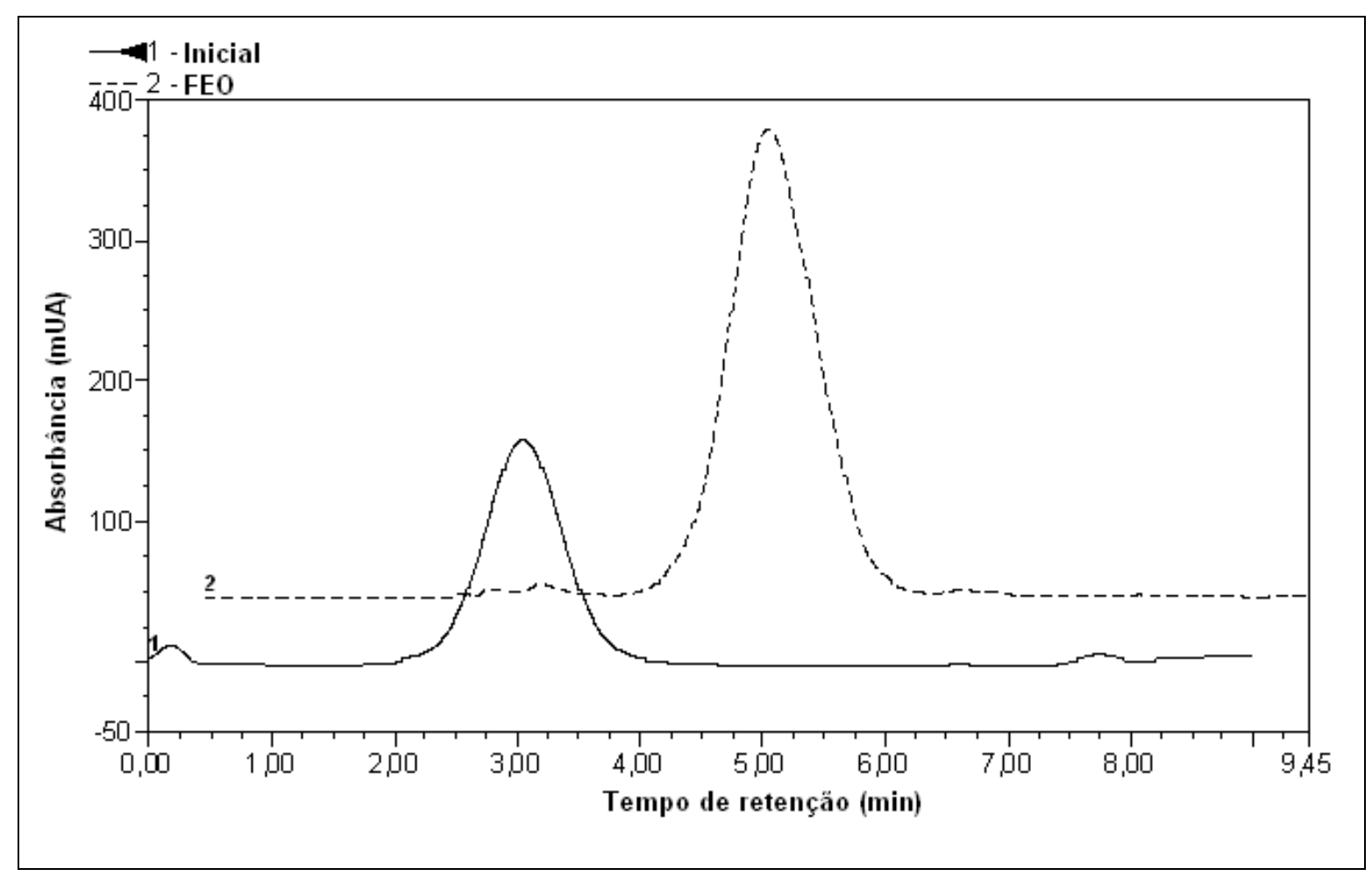

Figura 52: Comparação dos cromatrogramas da solução inicial e a tratada por FEO.

Na Figura 53 estão apresentados os voltamogramas da solução inicial e após o tratamento por FEO. Pode-se observar uma redução na intensidade do pico 
de oxidação, devido à redução no teor de fenol e a não detecção de benzoquinonas, as quais produziriam um aumento no pico. Esse comportamento revela que os produtos formados na degradação do fenol não são oxidados eletroquimicamente nessa faixa de potencial. Os ácidos orgânicos de cadeia curta, detectados por $\mathrm{Cl}$, apresentam esse comportamento, são compostos que podem ser oxidados por processos biológicos, mas não por processos eletroquímicos. Portanto, a grande redução no teor de fenol, a ausência de benzoquinonas e presença de ácidos orgânicos após o processo de FEO explica esse comportamento eletroquímico.

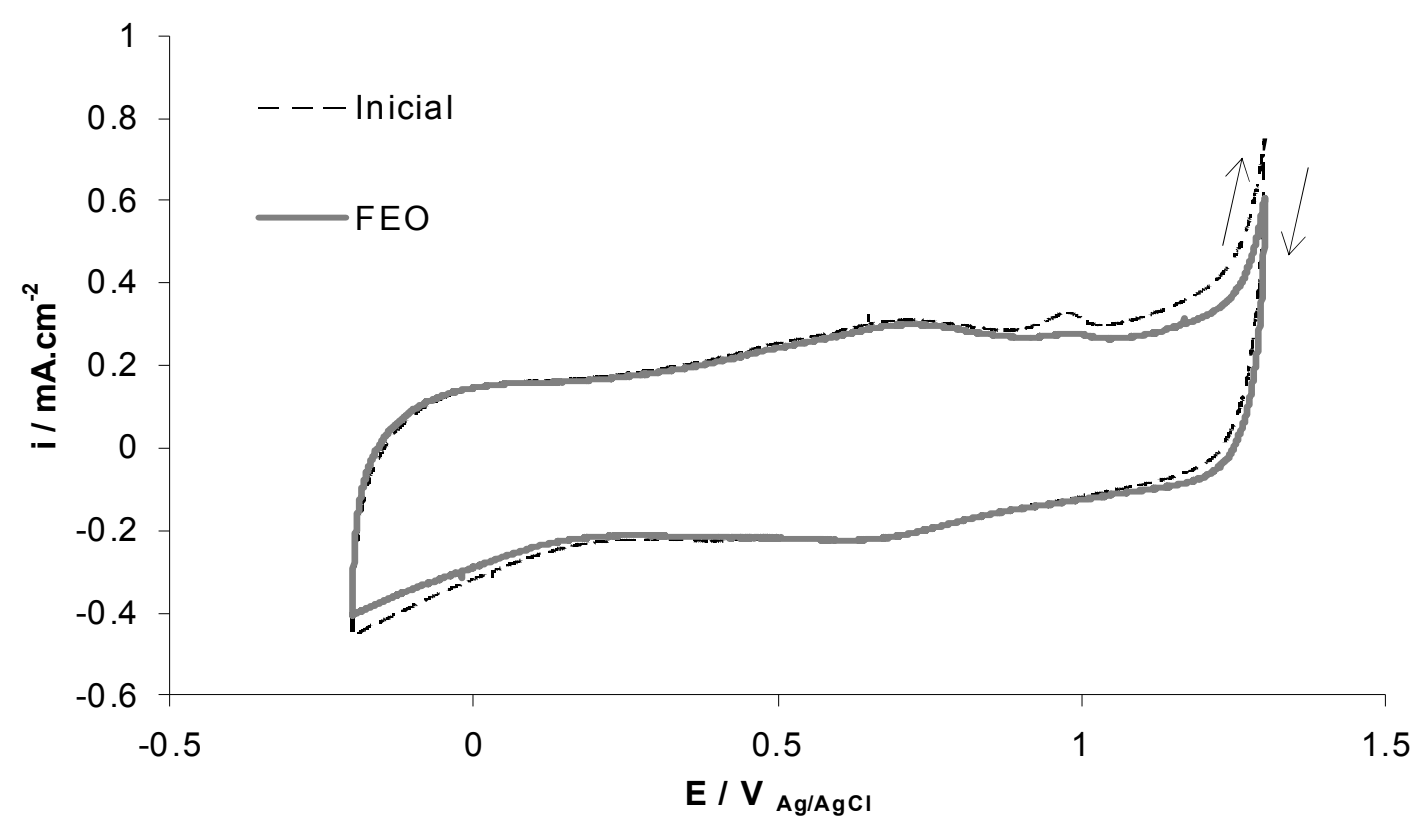

Figura 53: Comparação entre os voltamogramas obtidos para a solução de fenol inicial e tratada por $E L, v=60 \mathrm{mV} \cdot \mathrm{s}^{-1}$. $\left(\mathrm{ET}=\mathrm{Ti} / \mathrm{Ru}_{0}, 3 \mathrm{Ti}_{0,7} \mathrm{O}_{2}, \mathrm{CE}=\mathrm{Pt} \mathrm{e}\right.$ $\mathrm{ER}=\mathrm{Ag} / \mathrm{AgCl})$.

\subsubsection{Discussão dos resultados dos experimentos de FEO}

Face ao exposto nos resultados pode-se fazer algumas aferições, tais como: a reação de eletrooxidação do fenol ocorreu predominantemente por meio de conversão eletroquímica, de forma irreversível, gerando produtos intermediários de reação como ácidos orgânicos de cadeia curta, principalmente ácido cítrico. A redução no teor de matéria orgânica atingiu baixos percentuais, indicando que o 
processo de FEO não promoveu a mineralização total da matéria orgânica presente. Contudo se obteve uma maior concentração de ácidos orgânicos, substâncias menos prejudiciais ao meio ambiente que o fenol e as quinonas. O surgimento de coloração marrom amarelada na solução tratada pode ser resultado da geração de oligômeros, oriundos da polimerização parcial do fenol devido ao efeito da temperatura sobre a superfície do tubo de quartzo. O processo de FEO demonstrou ser capaz de degradar esse composto orgânico refratário, portanto, representa uma alternativa tecnológica para a degradação desses perigosos compostos. 


\subsection{COMPARAÇÃO DOS EXPERIMENTOS DE ELETRÓLISE E FOTOELETROOXIDAÇÃO}

Para melhor visualizar os resultados obtidos nos experimentos de EL e FEO, neste capítulo será feito um estudo comparativo dos dois processos. Serão comparados os experimentos 02 e 06.

Na Figura 54 pode-se verificar as reduções obtidas nos teores de fenol, DQO e COT, relativos à fração orgânica presente nas soluções. Observa-se uma maior redução para os experimentos de FEO em todos os parâmetros avaliados.



Figura 54: Comparação dos valores médios de redução nos teores de matéria orgânica entre os processos de EL e FEO.

Os espectrogramas obtidos por espectroscopia de UV/Visível são apresentados na Figura 55. Como já salientado nos capítulos anteriores, a mudança na intensidade e formato dos picos estão relacionadas com os produtos obtidos da eletrooxidação do fenol, como quinonas e ácidos orgânicos. O aumento da intensidade dos picos após o processo de EL é decorrente da presença de compostos como a benzoquinona, que absorve na mesma faixa do fenol, e sua redução após o processo de FEO e devido a redução no teor de fenol e a ausência de benzoquinonas. Já o alargamento do pico em torno de $270 \mathrm{~nm}$, para ambos os 
casos, está relacionado à formação de ácidos orgânicos oriundos da degradação do fenol.

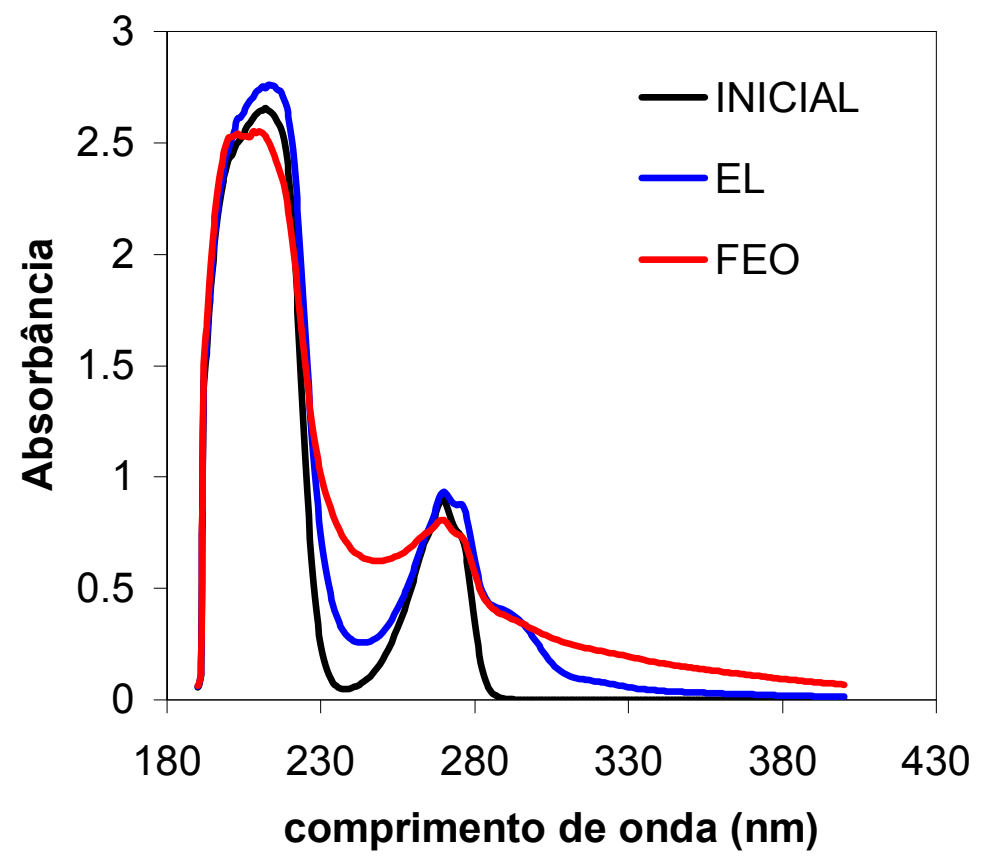

Figura 55: Avaliação dos processos de EL e FEO pela técnica de espectroscopia de UVIVIS.

$\mathrm{Na}$ 
Tabela 8 pode-se verificar que no processo de FEO se obteve maior quantidade desses ácidos, o que produziu um maior alargamento desse pico. Também é possível dizer que no processo de FEO a eletrooxidação do fenol evoluiu mais que no processo de $E L$, pois se obteve uma maior concentração de ácidos orgânicos e não se observou a presença de benzoquinona, composto formado em uma etapa anterior a produção dos ácidos orgânicos. Como a concentração inicial de fenol na solução era de $588 \mathrm{mg} \cdot \mathrm{L}^{-1}$ se verifica que parte foi convertida nesses ácidos orgânicos, sendo que outros ácidos orgânicos também podem ter se formado devido a oxidação das benzoquinonas, conduto não foram analisados. 
Tabela 8: Concentração de ácidos orgânicos obtidas por $\mathrm{Cl}$ para os experimentos 02 e 06 .

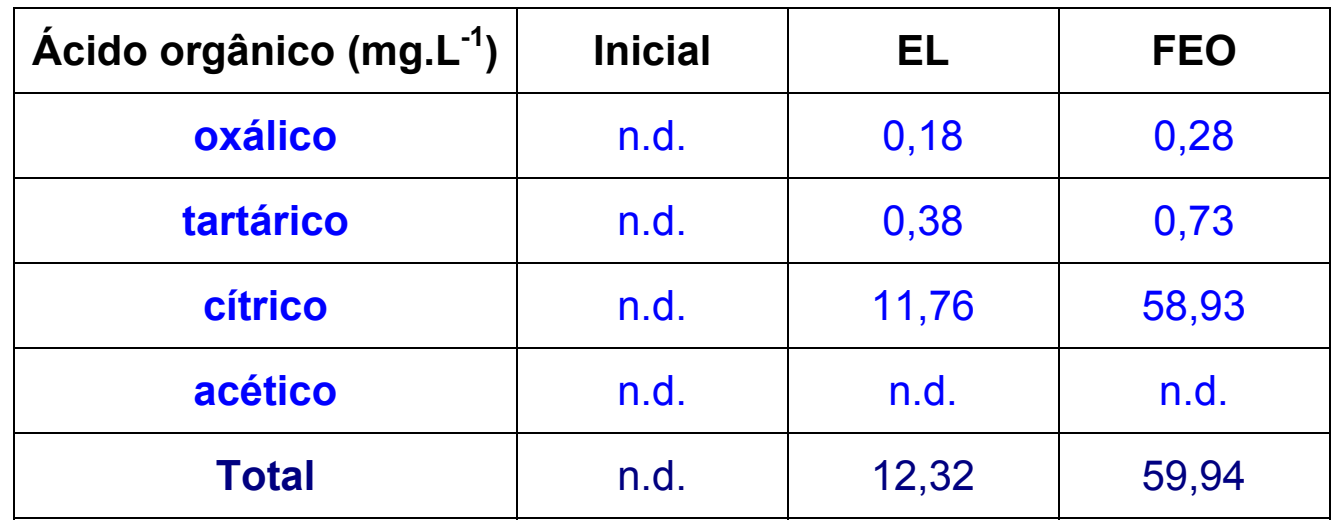

Observando os voltamogramas obtidos para ambos os experimentos verifica-se que a intensidade do pico de oxidação se desloca após os processos de tratamento, Figura 56. Após o processo de EL a corrente de pico aumenta e aparece um pico de redução entre 0,25 e 0,50 V vs $\mathrm{Ag} / \mathrm{AgCl}$. Esse comportamento está relacionado com a presença de produtos intermediários da oxidação do fenol, como a benzoquinona. Esse composto, por ser menos estável que o fenol, reage de forma reversível, gerando picos de oxidação e redução. Já no caso do processo de FEO ocorre uma redução na intensidade do pico de oxidação, provavelmente devido à formação dos ácidos orgânicos, que não são oxidáveis eletroquimicamente, a redução no teor de fenol e à ausência de compostos intermediários da oxidação do fenol, como as benzoquinonas. Neste caso não se observa formação de picos de redução, que ocorreriam devido à presença desses compostos. Essa diferença do comportamento eletroquímico das soluções, após passar pelos tratamentos de oxidação, evidencia o que já foi observado analisando-se os resultados obtidos pelas técnicas de espectroscopia de UV/Visível e $\mathrm{Cl}$, ou seja, que no processo de FEO se evoluiu mais na direção de oxidação completa do fenol presente nas soluções que no processo de EL. 


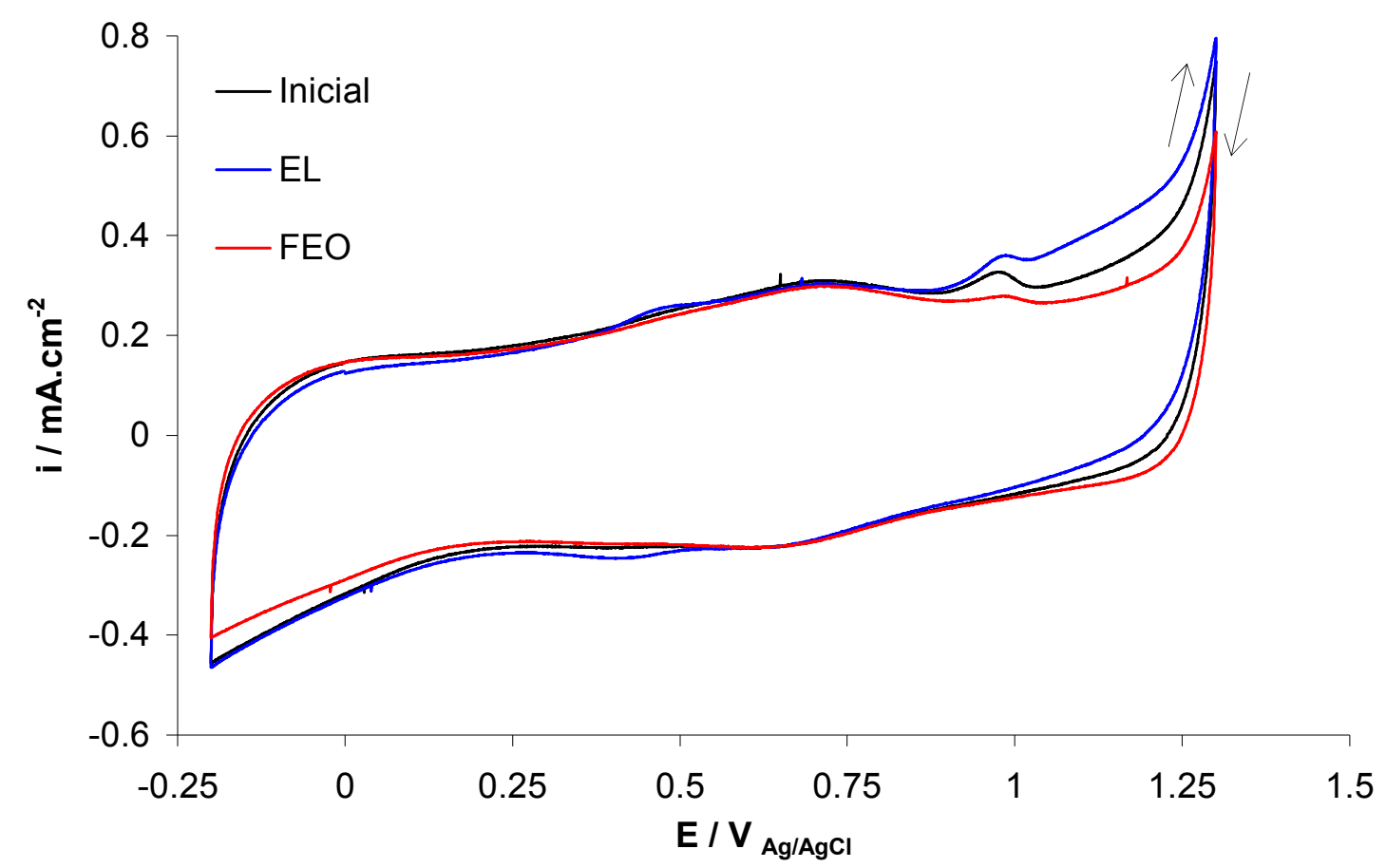

Figura 56: Comparação entre os voltamogramas obtidos para a solução de fenol inicial, tratada por EL e tratada por FEO, $v=60 \mathrm{mV} \cdot \mathrm{s}^{-1}$. (ET = $\mathrm{Ti} / \mathrm{Ru}_{0,3} \mathrm{Ti}_{0,7} \mathrm{O}_{2}, \mathrm{CE}=\mathrm{Pt}$ e ER $\left.=\mathrm{Ag} / \mathrm{AgCl}\right)$.

Na Figura 57 pode-se ver a diferença de coloração após os processos de EL e FEO. São apresentas as soluções, da esquerda para a direita, inicial de $0,5 \mathrm{M} \mathrm{H}_{2} \mathrm{SO}_{4} / 6,25 \mathrm{mM}$ fenol, que é incolor, no próximo tubo após o tratamento por EL e no outro tubo após o tratamento por FEO, o qual apresenta coloração mais escura. O surgimento de coloração na solução tratada pose estar relacionado com a geração de benzoquinonas e oligômeros, resultantes da oxidação ou polimerização do fenol. 


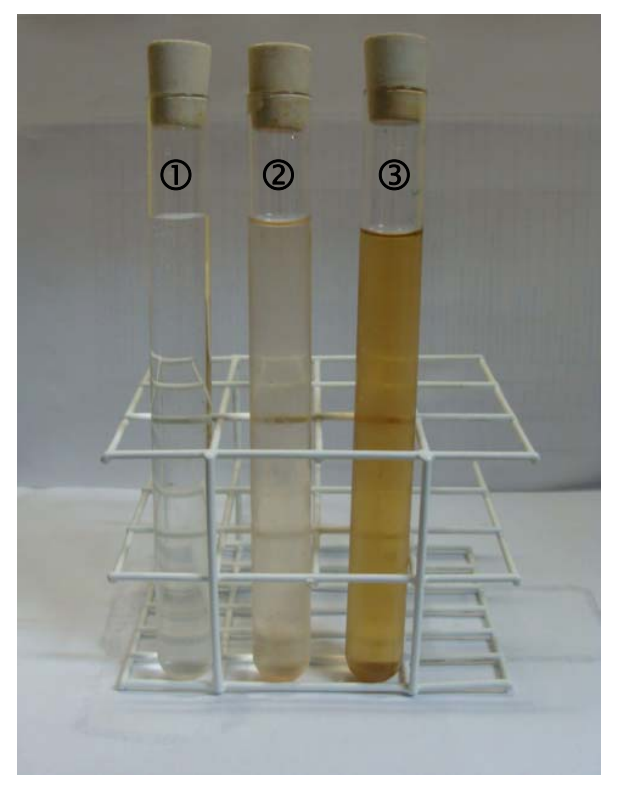

Figura 57: Amostras das soluções: 1) inicial, 2) após EL e 3) após FEO.

Analisando os resultados obtidos por $\mathrm{Cl}$ apresentados na Figura 58 podese verificar que o pico inicial desaparece após o tratamento e que surgem novos picos em outros tempos de retenção, alguns deles relativos à presença dos ácidos orgânicos analisados.

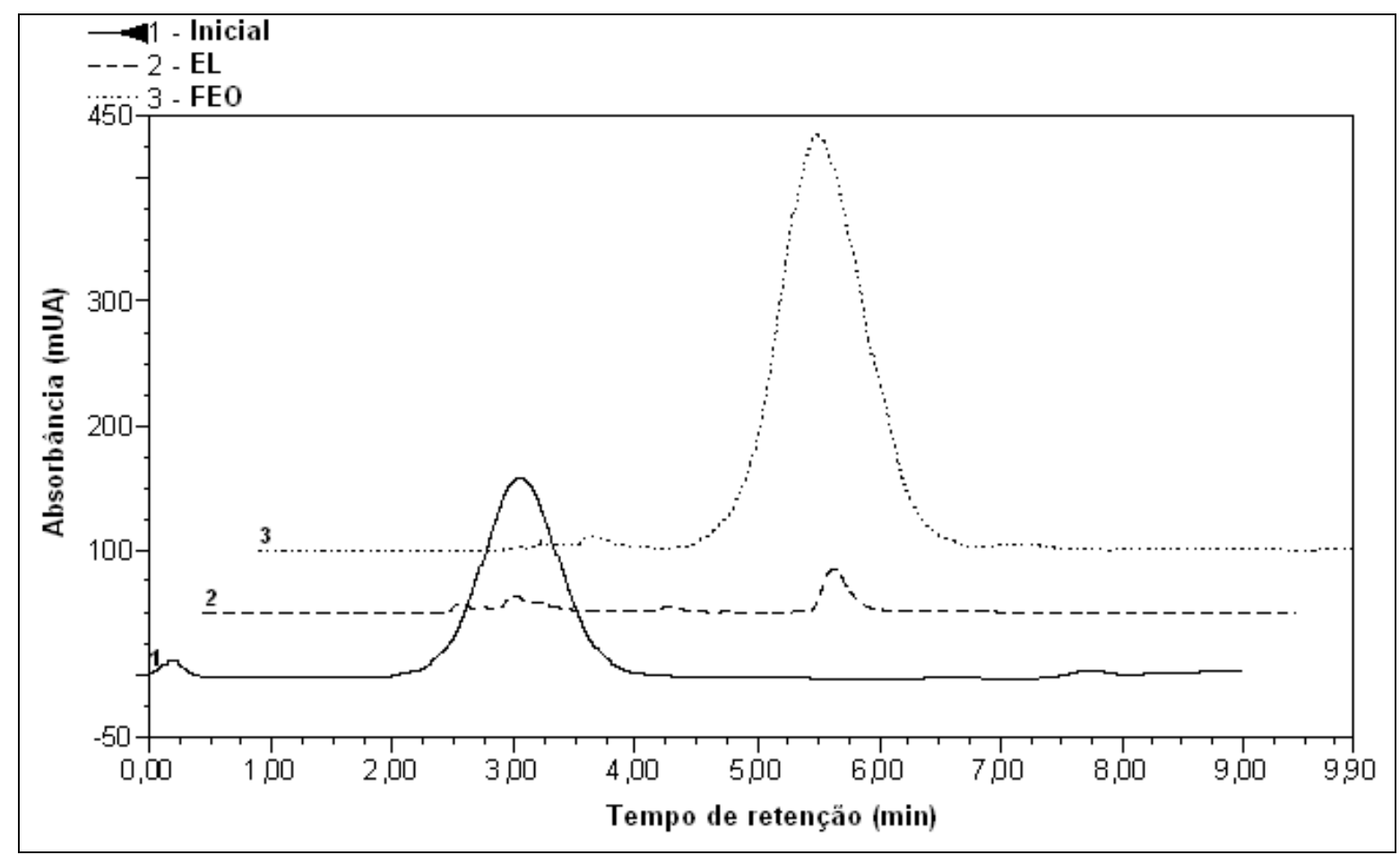

Figura 58: Comparação dos cromatrogramas da solução inicial e a tratada por EL e FEO. 


\subsubsection{Discussão da comparação dos experimentos de EL e FEO}

A aplicação de ambos os POA's testados resultou na redução significativa da concentração de fenol, além de uma diminuição no teor de matéria orgânica presente na solução inicial. Durante o processo de EL foi detectada a presença de benzoquinona e ácidos orgânicos, que são produtos intermediários da eletrooxidação do fenol. Contudo o processo de FEO gerou uma maior quantidade de ácidos orgânicos e não foi detectada a presença de benzoquinona, indicando uma oxidação mais eficaz do fenol por esse processo.

O surgimento de coloração após os processos oxidativos está relacionado com a presença de benzoquinonas no caso da EL e com a formação de oligômeros durante o processo de FEO.

Para ambos os casos não foi possível se atingir a mineralização completa da matéria orgânica. Contudo parte dela se mineralizou e outra parte foi decomposta a moléculas menores e menos nocivas ao meio ambiente, como os ácidos orgânicos de cadeia curta.

Analisando os dados do anexo III pode-se observar um maior consumo de energia no processo de FEO, já que se agrega o consumo energético da fonte de radiação UV. Contudo, os resultados obtidos nos experimentos FEO demonstram um maior teor de ácidos orgânicos, a ausência de benzoquinonas e uma maior mineralização, salientando ainda que as benzoquinonas são compostos perigosos, enquanto os ácidos orgânicos não são tóxicos e são biodegradáveis. 



\section{CONCLUSÕES}

Face ao exposto nos resultados apresentados nesse trabalho é possível estabelecer algumas conclusões.

As reações de eletrooxidação do fenol sobre eletrodo de platina são irreversíveis, pois apresentam deslocamento do Ep para valores mais positivos com o aumento da velocidade de varredura. Essas reações apresentam controle difusional, uma vez que se verificou uma relação linear da Ip com a raiz quadrada da velocidade de varredura. Foi observado dois comportamentos distintos: Ip aumenta com a concentração de fenol e atinge um valor máximo para concentrações de fenol inferiores a $6,25 \mathrm{mM}$, depois permanece praticamente constante para concentrações de fenol superiores a $6,25 \mathrm{mM}$. Na faixa de $\mathrm{pH}$ investigada neste trabalho, a concentração de ácido sulfúrico tem pouco efeito sobre Ip, especialmente para valores de $\mathrm{pH}$ variando entre 0,2 e 0,4, correspondendo às concentrações de ácido sulfúrico 1 e 0,5 M, respectivamente. Ocorre uma mudança significativa no Ep para valores mais positivos na concentração de ácido sulfúrico $1 \mathrm{M}(\mathrm{pH}=0,2)$. Este deslocamento para valores mais positivos de potencial observada em $\mathrm{pH} 0,2$ pode ser devido a uma menor influência dos fenômenos de polimerização e adsorção na superfície do eletrodo, em soluções fortemente ácidas.

Para todos os materiais testados como eletrodo de trabalho se observou a presença de um pico de oxidação em uma faixa de potencial próxima a de liberação de oxigênio.

Dentre os materiais testados como eletrodo de trabalho nessa investigação, o eletrodo de $\mathrm{Ti} / \mathrm{Ru}_{0,3} \mathrm{Ti}_{0,7} \mathrm{O}_{2}$, do tipo $\mathrm{DSA}^{\circledR}$, foi o único a não apresentar bloqueio da superfície, o que viabilizou seu estudo na degradação de compostos orgânicos refratários. Mesmo trabalhando em condições experimentais desfavoráveis à polimerização do fenol, os eletrodos de platina, carbono vítreo e titânio apresentaram bloqueio da superfície após poucos ciclos nos experimentos de voltametria cíclica de varredura. 
A agitação mecânica mostrou-se um importante parâmetro no processo oxidativo de eletrólise.

A reação de eletrooxidação do fenol pelo processo de eletrólise ocorreu predominantemente por meio de conversão eletroquímica, de forma irreversível, gerando produtos intermediários de reação, como benzoquinona e ácidos orgânicos.

O surgimento de coloração na solução tratada por eletrólise pode ser resultado da geração de benzoquinonas durante o tratamento.

O processo de eletrólise demonstrou ser capaz de degradar o fenol, portanto, representa uma alternativa tecnológica para a degradação de compostos orgânicos refratários.

As reações de fotoeletrooxidação do fenol ocorreram predominantemente por meio de conversão eletroquímica, de forma irreversível, gerando produtos intermediários de reação, como ácidos orgânicos, obtendo-se uma maior geração de ácidos orgânicos do que no processo de eletrólise.

O processo de fotoeletrooxidação demonstrou ser capaz de degradar esse composto orgânico refratário, portanto, também representa uma alternativa tecnológica para a degradação desses perigosos compostos.

Obteve-se alta redução no teor de fenol, tanto com o processo de eletrólise como com o de fotoeletrooxidação.

Da comparação entre os dois POA's investigados pode-se concluir que as reações de eletrooxidação do fenol por meio de fotoeletrooxidação foram mais eficazes, considerando que nesse processo oxidativo foi gerada maior quantidade de ácidos orgânicos, houve maior redução do teor de matéria orgânica e não se detectou a presença de benzoquinona. 


\section{SUGESTÕES PARA TRABALHOS FUTUROS}

Utilizar efluentes reais na investigação, avaliando o uso de processos oxidativos como alternativa tecnológica no tratamento desses efluentes, tanto na fase inicial de tratamento, como no pós-tratamento.

Investigar o uso de outros eletrodos do tipo DSA.

Efetuar estudos de eletrooxidação de fenol em diferentes tempos de tratamento.

Investigar mais detalhadamente a eficiência energética do processo de tratamento.

Testar fontes de radiação UV de diferentes potências e materiais.

Avaliar a presença de outros ácidos orgânicos possivelmente formados na eletrooxidação do fenol.

Estudos de toxicidade.

Avaliar a superfície dos eletrodos para verificar a polimerização.+ 



\section{PUBLICAÇÕES ORIGINADAS DA TESE}

\section{Artigos completos publicados em periódico}

1. An electrochemical Study of Phenol Oxidation in Acidic Medium. J. L. N. Xavier, E. Ortega, J. Z. Ferreira, A. M. Bernardes and V. Pérez-Herranz, International Journal of Electrochemical Science, 6 (2011) 622 - 636.

\section{Trabalhos publicados em anais de congressos}

1. Electrochemical oxidation of phenol in acid medium, XAVIER, J. L. N., HERRANZ, Valentin Perez, BERNARDES, A. M., J. Z. Ferreira, Congreso Mediterráneo de Ingeniería Química, 2008, Barcelona, Espanha.

2. Advanced oxidation processes (AOP's) applied in treatment of organic refractory pollutants. XAVIER, J. L. N., ORTEGA, E., HERRANZ, Valentin Perez, BERNARDES, A. M., J. Z. Ferreira $61^{\circ}$ Annual Meeting of the International Society of Electrochemistry, 2010, Nice, França.

3. Study of electrooxidation of phenol in different electrodes, XAVIER, J L N, NAVARRO, Emma Ortega, HERRANZ, Valentin Perez, BERNARDES, A. M., FERREIRA, Jane Zoppas In: 7th Spring eeting of the international society of electrochemistry - ISE, 2009, Sczzyrk, Polônia.

4. Use of advanced oxidative processes for degradation of organic refractary pollutants, Kátia F. Streit, José L. N. Xavier, Marco A. S. Rodrigues; Andréa M. Bernardes; Jane Zoppas Ferreira. Ozone and UV: Leading-edge science and technologies, Paris, 2011.

5. Treatment of phenol by electrochemical oxidation processes, J. L. N. Xavier, E. Ortega, J. Z. Ferreira, A. M. Bernardes, and V. Pérez-Herranz, $8^{\text {th }}$ European Congress of Chemical Engineering, DECHEMA, Sessão: Assessment of processes sustainability, Berlin, 2011. 

Int. J. Electrochem. Sci., 6 (2011) 622 - 636

International Journal of

ELECTROCHEMICAL

SCIENCE

www.electrochemsci.org

\title{
An electrochemical Study of Phenol Oxidation in Acidic Medium
}

\author{
J. L. N. Xavier ${ }^{1,2}$, E. Ortega ${ }^{2}$, J. Z. Ferreira ${ }^{1}$, A. M. Bernardes ${ }^{1}$ and V. Pérez-Herranz, ${ }^{2, *}$ \\ ${ }^{1}$ Universidade Federal do Rio Grande do Sul - Dept. de Materiais LACOR - Laboratório de Corrosão, \\ Proteção e Reciclagem de Materiais Av. Bento Gonçalves, 9500, 91501-970 - Porto Alegre - RS - \\ Brazil \\ ${ }^{2}$ IEC Group, Dept. Ingeniería Química y Nuclear, Universidad Politécnica de Valencia, Camino de \\ Vera, s/n, 46022 - Valencia, Spain \\ *E-mail: vperez@iqn.upv.es
}

Received: 19 January 2011 / Accepted: 9 February 2011 / Published: 1 March 2011

This work addresses the electrooxidation of phenol on platinum electrodes applying cyclic voltametry. The effect of different parameters on the electrooxidation of phenol, such as the scan rate, the inversion potential, the phenol concentration, the sulphuric acid concentration, and the stirring of the solution, were investigated using a conventional three-electrode cell. The results show the presence of an oxidation peak in the region around $1 \mathrm{~V} v s \mathrm{Ag} / \mathrm{AgCl}$ to all conditions evaluated. In cyclic voltametric experiments a gradual decrease of the oxidation peak with the number of cycles was observed, and after about four cycles there was no more evidence of a peak. This behavior was repeated for all phenol and sulphuric acid concentrations studied. This suggests the deactivation or blockage of the electrode surface by the adsorption of substances and/or phenoxy radical polymerization.

Keywords: Electrochemical oxidation, phenol, cyclic voltammetry, wastewater treatment

\section{INTRODUCTION}

Phenols are a large group of pollutants in industrial effluents and, due to their low degradability by conventional effluent treatment, even at low concentrations they present toxicity and bioaccumulation problems [1]. Phenolic compounds are present in effluents from coke production, food industries, chemical industries, such as those associated to the production of resins and pesticides, and petroleum refineries [2]. Many different technologies are in use or have been proposed for the recovery or destruction of phenols $[3,4]$. Among these technologies, there are processes dealing with 
collapse of microbubbles [5], anodic polymerization [6-8], oxidation by photocatalysis or by hydrogen peroxide [9-12], as well as electrooxidation with various electrode materials [13-16].

The electrochemical oxidation of organic substances is a promising technique for the treatment of industrial effluents and the electrooxidation of phenol has been evaluated by different authors [1721]. Comminellis and Pulgarim [17] studied the anodic oxidation of phenol on platinum and concluded that the most important parameters for this study are the phenol concentration and $\mathrm{pH}$. They have not reported any blocking effect on the electrode surface. Arslan et al. [18] studied, besides the effect of temperature and $\mathrm{pH}$, the influence of the phenol concentration in the process of phenol electrooxidation on platinum. They found a dependence of the peak potential on concentration and on temperature, and this dependence was more pronounced for the highest values of concentration and temperature studied. The authors reported the blocking of the electrode surface for high concentrations of phenol in alkaline medium and a phenol polymerization on the electrode surface explained this process. Kennedy et al. [19] investigated the oxidation and polymerization of amino-phenolic compounds in neutral solutions and they proposed a mechanism of substitution reaction, followed by oxidation and polymerization. Pacheco et al. [20] evaluated the degradation of phenol, catechol and cresol on boron doped diamond electrodes and concluded that the degradation process increases with increasing current densities. The effect of the solute concentration was also investigated; the results have shown that under conditions of diffusive control the degradation is independent of the concentration. Li et al. [21] investigated the electrochemical degradation of phenol on platinum electrodes in comparison with oxide electrodes, obtaining similar results for platinum and $\mathrm{Ti} / \mathrm{RuO}_{2}$ electrodes.

Although different works are associated to the electrooxidation of phenols, the study of this process is still a matter of research, since this technique is able to achieve good destruction rates. The electrooxidation of phenol occurs through the formation of the phenoxy radical, which either reacts with other species present in the solution generating products, or react with other phenol molecules producing a dimer radical. This radical can be oxidized following two different paths: the formation of polymers or quinones, depending on the conditions used. For high phenol concentrations and basic medium, polymerization is favored, while for low phenol concentrations and acid medium the formation of quinones is privileged [22]. From the oxidation reaction of quinone, carboxylic acids (maleic and oxalic) are obtained. These products are difficult to oxidize, but are biodegradable compounds, and therefore the electrooxidation process can be associated to a biological process [23, 24].

The electrooxidation of organic compounds on platinum electrodes can take place through the formation of an oxide film of the anode material on the electrode surface. The adsorption of the hydroxyl radical on the anode surface occurs as the first step according to the reaction:

$$
\mathrm{PtO}_{x}+\mathrm{H}_{2} \mathrm{O} \rightarrow \mathrm{PtO}_{x}(\cdot \mathrm{OH})+\mathrm{H}^{+}+\mathrm{e}^{-}
$$

In a second step, the hydroxyl radical can react with the oxygen present on the anodic oxide, producing a super oxide, as follows: 


$$
\mathrm{PtO}_{x}(\cdot \mathrm{OH}) \rightarrow \mathrm{PtO}_{x+1}+\mathrm{H}^{+}+\mathrm{e}^{-}
$$

Therefore, the coexistence of two states of active oxygen on the electrode surface can be considered, a chemically adsorbed state, and a hydroxyl radical physically adsorbed. In the lack of organic material, both active oxygen stages produce $\mathrm{O}_{2}$ according to reactions (3) and (4).

$$
\begin{gathered}
\mathrm{PtO}_{x}(\cdot \mathrm{OH}) \rightarrow \frac{1 / 2}{} \mathrm{O}_{2}+\mathrm{PtO}_{x}+\mathrm{H}^{+}+\mathrm{e}^{-} \\
\mathrm{PtO}_{x+1} \rightarrow 1 / 2 \mathrm{O}_{2}+\mathrm{PtO}_{x}
\end{gathered}
$$

In the presence of organic radicals $(\mathrm{R})$ it is possible to produce the complete mineralization, by the action of the hydroxyl radical, or selective oxidation products $\left(R_{\mathrm{o} x}\right)$ can be obtained, by the interaction with the active oxygen chemically adsorbed, as shown in reactions (5) and (6).

$$
\begin{gathered}
R+\mathrm{PtO}_{x}(\cdot \mathrm{OH}) z \rightarrow \mathrm{PtO}_{x}+z \mathrm{H}^{+}+z \mathrm{e}^{-}+\mathrm{CO}_{2} \\
R+P t O_{x+1} \rightarrow \mathrm{PtO}+R_{\mathrm{O} x}
\end{gathered}
$$

This work addresses the electrooxidation of phenol on platinum electrodes applying cyclic voltametry, in conditions that should not favored the polymerization in a way that the oxidation reaction occurs mainly according to reaction (5). Arslan et al. [18] observed that at low phenol concentrations and low $\mathrm{pH}$ values, the oxidation of phenol according to the route shown in reaction (5) has a higher probability. Nevertheless it was not possible in their studies to obtain a satisfactory result due to the blockage of the platinum electrode surface.

\section{EXPERIMENTAL}

Table 1 presents the solutions used at this work. All solutions were prepared using analytical grade reagents. Solutions containing phenol (Panreac) in five different concentrations of 0.5, 1, 6.25, 12.5 and $25 \mathrm{mM}$ and sulphuric acid (J. T. Baker) in four different concentrations of 0.01, 0.05, 0.5 and $1 \mathrm{M}$ were used. All solutions were prepared with distilled water. Acidic $\mathrm{pH}$ values were selected in order to prevent the undesirable phenomenon of phenol polymerization. The effect of different parameters on the electrooxidation of phenol, such as the scan rate, the phenol concentration, the sulphuric acid concentration, and the stirring of the solution, was investigated by cyclic voltametry using a conventional three-electrode cell.

The working electrode (WE) was a platinum rotating disc electrode (RDE), enclosed in Teflon, with a surface area of $0.058 \mathrm{~cm}^{2}$. $\mathrm{An} \mathrm{Ag} / \mathrm{AgCl}$ saturated $\mathrm{KCl}$ electrode was used as the reference electrode (RE) and a platinum electrode was used as the counter electrode (CE). All potentials reported here are expressed with respect to the $\mathrm{Ag} / \mathrm{AgCl}$ electrode. Before each electrochemical experiment, the 
solution was deoxygenated for 10 minutes with ultrapure nitrogen. This inert atmosphere was maintained during the whole measurement. The electrochemical experiments were controlled using a Potentiostat/Galvanostat PGSTAT20. The scan rate was varied from 10 to $200 \mathrm{mVs}^{-1}$. The initial potential was the open circuit potential, and the polarization was first in the positive direction.

Table 1. Working solutions, $\mathrm{pH}$ and conductivity.

\begin{tabular}{|c|c|c|c|}
\hline $\begin{array}{c}\mathrm{H}_{2} \mathrm{SO}_{4} \text { Concentration } \\
(\mathrm{M})\end{array}$ & $\begin{array}{c}\text { Phenol } \\
\text { Concentration }(\mathrm{mM})\end{array}$ & $\begin{array}{l}\text { Conductivity } \\
(\mathrm{mS})\end{array}$ & $\mathrm{pH}$ \\
\hline \multirow[t]{5}{*}{0.01} & 25.0 & 4.25 & 1.92 \\
\hline & 12.5 & 4.25 & 1.92 \\
\hline & 6.25 & 4.37 & 1.91 \\
\hline & 1.0 & 4.50 & 1.89 \\
\hline & 0.5 & 4.31 & 1.92 \\
\hline \multirow[t]{5}{*}{0.05} & 25.0 & 14.65 & 1.10 \\
\hline & 12.5 & 13.73 & 1.14 \\
\hline & 6.25 & 13.68 & 1.15 \\
\hline & 1.0 & 13.21 & 1.18 \\
\hline & 0.5 & 12.10 & 1.23 \\
\hline \multirow[t]{5}{*}{0.5} & 25.0 & 14.75 & 0.45 \\
\hline & 12.5 & 14.57 & 0.44 \\
\hline & 6.25 & 14.94 & 0.42 \\
\hline & 1.0 & 15.14 & 0.42 \\
\hline & 0.5 & 14.60 & 0.47 \\
\hline \multirow[t]{5}{*}{1.0} & 25.0 & 16.34 & 0.21 \\
\hline & 12.5 & 16.54 & 0.20 \\
\hline & 6.25 & 16.86 & 0.20 \\
\hline & 1.0 & 17.12 & 0.19 \\
\hline & 0.5 & 17.71 & 0.19 \\
\hline
\end{tabular}

All experiments were carried out at room temperature with a solution volume of $25 \mathrm{~mL}$. Prior to each experiment, the Pt surface was mechanically polished with emery paper down to 4000 grit, and then with alumina, being the electrode finally washed with distilled water.

At last, in order to verify the possible blocking of the electrode surface due to phenol polymerization, a series of six cycles without cleaning the electrode were carried out.

\section{RESULTS AND DISCUSSION}

Figure 1 shows the cyclic voltammograms of phenol at different concentrations $(0,0.5,1,6.25$, 12.5 and $25 \mathrm{mM}$ ) in the presence of sulphuric acid $0.05 \mathrm{M}$ recorded at a scan rate of $60 \mathrm{mV} \cdot \mathrm{s}^{-1}$. The 
comparison of the cyclic voltammograms of the electrode obtained in presence and absence of phenol shows that oxidation of phenol takes place at an electrode potential of about $1 \mathrm{~V}$. This peak is not proportional to concentration and is shifted to less positive potentials as the concentration increases. The presence of only an anodic oxidation peak, without cathodic counter part, suggests that the electrochemical process of phenol is totally irreversible. The cyclic voltammograms of all investigated solutions containing phenol have the same shape.

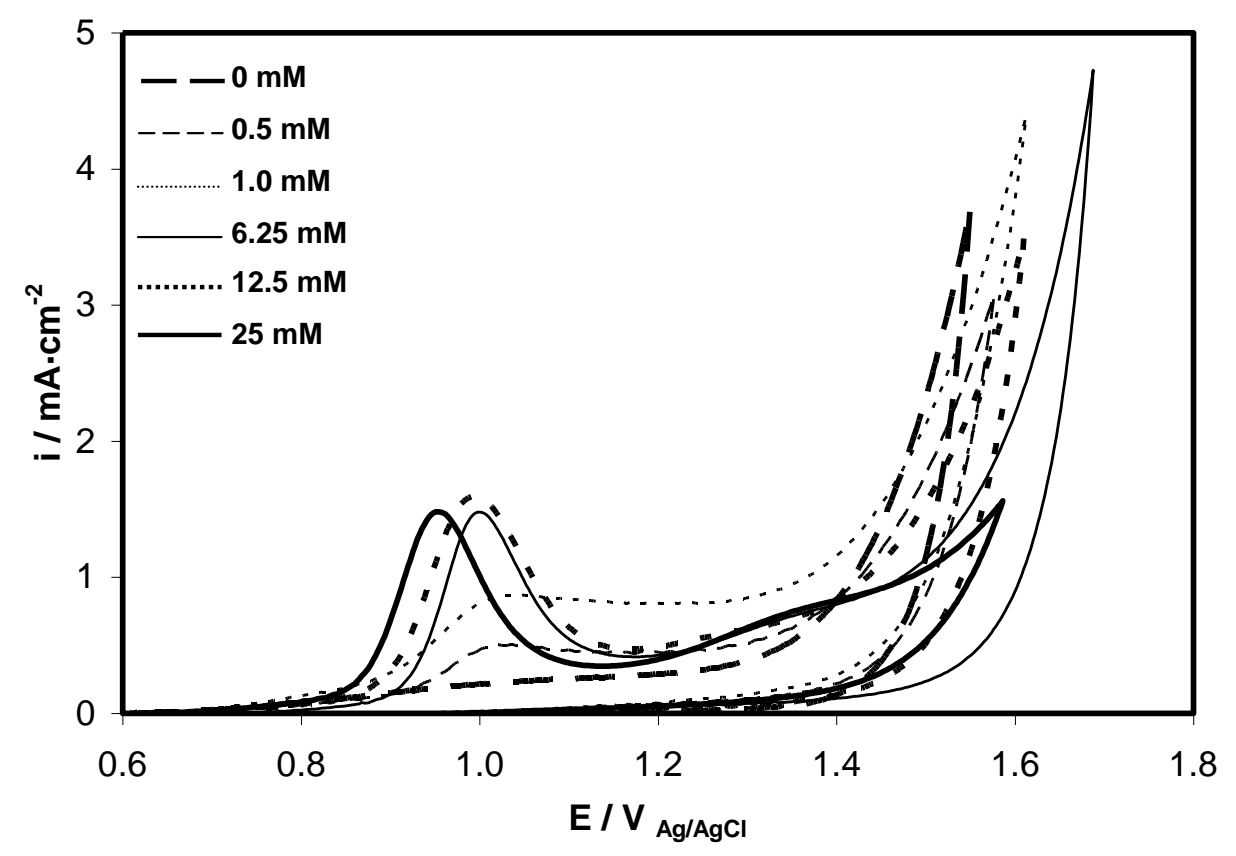

Figure 1. Cyclic voltammogram of $\mathrm{Pt}$ in $0.05 \mathrm{M} \mathrm{H}_{2} \mathrm{SO}_{4}$ solution with different phenol concentrations. Scan Rate $=60 \mathrm{mV} \cdot \mathrm{s}^{-1}$. (WE $\left.=\mathrm{Pt}, \mathrm{CE}=\mathrm{Pt}, \mathrm{RE}=\mathrm{Ag} / \mathrm{AgCl}\right)$.

The oxidation peak current density versus phenol concentration is plotted in Figure 2 for different concentrations of sulphuric acid. This figure shows that the peak current density increases with phenol concentration, reaches a maximum value and then decreases for phenol concentrations higher than $12.5 \mathrm{mM}$. This behavior may be due to a decreased activity of the electrode at high phenol concentrations, probably due to competition for active sites on the electrode surface or to the formation of a larger amount of phenoxy radicals. These radicals are involved in electropolymerization processes, causing faster deactivation of the electrode with the increase in phenol concentration. Wang and Lee [25] have observed that the fouling of the electrode by the phenolic oxidation products is more prominent at higher concentrations. Similar results have been found by other authors studying the oxidation of phenolic compounds both in acidic and in alkaline media [18, 26-28]. In this way, for phenol concentrations below $10 \mathrm{mM}$, the peak current density increases linearly with the concentration of phenol, while for higher phenol concentrations, the peak current density remain constant or decrease with the concentration of phenol. On the other hand, as can be seen in Figure 2, for a given phenol concentration, the peak current density increases with the increase of sulphuric acid concentration since the polymerization of phenol is less favored at low $\mathrm{pH}[17,19]$. 


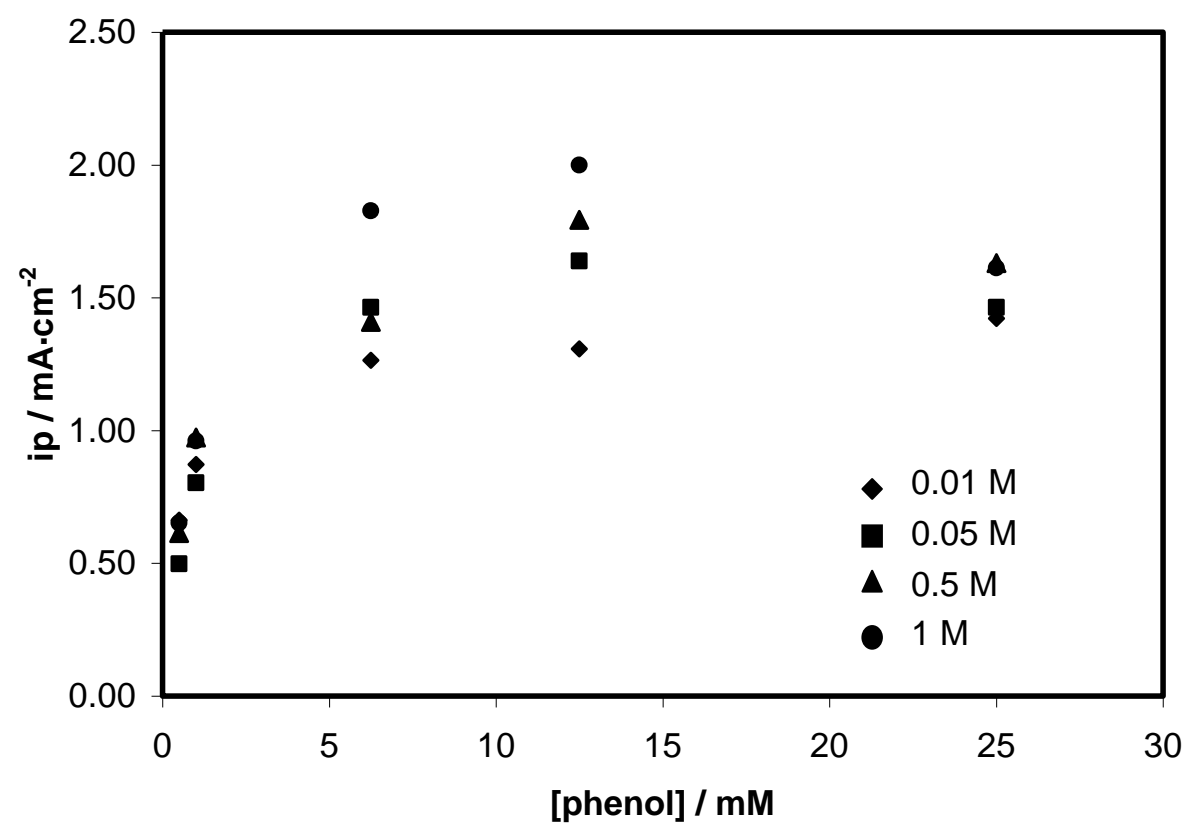

Figure 2. Peak current density as a function of phenol concentration for different concentrations of sulphuric acid.

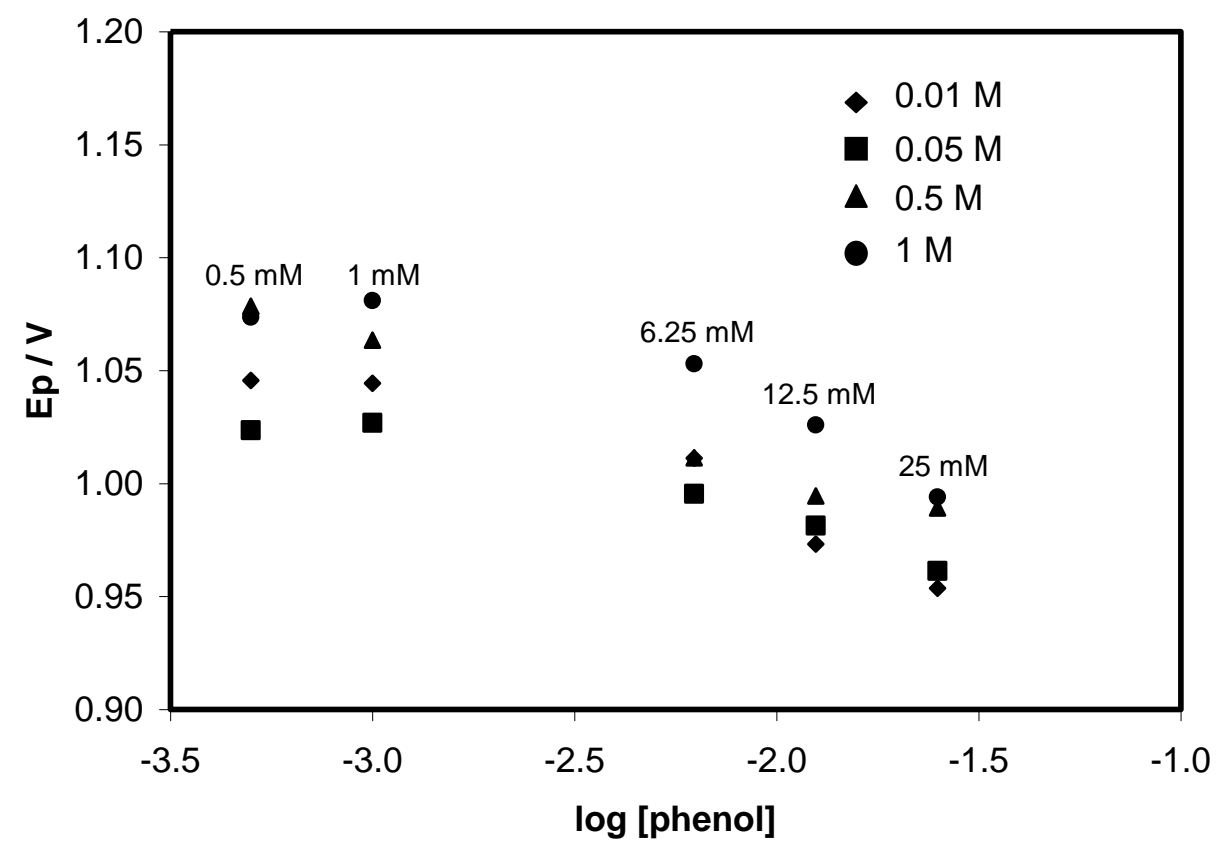

Figure 3. Peak potential as a function of phenol concentration for different concentrations of sulphuric acid.

Peak potentials are also related to phenol concentration. Figure 3 shows the variation of the peak potential with respect to the logarithm of phenol concentration for different concentrations of sulphuric acid. For phenol concentrations lower than $1 \mathrm{mM}$, the peak potential is found to be practically unchanged with the phenol concentration. However, for phenol concentrations higher than 
$1 \mathrm{mM}$ the peak potential shifts to less anodic values, from 1 to $0.9 \mathrm{~V}$, with increasing phenol concentration. Singh et al. [28] found that for phenol concentrations lower than $5 \mathrm{mM}$ the peak potential was practically unchanged with the phenol concentration, while Arslan et al. [18] found that when the phenol concentration was increased to $0.1 \mathrm{M}$, the peak potential shifted to negative values both in acidic and in alkaline media. This behaviour could be explained by a more availability of phenoxy radical associated to a higher phenol concentration, which favors the oxidation reactions that occur at less anodic potentials [18].

Noble electrodes usually exhibit short-lived activity for phenol oxidation as a consequence of surface fouling by adherent films, generated by polymerization of the phenoxy radicals produced in the oxidation. Then, in order to examine the electrode stability, repetitive cyclic voltammograms in a solution containing $0.5 \mathrm{mM}$ of phenol in $0.5 \mathrm{M} \mathrm{H}_{2} \mathrm{SO}_{4}$ at a scan rate of $60 \mathrm{mV} \cdot \mathrm{s}^{-1}$ were performed. The current involved in the oxidation of phenol drops gradually with increasing the number of cycles until almost zero after about four cycles as can be seen in Figure 4. However, the peak potential $\left(E_{p}\right)$ value corresponding to the oxidation peak does not change with the number of cycles. This inhibition process might be attributed to the electrode fouling produced by the formation of a nonconductive polymeric product coming from phenol oxidation that blocks the electrode surface. Phenoxy radicals produce a polymer layer that inhibits the direct oxidation of phenol at the anode surface. Similar deactivation of different electrodes in the presence of aromatic organic substrates such as phenol, chlorophenols and safrole has already been reported in the literature [28-35]. So, in subsequent studies, the oxidation peak current density of the first anodic cycle was considered for analysis of results.

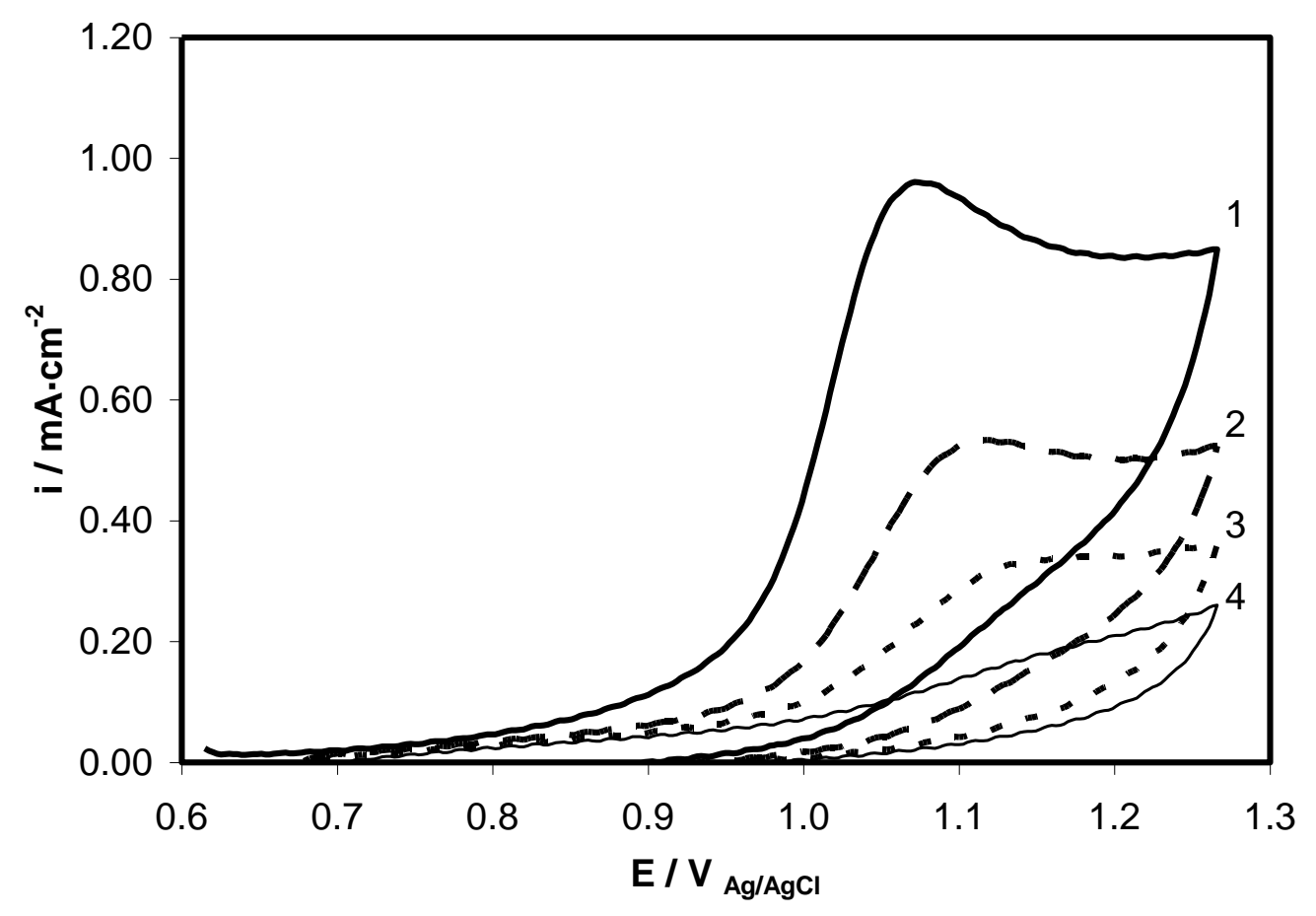

Figure 4. Cyclic voltammograms with a solution containing $0.5 \mathrm{mM}$ phenol and $0.5 \mathrm{M} \mathrm{H}_{2} \mathrm{SO}_{4}$. Scan Rate $=60 \mathrm{mV} \cdot \mathrm{s}^{-1} .(\mathrm{WE}=\mathrm{Pt}, \mathrm{CE}=\mathrm{Pt}, \mathrm{RE}=\mathrm{Ag} / \mathrm{AgCl})$. 
Chronoamperometry was used further to show the stability of the Pt electrode. Figure 5 displays the potentiostatic i-t curve obtained in a stirred solution of $0.5 \mathrm{mM}$ of phenol at an applied potential of $1.1 \mathrm{~V}$ on the Pt electrode. It can be seen that the current density decreases to very low values after a few minutes due to blocking of the electrode surface by the deposition of polymeric adhesive products, as was already found in cyclic voltammetry measurements.

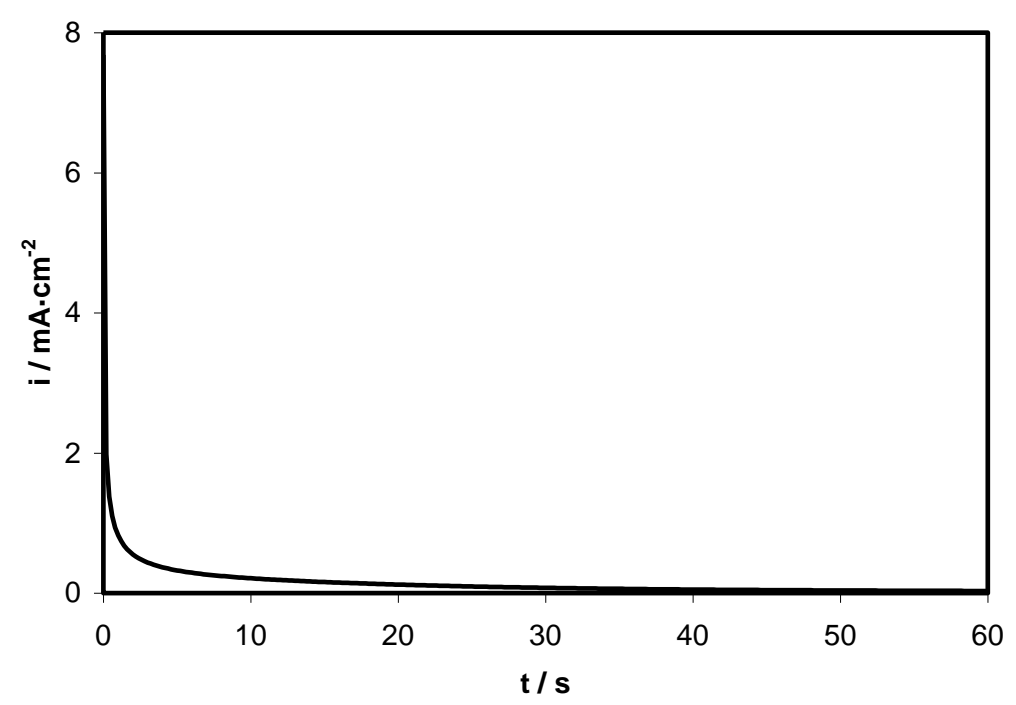

Figure 5. Potentiostatic $i$ - $t$ curves recorded at $1.1 \mathrm{~V}$ in a solution of $0.5 \mathrm{mM}$ phenol and $0.5 \mathrm{M} \mathrm{H}_{2} \mathrm{SO}_{4}$. Scan Rate $=60 \mathrm{mV} \cdot \mathrm{s}^{-1}$. (WE $\left.=\mathrm{Pt}, \mathrm{CE}=\mathrm{Pt}, \mathrm{RE}=\mathrm{Ag} / \mathrm{AgCl}\right)$.

A comparison of the cyclic voltammograms obtained at different RDE rotation rates for a phenol concentration of $12.5 \mathrm{mM}$ and two sulphuric acid concentrations of $0.05 \mathrm{M}$ and $0.5 \mathrm{M}$ is shown in Figure $6 \mathrm{~A}$ and $\mathrm{B}$ respectively. The RDE rotation rate has no important influence on the peak height or peak potential.

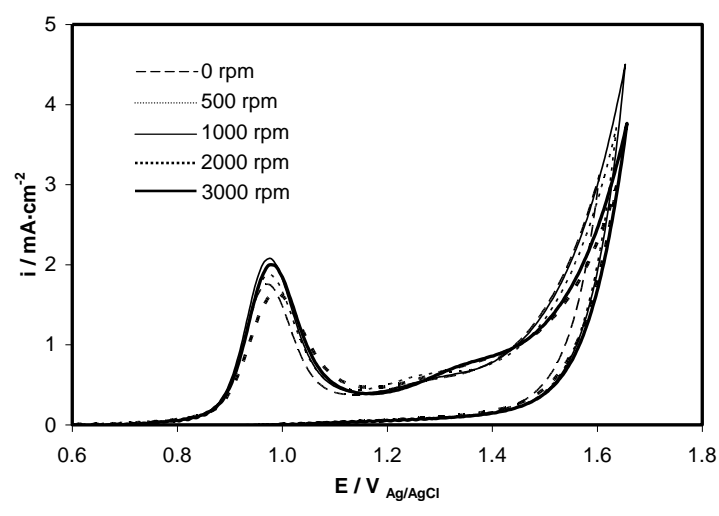

(a)

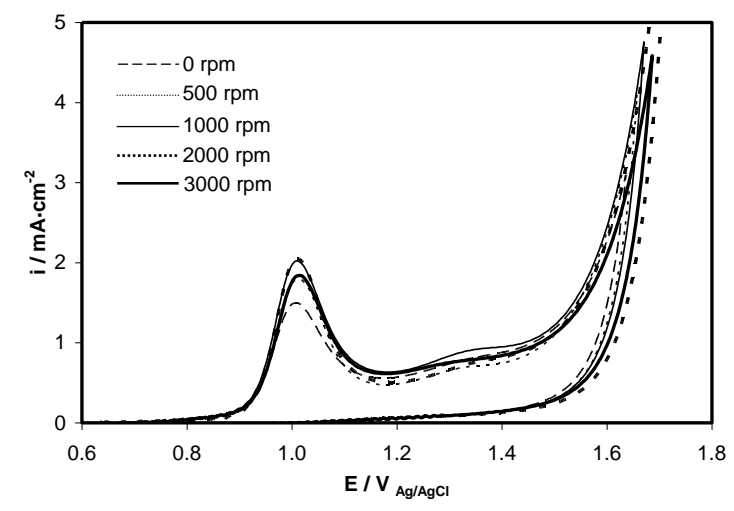

(b)

Figure 6. Cyclic voltammograms using a Rotating Disk Electrode in Solutions: (A) $12.5 \mathrm{mM}$ phenol and $0.05 \mathrm{M} \mathrm{H}_{2} \mathrm{SO}_{4}$ and (B) $12.5 \mathrm{mM}$ phenol and $0.5 \mathrm{M} \mathrm{H}_{2} \mathrm{SO}_{4}$. Scan Rate $=60 \mathrm{mV} \cdot \mathrm{s}^{-1}$. $(\mathrm{WE}=$ $\mathrm{Pt}, \mathrm{CE}=\mathrm{Pt}, \mathrm{RE}=\mathrm{Ag} / \mathrm{AgCl})$. 
Figure 7 shows a comparison of the cyclic voltammograms of phenol as a function of scan rate recorded at $\mathrm{Pt}$ working electrode for a sulphuric acid concentration of $0.05 \mathrm{M}$ and two phenol concentrations of $1.0 \mathrm{mM}$ and $6.25 \mathrm{mM}$ (Figures $8 \mathrm{~A}$ and $8 \mathrm{~B}$, respectively). Anodic peak potentials, as well as the corresponding peak currents, changed with the scan rate. An increase of potential scan rate $(v)$ increases the peak current density $\left(i_{p}\right)$ and shifts the peak potential $\left(E_{p}\right)$ in the positive direction as is typical of totally irreversible systems [27]. This effect was more pronounced for the highest phenol concentration (Figure $7 \mathrm{~B}$ ). In all cases, the difference in the value of $\left|\mathrm{E}_{\mathrm{p}}-\mathrm{E}_{\mathrm{p} / 2}\right|$ is much higher than the value required for a reversible process $(24.7 \mathrm{mV}$ at $373 \mathrm{~K})$ [36], indicating that, in the range of the experimental conditions used in this work, the oxidation of phenol in sulphuric acid at Pt electrode is not only controlled by diffusion but also by charge transfer kinetics.

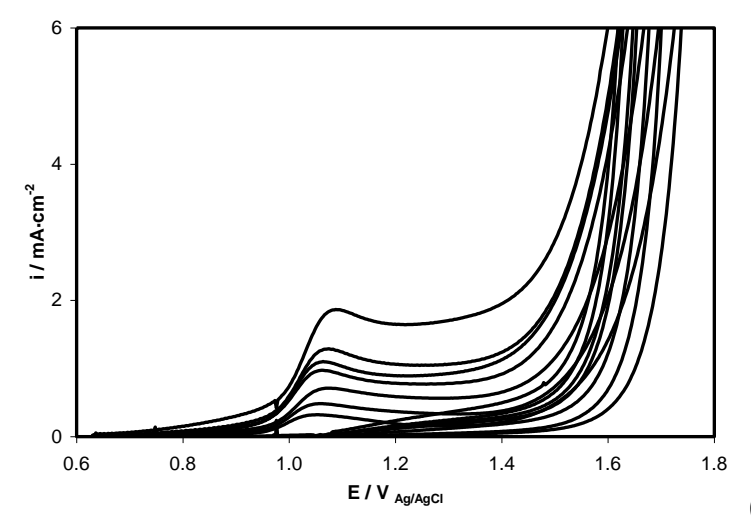

(a)

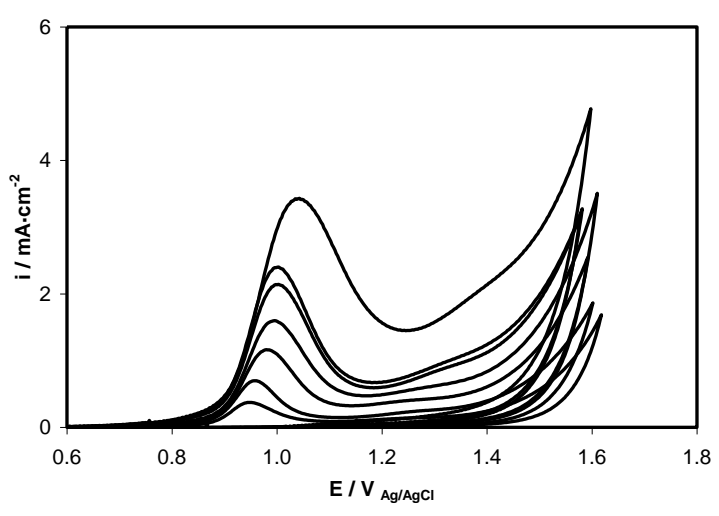

(b)

Figure 7. Cyclic voltammograms at different scan rate (10, 20, 40, 60, 80, 100 and $200 \mathrm{mV} / \mathrm{s}):(\mathrm{A}) 1.0$ $\mathrm{mM}$ phenol and $0.05 \mathrm{M} \mathrm{H}_{2} \mathrm{SO}_{4}$ and (B) $6.25 \mathrm{mM}$ phenol and $0.05 \mathrm{M} \mathrm{H}_{2} \mathrm{SO}_{4}$. (WE $=\mathrm{Pt}, \mathrm{CE}=$ $\mathrm{Pt}, \mathrm{RE}=\mathrm{Ag} / \mathrm{AgCl})$.

Experiments were performed for different sulphuric acid concentrations, since studies on this subject emphasize the influence of $\mathrm{pH}$ on the process of electrooxidation of phenol, and found that in strongly acidic media the oxidation reaction would be favoured.

The effect of sulphuric acid on the electrooxidation of phenol is shown in Figure 8 which represents the cyclic voltammograms obtained for two phenol concentrations of $1 \mathrm{mM}$ and $6.25 \mathrm{mM}$ (A and $\mathrm{B}$, respectively) and different concentrations of sulphuric acid at a scan rate of $60 \mathrm{mVs}^{-1}$. As shown in Figure 8, under the conditions investigated in this work, the concentration of sulphuric acid has little effect on the peak current density, especially for $\mathrm{pH}$ values ranging between 0.2 and 0.4 , corresponding to sulphuric acid concentrations of $1 \mathrm{M}$ and $0.5 \mathrm{M}$ respectively.

However, there is a significant shift in the peak potential towards more positive values at the highest sulphuric acid concentration of $1 \mathrm{M}(\mathrm{pH}=0.2)$ for all phenol concentrations studied in this work. This shift towards more positive potential values observed at $\mathrm{pH} 0.2$ may be due to a weaker influence of the polymerization phenomena and adsorption on the electrode surface in strongly acidic solutions [18]. 

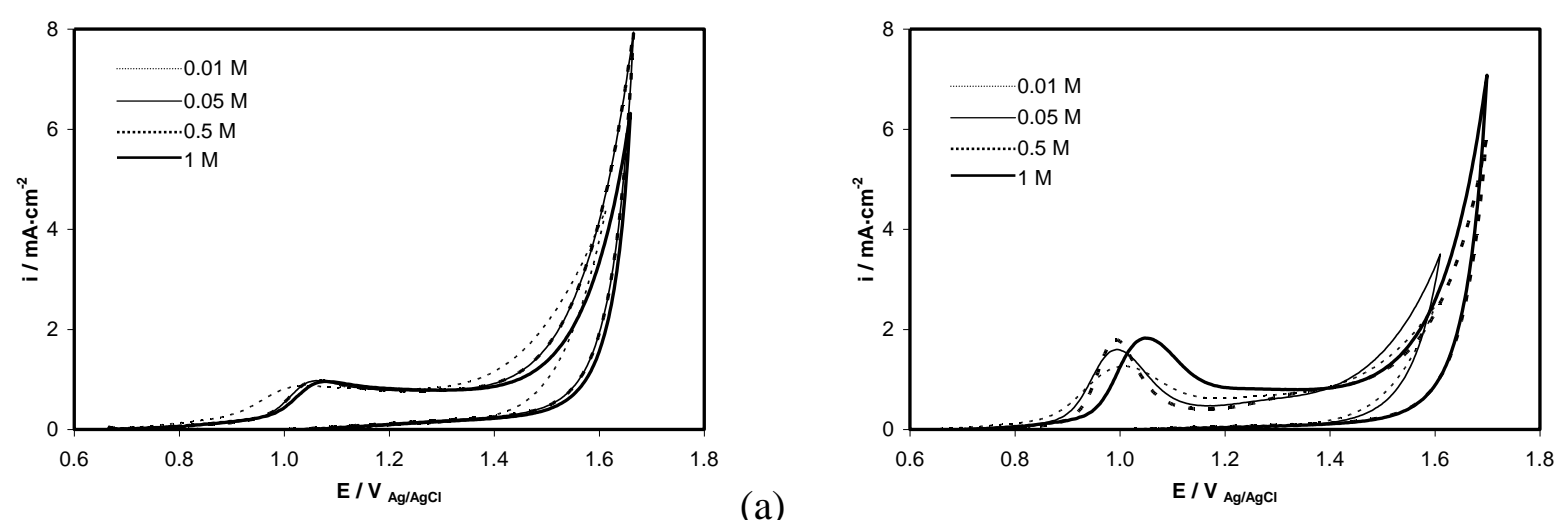

Figure 8. Cyclic voltammograms with 4 different $\mathrm{H}_{2} \mathrm{SO}_{4}$ concentrations in solutions: (A) $1.0 \mathrm{mM}$ phenol and (B) $6.25 \mathrm{mM}$ phenol. Scan Rate $=60 \mathrm{mV} \cdot \mathrm{s}^{-1}$. (WE $\left.=\mathrm{Pt}, \mathrm{CE}=\mathrm{Pt}, \mathrm{RE}=\mathrm{Ag} / \mathrm{AgCl}\right)$.

From the results discussed previously, it can be concluded that under the conditions used in this work, sulphuric acid concentration has little effect on the electrooxidation of phenol, while there is a higher influence of phenol concentration in the peak current density, peak potential and in the shape of the oxidation peak. It has also been observed an increase in peak current density and a shift of the peak potential towards more anodic values with the scan rate, which may indicate an irreversible mechanism in the oxidation process of phenol.

In order to carry out a more detailed analysis of the influence of the different parameters used in this work, on the process of phenol electrooxidation, a study about the variation of the peak potential and the peak current density, associated to the scan rate, for different phenol and sulphuric acid concentrations, was accomplished.

A plot of the anodic peak potential $\left(\mathrm{E}_{\mathrm{p}}\right)$ as a function of the logarithm of the scan rate $(\log v)$ for the oxidation of phenol at Pt electrode is shown in Figure 9 for a sulphuric acid concentration of $0.05 \mathrm{M}$ and different phenol concentrations.

For phenol concentrations below $1 \mathrm{mM}$, phenol concentration does not affect the peak potential, while for concentrations above $1 \mathrm{mM}$, the peak potential decreases with the phenol concentration. This behaviour may be due to the availability of the phenoxy radical. Thus, for low phenol concentrations, the availability of phenoxy radical is lower, so that the polymerization phenomenon, or adsorption of phenoxy radical on the electrode surface, is either less probable or slower. As a consequence, a higher peak potential will be necessary to produce the electrode surface blockage. This same behaviour was observed by Arslan et al. [18] in their studies on the electrooxidation of phenol.

The anodic peak current varied linearly with the square root of the potential scan rate, as shown in Figure 10 for a $0.05 \mathrm{M}$ sulphuric acid solution with different phenol concentrations, showing that the electrode process is diffusion controlled [27, 31, 37]. It can be seen that for phenol concentrations below $6.25 \mathrm{mM}$, the peak current density increases with phenol concentration, while for concentrations higher than $6.25 \mathrm{mM}$, the peak current density does not vary with phenol concentration. 


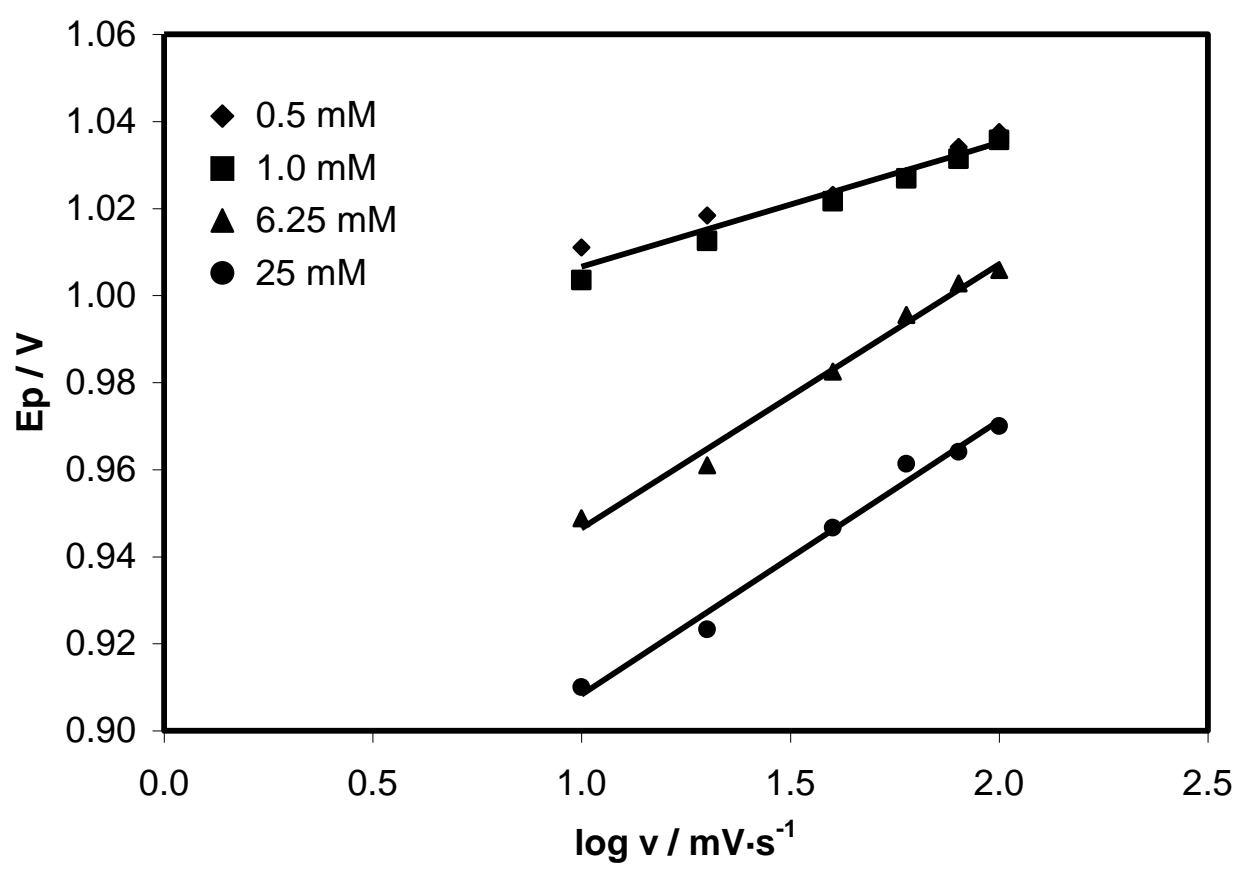

Figure 9. Peak potential as a function of the logarithm of the scan rate for different concentrations of phenol in $0.05 \mathrm{M} \mathrm{H}_{2} \mathrm{SO}_{4}$ solution.

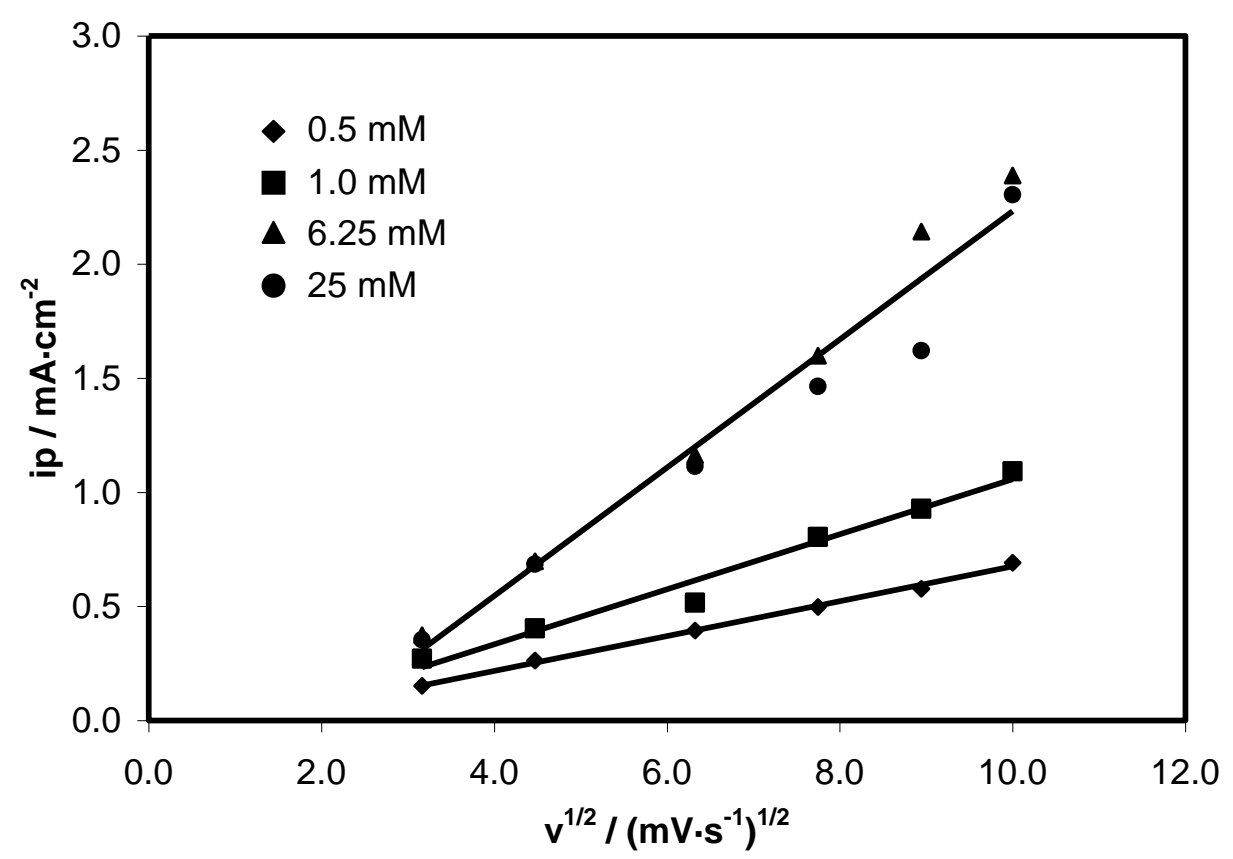

Figure 10. Peak current density as a function of the squared root of the scan rate for different concentrations of phenol in $0.05 \mathrm{M} \mathrm{H}_{2} \mathrm{SO}_{4}$ solution.

A plot of the anodic peak potential $\left(\mathrm{E}_{\mathrm{p}}\right)$ as a function of the logarithm of the scan rate $(\log v)$ is shown in Figure 11 for two different phenol concentrations ( $1 \mathrm{mM}$ and $6.25 \mathrm{mM})$ and sulphuric acid concentrations varying from 0.01 to $1 \mathrm{M}$. For both phenol solutions it can be seen that the higher the acid concentration is, the higher the peak potential is. It is also possible to see two different ranges of 
variation, one for the two highest sulphuric acid concentration $(0.5$ and $1 \mathrm{M})$, and another for the other two acid solutions, that can be associated to a weaker influence of the polymerization phenomena and adsorption on the electrode surface in strongly acidic solutions, as was commented previously.
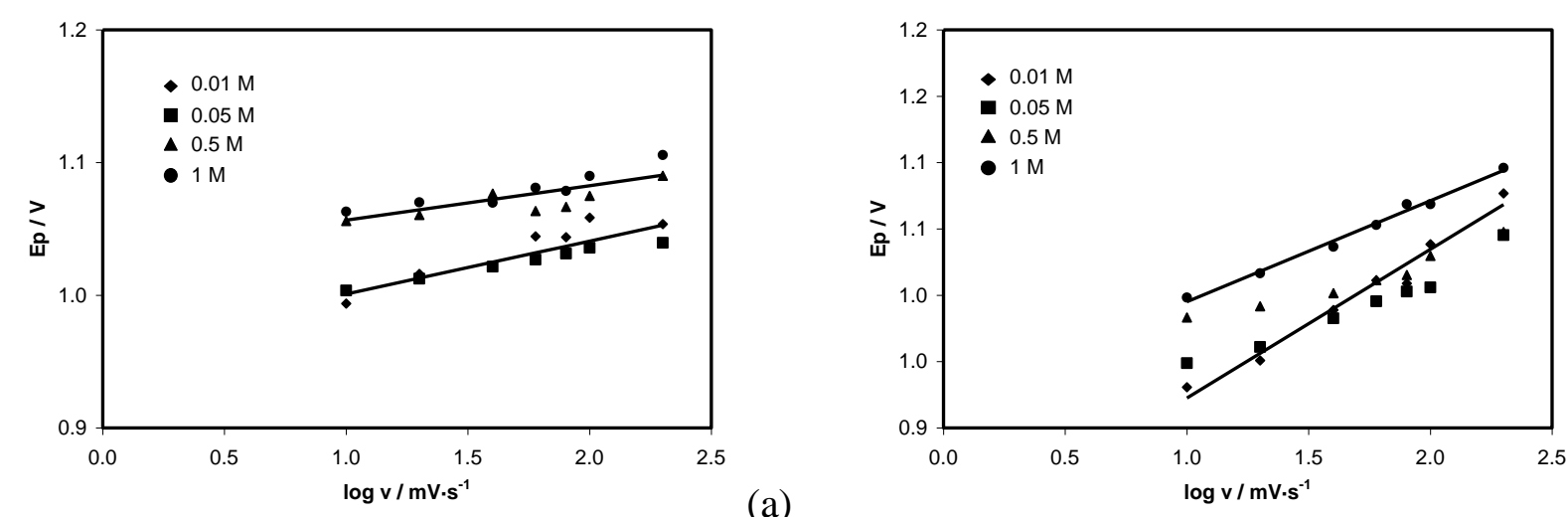

(a)

Figure 11. Peak potential as a function of the logarithm of the scan rate for different $\mathrm{H}_{2} \mathrm{SO}_{4}$ concentrations with two different concentrations of phenol: (A) $1 \mathrm{mM}$ and (B) $6.25 \mathrm{mM}$.

Figure 12 shows the peak current density as a function of the square root of the scan rate for two different phenol concentrations $(1 \mathrm{mM}$ and $6.25 \mathrm{mM})$ and sulphuric acid concentrations varying from 0.01 to $1 \mathrm{M}$. It can be seen that for both phenol concentrations the peak current density increases with the squared root of the scan rate and with the concentration of sulphuric acid.

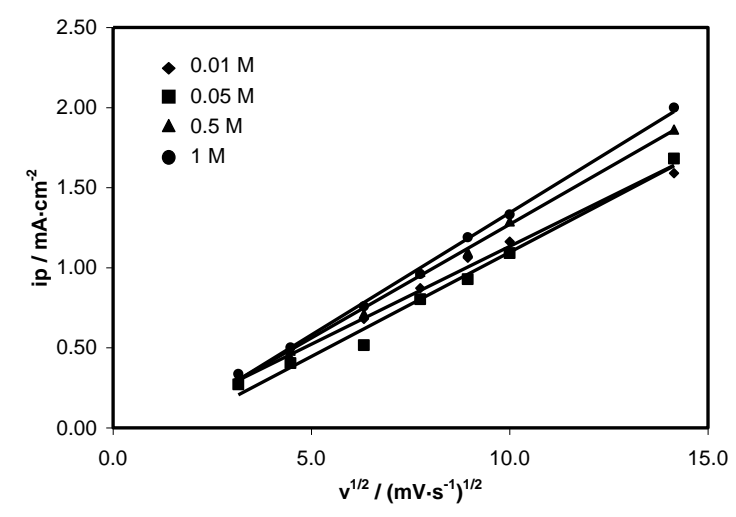

(a)



(b)

Figure 12. Peak current density as a function of the squared root of the scan rate for different $\mathrm{H}_{2} \mathrm{SO}_{4}$ concentrations with two different concentrations of phenol: (A) $1 \mathrm{mM}$ and (B) $6.25 \mathrm{mM}$.

For a non-reversible process, under potentiodynamic conditions, the shift in $\mathrm{E}_{\mathrm{p}}$ per a 10 -fold increase in scan rate by is given by the following equation [36]: 


$$
\Delta \mathrm{E}_{\mathrm{p}}=\frac{1.15 \mathrm{RT}}{\alpha \cdot \mathrm{n}_{\alpha} \mathrm{F}}
$$

where $\alpha$ is the charge transfer coefficient and represents a measure of symmetry barrier in a non-reversible electrode process, $\mathrm{n}_{\alpha}$ is the number of electrons involved in the rate determining step, $\mathrm{F}$ the Faraday constant and $\mathrm{T}$ is the absolute temperature in $\mathrm{K}$.

On the other hand, the relationship between the anodic peak current density $\left(i_{p}\right)$ and the scan rate $(v)$ for an irreversible process is given by the following equation $[36,38]$ :

$$
i_{p}=0.496 n F C D^{1 / 2}\left(\frac{\left(\alpha \cdot n_{\alpha}\right) F v}{R T}\right)^{1 / 2}
$$

where $\mathrm{n}_{\alpha}$ is the number of electrons transferred, $\mathrm{D}$ is the diffusion coefficient of the species being oxidized in $\mathrm{cm}^{2} \cdot \mathrm{s}^{-1}, \mathrm{C}$ is the phenol concentration in the bulk solution in $\mathrm{mol} \cdot \mathrm{cm}^{-3}$ and $v$ is the scan rate in $\mathrm{V} \cdot \mathrm{s}^{-1}$. As can be seen in Figures 10 and 12, the peak current density is proportional to the square root of the scan rate but doesn't pass through origin, which is also a feature of the irreversibility of the phenol oxidation process [39].

Form the slope of the linear variation of $E_{p}$ with respect to the logarithm of the scan rate of the data presented in Figures 9 and 11, the value of $\alpha \cdot \mathrm{n}_{\alpha}$ can be determined using equation (7). Once the value of $\alpha \cdot n_{\alpha}$ is known, the diffusion coefficient of phenol can be estimated from the slope of the straight lines presented in Figures 10 and 12 using equation (8). The values of $\alpha \cdot \mathrm{n}_{\alpha}$ and the diffusion coefficient of phenol are presented in Table 2.

\begin{tabular}{|c|c|c|c|c|c|c|c|c|}
\hline$\left[\mathrm{H}_{2} \mathrm{SO}_{4}\right]$ & \multicolumn{2}{|c|}{0.01} & \multicolumn{2}{|c|}{0.05} & \multicolumn{2}{|c|}{0.5} & \multicolumn{2}{|c|}{1} \\
\hline $\begin{array}{c}\text { [Phenol] } \\
(\mathrm{mM})\end{array}$ & $\alpha \cdot \mathrm{n}_{\alpha}$ & $\begin{array}{c}\mathrm{D} \times 10^{9} \\
\left(\mathrm{~m}^{2} \cdot \mathrm{s}^{-1}\right)\end{array}$ & $\alpha \cdot \mathrm{n}_{\alpha}$ & $\begin{array}{c}\mathrm{D} \times 10^{9} \\
\left(\mathrm{~m}^{2} \cdot \mathrm{s}^{-1}\right)\end{array}$ & $\alpha \cdot \mathrm{n}_{\alpha}$ & $\begin{array}{c}\mathrm{D} \times 10^{9} \\
\left(\mathrm{~m}^{2} \cdot \mathrm{s}^{-1}\right)\end{array}$ & $\alpha \cdot \mathrm{n}_{\alpha}$ & $\begin{array}{l}\mathrm{D} \times 10^{9} \\
\left(\mathrm{~m}^{2} \cdot \mathrm{s}^{-1}\right)\end{array}$ \\
\hline 0.5 & 0.64 & 23.16 & 0.97 & 8.02 & 0.93 & 10.18 & 1.92 & 7.93 \\
\hline 1 & 0.58 & 7.16 & 1.01 & 4.69 & 1.35 & 4.19 & 0.97 & 6.68 \\
\hline 6.25 & 0.26 & 1.87 & 0.42 & 1.41 & 0.60 & 0.88 & 0.39 & 2.71 \\
\hline 12.5 & 0.27 & 0.42 & & & 0.56 & 0.36 & & \\
\hline 25 & 0.29 & 0.12 & 0.36 & 0.10 & 0.53 & 0.12 & 0.56 & 0.13 \\
\hline
\end{tabular}

Table 2. Values of $\alpha \cdot \mathrm{n}_{\alpha}$ and Diffusion coefficient of phenol.

The values of $\alpha \cdot n_{\alpha}$ decrease with the increase of phenol concentration and with the decrease of sulphuric acid concentration because the oxidation of phenol is favored at low phenol concentrations and in acidic solutions, where the polymerization is not favored. The calculated diffusion coefficients decrease with the increase of phenol concentration, probably due to the blockage of the electrode surface with increasing the concentration of phenol. The values obtained in this work are similar to 
those obtained by other authors [40], and to phenol diffusivity in water calculated as $8.47 \cdot 10^{-10} \mathrm{~cm}^{2} \cdot \mathrm{s}^{-1}$ from Wilke and Chang equation [41].

\section{CONCLUSIONS}

In this work the electrooxidation of phenol on platinum electrodes was carried out. For all phenol concentrations and $\mathrm{pH}$ ranges evaluated, the presence of a peak in the anodic oxidation was verified and this peak is proportional to the scan rate and to the phenol concentration.

The peak current density is not affected by the $\mathrm{pH}$ variation, in the $\mathrm{pH}$ range studied at this work. Nevertheless there is a strong relationship between the peak current density and phenol concentration, as well as scan rates, the peak current density presenting a linear behavior related to the square root of the scan rate, which is typical of diffusion controlled processes.

Considering that the peak current density increases with the scan rate increase and is non-linear regarding to phenol concentration and that the peak potential shrinks in the positive direction with the scan rate increase, it is not possible to envisage whether the electrode blockage occurs as a function of reagents or reaction products adsorption.

On cyclic voltametry experiments there is a gradual decrease of the oxidation peak with the cycles, probably due to the adsorption of substances on the electrode surface.

Given the results of this research work, in the range of $\mathrm{pH}$ and phenol concentration evaluated, it is not recommended the use of platinum electrodes for phenol oxidation.

\section{ACKNOWLEDGEMENTS}

We wish to express our gratitude for the support of this work by the CAPES - Brazil (ref. no. 080/04) and the Ministerio de Ciencia y Tecnología - Spain (ref. no. PHB2003-0093-PC).

\section{References}

1. D. Raghu and H. Hsieh. Int. J. Environ. Stud., 30 (1987) 277.

2. P. Saravanan, K. Pakshirajan and P. Saha. Bioresource Technol., 100 (2009) 4111.

3. S. Trasatti. Electrochim. Acta, 37 (1992) 2137.

4. F. Q. Liu, M. F. Xia, S. L. Yao, A. M. Li, H. S. Wu and J. L. Chen. J. Hazard. Mater., 152 (2008) 715.

5. P. Li, M. Takahashi and K. Chiba. Chemosphere, 75 (2009) 1371.

6. N. B. Tahar and A. Savall. Electrochim. Acta, 54 (2009) 4809.

7. E. Hur, G. Bereket, B. Duran, D. Ozdemir and Y. Sahin. Prog. Org. Coat., 60 (2007) 153.

8. G. Mengoli and M. M. Musiani. Electrochim. Acta, 31 (1986) 201.

9. B. Tryba, A. W. Morawski, M. Inagaki and M. Toyoda. Appl. Catal. B-Environ., 65 (2006) 86.

10. R. Alnaizy and A. Akgerman. Adv. Environ. Res., 4 (2000) 233.

11. H. Kawaguchi. Chemosphere, 24 (1992) 1707.

12. M. Czaplicka. J. Hazard. Mater., 134 (2006) 45.

13. P. D. P. Alves, M. Spagnol, G. Tremiliosi and A. R. de Andrade. J. Brazil. Chem. Soc., 15 (2004) 626. 
14. O. Scialdone, S. Randazzo, A. Galia and G. Silvestri. Water Res., 43 (2009) 2260.

15. M. S. Ureta-Zanartu, P. Bustos, C. Berrios, M. C. Diez, M. L. Mora and C. Gutierrez. Electrochim. Acta, 47 (2002) 2399.

16. Y. Yavuz and A. S. Koparal. J. Hazard. Mater., 136 (2006) 296.

17. C. Comninellis and C. Pulgarin. J. Appl. Electrochem., 21 (1991) 703.

18. G. Arslan, B. Yazici and M. Erbil. J. Hazard. Mater., 124 (2005) 37.

19. B. Kennedy, A. Glidle and V. J. Cunnane. J. Electroanal. Chem., 608 (2007) 22.

20. M. J. Pacheco, A. Morao, A. Lopes, L. Ciriaco and I. Goncalves. Electrochim. Acta, 53 (2007) 629.

21. X. Y. Li, Y. H. Cui, Y. J. Feng, Z. M. Xie and J. D. Gu. Water Res., 39 (2005) 1972.

22. G. Mengoli, S. Daolio and M. M. Musiani. J. Appl. Electrochem., 10 (1980) 459.

23. G. Busca, S. Berardinelli, C. Resini and L. Arrighi. J. Hazard. Mater., 160 (2008) 265.

24. G. H. Chen. Sep. Purif. Technol., 38 (2004) 11.

25. J. Wang and R. L. Li. Anal. Chem., 61 (1989) 2809.

26. H. C. Yi, K. B. Wu, S. S. Hu and D. F. Cui. Talanta, 55 (2001) 1205.

27. T. Mafatle and T. Nyokong. Anal. Chim. Acta, 354 (1997) 307.

28. R. N. Singh, D. Mishra and Anindita. Int. J. Electrochem. Sci., 4 (2009) 1638.

29. J. Iniesta, P. A. Michaud, M. Panizza, G. Cerisola, A. Aldaz and C. Comninellis. Electrochim. Acta, 46 (2001) 3573.

30. M. Panizza and G. Cerisola. Electrochim. Acta, 48 (2003) 3491.

31. A.Safavi, N. Maleki and F. Tajabadi. Analyst, 132 (2007) 54.

32. R. Berenguer, T. Valdes-Solis, A. B. Fuertes, C. Quijada and E. Morallon. J. Electrochem. Soc., 155 (2008) K110-K115.

33. J. D. Rodgers, W. Jedral and N. I. Bunce. Environ. Sci. Technol., 33 (1999) 1453.

34. C. L. P. S. Zanta, A. R. de Andrade and J. F. C. Boodts. J. Appl. Electrochem., 30 (2000) 467.

35. P. Canizares, F. Martinez, M. Diaz, J. Garcia-Gomez and M. A. Rodrigo. J. Electrochem. Soc., 149 (2002) D118.

36. A.J. Bard and L. R. Faulkner, Electrochemical methods. Fundamentals and Applications, $2^{\text {nd }}$ ed., John Wiley \& Sons, New York, 2001

37. C. Y. Li. Microchim. Acta, 157 (2007) 21.

38. Z. Galus and W. A. C. Bryce, Fundamentals of Electrochemical Analysis, $2^{\text {nd }}$ ed., Ellis Horwood, New York, 1994.

39. U. O. S. Southampton electrochemistry Group, Instrumental Methods in Electrochemistry, Horwood Publishing, 2001.

40. H. Beyenal, S. Seker, A. Tanyolac and B. Salih. AIChE J., 43 (1997) 243.

41. C. R. Wilke and P. Chang. AIChE J., 1 (1955) 264. 

ANEXO I - TABELAS DE CÁLCULOS PARA ELETRODO DE PLATINA 

$1 \mathrm{M} \mathrm{H}_{2} \mathrm{SO}_{4}$

$0,5 \mathrm{mM} \mathrm{C}_{6} \mathrm{H}_{5} \mathrm{OH}$

\begin{tabular}{cccccccc}
\hline $\mathbf{v}(\mathbf{m V} / \mathbf{s})$ & $\mathbf{v}^{\mathbf{1 / 2}}$ & $\mathbf{I n} \mathbf{v}$ & $\mathbf{I}(\mathbf{m A})$ & $\mathbf{I n ~ I}$ & $\mathbf{E}(\mathbf{V})$ & $\mathbf{E}_{\mathbf{1 / 2}}(\mathbf{V})$ & $\boldsymbol{\Delta} \mathbf{E}(\mathbf{m V})$ \\
\hline 10 & 3.1623 & 2.3026 & 0.0126 & -11.2818 & 1.0666437 & 1.0197 & 46.90 \\
20 & 4.4721 & 2.9957 & 0.0197 & -10.8349 & 1.075897 & 0.9588 & 117.10 \\
40 & 6.3246 & 3.6889 & 0.0301 & -10.4110 & 1.079865 & 0.9713 & 108.57 \\
60 & 7.7460 & 4.0943 & 0.0378 & -10.1832 & 1.076202 & 0.9780 & 98.20 \\
80 & 8.9443 & 4.3820 & 0.0499 & -9.9055 & 1.085052 & 0.9858 & 99.18 \\
100 & 10.0000 & 4.6052 & 0.0532 & -9.8415 & 1.07605 & 0.9910 & 85.05 \\
200 & 14.1421 & 5.2983 & 0.0866 & -9.3542 & 1.087036 & 1.0015 & 85.54
\end{tabular}

$1 \mathrm{mM} \mathrm{C}_{6} \mathrm{H}_{5} \mathrm{OH}$

\begin{tabular}{cccccccc}
\hline $\mathbf{v}(\mathbf{m V} / \mathbf{s})$ & $\mathbf{v}^{\mathbf{1 / 2}}$ & $\mathbf{I n} \mathbf{V}$ & $\mathbf{I}(\mathbf{m A})$ & $\mathbf{I n ~ I}$ & $\mathbf{E}(\mathbf{V})$ & $\mathbf{E}_{\mathbf{1 / 2}}(\mathbf{V})$ & $\boldsymbol{\Delta} \mathbf{E}(\mathbf{m V})$ \\
\hline 10 & 3.1623 & 2.3026 & 0.0195 & -10.8451 & 1.0629 & 1.0162 & 46.73 \\
20 & 4.4721 & 2.9957 & 0.0291 & -10.4448 & 1.0700 & 0.9548 & 115.30 \\
40 & 6.3246 & 3.6889 & 0.044 & -10.0313 & 1.0696 & 0.9687 & 100.94 \\
60 & 7.7460 & 4.0943 & 0.0557 & -9.7955 & 1.0809 & 0.9869 & 94.03 \\
80 & 8.9443 & 4.3820 & 0.069 & -9.5814 & 1.0786 & 0.9910 & 87.64 \\
100 & 10.0000 & 4.6052 & 0.0773 & -9.4678 & 1.0899 & 0.9936 & 96.34 \\
200 & 14.1421 & 5.2983 & 0.116 & -9.0619 & 1.1056 & 0.9963 & 109.35
\end{tabular}

$6,25 \mathrm{mM} \mathrm{C}_{6} \mathrm{H}_{5} \mathrm{OH}$

\begin{tabular}{cccccccc}
\hline $\mathbf{v}(\mathbf{m V} / \mathbf{s})$ & $\mathbf{v}^{\mathbf{1 / 2}}$ & $\mathbf{I n} \mathbf{v}$ & $\mathbf{I}(\mathbf{m A})$ & $\mathbf{I n ~ I}$ & $\mathbf{E}(\mathbf{V})$ & $\mathbf{E}_{\mathbf{1 / 2}}(\mathbf{V})$ & $\boldsymbol{\Delta} \mathbf{E}(\mathbf{m V})$ \\
\hline 10 & 3.1623 & 2.3026 & 0.0284 & -10.4691 & 0.9982 & 0.9540 & 44.23 \\
20 & 4.4721 & 2.9957 & 0.0469 & -9.9675 & 1.0165 & 0.9609 & 55.64 \\
40 & 6.3246 & 3.6889 & 0.0792 & -9.4435 & 1.0365 & 0.9687 & 67.83 \\
60 & 7.7460 & 4.0943 & 0.106 & -9.1521 & 1.0530 & 0.9780 & 75.01 \\
80 & 8.9443 & 4.3820 & 0.137 & -8.8955 & 1.0646 & 0.9806 & 84.01 \\
100 & 10.0000 & 4.6052 & 0.162 & -8.7279 & 1.0685 & 0.9780 & 90.57 \\
200 & 14.1421 & 5.2983 & 0.271 & -8.2134 & 1.0960 & 0.9886 & 107.44
\end{tabular}

$12,5 \mathrm{mM} \mathrm{C}_{6} \mathrm{H}_{5} \mathrm{OH}$

\begin{tabular}{cccccccc}
\hline $\mathbf{v}(\mathbf{m V} / \mathbf{s})$ & $\mathbf{v}^{\mathbf{1 / 2}}$ & $\mathbf{I n} \mathbf{v}$ & $\mathbf{I}(\mathbf{m A})$ & $\mathbf{I n ~ I}$ & $\mathbf{E}(\mathbf{V})$ & $\mathbf{E}_{\mathbf{1 / 2}}(\mathbf{V})$ & $\boldsymbol{\Delta} \mathbf{E}(\mathbf{m V})$ \\
\hline 10 & 3.1623 & 2.3026 & 0.0281 & -10.4797 & 0.9771 & 0.9330 & 44.17 \\
20 & 4.4721 & 2.9957 & 0.0497 & -9.9095 & 0.9895 & 0.9402 & 49.33 \\
40 & 6.3246 & 3.6889 & 0.0873 & -9.3462 & 1.0067 & 0.9599 & 46.88 \\
60 & 7.7460 & 4.0943 & 0.116 & -9.0619 & 1.0258 & 0.9677 & 58.15 \\
80 & 8.9443 & 4.3820 & 0.155 & -8.7721 & 1.0290 & 0.9884 & 40.65 \\
100 & 10.0000 & 4.6052 & 0.156 & -8.7657 & 1.0351 & 0.9832 & 51.96 \\
200 & 14.1421 & 5.2983 & 0.339 & -7.9895 & 1.0508 & 0.9912 & 59.67
\end{tabular}

$25 \mathrm{mM} \mathrm{C}_{6} \mathrm{H}_{5} \mathrm{OH}$

\begin{tabular}{cccccccc}
\hline $\mathbf{v}(\mathbf{m V} / \mathbf{s})$ & $\mathbf{v}^{\mathbf{1 / 2}}$ & $\mathbf{I n} \mathbf{v}$ & $\mathbf{I}(\mathbf{m A})$ & $\mathbf{I n ~ I}$ & $\mathbf{E}(\mathbf{V})$ & $\mathbf{E}_{\mathbf{1 / 2}}(\mathbf{V})$ & $\boldsymbol{\Delta} \mathbf{E}(\mathbf{m V})$ \\
\hline 10 & 3.1623 & 2.3026 & 0.0234 & -10.6628 & 0.9524 & 0.9091 & 43.35 \\
20 & 4.4721 & 2.9957 & 0.0381 & -10.1753 & 0.9661 & 0.9298 & 36.39 \\
40 & 6.3246 & 3.6889 & 0.0721 & -9.5375 & 0.9819 & 0.9547 & 27.20 \\
60 & 7.7460 & 4.0943 & 0.0935 & -9.2775 & 0.9939 & 0.9599 & 34.06 \\
80 & 8.9443 & 4.3820 & 0.137 & -8.8955 & 0.9953 & 0.9700 & 25.33 \\
100 & 10.0000 & 4.6052 & 0.163 & -8.7218 & 1.0046 & 0.9729 & 31.74 \\
200 & 14.1421 & 5.2983 & 0.277 & -8.1915 & 1.0205 & 0.9860 & 34.51
\end{tabular}


$0,5 \mathrm{M} \mathrm{H}_{2} \mathrm{SO}_{4}$

$0,5 \mathrm{mM} \mathrm{C}_{6} \mathrm{H}_{5} \mathrm{OH}$

\begin{tabular}{cccccccc}
\hline $\mathbf{v}(\mathbf{m V} / \mathbf{s})$ & $\mathbf{v}^{\mathbf{1 / 2}}$ & $\mathbf{I n} \mathbf{v}$ & $\mathbf{I}(\mathbf{m A})$ & $\mathbf{I n ~ I}$ & $\mathbf{E}(\mathbf{V})$ & $\mathbf{E}_{\mathbf{1 / 2}}(\mathbf{V})$ & $\boldsymbol{\Delta} \mathbf{E}(\mathbf{m V})$ \\
\hline 10 & 3.1623 & 2.3026 & 0.0149 & -11.1141 & 1.0562 & 0.9884 & 67.81 \\
20 & 4.4721 & 2.9957 & 0.0195 & -10.8451 & 1.0585 & 0.9904 & 68.10 \\
40 & 6.3246 & 3.6889 & 0.0292 & -10.4413 & 1.0756 & 0.9905 & 85.09 \\
60 & 7.7460 & 4.0943 & 0.0356 & -10.2432 & 1.0785 & 0.9991 & 79.39 \\
80 & 8.9443 & 4.3820 & 0.0415 & -10.0898 & 1.0779 & 0.9944 & 83.48 \\
100 & 10.0000 & 4.6052 & 0.0481 & -9.9422 & 1.0817 & 1.0021 & 79.60 \\
200 & 14.1421 & 5.2983 & 0.0733 & -9.5209 & 1.0986 & 1.0096 & 89.03
\end{tabular}

$1 \mathrm{mM} \mathrm{C}_{6} \mathrm{H}_{5} \mathrm{OH}$

\begin{tabular}{cccccccc}
\hline $\mathbf{v}(\mathbf{m V} / \mathbf{s})$ & $\mathbf{v}^{\mathbf{1 / 2}}$ & $\mathbf{I n} \mathbf{v}$ & $\mathbf{I}(\mathbf{m A})$ & $\mathbf{I n ~} \mathbf{I}$ & $\mathbf{E}(\mathbf{V})$ & $\mathbf{E}_{\mathbf{1 / 2}}(\mathbf{V})$ & $\boldsymbol{\Delta} \mathbf{E}(\mathbf{m V})$ \\
\hline 10 & 3.1623 & 2.3026 & 0.0186 & -10.8923 & 1.0559 & 0.9858 & 70.11 \\
20 & 4.4721 & 2.9957 & 0.0280 & -10.4833 & 1.0605 & 0.9930 & 67.49 \\
40 & 6.3246 & 3.6889 & 0.0413 & -10.0946 & 1.0767 & 1.0014 & 75.27 \\
60 & 7.7460 & 4.0943 & 0.0565 & -9.7813 & 1.0634 & 0.9959 & 67.49 \\
80 & 8.9443 & 4.3820 & 0.0636 & -9.6629 & 1.0666 & 0.9970 & 69.59 \\
100 & 10.0000 & 4.6052 & 0.0748 & -9.5007 & 1.0748 & 1.0047 & 70.13 \\
200 & 14.1421 & 5.2983 & 0.1080 & -9.1334 & 1.0901 & 1.0096 & 80.49
\end{tabular}

\section{6,25 mM C $6 \mathrm{H}_{5} \mathrm{OH}$}

\begin{tabular}{cccccccc}
\hline $\mathbf{v}(\mathbf{m V} / \mathbf{s})$ & $\mathbf{v}^{\mathbf{1 / 2}}$ & $\mathbf{I n} \mathbf{v}$ & $\mathbf{I}(\mathbf{m A})$ & $\mathbf{I n ~ I}$ & $\mathbf{E}(\mathbf{V})$ & $\mathbf{E}_{\mathbf{1 / 2}}(\mathbf{V})$ & $\boldsymbol{\Delta} \mathbf{E}(\mathbf{m V})$ \\
\hline 10 & 3.1623 & 2.3026 & 0.0216 & -10.7428 & 0.9833 & 0.9213 & 61.98 \\
20 & 4.4721 & 2.9957 & 0.0335 & -10.3040 & 0.9917 & 0.9429 & 48.77 \\
40 & 6.3246 & 3.6889 & 0.0658 & -9.6289 & 1.0014 & 0.9477 & 53.73 \\
60 & 7.7460 & 4.0943 & 0.0817 & -9.4125 & 1.0141 & 0.9477 & 66.40 \\
80 & 8.9443 & 4.3820 & 0.1040 & -9.1711 & 1.0153 & 0.9477 & 67.62 \\
100 & 10.0000 & 4.6052 & 0.1060 & -9.1521 & 1.0297 & 0.9606 & 69.06 \\
200 & 14.1421 & 5.2983 & 0.1980 & -8.5272 & 1.0477 & 0.9703 & 77.37
\end{tabular}

$12,5 \mathrm{mM} \mathrm{C}_{6} \mathrm{H}_{5} \mathrm{OH}$

\begin{tabular}{cccccccc}
\hline $\mathbf{v}(\mathbf{m V / s})$ & $\mathbf{v}^{\mathbf{1 / 2}}$ & $\mathbf{I n} \mathbf{~}$ & $\mathbf{I}(\mathbf{m A})$ & $\mathbf{I n ~ I}$ & $\mathbf{E}(\mathbf{V})$ & $\mathbf{E}_{\mathbf{1 / 2}}(\mathbf{V})$ & $\boldsymbol{\Delta} \mathbf{E}(\mathbf{m V})$ \\
\hline 10 & 3.1623 & 2.3026 & 0.0210 & -10.7710 & 0.9602 & 0.9213 & 38.94 \\
20 & 4.4721 & 2.9957 & 0.0332 & -10.3130 & 0.9702 & 0.9342 & 35.95 \\
40 & 6.3246 & 3.6889 & 0.0635 & -9.6645 & 0.9871 & 0.9429 & 44.19 \\
60 & 7.7460 & 4.0943 & 0.1040 & -9.1711 & 0.9944 & 0.9503 & 44.12 \\
80 & 8.9443 & 4.3820 & 0.0960 & -9.2512 & 1.0014 & 0.9477 & 53.73 \\
100 & 10.0000 & 4.6052 & 0.1400 & -8.8739 & 1.0066 & 0.9606 & 46.02 \\
200 & 14.1421 & 5.2983 & 0.2350 & -8.3559 & 1.0301 & 0.9730 & 57.12
\end{tabular}

$25 \mathrm{mM} \mathrm{C}_{6} \mathrm{H}_{5} \mathrm{OH}$

\begin{tabular}{cccccccc}
\hline $\mathbf{v}(\mathbf{m V / s})$ & $\mathbf{v}^{\mathbf{1 / 2}}$ & $\mathbf{I n} \mathbf{v}$ & $\mathbf{I}(\mathbf{m A})$ & $\mathbf{I n ~ I}$ & $\mathbf{E}(\mathbf{V})$ & $\mathbf{E}_{\mathbf{1 / 2}}(\mathbf{V})$ & $\boldsymbol{\Delta} \mathbf{E}(\mathbf{m V})$ \\
\hline 10 & 3.1623 & 2.3026 & 0.0184 & -10.9032 & 1.0429 & 0.9010 & 141.90 \\
20 & 4.4721 & 2.9957 & 0.0278 & -10.4905 & 1.0501 & 0.9956 & 54.50 \\
40 & 6.3246 & 3.6889 & 0.0413 & -10.0946 & 1.0740 & 1.0066 & 67.40 \\
60 & 7.7460 & 4.0943 & 0.0564 & -9.7830 & 1.0633 & 0.9918 & 71.50 \\
80 & 8.9443 & 4.3820 & 0.0635 & -9.6645 & 1.0665 & 0.9996 & 66.90 \\
100 & 10.0000 & 4.6052 & 0.0745 & -9.5047 & 1.0774 & 1.0099 & 67.50 \\
200 & 14.1421 & 5.2983 & 0.1080 & -9.1334 & 1.0952 & 1.0200 & 75.20
\end{tabular}


$0,05 \mathrm{M} \mathrm{H}_{2} \mathrm{SO}_{4}$

$0,5 \mathrm{mM} \mathrm{C}_{6} \mathrm{H}_{5} \mathrm{OH}$

\begin{tabular}{cccccccc}
\hline $\mathbf{v}(\mathbf{m V} / \mathbf{s})$ & $\mathbf{v}^{\mathbf{1 / 2}}$ & $\mathbf{I n} \mathbf{v}$ & $\mathbf{I}(\mathbf{m A})$ & $\mathbf{I n ~ I}$ & $\mathbf{E}(\mathbf{V})$ & $\mathbf{E}_{\mathbf{1 / 2}}(\mathbf{V})$ & $\boldsymbol{\Delta} \mathbf{E}(\mathbf{m V})$ \\
\hline 10 & 3.1623 & 2.3026 & 0.0114 & -11.3819 & 1.0223 & 0.9652 & 57.13 \\
20 & 4.4721 & 2.9957 & 0.0168 & -10.9941 & 1.0236 & 0.9587 & 64.86 \\
40 & 6.3246 & 3.6889 & 0.0269 & -10.5234 & 1.0284 & 0.9609 & 67.52 \\
60 & 7.7460 & 4.0943 & 0.0335 & -10.3040 & 1.0358 & 0.9765 & 59.30 \\
80 & 8.9443 & 4.3820 & 0.0455 & -9.9978 & 1.0349 & 0.9518 & 83.05 \\
100 & 10.0000 & 4.6052 & 0.0487 & -9.9298 & 1.0352 & 0.9414 & 93.76 \\
200 & 14.1421 & 5.2983 & 0.0779 & -9.4601 & 1.0593 & 0.9632 & 96.07
\end{tabular}

$1 \mathrm{mM} \mathrm{C}_{6} \mathrm{H}_{5} \mathrm{OH}$

\begin{tabular}{cccccccc}
\hline $\mathbf{v}(\mathbf{m V} / \mathbf{s})$ & $\mathbf{v}^{\mathbf{1 / 2}}$ & $\mathbf{I n} \mathbf{v}$ & $\mathbf{I}(\mathbf{m A})$ & $\mathbf{I n ~ I}$ & $\mathbf{E}(\mathbf{V})$ & $\mathbf{E}_{\mathbf{1 / 2}}(\mathbf{V})$ & $\Delta \mathbf{E}(\mathbf{m V})$ \\
\hline 10 & 3.1623 & 2.3026 & 0.0157 & -11.0618 & 1.0086 & 0.9463 & 62.31 \\
20 & 4.4721 & 2.9957 & 0.0234 & -10.6628 & 1.0165 & 0.9568 & 59.74 \\
40 & 6.3246 & 3.6889 & 0.0299 & -10.4177 & 1.0306 & 0.9724 & 58.18 \\
60 & 7.7460 & 4.0943 & 0.0466 & -9.9739 & 1.0269 & 0.9594 & 67.52 \\
80 & 8.9443 & 4.3820 & 0.0538 & -9.8302 & 1.0364 & 0.9672 & 69.18 \\
100 & 10.0000 & 4.6052 & 0.0633 & -9.6676 & 1.0310 & 0.9687 & 62.34 \\
200 & 14.1421 & 5.2983 & 0.0975 & -9.2357 & 1.0396 & 0.9695 & 70.08
\end{tabular}

$6,25 \mathrm{mM} \mathrm{C}_{6} \mathrm{H}_{5} \mathrm{OH}$

\begin{tabular}{cccccccc}
\hline $\mathbf{v}(\mathbf{m V} / \mathbf{s})$ & $\mathbf{v}^{\mathbf{1 / 2}}$ & $\mathbf{I n} \mathbf{v}$ & $\mathbf{I}(\mathbf{m A})$ & $\mathbf{I n ~ I}$ & $\mathbf{E}(\mathbf{V})$ & $\mathbf{E}_{\mathbf{1 / 2}}(\mathbf{V})$ & $\boldsymbol{\Delta} \mathbf{E}(\mathbf{m V})$ \\
\hline 10 & 3.1623 & 2.3026 & 0.0156 & -11.0682 & 1.0008 & 0.9567 & 44.10 \\
20 & 4.4721 & 2.9957 & 0.0231 & -10.6757 & 1.0061 & 0.9620 & 44.10 \\
40 & 6.3246 & 3.6889 & 0.0299 & -10.4177 & 1.0305 & 0.9724 & 58.10 \\
60 & 7.7460 & 4.0943 & 0.0462 & -9.9825 & 1.0295 & 0.9698 & 59.70 \\
80 & 8.9443 & 4.3820 & 0.0534 & -9.8377 & 1.0389 & 0.9828 & 56.10 \\
100 & 10.0000 & 4.6052 & 0.1390 & -8.8810 & 1.0032 & 0.9410 & 62.20 \\
200 & 14.1421 & 5.2983 & 0.1970 & -8.5323 & 1.0453 & 0.9676 & 77.70
\end{tabular}

$12,5 \mathrm{mM} \mathrm{C}_{6} \mathrm{H}_{5} \mathrm{OH}$

\begin{tabular}{cccccccc}
\hline $\mathbf{v}(\mathbf{m V} / \mathbf{s})$ & $\mathbf{v}^{\mathbf{1 / 2}}$ & $\mathbf{I n} \mathbf{v}$ & $\mathbf{I}(\mathbf{m A})$ & $\mathbf{I n ~ I}$ & $\mathbf{E}(\mathbf{V})$ & $\mathbf{E}_{\mathbf{1 / 2}}(\mathbf{V})$ & $\boldsymbol{\Delta} \mathbf{E}(\mathbf{m V})$ \\
\hline 10 & 3.1623 & 2.3026 & 0.0250 & -10.5966 & 1.0214 & 0.9591 & 62.30 \\
20 & 4.4721 & 2.9957 & 0.0349 & -10.2630 & 1.0026 & 0.9507 & 51.90 \\
40 & 6.3246 & 3.6889 & 0.0513 & -9.8778 & 0.9936 & 0.9469 & 46.70 \\
60 & 7.7460 & 4.0943 & 0.0851 & -9.3717 & 1.0054 & 0.9587 & 46.70 \\
80 & 8.9443 & 4.3820 & 0.1090 & -9.1242 & 1.0084 & 0.9617 & 46.70 \\
100 & 10.0000 & 4.6052 & 0.1460 & -8.8319 & 1.0102 & 0.9609 & 49.30 \\
200 & 14.1421 & 5.2983 & & & & &
\end{tabular}

$25 \mathrm{mM} \mathrm{C}{ }_{6} \mathrm{H}_{5} \mathrm{OH}$

\begin{tabular}{cccccccc}
\hline $\mathbf{v}(\mathbf{m V} / \mathbf{s})$ & $\mathbf{v}^{\mathbf{1 / 2}}$ & $\mathbf{I n} \mathbf{~}$ & $\mathbf{I}(\mathbf{m A})$ & $\mathbf{I n ~ I}$ & $\mathbf{E}(\mathbf{V})$ & $\mathbf{E}_{\mathbf{1 / 2}}(\mathbf{V})$ & $\boldsymbol{\Delta} \mathbf{E}(\mathbf{m V})$ \\
\hline 10 & 3.1623 & 2.3026 & 0.0155 & -11.0747 & 0.9956 & 0.9489 & 46.70 \\
20 & 4.4721 & 2.9957 & 0.0232 & -10.6714 & 1.0113 & 0.9594 & 51.90 \\
40 & 6.3246 & 3.6889 & 0.0301 & -10.4110 & 1.0383 & 0.9724 & 65.90 \\
60 & 7.7460 & 4.0943 & 0.0462 & -9.9825 & 1.0295 & 0.9672 & 62.30 \\
80 & 8.9443 & 4.3820 & 0.0537 & -9.8321 & 1.0363 & 0.9715 & 64.80 \\
100 & 10.0000 & 4.6052 & 0.0629 & -9.6740 & 1.0414 & 0.9687 & 72.70 \\
200 & 14.1421 & 5.2983 & 0.0988 & -9.2224 & 1.0421 & 0.9643 & 77.80
\end{tabular}


$0,01 \mathrm{M} \mathrm{H}_{2} \mathrm{SO}_{4}$

$0,5 \mathrm{mM} \mathrm{C}_{6} \mathrm{H}_{5} \mathrm{OH}$

\begin{tabular}{cccccccc}
\hline $\mathbf{v}(\mathbf{m V} / \mathbf{s})$ & $\mathbf{v}^{\mathbf{1 / 2}}$ & $\mathbf{I n} \mathbf{~}$ & $\mathbf{I}(\mathbf{m A})$ & $\mathbf{l n} \mathbf{I}$ & $\mathbf{E}(\mathbf{V})$ & $\mathbf{E}_{\mathbf{1 / 2}}(\mathbf{V})$ & $\Delta \mathbf{E}(\mathbf{m V})$ \\
\hline 10 & 3.1623 & 2.3026 & 0.0133 & -11.2277 & 0.9917 & 0.9371 & 54.57 \\
20 & 4.4721 & 2.9957 & 0.0187 & -10.8870 & 1.0114 & 0.9335 & 77.85 \\
40 & 6.3246 & 3.6889 & 0.0299 & -10.4177 & 1.0182 & 0.9378 & 80.42 \\
60 & 7.7460 & 4.0943 & 0.0384 & -10.1675 & 1.0457 & 0.9455 & 100.15 \\
80 & 8.9443 & 4.3820 & 0.0474 & -9.9569 & 1.0359 & 0.9304 & 105.52 \\
100 & 10.0000 & 4.6052 & 0.0518 & -9.8681 & 1.0316 & 0.9304 & 101.25 \\
200 & 14.1421 & 5.2983 & 0.0868 & -9.3519 & 1.0551 & 0.9228 & 132.35
\end{tabular}

$1 \mathrm{mM} \mathrm{C}_{6} \mathrm{H}_{5} \mathrm{OH}$

\begin{tabular}{cccccccc}
\hline $\mathbf{v}(\mathbf{m V} / \mathbf{s})$ & $\mathbf{v}^{\mathbf{1 / 2}}$ & $\mathbf{I n} \mathbf{v}$ & $\mathbf{I}(\mathbf{m A})$ & $\mathbf{I n ~ I}$ & $\mathbf{E}(\mathbf{V})$ & $\mathbf{E}_{\mathbf{1 / 2}}(\mathbf{V})$ & $\boldsymbol{\Delta} \mathbf{E}(\mathbf{m V})$ \\
\hline 10 & 3.1623 & 2.3026 & 0.0162 & -11.0305 & 0.9937 & 0.9184 & 75.25 \\
20 & 4.4721 & 2.9957 & 0.0247 & -10.6087 & 1.0161 & 0.9278 & 88.28 \\
40 & 6.3246 & 3.6889 & 0.0395 & -10.1392 & 1.0211 & 0.9225 & 98.62 \\
60 & 7.7460 & 4.0943 & 0.0506 & -9.8916 & 1.0443 & 0.9275 & 116.81 \\
80 & 8.9443 & 4.3820 & 0.0616 & -9.6948 & 1.0437 & 0.9339 & 109.80 \\
100 & 10.0000 & 4.6052 & 0.0674 & -9.6049 & 1.0585 & 0.9236 & 134.90 \\
200 & 14.1421 & 5.2983 & & -9.3519 & 1.0536 & 0.9213 & 132.32
\end{tabular}

$6,25 \mathrm{mM} \mathrm{C}_{6} \mathrm{H}_{5} \mathrm{OH}$

\begin{tabular}{cccccccc}
\hline $\mathbf{v}(\mathbf{m V} / \mathbf{s})$ & $\mathbf{v}^{\mathbf{1 / 2}}$ & $\mathbf{I n} \mathbf{v}$ & $\mathbf{I}(\mathbf{m A})$ & $\mathbf{I n ~ I}$ & $\mathbf{E}(\mathbf{V})$ & $\mathbf{E}_{\mathbf{1 / 2}}(\mathbf{V})$ & $\boldsymbol{\Delta} \mathbf{E}(\mathbf{m V})$ \\
\hline 10 & 3.1623 & 2.3026 & 0.0202 & -10.8098 & 0.9306 & 0.8813 & 49.33 \\
20 & 4.4721 & 2.9957 & 0.0341 & -10.2862 & 0.9508 & 0.8988 & 51.98 \\
40 & 6.3246 & 3.6889 & 0.0623 & -9.6835 & 0.9888 & 0.9152 & 73.57 \\
60 & 7.7460 & 4.0943 & 0.0733 & -9.5209 & 1.0112 & 0.91 & 101.20 \\
80 & 8.9443 & 4.3820 & 0.1000 & -9.2103 & 1.0089 & 0.9233 & 85.61 \\
100 & 10.0000 & 4.6052 & & -9.0619 & 1.0384 & 0.9294 & 108.96 \\
200 & 14.1421 & 5.2983 & & -8.5898 & 1.0768 & 0.9548 & 122.01
\end{tabular}

$12,5 \mathrm{mM} \mathrm{C}_{6} \mathrm{H}_{5} \mathrm{OH}$

\begin{tabular}{cccccccc}
\hline $\mathbf{v}(\mathbf{m V} / \mathbf{s})$ & $\mathbf{v}^{\mathbf{1 / 2}}$ & $\mathbf{I n} \mathbf{v}$ & $\mathbf{I}(\mathbf{m A})$ & $\mathbf{l n} \mathbf{I}$ & $\mathbf{E}(\mathbf{V})$ & $\mathbf{E}_{\mathbf{1 / 2}}(\mathbf{V})$ & $\Delta \mathbf{E}(\mathbf{m V})$ \\
\hline 10 & 3.1623 & 2.3026 & 0.0224 & -10.7064 & 0.9030 & 0.8599 & 43.12 \\
20 & 4.4721 & 2.9957 & 0.0358 & -10.2376 & 0.9326 & 0.8807 & 51.92 \\
40 & 6.3246 & 3.6889 & 0.0619 & -9.6900 & 0.9628 & 0.9005 & 62.33 \\
60 & 7.7460 & 4.0943 & 0.0758 & -9.4874 & 0.9732 & 0.9057 & 67.51 \\
80 & 8.9443 & 4.3820 & & -9.1427 & 0.9901 & 0.9257 & 64.44 \\
100 & 10.0000 & 4.6052 & & -9.0970 & 1.0088 & 0.9126 & 96.16 \\
200 & 14.1421 & 5.2983 & 0.1820 & -8.6115 & 1.0501 & 0.9411 & 109.01
\end{tabular}

$25 \mathrm{mM} \mathrm{C} \mathrm{H}_{5} \mathrm{OH}$

\begin{tabular}{cccccccc}
\hline $\mathbf{v}(\mathbf{m V} / \mathbf{s})$ & $\mathbf{v}^{\mathbf{1 / 2}}$ & $\mathbf{I n} \mathbf{~}$ & $\mathbf{I}(\mathbf{m A})$ & $\mathbf{I n ~} \mathbf{I}$ & $\mathbf{E}(\mathbf{V})$ & $\mathbf{E}_{\mathbf{1 / 2}}(\mathbf{V})$ & $\boldsymbol{\Delta} \mathbf{E}(\mathbf{m V})$ \\
\hline 10 & 3.1623 & 2.3026 & 0.0223 & -10.7109 & 0.8811951 & 0.8370 & 44.20 \\
20 & 4.4721 & 2.9957 & 0.0373 & -10.1965 & 0.917511 & 0.8604 & 57.11 \\
40 & 6.3246 & 3.6889 & 0.0625 & -9.6803 & 0.9381104 & 0.8862 & 51.91 \\
60 & 7.7460 & 4.0943 & 0.0825 & -9.4027 & 0.9536743 & 0.8888 & 64.87 \\
80 & 8.9443 & 4.3820 & 0.1000 & -9.2103 & 0.9692383 & 0.8940 & 75.24 \\
100 & 10.0000 & 4.6052 & 0.1180 & -9.04482 & 0.9791565 & 0.9017 & 77.46 \\
200 & 14.1421 & 5.2983 & 0.2010 & -8.51220 & 1.022797 & 0.9242 & 98.60
\end{tabular}


ANEXO II - TABELAS DE CÁLCULOS PARA ELETRODO DE TI/TI ${ }_{0,7} \mathrm{RU}_{0,3} \mathrm{O}_{2}$ 

$1 \mathrm{M} \mathrm{H}_{2} \mathrm{SO}_{4}$

$0,5 \mathrm{mM} \mathrm{C}_{6} \mathrm{H}_{5} \mathrm{OH}$

\begin{tabular}{cccccccc}
\hline $\mathbf{v}(\mathbf{m V} / \mathbf{s})$ & $\mathbf{v}^{\mathbf{1 / 2}}$ & $\mathbf{I n} \mathbf{v}$ & $\mathbf{I}(\mathbf{m A})$ & $\mathbf{I n ~ I}$ & $\mathbf{E}(\mathbf{V})$ & $\mathbf{E}_{\mathbf{1 / 2}}(\mathbf{V})$ & $\boldsymbol{\Delta} \mathbf{E}(\mathbf{m V})$ \\
\hline 10 & 3.1623 & 2.3026 & 0.5230 & 1.0049 & -9.8585 & 0.9762 & 28.74 \\
20 & 4.4721 & 2.9957 & 0.9610 & 1.0115 & -9.2501 & 0.9877 & 23.81 \\
40 & 6.3246 & 3.6889 & 1.7900 & 1.0188 & -8.6281 & 0.9950 & 23.81 \\
60 & 7.7460 & 4.0943 & 0.3780 & 1.0762 & -10.1832 & 1.0071 & 69.12 \\
80 & 8.9443 & 4.3820 & 3.3900 & 1.0466 & -7.9895 & 1.0155 & 31.13 \\
100 & 10.0000 & 4.6052 & 4.1600 & 1.0533 & -7.7848 & 1.0265 & 26.86 \\
200 & 14.1421 & 5.2983 & 7.8500 & 1.0601 & -7.1498 & 1.0374 & 22.64
\end{tabular}

$1 \mathrm{mM} \mathrm{C}_{6} \mathrm{H}_{5} \mathrm{OH}$

\begin{tabular}{cccccccc}
\hline $\mathbf{v}(\mathbf{m V} / \mathbf{s})$ & $\mathbf{v}^{\mathbf{1 / 2}}$ & $\mathbf{I n} \mathbf{~}$ & $\mathbf{I}(\mathbf{m A})$ & $\mathbf{I n ~ I}$ & $\mathbf{E}(\mathbf{V})$ & $\mathbf{E}_{1 / 2}(\mathbf{V})$ & $\boldsymbol{\Delta} \mathbf{E}(\mathbf{m V})$ \\
\hline 10 & 3.1623 & 2.3026 & 0.5300 & 0.9937 & -9.8452 & 0.9638 & 29.85 \\
20 & 4.4721 & 2.9957 & 0.6920 & 1.0121 & -9.5785 & 0.9823 & 29.81 \\
40 & 6.3246 & 3.6889 & 1.3900 & 1.0190 & -8.8810 & 0.9951 & 23.88 \\
60 & 7.7460 & 4.0943 & 2.1000 & 1.0263 & -8.4684 & 0.9965 & 29.80 \\
80 & 8.9443 & 4.3820 & 2.9000 & 1.0374 & -8.1456 & 1.0077 & 29.75 \\
100 & 10.0000 & 4.6052 & 3.6400 & 1.0417 & -7.9184 & 1.0060 & 35.71 \\
200 & 14.1421 & 5.2983 & 7.5600 & 1.0591 & -7.1875 & 1.0234 & 35.71
\end{tabular}

6,25 mM C $6 \mathrm{H}_{5} \mathrm{OH}$

\begin{tabular}{cccccccc}
\hline $\mathbf{v}(\mathbf{m V} / \mathbf{s})$ & $\mathbf{V}^{\mathbf{1 / 2}}$ & $\mathbf{I n} \mathbf{V}$ & $\mathbf{I}(\mathbf{m A})$ & $\mathbf{I n ~ I}$ & $\mathbf{E}(\mathbf{V})$ & $\mathbf{E}_{\mathbf{1 / 2}}(\mathbf{V})$ & $\boldsymbol{\Delta} \mathbf{E}(\mathbf{m V})$ \\
\hline 10 & 3.1623 & 2.3026 & 0.7250 & 0.9821 & -9.5319 & 0.9418 & 40.28 \\
20 & 4.4721 & 2.9957 & 1.3500 & 0.9946 & -8.9102 & 0.9588 & 35.82 \\
40 & 6.3246 & 3.6889 & 2.4100 & 1.0113 & -8.3307 & 0.9747 & 36.60 \\
60 & 7.7460 & 4.0943 & 3.5000 & 1.0212 & -7.9576 & 0.9901 & 31.10 \\
80 & 8.9443 & 4.3820 & 4.4900 & 1.0310 & -7.7085 & 1.0035 & 27.50 \\
100 & 10.0000 & 4.6052 & 5.4100 & 1.0353 & -7.5221 & 1.0035 & 31.80 \\
200 & 14.1421 & 5.2983 & 10.2000 & 1.0600 & -6.8880 & 1.0235 & 36.50
\end{tabular}

$12,5 \mathrm{mM} \mathrm{C}_{6} \mathrm{H}_{5} \mathrm{OH}$

\begin{tabular}{cccccccc}
\hline $\mathbf{v}(\mathbf{m V} / \mathbf{s})$ & $\mathbf{v}^{\mathbf{1 / 2}}$ & $\mathbf{I n} \mathbf{v}$ & $\mathbf{I}(\mathbf{m A})$ & $\mathbf{I n ~ I}$ & $\mathbf{E}(\mathbf{V})$ & $\mathbf{E}_{1 / 2}(\mathbf{V})$ & $\boldsymbol{\Delta} \mathbf{E}(\mathbf{m V})$ \\
\hline 10 & 3.1623 & 2.3026 & 0.7500 & 0.9410 & -9.4980 & 0.9109 & 30.10 \\
20 & 4.4721 & 2.9957 & 0.7660 & 0.9664 & -9.4769 & 0.9364 & 30.00 \\
40 & 6.3246 & 3.6889 & 1.1200 & 1.0012 & -9.0970 & 0.9414 & 59.75 \\
60 & 7.7460 & 4.0943 & 1.5800 & 1.0072 & -8.7529 & 0.9471 & 60.09 \\
80 & 8.9443 & 4.3820 & 2.1400 & 0.9996 & -8.4495 & 0.9394 & 60.20 \\
100 & 10.0000 & 4.6052 & 2.6500 & 1.0229 & -8.2358 & 0.9628 & 60.10 \\
200 & 14.1421 & 5.2983 & 5.7100 & 1.0464 & -7.4681 & 1.0163 & 30.10
\end{tabular}

$25 \mathrm{mM} \mathrm{C}_{6} \mathrm{H}_{5} \mathrm{OH}$

\begin{tabular}{cccccccc}
\hline $\mathbf{v}(\mathbf{m V} / \mathbf{s})$ & $\mathbf{v}^{\mathbf{1 / 2}}$ & $\mathbf{I n} \mathbf{V}$ & $\mathbf{I}(\mathbf{m A})$ & $\mathbf{I n ~ I}$ & $\mathbf{E}(\mathbf{V})$ & $\mathbf{E}_{\mathbf{1 / 2}}(\mathbf{V})$ & $\boldsymbol{\Delta} \mathbf{E}(\mathbf{m V})$ \\
\hline 10 & 3.1623 & 2.3026 & 0.5710 & 0.9831 & -9.7707 & 0.9801 & 3.03 \\
20 & 4.4721 & 2.9957 & 0.9390 & 1.0456 & -9.2733 & 1.0035 & 42.10 \\
40 & 6.3246 & 3.6889 & 1.5700 & 1.0742 & -8.7593 & 1.0217 & 52.50 \\
60 & 7.7460 & 4.0943 & 2.1100 & 1.1071 & -8.4637 & 1.0546 & 52.50 \\
80 & 8.9443 & 4.3820 & 2.6900 & 1.1158 & -8.2208 & 1.0609 & 54.90 \\
100 & 10.0000 & 4.6052 & 3.2200 & 1.1381 & -8.0410 & 1.0765 & 61.60 \\
200 & 14.1421 & 5.2983 & 5.4200 & 1.1502 & -7.5202 & 1.0934 & 56.80 \\
& & & & & & & 129
\end{tabular}


$0,5 \mathrm{M} \mathrm{H}_{2} \mathrm{SO}_{4}$

$0,5 \mathrm{mM} \mathrm{C}_{6} \mathrm{H}_{5} \mathrm{OH}$

\begin{tabular}{cccccccc}
\hline $\mathbf{v}(\mathbf{m V} / \mathbf{s})$ & $\mathbf{v}^{\mathbf{1 / 2}}$ & $\mathbf{I n} \mathbf{v}$ & $\mathbf{I}(\mathbf{m A})$ & $\mathbf{I n ~ I}$ & $\mathbf{E}(\mathbf{V})$ & $\mathbf{E}_{\mathbf{1 / 2}}(\mathbf{V})$ & $\boldsymbol{\Delta} \mathbf{E}(\mathbf{m V})$ \\
\hline 10 & 3.1623 & 2.3026 & ND & -- & ND & ND & - \\
20 & 4.4721 & 2.9957 & 0.0695 & -9.5742 & 0.9826 & 0.9530 & 29.60 \\
40 & 6.3246 & 3.6889 & 0.0693 & -9.5771 & 0.9805 & 0.9450 & 35.50 \\
60 & 7.7460 & 4.0943 & 0.1430 & -8.8527 & 0.9956 & 0.9640 & 31.60 \\
80 & 8.9443 & 4.3820 & 0.2920 & -8.1388 & 1.0176 & 0.9919 & 25.70 \\
100 & 10.0000 & 4.6052 & 0.3680 & -7.9074 & 1.0214 & 0.9939 & 27.50 \\
200 & 14.1421 & 5.2983 & 0.7380 & -7.2116 & 1.0391 & 1.0134 & 25.70
\end{tabular}

$1 \mathrm{mM} \mathrm{C}_{6} \mathrm{H}_{5} \mathrm{OH}$

\begin{tabular}{cccccccc}
$\mathbf{v}(\mathbf{m V} / \mathbf{s})$ & $\mathbf{v}^{\mathbf{1 / 2}}$ & $\mathbf{I n} \mathbf{v}$ & $\mathbf{I}(\mathbf{m A})$ & $\mathbf{I n} \mathbf{I}$ & $\mathbf{E}(\mathbf{V})$ & $\mathbf{E}_{\mathbf{1 / 2}}(\mathbf{V})$ & $\boldsymbol{\Delta} \mathbf{E}(\mathbf{m V})$ \\
\hline 10 & 3.1623 & 2.3026 & & & & & \\
20 & 4.4721 & 2.9957 & 0.0764 & -9.4795 & 1.0203 & 0.9812 & 39.10 \\
40 & 6.3246 & 3.6889 & 0.1390 & -8.8810 & 1.0499 & 1.0017 & 48.20 \\
60 & 7.7460 & 4.0943 & 0.1960 & -8.5374 & 1.0554 & 1.0188 & 36.60 \\
80 & 8.9443 & 4.3820 & 0.2500 & -8.2940 & 1.0581 & 1.0105 & 47.60 \\
100 & 10.0000 & 4.6052 & 0.3040 & -8.0985 & 1.0660 & 1.0246 & 41.40 \\
200 & 14.1421 & 5.2983 & ND & -- & ND & ND & --
\end{tabular}

6,25 $\mathrm{mM} \mathrm{C}_{6} \mathrm{H}_{5} \mathrm{OH}$

\begin{tabular}{cccccccc}
\hline $\mathbf{v}(\mathbf{m V} / \mathbf{s})$ & $\mathbf{v}^{\mathbf{1 / 2}}$ & $\mathbf{I n} \mathbf{v}$ & $\mathbf{I}(\mathbf{m A})$ & $\mathbf{I n ~ I}$ & $\mathbf{E}(\mathbf{V})$ & $\mathbf{E}_{\mathbf{1 / 2}}(\mathbf{V})$ & $\boldsymbol{\Delta} \mathbf{E}(\mathbf{m V})$ \\
\hline 10 & 3.1623 & 2.3026 & 0.9800 & -9.6835 & 1.0250 & 0.9427 & 82.31 \\
20 & 4.4721 & 2.9957 & 1.4400 & -9.1334 & 0.9980 & 0.9492 & 48.75 \\
40 & 6.3246 & 3.6889 & 2.1500 & -8.5791 & 1.0060 & 0.9714 & 34.63 \\
60 & 7.7460 & 4.0943 & 2.5200 & -8.2434 & 1.0130 & 0.9146 & 98.43 \\
80 & 8.9443 & 4.3820 & 3.2600 & -7.9749 & 1.0210 & 0.9909 & 30.09 \\
100 & 10.0000 & 4.6052 & 3.7000 & -7.7969 & 1.0170 & 1.0043 & 12.67 \\
200 & 14.1421 & 5.2983 & 6.1000 & -7.1691 & 1.0400 & 1.0197 & 20.26
\end{tabular}

$12,5 \mathrm{mM} \mathrm{C}_{6} \mathrm{H}_{5} \mathrm{OH}$

\begin{tabular}{cccccccc}
\hline $\mathbf{v}(\mathbf{m V} / \mathbf{s})$ & $\mathbf{v}^{\mathbf{1 / 2}}$ & $\mathbf{I n} \mathbf{v}$ & $\mathbf{I}(\mathbf{m A})$ & $\mathbf{I n ~ I}$ & $\mathbf{E}(\mathbf{V})$ & $\mathbf{E}_{\mathbf{1 / 2}}(\mathbf{V})$ & $\boldsymbol{\Delta} \mathbf{E}(\mathbf{m V})$ \\
\hline 10 & 3.1623 & 2.3026 & 0.3610 & -10.2292 & 0.9350 & 0.9049 & 30.10 \\
20 & 4.4721 & 2.9957 & 0.6410 & -9.6551 & 0.9602 & 0.9001 & 60.10 \\
40 & 6.3246 & 3.6889 & 1.3300 & -8.9252 & 0.9826 & 0.9225 & 60.10 \\
60 & 7.7460 & 4.0943 & 1.8900 & -8.5738 & 0.9994 & 0.9393 & 60.10 \\
80 & 8.9443 & 4.3820 & 2.5400 & -8.2782 & 1.0061 & 0.9460 & 60.10 \\
100 & 10.0000 & 4.6052 & 3.9500 & -7.8366 & 1.0238 & 0.9637 & 60.10 \\
200 & 14.1421 & 5.2983 & 6.8800 & -7.2817 & 1.0562 & 0.9960 & 60.20
\end{tabular}

$25 \mathrm{mM} \mathrm{C}_{6} \mathrm{H}_{5} \mathrm{OH}$

\begin{tabular}{cccccccc}
\hline $\mathbf{v}(\mathbf{m V} / \mathbf{s})$ & $\mathbf{v}^{\mathbf{1 / 2}}$ & $\mathbf{I n} \mathbf{v}$ & $\mathbf{I}(\mathbf{m A})$ & $\mathbf{I n ~ I}$ & $\mathbf{E}(\mathbf{V})$ & $\mathbf{E}_{\mathbf{1 / 2}}(\mathbf{V})$ & $\boldsymbol{\Delta} \mathbf{E}(\mathbf{m V})$ \\
\hline 10 & 3.1623 & 2.3026 & 0.8180 & -9.4112 & 0.9840 & 0.9333 & 50.70 \\
20 & 4.4721 & 2.9957 & 1.1300 & -9.0881 & 1.0307 & 0.9562 & 74.50 \\
40 & 6.3246 & 3.6889 & 2.0700 & -8.4828 & 1.0707 & 0.9974 & 73.30 \\
60 & 7.7460 & 4.0943 & 2.5500 & -8.2742 & 1.0974 & 1.0390 & 58.40 \\
80 & 8.9443 & 4.3820 & 2.9600 & -8.1252 & 1.0913 & 1.0412 & 50.10 \\
100 & 10.0000 & 4.6052 & ND & -- & ND & ND & -- \\
200 & 14.1421 & 5.2983 & ND & -- & ND & ND & --
\end{tabular}

Onde: ND = Não Detectado 
$0,05 \mathrm{M} \mathrm{H}_{2} \mathrm{SO}_{4}$

$0,5 \mathrm{mM} \mathrm{C}_{6} \mathrm{H}_{5} \mathrm{OH}$

\begin{tabular}{cccccccc}
\hline $\mathbf{v}(\mathbf{m V} / \mathbf{s})$ & $\mathbf{v}^{\mathbf{1 / 2}}$ & $\mathbf{I n} \mathbf{v}$ & $\mathbf{I}(\mathbf{m A})$ & $\mathbf{I n ~ I}$ & $\mathbf{E}(\mathbf{V})$ & $\mathbf{E}_{\mathbf{1 / 2}}(\mathbf{V})$ & $\boldsymbol{\Delta} \mathbf{E}(\mathbf{m V})$ \\
\hline 10 & 3.1623 & 2.3026 & 0.4060 & -10.1117 & 0.9413 & 0.9018 & 39.51 \\
20 & 4.4721 & 2.9957 & 0.8050 & -9.4273 & 0.9592 & 0.9250 & 34.18 \\
40 & 6.3246 & 3.6889 & 1.5500 & -8.7721 & 0.9765 & 0.9442 & 32.29 \\
60 & 7.7460 & 4.0943 & 2.2700 & -8.3906 & 0.9928 & 0.9568 & 36.00 \\
80 & 8.9443 & 4.3820 & 2.9900 & -8.1151 & 1.0057 & 0.9648 & 40.90 \\
100 & 10.0000 & 4.6052 & 3.6900 & -7.9047 & 1.0231 & 0.9742 & 48.90 \\
200 & 14.1421 & 5.2983 & 7.0000 & -7.2644 & 1.0586 & 1.0060 & 52.60
\end{tabular}

$1 \mathrm{mM} \mathrm{C}_{6} \mathrm{H}_{5} \mathrm{OH}$

\begin{tabular}{cccccccc}
\hline $\mathbf{v}(\mathbf{m V} / \mathbf{s})$ & $\mathbf{v}^{\mathbf{1 / 2}}$ & $\mathbf{I n} \mathbf{v}$ & $\mathbf{I}(\mathbf{m A})$ & $\mathbf{I n ~ I}$ & $\mathbf{E ~ ( V )}$ & $\mathbf{E}_{\mathbf{1 / 2}}(\mathbf{V})$ & $\boldsymbol{\Delta} \mathbf{E}(\mathbf{m V})$ \\
\hline 10 & 3.1623 & 2.3026 & 0.4580 & -9.9912 & 0.9443 & 0.8979 & 46.40 \\
20 & 4.4721 & 2.9957 & 0.8680 & -9.3519 & 0.9553 & 0.9132 & 42.07 \\
40 & 6.3246 & 3.6889 & 1.6400 & -8.7156 & 0.9741 & 0.9405 & 33.60 \\
60 & 7.7460 & 4.0943 & 2.3900 & -8.3390 & 0.9950 & 0.9510 & 44.00 \\
80 & 8.9443 & 4.3820 & 3.1200 & -8.0725 & 0.9970 & 0.9573 & 39.70 \\
100 & 10.0000 & 4.6052 & 3.8200 & -7.8701 & 1.0180 & 0.9680 & 50.00 \\
200 & 14.1421 & 5.2983 & ND & -- & ND & ND & --
\end{tabular}

$6,25 \mathrm{mM} \mathrm{C}_{6} \mathrm{H}_{5} \mathrm{OH}$

\begin{tabular}{cccccccc}
\hline $\mathbf{v}(\mathbf{m V} / \mathbf{s})$ & $\mathbf{v}^{\mathbf{1 / 2}}$ & $\mathbf{I n} \mathbf{v}$ & $\mathbf{I}(\mathbf{m A})$ & $\mathbf{I n ~ I}$ & $\mathbf{E}(\mathbf{V})$ & $\mathbf{E}_{\mathbf{1 / 2}}(\mathbf{V})$ & $\boldsymbol{\Delta} \mathbf{E}(\mathbf{m V})$ \\
\hline 10 & 3.1623 & 2.3026 & 0.6150 & -9.6965 & 0.9384 & 0.8938 & 44.60 \\
20 & 4.4721 & 2.9957 & 1.1400 & -9.0793 & 0.9573 & 0.9146 & 42.70 \\
40 & 6.3246 & 3.6889 & 2.0700 & -8.4828 & 0.9822 & 0.9388 & 43.40 \\
60 & 7.7460 & 4.0943 & 3.0200 & -8.1051 & 1.0095 & 0.9570 & 52.50 \\
80 & 8.9443 & 4.3820 & 3.7600 & -7.8859 & 1.0331 & 0.9648 & 68.30 \\
100 & 10.0000 & 4.6052 & 4.5200 & -7.7018 & 1.0478 & 0.9764 & 71.40 \\
200 & 14.1421 & 5.2983 & ND & -- & ND & ND & --
\end{tabular}

$12,5 \mathrm{mM} \mathrm{C}_{6} \mathrm{H}_{5} \mathrm{OH}$

\begin{tabular}{cccccccc}
\hline $\mathbf{v}(\mathbf{m V} / \mathbf{s})$ & $\mathbf{v}^{\mathbf{1 / 2}}$ & $\mathbf{I n} \mathbf{v}$ & $\mathbf{I}(\mathbf{m A})$ & $\mathbf{I n ~ I}$ & $\mathbf{E ~ ( V )}$ & $\mathbf{E}_{\mathbf{1 / 2}}(\mathbf{V})$ & $\boldsymbol{\Delta} \mathbf{E}(\mathbf{m V})$ \\
\hline 10 & 3.1623 & 2.3026 & 0.2450 & -10.6168 & 0.9748 & 0.9147 & 60.10 \\
20 & 4.4721 & 2.9957 & 0.4050 & -10.1142 & 0.9745 & 0.9445 & 30.00 \\
40 & 6.3246 & 3.6889 & ND & -- & ND & ND & -- \\
60 & 7.7460 & 4.0943 & ND & -- & ND & ND & -- \\
80 & 8.9443 & 4.3820 & ND & -- & ND & ND & -- \\
100 & 10.0000 & 4.6052 & ND & -- & ND & ND & -- \\
200 & 14.1421 & 5.2983 & ND & -- & ND & ND & --
\end{tabular}

$25 \mathrm{mM} \mathrm{C}_{6} \mathrm{H}_{5} \mathrm{OH}$

\begin{tabular}{cccccccc}
\hline $\mathbf{v}(\mathbf{m V} / \mathbf{s})$ & $\mathbf{v}^{\mathbf{1 / 2}}$ & $\mathbf{l n} \mathbf{v}$ & $\mathbf{I}(\mathbf{m A})$ & $\mathbf{I n ~}$ & $\mathbf{E}(\mathbf{V})$ & $\mathbf{E}_{\mathbf{1 / 2}}(\mathbf{V})$ & $\boldsymbol{\Delta} \mathbf{E}(\mathbf{m V})$ \\
\hline 10 & 3.1623 & 2.3026 & ND & -- & ND & ND & - \\
20 & 4.4721 & 2.9957 & ND & -- & ND & ND & - \\
40 & 6.3246 & 3.6889 & ND & -- & ND & ND & - \\
60 & 7.7460 & 4.0943 & ND & -- & ND & ND & - \\
80 & 8.9443 & 4.3820 & ND & -- & ND & ND & - \\
100 & 10.0000 & 4.6052 & ND & -- & ND & ND & - \\
200 & 14.1421 & 5.2983 & ND & -- & ND & ND & --
\end{tabular}

Onde: ND = Não Detectado 
$0,01 \mathrm{M} \mathrm{H}_{2} \mathrm{SO}_{4}$

$0,5 \mathrm{mM} \mathrm{C}_{6} \mathrm{H}_{5} \mathrm{OH}$

\begin{tabular}{cccccccc}
\hline $\mathbf{v}(\mathbf{m V} / \mathbf{s})$ & $\mathbf{V}^{\mathbf{1 / 2}}$ & $\mathbf{I n} \mathbf{v}$ & $\mathbf{I}(\mathbf{m A})$ & $\mathbf{I n} \mathbf{I}$ & $\mathbf{E}(\mathbf{V})$ & $\mathbf{E}_{\mathbf{1 / 2}}(\mathbf{V})$ & $\boldsymbol{\Delta} \mathbf{E}(\mathbf{m V})$ \\
\hline 10 & 3.1623 & 2.3026 & 0.4480 & -10.0133 & 0.9182 & 0.8840 & 34.20 \\
20 & 4.4721 & 2.9957 & 0.8730 & -9.3462 & 0.9376 & 0.9053 & 32.30 \\
40 & 6.3246 & 3.6889 & 1.6500 & -8.7096 & 0.9561 & 0.9310 & 25.10 \\
60 & 7.7460 & 4.0943 & 2.3800 & -8.3432 & 0.9774 & 0.9426 & 34.80 \\
80 & 8.9443 & 4.3820 & 3.0900 & -8.0822 & 0.9902 & 0.9481 & 42.10 \\
100 & 10.0000 & 4.6052 & 3.6800 & -7.9074 & 0.9973 & 0.9735 & 23.80 \\
200 & 14.1421 & 5.2983 & ND & -- & ND & ND & --
\end{tabular}

\section{$1 \mathrm{mM} \mathrm{C}_{6} \mathrm{H}_{5} \mathrm{OH}$}

\begin{tabular}{cccccccc}
$\mathbf{v}(\mathbf{m V} / \mathbf{s})$ & $\mathbf{v}^{\mathbf{1 / 2}}$ & $\mathbf{I n} \mathbf{v}$ & $\mathbf{I}(\mathbf{m A})$ & $\mathbf{I n} \mathbf{I}$ & $\mathbf{E}(\mathbf{V})$ & $\mathbf{E}_{\mathbf{1 / 2}}(\mathbf{V})$ & $\boldsymbol{\Delta} \mathbf{E}(\mathbf{m V})$ \\
\hline 10 & 3.1623 & 2.3026 & ND & - & ND & ND & -- \\
20 & 4.4721 & 2.9957 & ND & -- & ND & ND & - \\
40 & 6.3246 & 3.6889 & ND & -- & ND & ND & -- \\
60 & 7.7460 & 4.0943 & ND & -- & ND & ND & - \\
80 & 8.9443 & 4.3820 & ND & -- & ND & ND & - \\
100 & 10.0000 & 4.6052 & ND & -- & ND & ND & - \\
200 & 14.1421 & 5.2983 & ND & -- & ND & ND & -
\end{tabular}

\section{6,25 mM C $6 \mathrm{H}_{5} \mathrm{OH}$}

\begin{tabular}{cccccccc}
\hline $\mathbf{v}(\mathbf{m V} / \mathbf{s})$ & $\mathbf{v}^{\mathbf{1 / 2}}$ & $\mathbf{I n} \mathbf{v}$ & $\mathbf{I}(\mathbf{m A})$ & $\mathbf{I n ~ I}$ & $\mathbf{E}(\mathbf{V})$ & $\mathbf{E}_{\mathbf{1 / 2}}(\mathbf{V})$ & $\boldsymbol{\Delta} \mathbf{E}(\mathbf{m V})$ \\
\hline 10 & 3.1623 & 2.3026 & 0.5470 & -9.8136 & 0.9208 & 0.8854 & 35.40 \\
20 & 4.4721 & 2.9957 & 1.0100 & -9.2004 & 0.9477 & 0.9111 & 36.60 \\
40 & 6.3246 & 3.6889 & 1.8000 & -8.6226 & 0.9866 & 0.9524 & 34.20 \\
60 & 7.7460 & 4.0943 & ND & -- & ND & ND & -- \\
80 & 8.9443 & 4.3820 & ND & -- & ND & ND & -- \\
100 & 10.0000 & 4.6052 & ND & -- & ND & ND & -- \\
200 & 14.1421 & 5.2983 & ND & -- & ND & ND & --
\end{tabular}

$12,5 \mathrm{mM} \mathrm{C}_{6} \mathrm{H}_{5} \mathrm{OH}$

\begin{tabular}{cccccccc}
$\mathbf{v}(\mathbf{m V} / \mathbf{s})$ & $\mathbf{v}^{\mathbf{1 / 2}}$ & $\mathbf{I n} \mathbf{v}$ & $\mathbf{I}(\mathbf{m A})$ & $\mathbf{I n ~ I}$ & $\mathbf{E}(\mathbf{V})$ & $\mathbf{E}_{1 / 2}(\mathbf{V})$ & $\boldsymbol{\Delta} \mathbf{E}(\mathbf{m V})$ \\
\hline 10 & 3.1623 & 2.3026 & 0.5380 & -9.8302 & 0.9762 & 0.9347 & 41.50 \\
20 & 4.4721 & 2.9957 & 0.6810 & -9.5945 & 1.0136 & 0.9642 & 49.40 \\
40 & 6.3246 & 3.6889 & ND & -- & ND & ND & - \\
60 & 7.7460 & 4.0943 & ND & -- & ND & ND & -- \\
80 & 8.9443 & 4.3820 & ND & -- & ND & ND & - \\
100 & 10.0000 & 4.6052 & ND & -- & ND & ND & - \\
200 & 14.1421 & 5.2983 & ND & -- & ND & ND & -
\end{tabular}

$25 \mathrm{mM} \mathrm{C}_{6} \mathrm{H}_{5} \mathrm{OH}$

\begin{tabular}{cccccccc}
\hline $\mathbf{v}(\mathbf{m V} / \mathbf{s})$ & $\mathbf{v}^{\mathbf{1 / 2}}$ & $\mathbf{I n} \mathbf{v}$ & $\mathbf{I}(\mathbf{m A})$ & $\mathbf{I n} \mathbf{I}$ & $\mathbf{E}(\mathbf{V})$ & $\mathbf{E}_{\mathbf{1 / 2}}(\mathbf{V})$ & $\boldsymbol{\Delta} \mathbf{E}(\mathbf{m V})$ \\
\hline 10 & 3.1623 & 2.3026 & 0.7140 & -9.5472 & 0.9317 & 0.8889 & 42.80 \\
20 & 4.4721 & 2.9957 & 1.1500 & -9.0706 & 0.9603 & 0.9237 & 36.60 \\
40 & 6.3246 & 3.6889 & ND & -- & ND & ND & -- \\
60 & 7.7460 & 4.0943 & ND & -- & ND & ND & -- \\
80 & 8.9443 & 4.3820 & ND & -- & ND & ND & - \\
100 & 10.0000 & 4.6052 & ND & -- & ND & ND & -- \\
200 & 14.1421 & 5.2983 & ND & -- & ND & ND & --
\end{tabular}

Onde: ND = Não Detectado 
ANEXO III - CONSUMO ENERGÉTICO 

Nesta seção é apresentado o consumo de energia elétrica nos experimentos de EL e FEO.

\begin{tabular}{|c|c|c|c|c|c|c|}
\hline \multirow{2}{*}{ Experimentos } & \multicolumn{3}{|c|}{ Fonte de Corrente } & \multirow{2}{*}{ Lâmpada } & \multirow{2}{*}{ Tempo (h) } & \multirow{2}{*}{ Total (kW/h) } \\
\cline { 2 - 5 } & I (A) & E (V) & P (W) & P (W) & & \\
\hline 01 & 0,81 & 2,30 & 1,86 & -- & 5 & 0,01 \\
\hline 02 & 3,01 & 2,50 & 7,52 & -- & 5 & 0,04 \\
\hline 03 & 4,96 & 2,60 & 12,89 & -- & 5 & 0,06 \\
\hline 04 & 8,14 & 2,90 & 23,60 & -- & 5 & 0,12 \\
\hline 05 & 0,81 & 2,30 & 1,86 & 250 & 5 & 1,26 \\
\hline 06 & 3,01 & 2,50 & 7,52 & 250 & 5 & 1,29 \\
\hline 07 & 8,14 & 2,90 & 23,60 & 250 & 5 & 1,37 \\
\hline
\end{tabular}





\section{REFERÊNCIAS BIBLIOGRÁFICAS}

1 Guido Busca, Silvia Barardinelli, Carlo Resini, Laura Arrighi, Technologies for the removal of phenol from fluid streams: a short review of recent development, Journal of Hazardous Materials, 160 (2008) 265-288.

2 Zvi Rappoport, The chemistry of Phenol, Ed. John Wiley Ltd, 2003, ISBN: 0-47149737-1.

3 Ghose, M. K., Complete physico-chemical treatment for coke plant effuents, Water Research, 36, (2002) 1127-1134.

4 Jaildes Marques Britto, Maria do Carmo Rangel, Processos avançados de oxidação de compostos fenólicos em efluentes industriais, Química Nova, 31 1, (2008), 114-122.

5 Higarashi, Martha M.; Jardim, Wilson F., "Remediation of pesticide contaminated soil usingnTiO2 mediated by solar light”, Catalysis Today ,76, 201-207, 2002.

6 Metcalf \& Eddy, "Wastewater Engineering: treatment and reuse", $4^{\text {th }}$, ISBN 0-07041878-0, Ed. Mc Graw Hill, 2003.

7 Abuzaid, N. S., Nakhla, G. F., "Effect of solution pH on the kinetics of phenolics uptake on granular activated carbon", Journal of Hazardous Materials, 49, 217230, 1996.

8 Moghadam, M A., Soheili, M., Esfahani, M. M., "Effect of lonic Strength on Settling of Activated Sludge", Iranian J Env Health Sci Eng, 2005.

9 Guilarduci, V., de Mesquita, J., Martelli, P., Gorgulho, H., "Adsorção de fenol sobre carvão ativado em meio alcalino", Química Nova, 29, 6, 2006

10 Nogueira, R. F. P.; Modé, D. F.; "Foto degradação de fenol e clorofenóis por processo foto-Fenton mediado por ferrioxalato", Eclética Química, v. 27, 2002.

11 Bolton, J.R. Bircher, K. G.; Tumas, W.; Tolman, C.A.; "Figures-of-Merit for the Technical Development and Application of Advanced Process" Journal of Advanced Oxidation Technologies, 1995. 
12 Sauer, T. P.; Casaril, L.; Moreira, R. F. M.; “Advanced oxidation process applied to tannery wastewater containing Direct Black 38 - Elimination and degradation kinetics", Journal of Hazardous Materials B, v. 135, p. 274-279, 2006.

13 Freire, R. S.; Pelegrine; R.; Kubota, L. T.; Durán, N.; Zamora, P. P. ,"Novas Tendências para o Tratamento de Resíduos Industriais Contendo Espécies Organocloradas", Química Nova, v. 23 (4), p 504-511,2000.

14 Kuns, A.; Peralta, P. P.; Moraes, de S. G.; Duran, N., "Novas Tendências no Tratamento de Efluentes Têxteis", Química Nova, v. 25, p 78-82, 2002.

15 Gogate, R. P.; "A Review of Imperative Technologies for Wastewater Treatment II: Hybrid Methods", Advances in Environmental Research, (8), p 553-597, 2004.

16 Alnaizy, R. ; Akgerman, A.; "Advanced Oxidation of Phenolic Compounds", Advances in Environmental Research, v. 4 p 233-244, 2000.

17 Adewuyi, Y.; "Sonochemistry in Environmental Remediation. Combinative and Hybrid Sonophotochemical Oxidation Process of the Treatment of Pollutants in Water", Environmental Science \& Technology, v. 39 (10), p 3409-3420, 2005.

18 Dziewinski, J.; Marczak, S.; Nuttall, E.; Purdy, G.; Zhou, C., "Developing and Testing Electrochemical Methods for Treating Metal salts, Cyanides and Organic Compounds in Waste Streams", Waste Management, (18), p 257-263, 1998.

19 Pelegrini, R.T.; Freire, R. S.; Durán, N.; Bertazzoli, R., "Photo assisted Electrochemical Degradation of Organic Pollutants on a DSA Type Oxide Electrode: Process Test for a Phenol Synthetic Solution and Its Application for the E1 Bleach Kraft Mill Effluent", Environmental Science \& Technology, v. 35, p 2849-2853, 2001.

20 Neelavannan, M. G.; Revathi, M.; Basha, C. A.; "Photocatalytic and electrochemical combined treatment of textile wash water"; Journal of Hazardous Materials, V. 149, p. $371-378,2007$.

21 Pelegrini, R.; Zamora, P. P.; Andrade, A. R.; Reyes, J., "Electrochemically Assisted Photocatalytic Degradation of Reactive Dyes", Applied Catalysis B: Environmental, v. 22, p. 83-90, 1999. 
22 Rodrigues, M. A. S.; Amado, F. D. R.; Xavier, J. L. N.; Streit, K. F.; Bernardes, A. M.; Ferreira, J. Z.; "Application of photoelectrochemical-electrodialysis treatment for the recovery and reuse of water from tannery effluents"; Journal of Cleaner Production, v.16, p. $605-611,2008$.

23 Tauchert, E.; Schneider, S.; Moraes, de J. L.; Peralta-Zamora, P.; "Photochemically-assisted electrochemical degradation of Lanlandfill leachate"; Chemosphere; V. 64, p. 1458 - 1463, 2006.

24 Moraes, P. B.; Bertazzoli, R.; "Electrodegradation of landfill leachate in a flow electrochemical reactor", Chemosphere, v. 58, p. 41-46, 2005.

25 Pinhedo, L.; Pelegrini, R.; Bertazzoli, R.; Motheo, A. J.; "Photo electrochemical degradation of humic acid on a 70TiO2/30RuO2 dimensionally stable anode", Applied Catalysis, V. 57, p. $75-81,2005$.

26 Freire, R. S.; Pelegrine; R.; Bertazzoli, R.; Kubota, L. T.; Durán, N., "Tratamento do efluente papeleiro Kraft E1 empregando o processo fotoeletroquímico", resumos SBQ, 2004.

27 Pelegrini, J. R.; Reyes, J.; Durán, N.; Zamora, P. P.; Andrade, de A.R., "Photoelectrochemical Degradation of Lignin", Journal of Applied Electrochemistry, v. 30, p 953-958, 2000.

28 Ebru, C.; Fikret; K., "Color, TOC and AOX removals from pulp mill effluent by advanced oxidation processes: A comparative study", Journal of Hazardous Materials B139 244-253, 2007.

29 Alnaizy, R.; Akgerman; A.; "Advanced oxidation of phenolic compounds", Advances in Environmental Research 4, 233-244, 2000

30 Li, F. B.; Li, X. Z.; Hou, M. F., "Photocatalitic Degradation of 2mercaptobenzothiazole in Aqueous La3+-TiO2 Suspension for Odor Control", Applied Catalysis B: Environmental, 2004.

31 Cavicchioli, A.; Gutz, I. G. R., "In-Line TiO2-assisted Photodigestion of Organic Matter in Aqueous Solution for Voltammetric Flow Analysis of Heavy Metals in Water Samples”, Analytica Chimica Acta, v. 445, p 127-138, 2001. 
32 Gkika, E.; Troupis, A.; Hiskia,A.; Papaconstantinou,E., "Photocatalytic Reduction of Chromium and Oxidation of Organics by Polyoxometalates", Applied Catalysis B: Environmental, v. 62, p 28-34, 2005.

33 Robertson, J. M. C.; Robertson, P. K. J.; Lawton, L. A., "A Comparison of the Effectiveness of TiO2 Photocatalysis and UVA Photolysis for the Destruction of Three Pathogenic Micro-organisms", Journal of Photochemistry and Photobiology A: Chemistry, 2005.

34 Wang, G.; Chen, H.; Kang, S., "Catalyzed UV oxidation of Organic Pollutants in Biologically Treated Wastewater Effluents", The Science of the Total Environment, v. 227, p 87-94, 2001.

35 Arslan, G.; Yazici, B.; Erbil, M.; "The effect of pH, temperature and concentration on electrooxidation of phenol", Journal of Hazardous Materials, v. 124, p. 37 - 43, 2005.

36 Bard, A. J., Faulkner, L. R., "Electrochemical methods. Fundamentals and Applications", 1980.

37 Comninellis, Ch., Pulgarin, C. "Anodic oxidation of phenol for waste water treatment", Journal of Applied Electrochemistry, 21, 703-708, 1991.

38 Guohua, C., "Electrochimical technologies in wastewater teratment", Separation and Purification Technology, 38, 11-41, 2004.

39 Ziolli, R. L.; Jardim, W. F., "Mecanismo de Fotodegradação de Compostos Orgânicos Catalisada por TiO2", Química Nova, v. 21 (3), p 319-325, 1998.

40 Chen, G.; "Electrochemical technologies in wastewater treatment", Separation and Purification Technology, V. 38, p. 11-41, 2004.

41 Deng, Y.; Englehardt, J. D.; “Electrochemical oxidation for landfill leachate treatment", Waste Management, 2006.

42 Wang, L., Hung, Y., Shammas, N., "Advanced physicochemical treatment technologies", Humana Press, New Jersey, ISBN 1-59745-173-8, 2007.

43 S.Trasatti, Electrocatalysis: understanding the success of DSA $尺$, Electrochimica Acta. 45, 2377-2385, 2000. 
44 Czaplicka, M., "Photo-degradation of chlorophenols in the aqueous solution", Journal of Hazardous Materials, 2005.

45 Borras, C.; Bersoy, C.; Mostany, J.; Herrera, J. C.; Scharifker, B. R ; “A comparison of the electrooxidation kinetics of $p$-methoxyphenol and $p$-nitrophenol on Sn-doped $\mathrm{SnO}_{2}$ surfaces: concentration and temperature affects", Applied Catalysis B: environmental, v. 72, p. 98 - 104, 2007.

46 Brillas, E., "Materiales y Procesos Electródicos”, INSDE, 1-28, 2002.

47 Tauchert, E.; Zamora-Peralta, P., "Avaliação de processos Fotoeletroquímicos no tratamento de Líquidos Lixiviados de Aterros Sanitários", Engenharia Sanitária Ambiental, v. 9, p 197-201, 2004.

48 Carp, O.; Huisman, C.L.; Reller, A., "Photo induced Reactivity of Titanium Dioxide", Progress in Solid State Chemistry, v 32, p. 33-177,2004.

49 Moraes, de P. B.; Bertazzoli, R., "Eletrodegradação de Chorume de Lixo Gerado em Aterros Sanitários", $22^{\circ}$ Congresso Brasileiro de Engenharia Sanitária e Ambiental, 2003.

50 Santana, V. S.; Machado, N. R., "Estudo da Fotodegradação de Corantes Têxteis em Suspensão Aquosa", 12 Congresso Brasileiro de Catálise, 2002.

51 Pelegrino, R. L.; Iglia, R. A.; Sanches, C. G.; Avaca, L. A.; Bertazzoli, R., "Comparative Study of Commercial Oxide Electrodes Performance in Electrochemical Degradation of Organics in Aqueous Solutions", Journal of Brazilian Chemical Society, v 13, p. 60-65, 2002.

52 Nogueira, R. F. P.; Jardim, W. F., "A Fotocatálise Heterogênea e sua Aplicação Ambiental", Química Nova, v. 21 (1), p 69-72, 1998.

53 Ferreira, I. V.; Daniel, L. A., "Fotocatálise Heterogênea com $\mathrm{TiO}_{2}$ Aplicada ao Tratamento de Esgoto Sanitário Secundário", Engenharia Sanitária e Ambiental, v. 09, p. 335-342, 2004.

54 Lassali, T. A.; Boodts, J. F.; Castro, S. C., "UHV and Electrochemical Studies of the Surface Properties of Ru+Pt+Ti Mixed Oxide Electrodes", Landers, R.; Trasatti, S., Electrochimica Acta, v. 39, p. 95-102, 1994. 
55 Faria, L. A.; Boodts, J. F. C.; Trasatti, S., "Electrocatalytic Properties of Ru+Ti+Ce Mixed oxide Electrodes for the $\mathrm{Cl}_{2}$ Evolution Reaction”, Electrochimica Acta, v. 42, p 3525-3530, 1997.

56 Fukunaga, M. T., Tese de Doutorado, "Estudo da degradação de efluentes aquosos derivados da indústria produtora de fenol através de eletrólise fotoassistida", Campinas, SP,2003.

57 Bertazzoli, R.; Pelegrini, R., "Descoloração e Degradação de Poluentes Orgânicos em Soluções Aquosas Através do, Processo Fotoeletroquímico", Química Nova, v. 35, p. 477-482, 2002.

58 Simond, O.; Schaller, V.; Comninellis, Ch., "Theoretical Model for the Anodic Oxidation of Organics on Metal Oxide Electrodes", Electrochimica Acta, v. 42, p. 2009-2012, 1997.

59 Santos, A., Yustos, P., Quintanilla, A., Rodríguez, S., García-Ochoa, F., "Route of the catalystic oxidation of phenol in aqueous phase", Applied Catalysis B: Environmental, 39, 97-113, 2002.

60 Cavicchioli, A.; Gutz, I. G., "O Uso de Radiação Ultravioleta para o Pré-tratamento de Amostras em Análise Inorgânica", Química Nova, v. 26, p. 913-921, 2003.

61 Sant Ana, T. D.; Oliveira, F. F.; Neto, J. V.; Zandonade, E.; Keller, R.; Gonçalves, R. F., "Influência do Tempo de Funcionamento das Lâmpadas UV na Eficiência de Reatores de Desinfecção de Esgoto Sanitário por Radiação Ultrvioleta", $22^{\circ}$ Congresso Brasileiro de Engenharia Sanitária e Ambiental, 2003.

62 Golimowski, J.; Golimowska, K., "UV-photooxidaction as Pretreatment Step in Inorganic Analysis of Environmental Simples", Analytica Chimica Acta, v. 325, p. 111-133, 1996.

63 Simond, O., Comninellis, Ch., "Anodic oxidation of organcs on Ti//rO2 anodes using Nafion as electrolyte", Electrochimica Acta, 42, 2013-2018, 1997.

64 Iniesta, J., Michaud, P., Panizza, M., Cerisola, G., Aldaz, A., Comninellis, Ch., "Electrochemical oxidation of phenol at boron-doped diamond electrode", Electrochimica Acta, 46, 3573-3578, 2001. 
65 Panizza, M., Kapalka, A., Comninellis, Ch., "Oxidation of organic pollutants on BDD anodes using modulated current electrolysis", Electrochimica Acta, 53, 2289-2295, 2008.

66 Pacheco, M., Morão, A., Lopes, A., Ciríaco, L., Gonçalves, I., "Degradation of Phenols using boron-doped diamond electrodes: A method for quantifying the extent of combustion", Electrochimica Acta, 53, 629-636, 2007.

67 Cañizares, P., lobato, J., Paz, R., Rodrigo, M., Sáez, C., "Electrochemical oxidation of phenolic waste with boron-doped diamond anodes", Water Research, 39, 2687-2703, 2005.

68 Ureta-Zañartu, M., Bustos, P., Berríos, C., Diez, M., Mora, M., Gutiérrez, C., "Electrooxidation of 2,4 - dichorophenol and other polycholonated phenol at a glassy carbon electode", Electrochimica Acta, 47, 2399-2406, 2002.

69 Alves, P., Spagnol, M., Tremiliosi-Filho, G., de Andrade, A., "Investigation of influence of the anode composition of DSA-tipe electrodes on the electrocatalytic oxidation of phenol in neutral medeium", journal of Brazilian Chemical Societies, $15,5,626-634,2004$.

70 Li, X., cui, Y., Feng, Y., Xie, Z., Gu, J., "Reaction pathways and mechanisms of the electrochemical degradation of phenol on different electrodes" Water Research, 39, 1972-1981, 2005.

71 Yavuz, Y., Koparal, A., "Electrochemical oxidation of phenol in a parallel plate reactor using ruthenium mixed metal oxide electrode", Journal of Hazardous Materials, B136, 296-302, 2006.

72 Heras, M., Lupu, S., Pigani, L., Pirvu, C., Seeber, R., Terzi, F., Zanardi, C., "A poly(3,4-ethylenedioxythiophene) - poly(styrene sulphonate) composite electrode coating in the electrooxidation of phenol", Electrochimica Acta, 50, 1685-1691, 2005.

73 Kennedy, B., Glidle, A., Cunnane, V. J., "A study of the oxidation and polymerisation of meta substituted phenol and aniline derivatives", Journal of Electroanalytical Chemistry, 608, 22-30, 2007. 
74 Skoog, Douglas. A.; "Principles of instrumental analysis"; 5th ed, Philadelphia, Harcourt Brace College, 1998.

75 Marder, L.; Navarro, E.; Pérez-Herranz, V.; Berdardes, A. M.; Ferreira, J. Z.; "Evaluation of transition metals transport properties through a cation-exchange membrane by chronopotentiometry"; Journal of Membrane Science; V. 284, 2006.

76 Brett, C. M. A., Brett, A. M. O., "Electrochemistry: principles, methods, and applications", Oxford University Press, ISBN 019855389 7, Oxford, 1993.

77 American Public Health Association, "Standard Methods for the examination of water and wastewater", Washington, 18 ed., APHA, 1992.

78 Wang J., Li, L., "Highly Stable Voltammetric Measurements of PhenolicCompounds at Poly(3-Methylthiophene)-Coated Glassy-Carbon Electrodes", Analytical Chemistry, 61, 2809-2811,1989.

79 Yi, H. C., Wu, K. B., Hu, S. S., Cui, D. F., "Adsorption stripping voltammetry of phenol at Nafion-modified glassy carbon electrode in the presence of surfactants", Talanta, 55, 1205-1210, 2001.

80 Mafatle, T., Nyokong, T., "Use of cobalt(II) phthalocyanine to improve the sensitivity and stability of glassy carbon electrodes for the detection of cresols, chlorophenols and phenol”, Analytica Chimica Acta, 354, 307-314, 1997.

81 Singh, R., Mishra, D., "Pd-1\%Ni Composite Electrodes for Electrooxidation of Phenol in Acid Solution", International Journal of Electrochemical Science, 4, 1638-1649, 2009.

82 Panizza, M., Cerisola, G., "Influence of anode material on the electrochemical oxidation of 2-naphthol - Part 1. Cyclic voltammetry and potential step experiments", Electrochimica Acta, 48, 3491-3497, 2003.

83 Zanta, P. S., de Andrade, A. R., Boodts, J. C., "Electrochemical behaviour of olefins: oxidation at ruthenium-titanium dioxide and iridium-titanium dioxide coated electrodes", Journal of Applied Electrochemistry, 30, 467-474, 2000. 
$84 \mathrm{Li}, \mathrm{C}$. Y., "Voltammetric determination of 2-chlorophenol using a glassy carbon electrode coated with multi-wall carbon nanotube-dicetyl phosphate film", Microchimica Acta 157, 21-26, 2007.

85 Galus, Z. and. Bryce, W. A. C; "Fundamentals of Electrochemical Analysis", $2^{\text {nd }}$ ed., Ellis Horwood, New York, 1994.

86 U. o. S. Southampton electrochemistry Group, Instrumental Methods in Electrochemistry, Horwood Publishing, 2001.

87 Beyenal, H., Seker, S., Tanyolac, A., Salih, B., AIChE, J., 43, 243,1997.

88 Wilke, C. R., Chang, P., AIChE, J., 1, 264,1955.

89 Bond, A. M., "Modern Polarographic Methods in Analytical Chemistry, Marcel Dekker Inc., New York, 191-235, 1980.

$90 \mathrm{Li}, \mathrm{C}$. Y., "Voltammetric determination of 2-chlorophenol using a glassy carbon electrode coated with multi-wall carbon nanotube-dicetyl phosphate film", Microchimica Acta 157, 21-26, 2007. 